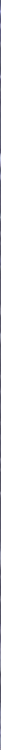

\title{
The Englishization of Higher Education in Europe
}


The Englishization of Higher

Education in Europe 



\title{
The Englishization of Higher Education in Europe
}

\author{
Edited by \\ Robert Wilkinson and \\ René Gabriëls
}


Cover image: Robert Wilkinson

Cover design: Coördesign, Leiden

Typesetting: Crius Group, Hulshout

ISBN $\quad 9789463727358$

e-ISBN 9789048553914 (pdf)

DOI $\quad 10.5117 / 978946372735^{8}$

NUR 133

\section{(C) (1) $\Theta \Theta$}

Creative Commons License CC BY NC ND (http://creativecommons.org/licenses/by-nc-nd/3.o)

@ All authors / Amsterdam University Press B.V., Amsterdam 2021

Some rights reserved. Without limiting the rights under copyright reserved above, any part of this book may be reproduced, stored in or introduced into a retrieval system, or transmitted, in any form or by any means (electronic, mechanical, photocopying, recording or otherwise). 


\section{Table of Contents}

Acknowledgements

1 Introduction

The tension between monolingualism and multilingualism

René Gabriëls and Robert Wilkinson

2 Higher Education in Flanders

English as the 'other' language

Frank van Splunder

3 The Englishization of higher education in Estonia and Latvia

Actors, positionings, and linguistic tensions

Josep Soler and Kerttu Rozenvalde

4 EMI in Spain

Striving to maintain a multilingual balance

David Lasagabaster

5 An ambivalent picture

The Englishization of higher education in France

Françoise Le Lièvre

6 English in Swiss higher education

The pragmatic way

Patrick Studer and Aisha Siddiqa

7 Englishization in Danish higher education

From critical to constructive conceptualizations

Slobodanka Dimova, Anna Kristina Hultgren, and Joyce Kling

8 Internationalization vs Englishization in Italian higher education 163 Reframing the issue

Amanda C. Murphy and Beatrice Zuaro

9 The place of English in the Russian higher education landscape $\quad 189$

Elena Belyaeva, Lyudmila Kuznetsova, Olga Nikiforova, and

Svetlana Suchkova 
10 Multiple dimensions of English-medium education

Striving to initiate change, sustainability, and quality in higher education in Sweden

Magnus Gustafsson and Jennifer Valcke

11 Englishization of Dutch higher education

Divergent language policies and practices

Robert Wilkinson and René Gabriëls

12 The Englishization of Polish higher education

Agnieszka Cierpich-Koziet and Elżbieta Mańczak-Wohlfeld

13 Englishization 'under the radar'

281

Facts, policies, and trends in Austrian higher education

Monika Dannerer, Martina Gaisch, and Ute Smit

14 Englishization of Croatian higher education

Conceptualizations, manifestations, and implications

Branka Drljača Margić

15 Affect in EMI at a German university

Comparing insights from teachers, home, and international students Michelle Hunter and Ursula Lanvers

16 Englishization as trap and lifeline

Philippe Van Parijs

Contributors

Index 


\section{List of figures and tables}

\section{Figures}

Figure 2.1 Belgium: official languages 38

Figure 9.1 Barriers to publishing research in English 200

Figure 10.1 Levels of governance affecting Englishization in Sweden 219

Figure 13.1 Overview of Austrian Research Universities $\quad 287$

Figure 13.2 Overview of Austrian UAS sector 288

Figure 13.3 Numbers of bachelor's and master's programmes at focal HEIs $\quad 291$

Figure 13.4 English-taught programmes at all Austrian UAS 295

Figure 15.1 Overview of the coding system 338

\section{Tables}

Table 2.1 Languages in Belgium 41

$\begin{array}{ll}\text { Table 6.1 HEIs analysed in this chapter } & 126\end{array}$

$\begin{array}{ll}\text { Table 8.1 Disciplinary areas in the INT corpus } & 173\end{array}$

Table 8.2 Disciplinary areas included in the IT corpus $\quad 175$

Table 8.3 Occurrences of words beginning with angl*and their positive or negative contexts in the Crusca corpus $\quad 178$

$\begin{array}{lll}\text { Table 9.1 } & \text { SPbU and HSE in numbers } & 194\end{array}$

Table 10.1 Condensed overview of university language policies in Sweden as of 2020

Table 11.1 Selected background characteristics of the students $\quad 248$

$\begin{array}{lll}\text { Table 11.2 Student perceptions on Englishization } & 249\end{array}$

Table 12.1 Articles, books and book chapters published in Poland in the English language $\quad 266$

Table 12.2 Modern language programmes vs EMI programmes 271

Table 12.3 Foreign language programmes: Language of instruction 272

Table 12.4 Most popular 1st, 2nd, and long cycle EMI programmes in Poland 273

Table 12.5 English versions of university websites in Poland $\quad 275$

Table 15.1 Students' responses to PANAS 339

Table 15.2 Student coding frequencies $\quad 341$

Table 15.3 Teachers' PANAS results $\quad 344$

Table 15.4 Teacher coding frequencies $\quad 344$ 



\section{Acknowledgements}

Many people have contributed to this wide-ranging book. We would like to thank all the contributors for their in-depth analyses of Englishization in the country they have examined. Our gratitude also goes to the following people who helped by reviewing chapters and providing incisive advice: Sara Atwater, Will Baker, Jean-Claude Beacco, Francesca Costa, Michele Gazzola, Harmut Haberland, John Harbord, Niina Hyninnen, Sarah Khan, Kathrin Kaufhold, Maria Kuteeva, Philippe Lecomte, Tarja Nikula, Ian Walkinshaw, Ying Wang, and Christopher Worthman. Our thanks go to the various authors of this book who also reviewed one or more chapters. We are indebted to our sponsors, without whose help this book would not have been published: The Centre for European Research in Maastricht (CERiM), the ICLHE Board, and the Board of the Faculty of Arts and Social Sciences (FASoS, Maastricht University). Last but certainly not least, we are grateful to Amsterdam University Press, particularly Julie Benschop-Plokker, Vicki Blud, and Irene van Rossum.

\section{Maastricht University}
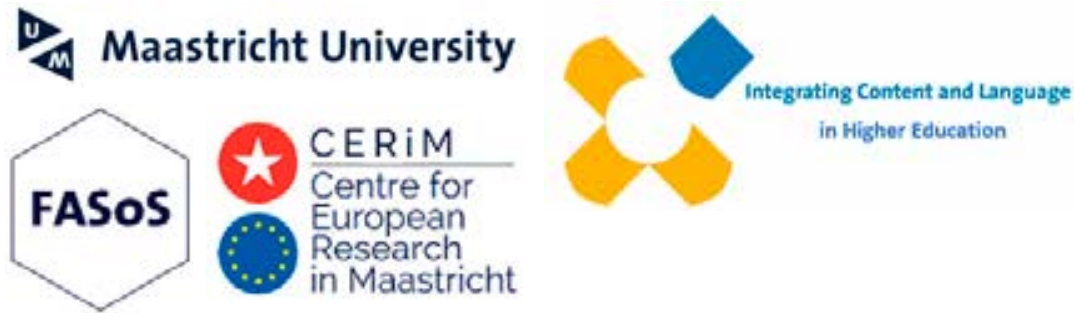

in Higher Education 



\title{
$1 \quad$ Introduction
}

The tension between monolingualism and multilingualism

René Gabriëls and Robert Wilkinson

\begin{abstract}
The tension between monolingualism and multilingualism has left its mark on the cultural history of Europe. Current public and academic debates about the Englishization of higher education pitch proponents of the monolingual ideal of a common language that promotes communication against advocates of the maintenance of linguistic diversity that does more justice to the multicultural reality and enriches life. Notwithstanding the differences between European countries, the switch from an initially monolingual curriculum to a bilingual and sometimes multilingual curriculum in higher education has led to debates about the consequences of the Englishization for the quality of higher education, cultural identity, inequality between stakeholders and the opportunities to express concern about this process.
\end{abstract}

Keywords: Englishization, higher education, monolingualism, multilingualism, glocalization, linguistic justice

\section{One language versus linguistic diversity}

In Europe, a paradise of one language for all people has long been placed in position against a world of linguistic diversity. In Christianity and Judaism, multilingualism ${ }^{1}$ is even seen as a punishment from God. Both religions cite

1 Unlike monolingualism, which refers to contexts where collectives communicate with each other through only one language, multilingualism refers to contexts where collectives communicate with more than one language. Perhaps it makes more sense to speak of a monolingual ideal, because in practice there are rarely, if ever, contexts in which collectives only communicate through one language.

Wilkinson, Robert, and René Gabriëls (eds), The Englishization of Higher Education in Europe. Amsterdam, Amsterdam University Press 2021 DOI: 10.5117/9789463727358_CHO1 
the Bible: the uniform language existing before the construction of the tower of Babel - the lingua adamica - came to be replaced by multilingualism because God was angered by human arrogance. Before God's anger, 'the whole earth had one language and the same words', but to punish human arrogance he 'confuse[d] their language there, so that they will not understand one another's speech' (New Oxford Annotated Bible, 2010, Gen. 11:1-9).

Advocates of multilingualism are often a minority in European cultural history. They could present Mithridates (135-63 BC), the king of Pontus, as their hero (Trabant, 2003). Not only was he the last serious adversary of the Roman Empire, but he also spoke 22 languages, or according to some legends, as many as $5^{\circ}$. While the Romans demanded of the peoples they ruled (with the exception of the Greeks) that they adopt their language, the polyglot Mithridates mastered the language of the peoples he conquered. His name is echoed not only in a tragedy by Racine and an opera by Mozart, but also by the Swiss scholar Conrad Gesner in the first encyclopaedia on some 130 world languages: Mithridates sive de differentiis linguarum tum veterum tum quae hodie apud diversas nationes in usu sunt (Mithridates, or on the differences between the languages, both ancient and now used by different nations), published in 1555 (Trabant, 2003). This Protestant humanist opposed the monolingualism of the Catholic Church, symbolized by Latin, and made, in the spirit of Mithridates, a clear plea for multilingualism.

In the 19th century, Johann Christoph Adelung and Johann Severin Vater followed in the footsteps of Gesner. They wrote a detailed overview of the different languages in the world under the title Mithridates oder allgemeine Sprachenkunde mit dem Vater Unser als Sprachprobe in bey nahe fünfhundert Sprachen und Mundarten (Mithridates or general linguistics with the Our Father as a language sample in almost five hundred languages and dialects), published between 1806 and 1817 (Adelung \& Vater, 1806-1817/2019). However, in the same century, language began to play a major role in nation state building, with a single language declared the standard at the expense of other languages. Language became a tool of political governance to establish a unified nation. At the beginning of the Italian unification (1848-1871), only two percent of the population spoke Italian, leading the nationalist political leader Massimo d'Azeglio to say: 'We have made Italy, now we must make Italians' (Maher, 2017, p. 76).

Since the 19th century, the construction of a national identity took place largely through the adoption of a standard language. Nationalist language policies entail a drive for monolingualism that is often accompanied by legislation that pursues a standard language and represses regional dialects and minority languages. In France, for example, regions were subject to 
Francization (francisée) that entailed the marginalization of Alsatian, Breton, Catalan, and Occitan (Maher, 2017, p. 81). Today, the European Union (EU) tries to protect these and other regional languages and to give shape to multilingualism. Further, 25 states have ratified the Council of Europe's European Charter for Regional or Minority Languages (ECRML), adopted in 1992.

Although many states enforce single language policies in administration, education and law, no state succeeds in being totally monolingual. To underline the tension between the monolingual ideal that is being pursued and multilingual practices, Yildiz (2012) elaborates the postmonolingual condition. This tension has left its mark on the cultural history of Europe to this day. One argument in favour of the monolingual ideal is that the diversity of languages leads to confusion and thus hinders communication. This problem could be overcome by learning other languages, which of course requires effort. An alternative argument for multilingualism is that learning other languages enriches life with novel perspectives on reality and does justice to linguistic particularities of regions and migrants. A plea for multilingualism could be based on the notion, traced back to Wilhelm von Humboldt, that language is not merely a means of conveying information, but as 'the cultivating organ of thought' (das bildende Organ des Gedanken) also expresses a 'worldview' (Weltansicht) that is constitutive for the cultural identity of a collective (Humboldt, 1836/2010). This implies that learning another language enables people to see the world as others might see it.

In the worldwide discussions about the increase in English-medium instruction (EMI) programmes in higher education, the tension between monolingualism and multilingualism plays an important role (Tsou \& Kao, 2017). This book bears witness to this and shows that in many European countries the switch from an initially monolingual curriculum to a more multilingual, most often bilingual, curriculum has led to public debates. In Estonia and Latvia (Soler \& Rozenvalde, this volume ${ }^{2}$ ), for example, there was a debate about linguistic hierarchies in higher education, questions on the quality of higher education and the role of legal measures applied to manage language matters at universities. It is noteworthy that in Switzerland the use of English in public schools at a primary and secondary level was subject to more controversy than it was at institutes of higher education at the tertiary level (Studer \& Siddiqa). In Italy it was the national Academy for the Italian language that sparked a debate after the renowned university Politecnico di Milano proposed to implement a unilateral use of English 
in MA and PhD courses (Murphy \& Zuaro). This book shows that in many other European countries there were public debates about the introduction of EMI programmes. However, there are exceptions. In Russia (Belyaeva et al.) there was no public debate and in Croatia (Drljača Margić) the debate concerned only the replacement in the media of Croatian expressions by English expressions and not the increase of EMI programmes. The latter is due to the fact that, in contrast with other European countries, relatively few EMI programmes are offered in Croatia. But in most countries these programmes led to public debates. Although the contexts of these debates varied with each country, it was not uncommon for them to be conducted in the same wording.

\section{Aspects of Englishization}

In recent years, the worldwide growth of EMI programmes in higher education has been increasingly discussed in terms of Englishization. This can be defined as the process in which the English language is increasingly gaining ground in domains where another language was previously used. In line with this definition of Englishization, six related aspects of this process can be distinguished that play an implicit or explicit role in public discussions about this.

The first aspect concerns the domain where English is displacing another language. In addition to the domain of education, it concerns the domains of politics, culture, and economics. The European Union (EU) is a good case for studying the Englishization of the domain politics (De Swaan, 2010, pp. 69-71; Van Parijs, 2011, pp. 6-17). While French was still accepted as the language in which politicians and civil servants communicated with each other in the 1950s when the EU was established, this language became relatively quickly replaced by English in 1973 with the EU's expansion. The Englishization of the cultural domain refers to the increase of consumption of English-language films, literature and music in a context where these cultural phenomena were articulated in the native language or a language other than English. Le Lièvre points out that France consciously protects its own film and music industry against Englishization, usually perceived as Americanization. With regard to the Englishization of Belgian culture, van Splunder points to differences between Wallonia and Flanders, because in the former region English-language films are dubbed and in the latter region subtitled. The Englishization of economics implies that the vernacular language 
of communication in companies and economic transactions is being increasingly replaced by English (Boussebaa et al., 2014; Pierini, 2016; Tietze, 2004). This development is mainly seen as the result of economic globalization. Although this book focuses on the Englishization of higher education, it is important to consider that this domain intrudes upon the other three domains. The domain loss in education, that is, when the vernacular language loses status due to the favouring of English, may have far-reaching consequences for the maintenance of the culture. Soler and Rozenvalde point out that in Estonia, so-called culturalists, as opposed to internationalists, fear that the Englishization threatens their culture.

The second aspect of Englishization concerns the stakeholders in the process. Within each domain where Englishization occurs, different stakeholders operate who may have contrasting and conflicting interests. Lasagabaster reports that students were more reluctant than administrative personnel and teachers towards compulsory EMI programmes, especially 'those students whose mother tongue was Basque, who were much more concerned about the alleged negative impact of English on Basque.' But the Englishization of a domain can also have consequences for stakeholders who operate outside it. For example, the Englishization of higher education concerns not only obvious stakeholders such as students, teachers, researchers and administrative staff, but also the citizens and shopkeepers who live and work in the city where a university is located. Citizens can be afraid of losing their language-bound cultural identity when English gets the upper hand, while retailers can hope for additional earnings.

The third aspect of Englishization affects the language policy of a country, public institution, or company. Language policy ${ }^{3}$ can stimulate or restrict Englishization. Nordic countries, for example, have established language policies based on parallel language use to protect the national language and minority languages (Nordic Council of Ministers, 2007). Dimova, Hultgren, and Kling underline that in response to concerns that parallel language use has downgraded the position of other foreign, heritage, and minority languages, 'more recent interpretations view its potential in promoting and normalizing the presencing of multiple languages in higher education.' It is not uncommon for there to be a gap between official language policy and language practice. For instance, Sweden is officially a monolingual country, but in practice this is different (Kuteeva et al., 2020, p. 4).

3 Much of what we refer to as language policy here reflects policy as stipulated in official policy documents, which Spolsky $(2004,2007)$ categorizes as management. Language policy also is formed by language practices and language beliefs. 
The fourth aspect of Englishization, legislation, relates closely to language policy, but should be distinguished from it. New legislation can give way to Englishization or, on the contrary, restrict it. When the French government, according to Le Lièvre, wanted to create more possibilities for EMI programmes with the Fioraso law, this led to fierce resistance. In Italy and the Netherlands, Englishization was the subject of a lawsuit (Pulcini \& Campagna, 2015; Edwards, 2016). In Europe, Englishization is not only about national legislation, but also about European legislation that offers both possibilities and restrictions.

The fifth aspect of Englishization concerns the material resources used in various domains. Englishization also means that English-language films, literature and music and icons of Anglophone culture are perceived in other cultures, which may imply the downgrading of products of some cultures. If EMI programmes predominate in higher education, does that mean that academically relevant sources in languages that have not been translated into English are still used? The question is whether EMI undermines cultural diversity. The production of material resources in the first language (L1) will be reduced if, as suggested in Latvia, $\mathrm{PhD}$ candidates have to produce their research in English, thus reducing the range of local research topics covered (Soler \& Rozenvalde).

The sixth aspect of Englishization concerns its normative dimension. Englishization is an evaluative-descriptive term; it is by no means a neutral concept. In public controversies about Englishization, the term acquires negative connotations for various stakeholders (Rivlina, 2013). Murphy and Zuaro point out that the Italian word for Englishization - Anglicizzazione - 'is mentioned solely in connection with the negative effect on other languages, which leads to monolingualism and subservience to Anglophone culture.' Because the burdens of Englishization are often not fairly distributed in reality (Boussebaa \& Tienari, 2019; Jackson \& Primecz, 2019), its normative dimension can be addressed in terms of linguistic justice (Alcalde, 2015). The implicit normative assumptions that underlie language policies and the public judgments about Englishization can be made explicit and critically examined on the basis of a well-founded idea of linguistic justice (Van Parijs, 2011).

The aim of this book is to describe, explain and assess the differences and similarities between European countries with regard to the Englishization of higher education. To this end, we asked eminent scholars to write a contribution on the Englishization of higher education in a specific country. Their analyses build on existing research into Englishization that has intensified over the last 15 years (Boussebaa \& Brown, 2017; Earls, 2013; Hultgren \& 
Thøgersen, 2014; Kirkpatrick, 2011; Lanvers \& Hultgren, 2018a; Tam, 2009 and 2019).

Research into the Englishization of higher education investigates three levels: micro (everyday research and education at the faculty level), meso (the university and the immediate environment), macro (nation state and the global context). At the micro level, questions relate how practitioners perceive the quality of education, the nature of knowledge, disciplinary differences and the impact of affect in EMI (Block \& Khan, 2020; Hunter \& Lanvers). At the meso level, questions concern the effects of Englishization on the immediate surroundings of the university, where services both within and outside the university may need to become bilingual or multilingual (Belyaeva et al.). At a macro level, questions address Englishization against the background of global developments. Gustafsson and Valcke, for instance, link it to the Sustainable Development Goals of the United Nations. Research at this level delves into the commodification of academic research and higher education as well as the balance of power.

The three distinct levels are interrelated. A macroscopic perspective is indispensable for an explanation of phenomena that take place at the micro and meso level. Certainly, when it comes to the increase in EMI programmes, the relationship between the meso and macro level is often discussed in the context of the internationalization of higher education (cf. Bowles \& Murphy, 2020; Gürtler \& Kronewald, 2015; Pulcini \& Campagna, 2015; Shimauchi, 2018; Tejada-Sánchez \& Molina-Naar, 2020). Internationalization and Englishization are not two sides of the same coin, rather two different processes. It is possible to have internationalization without Englishization. The Spanish language, for example, is not only used in higher education in Spain, but also in Latin America and serves the international cooperation of universities. Conversely, Englishization can occur without internationalization, for example in the Commonwealth (Van Parijs). In addition, Murphy and Mengistu (2020, p. 95) emphasize that Ethiopia is 'an intriguing counter-example of the idea that internationalization is synonymous with Englishization.'

\section{The glocalization of EMI}

The global dispersion of EMI can best be described in terms of glocalization. The concept of glocalization indicates that the global intensification of dependencies beyond national borders in different domains goes hand in hand with the articulation of local particularities (Robertson, 1992, 
pp. 173-174). This global-local nexus can also be applied to the worldwide dispersion of EMI (Alsagoff, 2010; Shi, 2013). In this case, glocalization means that universities across the world offer EMI programmes, but they do so in their own way. This implies that Englishization differs according to time and place. This volume presents several examples of localized varieties of the Englishization of higher education in Europe. In Belgium, for example, because of the language conflict conducted there, there is more reluctance towards the Englishization of higher education than in Austria, where it is hardly a topic of discussion (Dannerer, Gaisch \& Smit; Van Splunder). Nevertheless, there are also similarities between the various European countries. The concept of glocalization can yield a better understanding of how English is adapted in different contexts. Glocalization underlines that English becomes modified in the different parts of the world and often generates interesting hybrids (Alsagoff, 2010).

Localized expressions of English by non-natives may not meet the assumed standard English, but they are unavoidable. The kinds of English used in communication are often very different from the English taught in classrooms and that of English L1 speakers. Efficient communication among non-English Li speakers can occur through hybrid forms or translanguaging (Gustafsson \& Valcke; Le Lièvre). The concept of glocalization presupposes that there is a tension between the local and the global. This is by no means a process that runs smoothly and is free from conflict and resistance. Global forces to meet certain standards often lead to local resistance.

The fact that there is local resistance to a global phenomenon such as Englishization shows that it is not useful to speak of linguistic imperialism, because this concept assumes that a language is imposed top-down and there is little or no room to do something bottom-up against it. Phillipson, who coined this concept, argues that 'the dominance of English is asserted and maintained by the establishment and continuous reconstitution of structural and cultural inequalities between English and other languages' (Phillipson, 1992, p. 47). The concept of linguistic imperialism presupposes an imperial power that intends to impose its language policy on third parties. However, the reality looks different. It is true that Englishization involves specific power relations, but the power of some agents (for instance the British Council, the IMF and the World Bank) has never been so totalizing that no other agents have the possibility of establishing countervailing powers. Actors do have possibilities, however limited, to resist the language imposed on them and to partially shape it themselves.

In contrast to the concept of linguistic imperialism, the concept of glocalization does justice to the linguistic dimension of the agency-structure 
problem, which concerns the extent to which individuals and collectives act as free agents or are determined by socio-economic and other structures (Giddens, 1984). Whereas the concept of linguistic imperialism suggests individuals and collectives locally cannot withstand global structures pushing Englishization, the concept of glocalization underlines that Englishization is not a unidimensional but a multidimensional process in which the global and the local must be conceived as dialectically interconnected. This dialectical interconnectedness is based on the assumption that agency and structure are complementary and mutually constitutive forces - that is to say that the actions of individuals and collectives are influenced and constrained by structures, but that their actions can change these structures to some extent. Simultaneously, the structures changed by Englishization shape and constrain the actions of individuals and collectives, and they have the ability to empower and to inspire resistance. For example, at the Politecnico di Milano in Italy, teachers and students were successful with their opposition to a majority decision of the senate to offer all MA programmes and $\mathrm{PhD}$ courses in English (Pulcini \& Campagna, 2015; Quick, 2021, p. 59). Agents can freely discuss and consciously alter the linguistic landscape in which they operate. It is not clear a priori that they cannot make a change in a specific linguistic landscape, because of Englishization.

\section{Crucial issues}

The worldwide discussion about Englishization is usually about its consequences. This mainly concerns four related issues: quality, cultural identity, inequality and voice. What are the consequences of Englishization for the quality of research and education at universities, the cultural identity of a region or country, the inequality between stakeholders and their voice? These crucial issues, addressed in various contributions to this book, deserve a brief explanation.

A recurring point of discussion is the suggestion that the increase in EMI programmes in higher education harms the quality of research and education. In public debates about Englishization it is often suggested that the language proficiency of non-native researchers and students could never be good enough to articulate linguistically the nuances necessary for science (Le Lièvre; Soler \& Rozenvalde; Wilkinson \& Gabriëls). Moreover, proficiency in the L1 would be damaged by Englishization. Many students trained in EMI will find jobs where command of the spoken and written Li must be at a high level. This applies, for example, to doctors, psychologists, lawyers 
and managers who have to use the local L1. In order to safeguard the local L1 a country could offer, alongside the EMI provision, programmes in this language for international students. In Germany, some programmes require international students to engage in German language classes, increasing their opportunities in the attractive German job market (Hunter \& Lanvers). Meanwhile, in countries such as Austria (Dannerer, Gaisch, \& Smit) and Russia (Belyaeva, Kuznetsova, Nikiforova, \& Suchkova), there are hardly any quality assurance policies with regard to English proficiency. In various countries there are tests, accreditation procedures and certificates (Dimova, Hultgren, \& Kling; Gustafsson \& Valcke; Lasagabaster; Van Splunder).

Assuming that the identity of individuals and collectives is largely based on language, Englishization is associated with identity (Preece, 2016). Englishization is perceived as a threat to cultural identity in countries and regions that were unwillingly forced to use a foreign language and were liberated from the imposition by historical developments (Lasagabaster; Soler \& Rozenvalde; Van Splunder), but also in smaller countries and regions that have not experienced previous imposition (see also Lanvers \& Hultgren, 2018b). Englishization has an impact on the input that academics give directly or indirectly to the art, culture and social life of a country, because that depends to a great extent on a shared language. Englishization could create an even (larger) cultural gap between the academic and non-academic world. In Denmark, the question has been raised concerning how those who do not have a sufficient level of English proficiency are able to gain access to scientific knowledge that is mainly disseminated in English (Dimova, Hultgren, \& Kling). Another problem concerning cultural identity is whether Englishization will lead to the disappearance of French, German, Italian, Swedish, and so on, as academic languages. For cultural identity, the input of the humanities and to a somewhat lesser extent the social sciences is perhaps more important than that of the natural sciences. But Englishization is not necessarily a threat to the identity of a country or region. In higher education, EMI programmes enable various stakeholders to communicate across cultural boundaries and diversify their identity. People who, in addition to their L1, use English to communicate cross-culturally have a linguistic repertoire that reflects a multicultural rather than a monocultural identity (Gustafsson \& Valcke).

The issues of both cultural identity and inequality show that discussions about Englishization relate not only to higher education, but to society as a whole. The question is whether Englishization entails the emergence of new enclaves in which some are privileged and others marginalized. Does this process create a cleft between Englishized students who can move around the world as nomads and socially less advantaged students who 
are confined to their own state or region? The opportunities to follow EMI are not equal within and between countries. Within countries English may be an additional barrier for students who already find studying in the L1 a challenge. In Italy research indicates that students from higher social classes benefit more from EMI than students from lower classes (Murphy \& Zuaro). In a country like Croatia, for example, there are fewer options for following EMI programmes than in Denmark (Dimova, Hultgren, \& Kling; Drljača Margić). However, some argue that when certain conditions are met the use of English can contribute to greater equality (Van Parijs, 2011).

In practice, stakeholders who are involved in Englishization or who bear its consequences often have little opportunity to voice their concerns about language policy. The possibilities to voice opinions regarding Englishization may be frustrated by top-down language policies that prevent stakeholders from being heard (Le Lièvre; Soler \& Rozenvalde; Van Splunder). The contrast is substantial between the top-down discourses of policymakers and the bottom-up discourses of 'those endowed with less or no institutional power to influence the extent of English used, but who may nevertheless have strong attitudes to it' (Lanvers \& Hultgren, 2018a, p. 5). There is a democratic deficit if stakeholders do not have possibilities to shape the language policy to which they are subject. Democracy implies that those affected by policies have the opportunity to significantly set their mark on it. Top-down language policies do not give all stakeholders this option, certainly not those outside the academic world. With regard to the last point, it can be pointed out that Englishization undermines the democratization of knowledge by inhibiting the development of a lexicon that keeps track, in the local language, of scientific advances and by hindering the flow of knowledge and ideas between universities and the rest of society' (Van Parijs).

Notwithstanding differences between Europe and other continents regarding Englishization, it is noteworthy that crucial issues such as quality, cultural identity, inequality and voice are the subject of academic and public debates all over the world (Tam, 2009; McIlwraith, 2015; Tejada-Sánchez \& Molina-Naar, 2020). Similarly, there is also an increase of research into Englishization in Africa, Australia, Asia and America. Analysing developments beyond Europe would help avoid a Eurocentric view of Englishization.

\section{The political economy of Englishization}

A macroscopic perspective is indispensable for explaining the phenomena of Englishization described above. For example, the tremendous growth of EMI 
programmes at a micro-level and the language policy developed at a meso level can only be properly understood if they are linked to what happens at a macro level. Linguistic and other phenomena at the macro level influence the actions by individuals and collectives on a micro and meso level, which could subsequently lead to (new) phenomena at the macro level, that is, the global language system. The possibilities and constraints of individual actors regarding the use of language on a micro and meso level depend on the way the global language system is structured. The political economy of Englishization studies the nature of the interdependencies between and within these levels and looks for explanatory factors for English increasingly gaining ground in domains where another language was previously used.

Individuals often prefer the English language because it provides them with greater communicative advantage than any other language (De Swaan, 2001). Their preferences and the choices based on them with regard to English cannot be seen in isolation from the way in which the economy is structured. Since the late 1970s, the global economy has been structured in line with neoliberal principles, influencing language policies and practices at the local level (Block, Gray, \& Holborow, 2012).

The concept of neoliberalism is a contested concept because there is disagreement about its meaning (Biebricher, 2021; Harvey, 2007; Peck, 2010). To avoid conceptual hair-splitting, neoliberalism may be defined as the idea that the economic order and the political order contribute best to the welfare and freedom of all under the conditions of the deregulation of financial market, the privatization of public services, the flexibilization of the labour market, the reform of the welfare state by reductions of public expenditures, the free movement of goods, services, labour and capital, the maximizing of shareholder value and private ownership legally anchored. Implementing neoliberal policies influenced Englishization in general and in higher education in particular (Giroux, 2014; Sabaté-Dalmau, 2020). This is also pointed out by various authors in this volume (Dannerer, Gaisch, \& Smit; Le Lièvre; Studer \& Siddiqa; Van Splunder; Wilkinson \& Gabriëls).

Due to globalization, the sociolinguistic contexts have changed (Blommaert, 2010). In particular, the increased transnational economic dependencies and the dominant position of the United States have led to an increase in the market value of English. English is a medium that is central where economic transactions take place. Because neoliberalism highly values the free movement of goods, services and capital, international organizations and transnational corporations support the learning of English. The assumption is that it is not only organizations and corporations that benefit from a 
high level of English proficiency, but individuals too, because English will contribute to increasing their job opportunities.

Higher education has become more receptive to and serves as an agent of Englishization, because neoliberalism transformed the classical university into an entrepreneurial university (Bok, 2003). The entrepreneurial university is characterized by the commodification of education and research (Radder, 2010). In a global academic market, universities compete to attract the best students and scholars and capitalize on their successes. Rankings, for instance, are an important indicator for universities in determining their competitive position. Because the degree of internationalization is one of the indicators in the rankings, universities attract as many international students as possible. To do so, they offer more and more EMI programmes.

The more universities are modelled on companies, the more university administrators become managers (Boomkens \& Gabriëls, 2008). The rise of New Public Management (NPM) plays an important role in the context of higher education. NPM requires academics to have the habitus of a homo economicus who knows how to capitalize the acquisition and transfer of knowledge and not the habitus of the classical homo academicus (Münch, 2011, pp. 94-131). Where the homo economicus prevails, language is seen as an instrument, merely as a medium to transfer information to another person in an efficient manner. This would seem to invalidate objections to Englishization. On the other hand, those who use language as the bearer of a specific cultural identity may not easily support Englishization.

The political economy of Englishization draws attention to the consequences that the allocation of a resource such as language has for the quality of education, cultural identity, inequality and voice. As mentioned before, quality of education is mainly about two issues: the question of whether proficiency in English provides sufficient quality of education and research and the question whether Englishization implies that people can no longer express themselves at a high level in their L1. If language is central to people's identity, then the neoliberal push towards Englishization could be perceived as a threat to their identity. Englishization, as Boussebaa and Brown (2017) suggest, contributes to identity regulation that turns locals into Anglophones who have internalized the values of entrepreneurship. The growing socio-economic inequality inherent in neoliberalism is reflected in the fact that access to EMI programmes is often limited to those who can afford it. English functions as a gatekeeper and can increase the difference between those who master this language and those who do not (Price, 2014, p. 586). This may explain why in many countries the call is getting louder 
to democratize higher education and to involve more stakeholders in the development of (language) policies.

\section{Linguistic justice and democracy}

The phenomena of Englishization in higher education and the politicoeconomic explanation merit an assessment. Public controversies about and research into Englishization are by no means neutral. The negative connotation surrounding the term Englishization in various contexts indicates that this is a normatively loaded issue (Lasagabaster). For the assessment of Englishization in higher education, the concepts linguistic justice and democracy can be used.

Linguistic justice deserves more attention in the research into Englishization of higher education than it has received so far, because the consequences of language policies may lead to inequalities that are perceived as unfair by those involved. Gustafsson and Valcke argue that universities should commit to policies that contribute to social justice. Assessing the fairness of language policies and practices that promote Englishization entails describing and justifying ideas about linguistic justice.

Without entertaining the various (liberal, communitarian and other) theories on linguistic justice, only three interpretations of linguistic justice distinguished by Van Parijs (2011) are mentioned here, because they offer good starting points for the critical assessment of Englishization in higher education.

The first interpretation is linguistic justice as cooperative justice. Since English functions as a public good that enables people who speak this language to communicate with each other, their cooperation is fair if the burdens are distributed fairly. The crucial issue now is what, according to this interpretation of linguistic justice, is the most defensible criterion. According to Van Parijs, the criterion of equal cost-benefit ratios underpins this interpretation of linguistic justice, and this requires a contribution from Anglophones, whether or not in the form of a linguistic tax.

Van Parijs considers the second interpretation of linguistic justice, namely as distributive justice, of greater importance. In this interpretation, based on an egalitarian conception of global distributive justice, language is not seen as a public good, but as an individual asset that in principle contributes to everyone having an equal chance of achieving a good life. However, the growing dominance of English language is based on inequalities of opportunities. In view of language policies and practices, the best way to 
deal with this is 'by accelerating the dissemination of the lingua franca beyond the elite of each country' (Van Parijs, 2011, pp. 115-116).

The third interpretation of linguistic justice, namely as parity of esteem, views language not only as a communication tool, but also a marker of identity. This notion of justice is based on the idea that language is constitutive of the collective identity of those who master it and expect their language to be treated with equal respect. It would be unfair if people are stigmatized for not being proficient in English. To do justice to linguistic diversity and avoid the dominance of a language, Van Parijs proposes a territorially differentiated coercive linguistic regime in which the coercive rules differ from place to place (Van Parijs, 2011, pp. 133-137). His proposal is not uncontroversial. Some scholars argue that his idea of a territorially differentiated coercive linguistic regime does not do justice to the frequent incongruence between territory and language. Moreover, multiple language groups may claim the same territory, and there are Englishes with different statuses and linguistically hybrid settings (De Schutter \& Robichaud, 2015; May, 2015).

The concept of linguistic justice could be applied to the assessment of language policies and practices in higher education. Does Englishization frustrate burden sharing? As a linguistic community, does higher education offer equal opportunities for everyone? Do students and staff in higher education feel that there is parity of esteem with regard to the prevailing linguistic regime?

Linguistic justice touches upon democracy. After all, without linguistic justice it is impossible to speak of fully-fledged democratic conditions at the micro, meso, and macro level. For a democracy to function properly the members of a political community must share a common language and possess a corresponding linguistic competence. A common language is important for a shared political culture and ensures a kind of affinity among citizens. However, political practice often shows a tension between a common language and the maintenance of linguistic diversity. A democracy benefits from a common language because it contributes to establishing equal opportunities for citizens to participate in public deliberation and decision making. National states or the European Union must establish one or more official languages for this purpose. However, if a majority or hegemonic language is selected as the official language, it could jeopardize the participation of some citizens.

A crucial question is whether the language policies that drive the Englishization of higher education are democratic or are the result of a top-down implementation that is inherent to New Public Management 
(Dimova, Hultgren, \& Kling; Gustafsson \& Valcke). Democracy means selfgovernment, that those affected by policies should have some say in them. In the case of EMI, stakeholders should have the rights and possibilities to shape the language policy to which they are subject. However, at all levels policymakers take 'shortcuts that bypass public deliberation about political decisions', which erodes 'the fundamental commitment of the democratic ideal of self-government' (Lafont, 2020, p. 3). The hierarchies of languages (De Swaan, 2001) as well as ideologies that hide the gap between official policy and practice and the top-down implementation of EMI programmes (Hultgren et al., 2014; Dannerer, Gaisch, \& Smit; Le Lièvre) may be reasons to question the democratic legitimacy of language policies.

\section{$7 \quad$ The legacy of Mithridates}

Returning to the beginning of this introduction, the EU has set great store by the legacy of Mithridates, but the Englishization of higher education in Europe shows that in practice there is still much to be desired. In some countries more than others, Englishization is perceived as both an opportunity and a problem. For example, many contributions in this volume note that the quality of education suffers from insufficient English proficiency among students and teachers. Furthermore, the status of the national language, so important for cultural identity, social cohesion, and democracy, would be affected by Englishization. Moreover, Englishization would widen the gap between academia and society and would make English a barrier to less advantaged citizens. As long as these problems are not resolved, as evidenced by various public controversies in Europe, there is a chance that the proliferation of EMI programmes will be politicized.

Because of the problematic sides of Englishization, there is a great temptation to reverse this process. But that is impossible (Van Parijs). For the time being, Englishization is an irreversible process that can at most be managed in certain directions. From a sociological perspective, Münch (2007, pp. 10-34) raises three related reasons for this. First, the functional adaptation of higher education leads to ever closer global markets of education and research. Second, the institutional path dependence entails that every step that actors take on an academic path reduces the chance that they will take an alternative path, because the costs (money, status, and power) of a turnaround will only increase. Third, the functional adaptation and the institutional path taken are legitimized and consolidated by a language ideology that uses a specific vocabulary (namely that of New 
Public Management in which ranking, competition, internationalization and excellence are key concepts).

Taken together, the functional adaptation, the institutional path dependence and the language ideology ensure that Englishization will continue for the time being. This does not mean that nothing can be done about the problems raised (Dimova, Hultgren, \& Kling; Drljača Margić; Gustafsson \& Valcke). For this, from the point of view of democracy, all stakeholders affected by Englishization should have a voice, and not only those in academia.

Taking account of the legacy of Mithridates means recognizing that power relations make up the linguistic landscape and that language conveys a certain world view. The difference between disciplines comes into play here (Cierpich-Kozieł \& Mańczak-Wohlfeld; Le Lièvre; Van Splunder). The content conveyed, especially by the humanities and social sciences, is vested in the local culture and language. Domain loss as a result of Englishization in the humanities and social sciences is anything but conducive to innovative input to the local culture and language, as well as their reproduction. Mithridates embodies Humboldt's idea that language is not merely a means of conveying information but expresses a world view that shapes a culture.

Human beings are self-interpreting animals that are embedded in one or more cultures (Taylor, 1985, 2016). Language is no mere communication tool but discloses the world in which human beings live. Mithridates understood that learning another language does not mean appropriating the same tools. Learning another language is actually the appropriation of a shared linguistic world disclosure. And that can be very enriching.

\section{An outline of the contributions}

The contributions of this book examine the Englishization of higher education in various European countries. It is impossible to discuss all European countries. Nevertheless, this volume provides a relatively good picture, because countries from Eastern, Western, Southern, and Northern Europe are represented. Of course, the following outline cannot do justice to the richness and complexity of each contribution.

Van Splunder (chap. 2) argues that English has gained a foothold in higher education despite all kinds of government restrictions. Englishization has sparked a public debate in Belgium on identity, equality, and justice. An analysis of this debate and research into EMI shows that Englishization may 'mean internationalization and access to the world', but 'does not mean access to the whole world.' Soler and Rozenvalde (chap. 3) address the 
way in which Estonia and Latvia have publicly debated the opportunities and threats of the Englishization of higher education. Despite interesting differences between the two countries (for example with regard to the use of Russian in universities), there are fundamental similarities. In both Estonia and Latvia, language-related issues have played an important role in the nation-rebuilding process, and universities must appropriate the top-down language policies of the state. Public debates concern whether the Englishization of higher education affects other spheres in society and whether academia should primarily serve state interests.

Lasagabaster (chap. 4) addresses the impact of Englishization on multilingual Spain where officially bilingual universities play a key role in revitalizing the minority languages Basque, Catalan and Galician. Some perceive Englishization as a potential Trojan horse that might erode the results of four decades of revitalization. Besides this, other linguistic strains caused by Englishization are highlighted, such as the consequences of low level of English proficiency of teachers, students and administrative staff, and disciplinary differences regarding the importance of English. Le Lièvre (chap. 5) sketches an ambivalent picture of the Englishization of higher education in France. This picture is the result of an ongoing debate between the proponents and opponents of EMI programmes who, despite their different perspectives, have in common that they are blind regarding translingual practices. In practice, the linguistic landscape in France is characterized by hybrids, code-switching, and code-mixing rather than by clearly separate and distinguishable languages. Studer and Siddiqa (chap. 6) analyse legal, strategy and policy documents to ascertain how the increased use of English in Swiss higher education has been addressed by policymakers at national and institutional levels. They discuss the concern whether English in Switzerland has become the fifth national language in addition to the four official national languages (German, French, Italian and Romansh). With respect to multilingualism and internationalization, there is a remarkable difference in the way in which institutions in the German-speaking and French-speaking parts of Switzerland assess Englishization: while the former do so pragmatically, on the basis of a cost-benefit analysis, the latter principally do so from the perspective that language gives expression to the cultural identity of a community.

Dimova, Hultgren, and Kling (chap. 7) adopt a longitudinal perspective to the Englishization of higher education in Denmark that shows a shift over time from a critical to a constructive approach. Initially, the alleged consequences of the increasing use of English were critically examined, such as domain loss, inequality among the general public regarding a 
sufficient level of English proficiency and a threat to the cultural heritage based on Danish. In Denmark, the critical approach has given way to a constructive approach that assesses Englishization pragmatically, recognizing that the expansion of EMI is inevitable and practical solutions regarding its implementation must be found. Murphy and Zuaro (chap. 8) investigate how the ideas of internationalization and Englishization are conceptualized in academic research on higher education in Italy. While the concept of internationalization is used in a neutral way, the concept of Englishization is endowed with negative connotations (by portraying it as a monolingual and hegemonic process that threatens cultural identity and involves injustice). However, based on Englishization as the medium of instruction, internationalization can 'represent a bridge to other cultures and a way of making Italian academic culture more accessible to international audiences, rather than a threat to its identity.'

Belyaeva, Kuznetsova, Nikiforova and Suchkova (chap. 9) argue that it is inappropriate to apply the concept Englishization to higher education in Russia, because the use of English is not far-reaching enough. Moreover, in Russia there is an incongruity between the language policy at the national level and the language policy at the level of higher education institutions. Although EMI is slowly but steadily acquiring more status in the European part of Russia, and there is evidence that other territories of the Russian Federation will follow this trend, it is noteworthy that in the Far East and elsewhere, Chinese is becoming increasingly popular.

Valcke and Gustafsson (chap. 10) analyse the way in which two universities in Sweden have undertaken curricular reform and managed the opportunities and challenges of teaching and learning through English. Both case studies show that in practice educational dynamics can differ from university to university and it makes sense to adopt the concept EMEMUS: English Medium Education in Multilingual University Settings (Dafouz \& Smit, 2016). However different the multilingual university settings at the two Swedish universities, they both show that it is important to develop the multicultural sensitivities of the teaching staff in view of classrooms that are more inclusive and equitable. Wilkinson and Gabriëls (chap. 11) note that in the Netherlands there is an incongruity between the discourse of the university administrators and the critical voices of eminent scholars and intellectuals during a public controversy about Englishization. One explanation for this incongruity is that administrators of Dutch universities manage according to the guidelines of the neoliberal New Public Management and therefore defend other interests than those who publicly question the consequences of Englishization for Dutch culture and society. Although the Englishization of 
Dutch higher education also meets the interests of students who consciously choose EMI programmes, many of them believe that this process results in Anglophone cultural dominance and harms Dutch culture.

Cierpich-Kozieł and Mańczak-Wohlfeld (chap. 12) describe the phenomena of what they call an English-Polish alliance, which amounts to the equalization of the status of English and Polish as languages of instruction. Features of this alliance include the strong growth of EMI programmes, publications in English and the increased importance of this language in job competition. Englishization in Polish higher education is subsumed under the concept of internationalization, which has led to increased status for EMI programmes. Based on analyses of policy texts and statistical data, Dannerer, Gaisch, and Smit (chap. 13) present a differentiated picture of the Englishization of traditional research universities and universities of applied sciences in Austria. It is noticeable that the issue of language in general, and English in particular, is under the radar in Austria, suggesting a lack of awareness that EMI may undermine the use of German in higher education. This corresponds to a utilitarian view of language inherent in Austrian policies.

From an in-depth investigation into EMI at the University of Rijeka in Croatia, Drljača Margić (chap. 14) concludes that no one thinks English should replace Croatian. Only a small minority of teachers and students express concerns about the future status of Croatian in higher education and that EMI will spur a brain drain. This might be because the overall adoption of EMI is rather low with only $3 \%$ of study programmes in English. Hunter and Lanvers (chap. 15) report research into how students and teachers experience the affective dimension of Englishization in German institutions of higher education. This research is unique because there are no studies that have examined the impact of affect in EMI on both students and teachers. Although anxiety over proficiency was present among most students and teachers, international students and teachers show a more positive affect towards EMI than local students and teachers, apart from those international students who are more concerned about face-saving.

In the epilogue of this book, Van Parijs (chap. 16) asks himself whether the Englishization of higher education in Europe is a problem and, if so, whether there is anything that can and should be done about it. Higher education confronts many challenges such as the quality of education, access of less advantaged students, the widening gap between academia and society, and the weakening of the national language that is so important to culture and identity. Internationalization entraps immense costs, often invested in Englishization. Addressing these issues is a balancing act: 'a fragile, conflict-ridden balance between giving enough place to English 
not to fall behind and protecting the local languages against domain loss and slow agony.'

\section{References}

Adelung, J. C. \& Vater, J. S. (2019). Mithridates Oder Allgemeine Sprachenkunde Mit Dem Vater Unser ALS Sprachprobe in Bey Nahe Fuenfhundert Sprachen Und Mundarten. Forgotten Books. (Original work published 1806-1817)

Alcalde, J. (2015). Linguistic justice: An interdisciplinary overview of the literature. Amsterdam Working Papers on Multilingualism, 3, 27-96.

Alsagoff, L. (2010). Hybridity in ways of speaking: The glocalization of English in Singapore. In L. Lim, A. Pakir, \& L. Wee (Eds.), English in Singapore: Modernity and management (pp. 109-130). Hong Kong University Press.

Baik, M. J. (2001). Aspects of Englishization in Korean discourse. In E. Thumboo (Ed.), The three circles of English (pp. 181-193). UniPress.

Biebricher, Th. (2021). Die politische Theorie des Neoliberalismus. Suhrkamp.

Block, D., Gray, J., \& Holborow, M. (2012). Neoliberalism and Applied Linguistics. Routledge.

Block, D., \& Khan, S. (Eds.) (2020). The secret life of English-medium instruction in higher education: Examining microphenomena in context. Routledge.

Blommaert, J. (2010). The sociolinguistics of globalization. Cambridge University Press.

Bok, D. (2003). Universities in the marketplace: The commercialization of higher education. Princeton University Press.

Boomkens, R., \& Gabriëls, R. (2008). Paradoxen van het academisch kapitalisme. In Ch. Lorenz (Ed.), Ifyou're so smart, why aren't you rich? Universiteit, Markt \& Management (pp. 107-130). Boom.

Boussebaa, M., \& Brown, A. D. (2017). Englishization, identity regulation and imperialism. Organization Studies, 38(1), 7-29.

Boussebaa, M., Sinha, S., \& Gabriel, Y. (2014), Englishization in offshore call centers: A postcolonial perspective. Journal of International Business Studies, 4o(9), 1152-1169. DOI: 10.1057/jibs.2014.25

Boussebaa, M., \& Tienari, J. (2019). Englishization and the politics of knowledge production in management studies. Journal of Management Inquiry, 3o(1), 59-67. DOI: 10.1177/1056492619835314

Bowles, H., \& Murphy, A. C. (Eds.) (2020). English-medium instruction and the internationalization of universities. Palgrave Macmillan.

Bradford, A., \& Brown, H. D. (Eds.) (2017). English-medium instruction in Japanese higher education: Policy, challenges and outcomes. Multilingual Matters. 
Dafouz, E. \& Smit, U. (2016). Towards a dynamic conceptual framework for Englishmedium education in multilingual university settings. Applied Linguistics, $37(3), 397-415$.

De Schutter, H., \& Robichaud, D. (2015). Van Parijsian linguistic justice: Context, analysis and critiques. Critical Review of International Social and Political Philosophy, 18, 87-112.

De Swaan, A. (2001). Words of the world. The global language system. Polity Press.

De Swaan, A. (2010). Language systems. In N. Coupland (Ed.), The handbook of language and globalization (pp. 56-114). Wiley-Blackwell.

Dimova, S., Hultgren, A. K., \& Jensen, C. (Eds.) (2015). English-medium instruction in European higher education (English in Europe, vol. 3). De Gruyter.

Doíz, A., Lasagabaster, D., \& Sierra, J. M. (2014). Language friction and multilingual policies in higher education: The stakeholders' view. Journal of Multilingual and Multicultural Development, 35(4), 345-36o. DOI: 10.1080/01434632.2013.874433

Earls, C. W. (2013). Setting the Catherine wheel in motion: An exploration of 'Englishization' in the German higher education system. Language Problems \& Language Planning, 37(2), 125-150.

Edwards, A. (2016). English in the Netherlands: Functions, forms and attitudes. John Benjamins.

Fang, F. (2018). Review of English as a medium of instruction in Chinese universities today: Current trends and future directions. English Today, 34(1), 32-37.

Giddens, A. (1984). The constitution of society. Polity Press.

Giroux, H. (2014). Neoliberalism's war on higher education. Haymarket Books

Gürtler, K., \& Kronewald, E. (2015). Internationalization and English-medium instruction in German higher education. In S. Dimova, A. K. Hultgren, \& C. Jensen (Eds.), English-medium instruction in European higher education (English in Europe, vol. 3) (pp. 89-114). De Gruyter.

Harvey, D. (2007). A brief history of neoliberalism. Oxford University Press.

Hultgren, A. K. (2015). English as an international language of science and its effect on Nordic terminology: The view of scientists. In A. Linn, N. Bermel, \& G. Ferguson (Eds.), Attitudes towards English in Europe. (English in Europe, vol 1 ) (pp. 139-163). De Gruyter.

Hultgren, A. K. (2014). English language use at the internationalized universities of Northern Europe: Is there a correlation between Englishization and world rank? Multilingua, 33(3-4), 389-411.

Hultgren, A. K., Gregersen, F., \& Thøgersen, J. (Eds.) (2014). English in Nordic universities: Ideologies and practices. John Benjamins.

Hultgren, A. K., \& Thøgersen, J. (2014). Englishization of Nordic universities: Policy and practice: A disconnect. Language Problems \& Language Planning, 38(3), 247-264. 
Humboldt, W. von (2010). Über die Verschiedenheit des Menschlichen Sprachbaues und ihren Einfluss aufdie Geistige Entwickelung des Menschengeschlechts. Nabu Press. (Original work published 1836)

Hung, D. M., \& Lan, L. T. D. (2017). Content lecturers' challenges in EMI classroom. European Journal of English Language Teaching, 2(1), 1-21.

Hynninen, N., \& Kuteeva, M. (2020). Researchers' language practices concerning knowledge production and dissemination: Discourses of mono- and multilingualism. In M. Kuteeva, K. Kaufhold, \& N. Hynninen (Eds.), Language perceptions and practices in multilingual universities (pp. 323-35o). Palgrave Macmillan.

Jackson, T., \& Primecz, H. (2019). Cross-cultural management studies and the Englishization of scholarly communication: A paradox. International Journal of Cross-Cultural Management, 19(2), 1-5. DOI: 10.1177/1470595819865095

Kirkpatrick, T. A. (2011). Internationalization or Englishization: Medium of instruction in today's universities. Hong Kong Institute of Education, Centre for Governance and Citizenship [pre-publication] https://pdfs.semanticscholar. org/fdaf/d13bo428dgcfa31966f242e1a6416f29c94c.pdf

Kuteeva, M. (2020). If not English, then what? Unpacking language hierarchies at university. In M. Kuteeva, K. Kaufhold, \& N. Hynninen(Eds.), Language perceptions and practices in multilingual universities (pp. 27-55). Palgrave Macmillan.

Kuteeva M., Kaufhold, K., \& Hynninen N. (2020). Introduction: Language perceptions and practices in multilingual universities. In M. Kuteeva, K. Kaufhold, \& N. Hynninen (Eds.), Language perceptions and practices in multilingual universities (pp. 1-24). Palgrave Macmillan.

Lafont, C. (2020). Democracy without shortcuts: A participatory conception of deliberative democracy. Oxford University Press.

Lanvers, U., \& Hultgren, A. K. (2018a). The Englishization of European education: Foreword. European Journal of Language Policy, 10(1), 1-11.

Lanvers, U., \& Hultgren, A. K. (2018b). The Englishization of European education: Concluding remarks. European Journal of Language Policy, 10(1), 147-152.

Macaro, E. (2018). English medium instruction. Oxford University Press.

Macaro, E., Curle, S., Pun, J., An, J., \& Dearden, J. (2018). A systematic review of English medium instruction in higher education. Language Teaching, 51(1), 36-76. DOI: 10.1017/So261444817000350.

Maher, J.C. (2017). Multilingualism. Oxford University Press.

May, S. (2015). The problem with English(es) and linguistic (in)justice. Addressing the limits of liberal egalitarian accounts of language. Critical Review of International Social and Political Philosophy, 18, 131-148.

McIlwraith, H. (2015). Language rich. Africa policy dialogue. British Council. Münch, R. (2007). Die akademische Elite. Suhrkamp. 
Münch, R. (2011). Akademischer Kapitalismus. Über die politische Ökonomie der Hochschulreform. Suhrkamp.

Murphy, A. C., \& Mengistu, M. S. (2020). The challenges of internationalization in EMI tertiary education in Ethiopia. In H. Bowles \& A. C. Murphy (Eds.), English-medium instruction and the internationalization of universities (pp. 77101). Palgrave Macmillan.

New Oxford Annotated Bible. New Revised Standard Version. (2010).

Nordic Council of Ministers. (2007). Deklaration om nordisk språkpolitik 2006 [Declaration on Nordic Language policy 2006]. Copenhagen: Nordiska Ministerradet. Retrieved from https://www.norden.org/en/node/6978

Peck, J. (2010). Constructions of neoliberal reason. Oxford University Press.

Phillipson, R. (1992). Linguistic imperialism. Oxford University Press.

Pierini, F. (2016). Multilingualism and Englishization in international business communication: The case of some Italian wine producers. English Today, 32(1), 48-55.

Preece, S. (Ed.) (2016). The Routledge handbook oflanguage and identity. Routledge.

Price, G. (2014). English for all? Neoliberalism, globalization, and language policy in Taiwan. Language in Society, 43, (567-589).

Pulcini, V., \& Campagna, S. (2015). Internationalisation and the EMI controversy in Italian higher education. In S. Dimova, A. K. Hultgren, \& C. Jensen (Eds.), English-medium instruction in European higher education (English in Europe, vol. 3) (pp. 65-87). De Gruyter.

Quick, E. (2021). Aligning policy and practice: Linguistic and pedagogical strategies for the EMI classroom. In L. Mastellotto \& R. Zanin (Eds.) (2021), EMI and beyond: Internationalising higher education curricula in Italy (pp. 53-76). Bozen-Bolzano University Press.

Radder, H. (Ed.) (2010). The commodification of academic research. Science and the modern university. University of Pittsburgh Press.

Räsänen, A., \& Klaassen, R. (2004). Academic competences in a multilingual learning environment. In R. Wilkinson (Ed.), Integrating content and language: Meeting the challenge of a multilingual higher education (pp. 565-570). Universitaire Pers Maastricht.

Rivlina, A. A. (2013). Englishization of Russian and bilingual lexical variation. Higher School of Economics Working Paper, WP BRP 05/LNG/2013.

Robertson, R. (1992). Globalization: Social theory and global culture. Sage.

Rubio-Alcalá, F. D., \& Coyle, D. (2021). Developing and evaluating quality bilingual practices in higher education. Multilingual Matters.

Sabaté-Dalmau, M. (2020). Neoliberal language policies and linguistic entrepreneurship in higher education: Lecturers' perspectives. Language, Culture and Society, 2(2), 174-196. 
Shi, X. (2013). The glocalization of English: A Chinese case study.Journal of Developing Societies, 20, 89-122.

Shimauchi, S. (2018). English-medium instruction in the internationalization of higher education in Japan: Rationales and issues. Educational Studies in Japan: International Yearbook, 12, 77-90.

Spolsky, B. (2004). Language policy. Cambridge University Press.

Spolsky, B. (2007). Towards a theory of language policy. Working Papers in Educational Linguistics, 22(1), 1-14.

Studer, P. (2021). Internationalization, quality and multilingualism in higher education: A troublesome relationship. In F. D. Rubio-Alcalá \& D. Coyle (Eds.), Developing and evaluating quality bilingual practices in higher education (pp. 9-3o). CPI Books.

Tam, K.-k. (Ed.) (2009). Englishization in Asia: Language and cultural issues. Open University of Hong Kong Press.

Tam, K.-k. (2019). The Englishized subject: Postcolonial writings in Hong Kong, Singapore and Malaysia. Springer.

Taylor, C. (1985). Self-interpreting animals. In C. Taylor, Human agency and language. Philosophical papers 1 (pp. 45-76). Cambridge University Press.

Taylor, C. (2016). The language animal. The full shape of the human linguistic capacity. The Belknap Press of Harvard University Press.

Tejada-Sánchez, I., \& Molina-Naar, M. (2020). English medium instruction and the internationalization of higher education in Latin America: A case study from a Colombian University. Latin American Journal of Content \& Language Integrated Learning, 13(2), 339-367.

Tietze, S. (2004). Spreading the management gospel - in English. Language and Intercultural Communication, 4(3), 175-189. DOI: 10.1080/14708470408668871

Trabant, J. (2003). Mithridates im Paradies. Kleine Geschichte des Sprachdenkens. Beck Verlag.

Tsou W., \& Kao S. M. (2017). Overview of EMI development. In W. Tsou \& S. M. Kao. (Eds.), English as a medium of instruction in higher education (pp. 3-18). Springer. Van Parijs, P. (2011). Linguistic justice for Europe and for the world. Oxford University Press.

Wallerstein, I. (1974). The modern world-system, vol. I: Capitalist agriculture and the origins of the European world-economy in the sixteenth century. Academic Press.

Yildiz, Y. (2012). Beyond the mother tongue: The postmonolingual condition. Fordham University Press. 


\section{About the authors}

RENÉ GABRIËLS is a lecturer in philosophy at Maastricht University (Netherlands). His research concerns social philosophy, sociolinguistics, philosophy of language and sociology of stratification. He focuses on democracy, inequality, human rights, linguistic justice, poverty and the relation between semantics and pragmatics, with current research on English-medium instruction (EMI) at universities and on food banks.

Robert WiLKINSON is a visiting Research Fellow in the Department of Philosophy at Maastricht University (Netherlands) and conducts research on English-medium instruction (EMI) and multilingualism. He previously worked at Maastricht University's Language Centre, and earlier in Scotland, Czechoslovakia and France. He is currently chair of the ICLHE Association. 


\title{
$2 \quad$ Higher Education in Flanders
}

\author{
English as the 'other' language
}

Frankvan Splunder

\begin{abstract}
English is firmly rooted in Flemish academia, in spite of restrictions imposed by the Flemish government. The government's language policy is informed by the view that Dutch (Flanders' official language) should be promoted and that the use of languages other than Dutch should be managed carefully. Yet English has become the dominant 'other' language in Flemish higher education, including as an additional medium of instruction. Even though English is widely used, it is also a matter of public debate, touching on issues concerning identity, equality, and justice. In comparison with the Netherlands, the Englishization of higher education remains fairly limited, yet English is far more prominent in the north of Belgium (Dutch-speaking Flanders) than in the south (French-speaking Wallonia).
\end{abstract}

Keywords: Belgium, Flanders, globalization, identity, language struggle, multilingualism

\section{Introduction}

This chapter deals with Flanders, the Dutch-speaking part of Belgium. It first contextualizes the linguistic situation in Belgium, after which it focuses on the current use of English in Flemish higher education. In this chapter, English is conceptualized as the main 'other' language in an increasingly multilingual context.

Wilkinson, Robert, and René Gabriëls (eds), The Englishization of Higher Education in Europe. Amsterdam, Amsterdam University Press 2021 DOI: 10.5117/9789463727358_CHO2 
Figure 2.1 Belgium: official languages

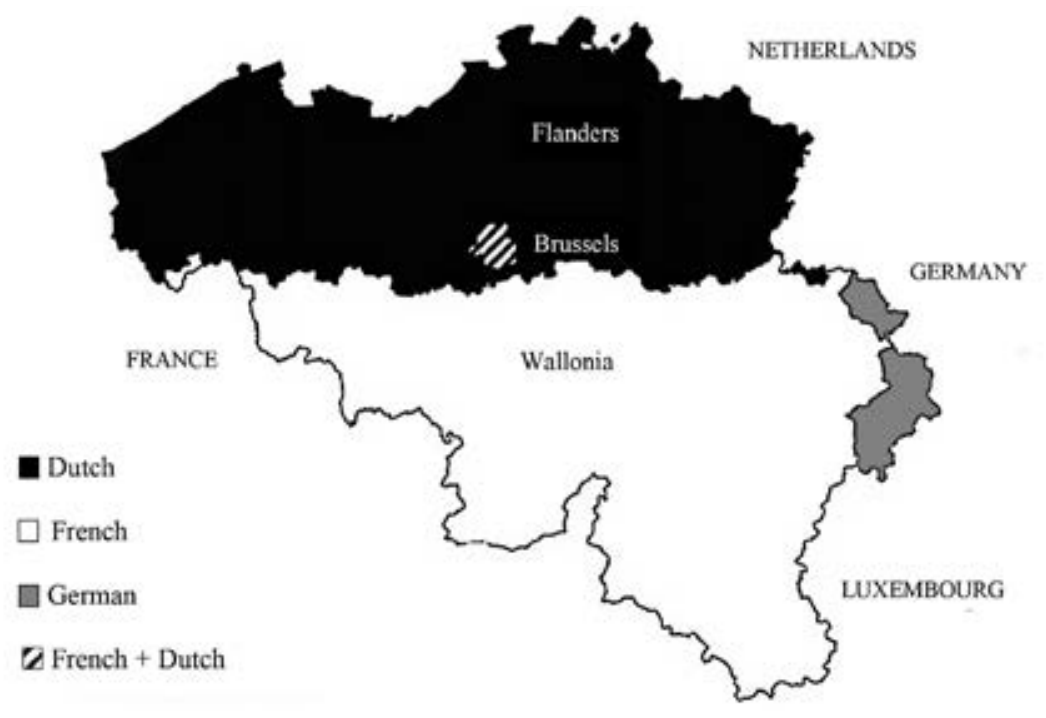

\section{Languages in Belgium}

Language is a sensitive and divisive issue in Belgium. Although the country has three official languages, none of them is official in the whole country, but in certain designated regions only: Dutch is official in Flanders, French in Wallonia, and both are official in the Brussels-Capital region. In addition, there is a small German-speaking community, which is part of the Walloon region. Due to migration from other European as well as non-European countries and the presence of international corporations and institutions (e.g., the European Parliament, NATO), many other languages are being used in Belgium, but they lack official recognition. In spite of its institutionalized regional monolingualism (or bilingualism in some areas), Belgium is a highly multilingual country, especially in urban areas. English increasingly serves as the de facto second language, even though it is not an official language either. In a Belgian context, English is more 'neutral' than either French or Dutch, and in Flanders as well as in Wallonia, young people tend to be more fluent in English than in their neighbours' language, and their attitudes towards English are far more positive too (e.g., Dewaele, 20o8; O'Donnell \& Toebosch, 2008; Grover, 2019).

The creation of monolingual areas in Belgium reflects the 19th century language struggle in which Flanders sought recognition for its language (Dutch, which was usually called Flemish back then) alongside French. 
Even though French was the minority language, it was the dominant language in the whole country, and a prerequisite for upward social mobility (van Splunder, 2020, pp. 86-88). As a consequence, French was synonymous with social, cultural, economic, and political power. Moreover, higher education was entirely in French, as a result of which Flemings could not study in their own language. Even though the language struggle may be a relic of the past, language remains a core issue in Belgian politics, resulting in a labyrinth of language laws. Through a series of state reforms from the 1970 os onwards, Belgium was gradually transformed from a unitary into a federal state, based on regions and communities (linguistic identities) with a relatively high degree of autonomy. As a result of the 1988-1989 state reform, the linguistic communities have become responsible for their own educational system. Thus, there are three Ministries of Education in Belgium: one for the Dutch-speaking community, one for the Frenchspeaking community, and one for the German-speaking community, all of which pursue independent policies. In the bilingual Brussels-Capital region, two distinct monolingual educational systems exist, organized by the Dutch-speaking and the French-speaking communities respectively.

While Flanders and Wallonia are growing apart, both regions have set up ties with their neighbours across the state border. Flanders and the Netherlands work closely together in the Dutch Language Union (Taalunie), an intergovernmental organization committed to a common language policy. Although the main focus of the organization is on issues regarding the Dutch language, it actually promotes multilingualism and linguistic diversity. As a possible alternative to English as a lingua franca (ELF), the use of lingua receptiva (LaRa) is stimulated: interlocutors speak their own language, while relying on their receptive skills in the other language (ten Thije, 2013). This is possible in a context where two or more languages co-occur, for instance Dutch and French in Belgian politics (e.g., a Flemish journalist asks questions in Dutch and a Walloon politician replies in French). However, this is only feasible if both interlocutors understand the other person's language well enough. Concerning higher education, Flanders and the Netherlands collaborate in the NVAO (Dutch-Flemish Accreditation Organization), an independent educational organization which assesses the quality of higher education institutions and recognizes study programmes in both areas. In addition, Flemish and Dutch higher education institutions have set up joint organizations such as NUT (Dutch and Flemish University Language Centres, Nederlandse en Vlaamse Universitaire Talencentra) and the Language Policy Platform (Nederlands/Vlaams Platform Taalbeleid Hoger Onderwijs), which aim to share information 
and expertise concerning, inter alia, language policies and practices in higher education. In line with the Dutch Language Union, they promote multilingualism and linguistic diversity, while at the same time they stress the seminal importance of Dutch in higher education. In addition, they recognize the crucial role of English, for instance as an additional language of instruction.

French-speaking Wallonia is linguistically and culturally oriented towards France. Like France, Wallonia used to practise monolingual language policies, and it paid little attention to foreign language learning until the 199os, when CLIL (Content and Language Integrated Learning) was introduced with Dutch, English, or German as content languages (Van de Craen et al., 2012). English language proficiency remains considerably higher in the Dutch-speaking part of Belgium than in the French-speaking part. Whereas in Flanders proficiency in English is generally very high (almost as high as in the Netherlands), in Wallonia it is rather moderate (but higher than in France) (Education First, 2019). English is also far more present in Flanders than in Wallonia. For instance, in Wallonia English-language films are dubbed in French, while in Flanders they are subtitled. English-medium instruction is less widespread in Wallonia than in Flanders, and it is far less institutionalized in terms of language requirements and testing. In addition, language legislation in higher education (Communauté française, 2013, p. 35) is not as elaborate as in Flanders. The small German-speaking community of Belgium is largely dependent on higher education institutions in neighbouring Wallonia and Germany, as there are no universities in East Belgium (Ostbelgien in German). German-speaking Belgian students tend to have better English language skills than their French-speaking counterparts and better French language skills than Flemish students (Doerflinger \& Knipprath, 2018, p. 43).

Unlike most other language learners in Europe, Flemish pupils learn French as their first foreign language. French is taught from the age of 11, whereas English tuition starts at 13. However, while French is basically taught in an instructed setting (i.e., a classroom), Flemish pupils are exposed to English outside the classroom through pop music, television, computer games, the internet, and social media. As a result, they have massive exposure to English, but not to French (Peters et al., 2019). Consequently, most Flemish pupils are much more fluent in English than in French. Even though English may be their third language officially, in practice it is their second language. English is embraced by both regions in higher education, but it is more salient in Flanders. 
There may be some irony in the fact that higher education in multilingual Belgium is organized along monolingual lines, reflecting monolingual language ideologies. As previously observed, this is due to historical and political circumstances, and the unequal relationship between Dutch and French in the past. As a result of the bitter language struggle of the 196os, the then bilingual university of Leuven (the oldest university in the Low Countries) was split into two monolingual universities: the Dutch-language University of Leuven and the French-language University of Louvain, which was relocated in Wallonia (and renamed Louvain-la-Neuve, New Leuven). In the meantime, both universities have introduced English as their additional language. Communication between Flemish and Walloon academics is often in English too (e.g., by email).

Apart from the official regional languages Dutch, French, and German, English increasingly serves as the unofficial language of wider communication in Belgium. In addition to these four languages, many other unofficial languages are being used in the country, including minority-ethnic languages/dialects (e.g., Italian, Spanish, Turkish, Arabic/Tamazight, Polish), regional languages/dialects (e.g., varieties of Flemish, Walloon, German/Luxembourgian), and sign languages (e.g., French-Belgian and Flemish Sign Language, both of which have been recognized in their respective communities). In the Brussels region, for instance, more than a hundred languages are spoken. While English is the de facto second language in Brussels (after French, but before Dutch), $8 \%$ of the Brussels population only speaks languages other than French, English, or Dutch (Janssens, 2018). This multilingual reality runs counter to the conceptualization of Belgium as a bilingual (Dutch-French) or trilingual (Dutch-French-German) state, consisting of homogeneous and standardized languages.

Table 2.1 Languages in Belgium

\begin{tabular}{lllll}
\hline & Flanders & Wallonia & Brussels & East Belgium \\
\hline $\begin{array}{l}\text { Official } \\
\text { language(s) }\end{array}$ & Dutch & French & French & German \\
$\begin{array}{l}\text { Language of wider } \\
\text { communication }\end{array}$ & English & English & English & French \\
\hline
\end{tabular}

The remainder of this chapter will focus on the use of English in higher education in Flanders, where English is far more prominent than in the French-speaking part of the country. 


\section{Englishization in Dutch-speaking Flanders}

The following paragraphs discuss language policies and practices in Flanders. While language policy can be described as dealing with laws and other regulations, language practice is about what actually happens with those policies. This view ties in with the conceptualization of language policy research as a multi-layered and discursive process which takes into account the social reality in which language policies are shaped, developed, and negotiated (Barakos \& Unger, 2016; Bonacina-Pugh et al., 2020). The section on language policy discusses the Flemish political and linguistic context, language legislation in higher education, language testing, and university policies. The section on language practices deals with university practices and public debates on English.

\subsection{Language policy}

Language is a highly politicized issue in Flanders, which seeks to protect Dutch vis-à-vis other languages. Language policy in Flanders should be understood in the context of a long tradition of language regulation. Apart from protecting Dutch (for instance as a medium of instruction), it aims to manage the use of languages other than Dutch. In spite of efforts to promote multilingualism, Flemish language policy is firmly based on the ideology of territorial monolingualism (Blommaert, 2011). Therefore, Dutch has a pivotal role as a medium of instruction in Flanders. This is particularly obvious in primary and secondary education. As a consequence of the 1963 law stipulating that all teaching in Flemish schools (except foreign languages) must be in Dutch, CLIL (with French, English, or German as content languages) was introduced only in 2014 (Bulté et al., 2020). Moreover, students are discouraged from using their home languages (often minority-ethnic languages such as Turkish or Arabic) in Flemish schools and encouraged to speak Dutch only (Sierens \& Van Avermaet, 2014). At the same time, however, English is increasingly present in (higher) education, where it is commonly presented as 'internationalization', as in many other countries and regions (Wilkinson \& Walsh, 2015, p. 10).

From a historical perspective, the 'other' language in Flanders was French, the minority language spoken by the elite in Belgium (in Wallonia as well as in Flanders). After a long struggle of emancipation, in which the Dutch language was promoted as the crucial element of Flemish identity, the Flemish majority gradually obtained linguistic and other equality. For instance, it was not until 1930 when Dutch was recognized as a language 
of higher education in Flanders. In today's Flanders, French has lost its dominant position, and English has become the 'other' language. In general, attitudes towards English are far more positive than towards French. Yet there are fears that Dutch might lose its position again, in particular in higher education. As a result, the Flemish government has taken measures to protect Dutch, and to ensure that students can study in Dutch, even though an increasing number of them do not speak Dutch as their home language. As observed earlier, these 'other' languages (e.g., Turkish or Arabic) are commonly regarded as deficient in a Flemish educational context. Flemish language sensitivity is pervasive across the whole political spectrum, but it is particularly salient in Flemish nationalism, which dominates the current political landscape.

While Flanders and Wallonia share a country (Belgium), they do not share a language. In contrast, Flanders and the Netherlands share a language (Dutch) but not a country. In spite of their commitment to a common language policy, Flanders and the Netherlands pursue different language practices, which is due to the different historical and political context. This is particularly striking concerning the use of English in higher education. Whereas the Netherlands have embraced English as their medium of instruction at the expense of Dutch, Flanders is far more reluctant concerning English-medium instruction. Moreover, Flemish universities have to abide by the rules set out by the Flemish government, whereas Dutch universities have more freedom to develop their own language policies. While the Flemish top-down policy reflects Flemish language sensitivity and the belief that language needs to be regulated, the Dutch bottom-up language policy is more in line with Anglo-American liberal attitudes towards language use (van Splunder, 2015).

In Flanders, the use of English in higher education has been embodied by complex legislation which seeks to quantify language policy. The 2012 Decree (Flemish law) states, inter alia, that Dutch is the language of instruction at all Flemish universities and university colleges (hogescholen). Recently the name 'universities of applied science' was adopted as an alternative to 'university college', as the word college can also refer to schools of secondary education, as is indeed the case in Flanders (VLOHRA, 2021). The law also states that languages other than Dutch may be used on condition that they provide an 'added value' (meerwaarde) and that there is an equivalent programme in Dutch (e.g., at another university in Flanders), so that students can pursue their studies entirely in Dutch (Vlaamse Codex, 2012). Students also have the right to sit their exams in Dutch, even when the course was taught in another language. In addition, the use of languages other than Dutch 
is restricted to $18.33 \%$ in initial bachelor programmes and $50 \%$ in initial master's programmes (i.e., at an individual institution). If the percentages are higher, the programme is not considered a Dutch-language programme anymore. This is an important issue, as Flemish institutions of higher education can provide maximum $9 \%$ (6\% before 2020) of their bachelor programmes and $35 \%$ of their master's programmes in languages other than Dutch. In reality, the picture is far more complicated, as there are many exceptions, including international programmes which are taught entirely in English. This also reveals that 'languages other than Dutch' in practice means English, as English is the only language which is widely used as an additional medium of instruction. In spite of its former status as a language of instruction, French has almost completely disappeared in Flemish higher education. For instance, the 2019 survey lists 30 bachelor programmes in languages other than Dutch: 27 in English versus 3 in French. It should be noted that one of these 'French' programmes is in fact a trilingual (Dutch, English, French) bachelor's degree in nursing, and the other two programmes are taught at the Antwerp Maritime Academy, which provides courses in Dutch and English as well (Vlaams Parlement, 2019).

Apart from this strict language regulation Flemish universities and university colleges/universities of applied sciences have to abide by, they are closely monitored by the government. The current figures show that the number of programmes taught in English is well below the maximum set by the government. In 2019, $5.82 \%$ of the bachelor's programmes and $24 \%$ of the master's programmes were taught in languages other than Dutch, which in practice means English (Vlaams Parlement, 2020). A recent proposal to increase the maximum percentages of instruction in languages other than Dutch (i.e., from $18.33 \%$ to $50 \%$ ) was rejected. The current Education Minister (a Flemish nationalist) declared himself in favour of the current restrictions and he would not increase the percentages, a move which was widely supported by his political allies. This may indicate that the use of English as a medium of instruction remains relatively limited in Flemish higher education (in particular when compared to the Netherlands). On the other hand, it should be noted that these percentages may hide a more complex reality as, for instance, a course which is taught officially in Dutch may be taught in English after all (e.g., if there are not enough students enrolled in the Dutch-language programme). Some of these fake programmes (spookopleidingen) may be regarded as 'creative solutions' to circumvent restrictions imposed by the law (van Splunder \& Engelen, 2018).

Most English-taught programmes are at master's level, in the areas of Applied Economics, Commercial Sciences and Business Administration, 
and Applied Sciences. At PhD level, English is dominant in other areas as well, as more than $90 \%$ of all journal articles and theses are written in English (Rys, 2019, p. 263). A comparative study revealed that there are significant differences between study areas. For instance, whereas English was found to be dominant in mathematics, Dutch remains very important in history (e.g., as a language of publication and in vivas) (Rys, 2019, p. 269). Even though Flemish students are legally entitled to pursue their studies in Dutch, many actually prefer to study in English and take their exams in English as well. The main argument in favour of English is that it is the academic lingua franca and studying in English opens the gateway to the world. An obvious counter-argument is that many graduates will work in Flanders, where they will need Dutch rather than English. Moreover, the exclusive focus on English runs counter to the idea of multilingualism, which is supported by the Dutch Language Union, the Flemish government as well as organizations representing Flemish academics and students. Overall, Flemish students tend to have positive attitudes towards multilingual education (Rys, 2019, p. 262).

As part of their language policy, the Flemish government set up language requirements for lecturers and students in higher education. For teaching purposes, the C1-level of the CEFR (Common European Framework for Languages) is required, that is, the advanced level needed for social, academic, and professional purposes. As a consequence, all lecturers teaching in a 'language different from their mother tongue' (usually English) are required to take one of the language tests recognized by the government. In addition, non-native speakers of Dutch have to master Dutch at A2-level ('basic user') after two years and B2 ('independent user') after five years. These strict language requirements may deter some international applicants, for whom learning Dutch may be an additional burden. Students usually need a B2-level, but for some courses (e.g., language studies) $\mathrm{C}_{1}$ is required. Whereas students from abroad have to prove their level, students who studied in Flemish secondary education are assumed to have a B2-level. Yet this is not always the case, as their assignments in higher education reveal. Interestingly, students tend to overrate their level of English, and to underrate their lecturers' English. Most of the students' complaints deal with their lecturers' spoken English, and their 'bad' pronunciation in particular (van Splunder, 2014, p. 236). Many students have poor writing skills, and academic writing (in English as well as in Dutch) is a particular problem. It should be added that English is commonly conceptualized as 'standard' British or, to a lesser extent, American English. Moreover, the 'native speaker' model is still dominant in language learning, teaching, and testing, even though 
this model is highly problematic (Seidlhofer, 2011, p. 33). In addition, most Flemish people actually speak and write Dutch English (sometimes called Dunglish) rather than British or American English.

As a consequence of the government's policy, Flemish universities decided to set up a unique collaboration to design their own language test, the ITACE (Interuniversity Test of Academic English). The ITACE, which is a high-stakes test and currently the most common English language test at Flemish universities, meets the international test standards set by ALTE (Association of Language Testers in Europe) and it has been recognized by the Flemish government alongside other tests such as IELTS and TOEFL. The main difference with tests developed in English-speaking countries is that the ITACE is aimed at a specific academic context in which English is used as an additional language of instruction which is not the lecturers' or students' first language. The implementation of a mandatory language test reflects Flemish language sensitivity as well as a strong tradition of top-down language control. Together with the language test, Flemish universities set up additional language support and remedial courses for lecturers as well as students. Most of these courses are provided by the universities' language centres, and most of them are free of charge. Even though the obvious aim of the ITACE was to test the lecturers' language command when teaching in English and to improve the quality of education, it sparked a media storm which entirely neglected the very purpose of the test (van Splunder \& Verguts, 2017). The test was even perceived as a political tool to curb the use of English (which made no sense at all), and some lecturers refused to take the test. However, the large majority of test-takers passed, and in the meantime the storm has died down. Nowadays, the language test is taken for granted and language courses are in high demand, as lecturers are motivated to improve their skills in academic English.

In accordance with the Decree, Flemish higher institutions are required to draw up a Code of Conduct regarding their language(s) of instruction, and to report annually to the Flemish government. Apart from reflecting the current legislation, these texts negotiate a compromise between the official language of instruction (Dutch) and the academic lingua franca (English). It is also quite striking that the texts tend to avoid the word 'English', and that they prefer generic references to 'other languages' or 'foreign languages'. Similarly, the term 'Englishization' (verengelsing) is avoided and subsumed under concepts such as 'internationalization' and 'multilingualism', even though French, German, and other foreign languages play hardly any role as a medium of instruction in Flemish higher education. Moreover, the term verengelsing has negative connotations, as it implies that English 
will replace Dutch (or any other language). In higher education, the term mainly refers to the perceived excessive use of English in text materials (e.g., US handbooks), its use as a medium of instruction, and the dominance of Anglo-American paradigms in academia.

\subsection{Language practices}

English is very much present on Flemish campuses, in spite of the government's restrictive language policy. A survey of university websites revealed that all Flemish universities have bilingual websites (Dutch-English), even though not all information may be available in both languages. For some courses taught in Dutch, only basic information may be provided in English, for instance. In general, however, course descriptions are provided in both languages. Perhaps surprisingly, course names tend to be in English, even when a course is taught in Dutch. Most Flemish universities provide English translations of their names (but some stick to their name or acronym in Dutch). Notice boards and other public announcements on campus reveal a mixture of both languages, as some announcements are available either in Dutch or in English. Announcements for an international audience tend to be in English only. Apart from its use as a medium of instruction, English is used in oral and in written communication, such as meetings or email. Messages sent out to groups tend to be bilingual: first Dutch, then English. For instance, during the 2020 coronavirus pandemic, care was taken to provide all information in both languages. Due to the presence of international staff and students, English often features as the de facto first language, particularly in oral communication. The ripple effect of English can also be observed beyond the campus, as English is very prominent in bars, restaurants, shops, advertisements, and so on. Moreover, English is increasingly used as a lingua franca in Flanders. The language is firmly rooted in Flemish daily life, where it has largely replaced French as a second language. In Brussels, where French is still far more dominant than in Flanders, Flemings use Dutch, French, and English in their daily lives (Taalunie, 2020).

A case study (Moors, 2020) at the University of Antwerp revealed that Dutch was more prominent than English on the university's website, in its magazines (which only provide abstracts in English), as well as social media. Even though most programmes are taught in Dutch, a substantial part of them are actually taught in English, and most of the literature is in English anyway. The choice of language may be flexible, and 'switches' between Dutch and English occur. For instance, when one participant does not speak 
Dutch, everyone will switch to English. While meetings related to policy issues tend to be in Dutch, meetings related to research tend to be in English. Minutes can be drawn up in either language, depending on the language of the meeting. These examples show that language practices tend to be more flexible than language policies. Other Flemish higher education institutions have launched ambitious programmes promoting multilingualism rather than Englishization. That is, the students' full linguistic potential should be addressed, not just their knowledge of Dutch and English. For instance, speakers of minority-ethnic languages can gain access to communities which cannot be reached with Dutch or English. This recognition of linguistic diversity is based on a positive attitude towards language rather than on a deficiency theory, which perceives some languages as inaccurate or inferior. The focus on multilingualism fits in with the idea of linguistic and cultural diversity, social equality, and justice, which have long been neglected in language education (Duchêne, 2019).

By and large, the public debate on the use of English in Flemish higher education is informed by different discourses on language. The first is the discourse of globalization, which emphasizes the necessity of English in an international academic context. That is, English is seen as a prerequisite to gain access to the world, which is vital for a relatively small language area. This discourse is particularly salient in areas of research with an economic or commercial impact (e.g., business studies or marketing). In contrast, the humanities and social sciences are less market-driven and often object to the marketization and commodification of higher education, which can be regarded as undesirable by-products of globalization. Moreover, in these disciplines, language is intrinsically linked to the area of research (e.g., literary studies or sociology) and it does not merely have an instrumental function (as in the natural sciences). Yet these areas of research need English, too, to reach beyond the national borders.

Second, the identity discourse, which is frequently influenced by rightwing Flemish nationalism, focuses on the protection or promotion of Dutch and the perceived threat of English (or any other language) to the Dutch language and Flemish identity. This discourse reflects the 19th century language struggle, when Dutch was dominated by French, even though the political and cultural context was entirely different. Metaphors of war (as in the very concept of 'language struggle', taalstrijd) are quite common in this discourse. Whereas the 'struggle' for Dutch and the eventual Dutchification (vernederlandsing) of higher education in Flanders are seen as milestones in the emancipation of Flanders, the former Frenchification (verfransing) and the current Englishization (verengelsing) are seen as detrimental. In the 
identity discourse, Englishization is often equated with Americanization and the dominance of Anglo-American paradigms in academia, an argument which can also be heard in left-wing discourses on Englishization. In a more inclusive view of identity, English can be seen as an additional identity. Many young people have layered identities, whose elements are not mutually exclusive. Thus, one can be a speaker of Dutch, Turkish, English, and maybe a couple of other languages too, all expressing layers of one's identity.

Third, the academic discourse focuses on the position of Dutch as an academic language and its domain loss in particular areas of research. For instance, academic literature may be available in English only, and even a term such as 'bachelor' does not have an equivalent in Dutch. One of the aims of the Dutch Language Union is to save Dutch as a scientific language and to ensure that scientific research remains also available in Dutch (Taalunie, 2020, p. 13). In his 2019-2024 policy note on education, the Flemish Minister of Education stipulates that research funded by the Flemish Government should always be accompanied by a concise translation into Dutch to ensure that Dutch, as a language of science, retains its standing (Weyts, 2019, p. 6o).

Fourth, the quality of education discourse deals with the impact of Englishmedium instruction (EMI) on the quality of higher education. While its economic and institutional benefits may be obvious (e.g., increased revenues, higher rankings), EMI is a linguistic challenge to all parties involved (Galloway, 2020, pp. 32-36). However, this challenge is often neglected or overlooked. While some content lecturers tend to downplay the importance of language ('I don't care about grammar or spelling mistakes in my students' assignments in English' is a common comment), others think language is of paramount importance. As a consequence, in several study programmes additional language support is provided to improve the students' writing skills in English.

Last but not least, the social discourse is concerned with how English may affect certain groups of people, such as minority-ethnic students, for whom it is already difficult to study in Dutch. This may also apply to other students, for instance students who attended the technical strand of secondary education and whose academic language skills tend to be more limited (Deygers, 2017). English may therefore be an additional barrier, as not everyone has the same access to English. This may also explain why certain students prefer to study in Dutch, while other students prefer English. While English may be a barrier, it has been argued that the use of English as a lingua franca can be a means to obtain more equality and justice worldwide, when certain conditions are met (Van Parijs, 2011). It should be noted that these discourses on languages are not mutually exclusive, and 
they even overlap. Thus, English(ization) is an issue in right-wing as well as in left-wing discourses. Moreover, proponents and opponents of English often use the same arguments, but interpret them differently (e.g., the use of English can be seen as a way to lose or to gain identity).

As indicated earlier, the Englishization of higher education in Flanders is a matter of fierce debate in the press and in academia as well. Again, the debate reveals a rift between various discourses. On the one hand, the Flemish government's attempt to promote Dutch and to curb the use of English has been described as 'nanny state interventionism' or even as 'narrow-minded Flemish nationalism', as the implementation of the ITACE revealed (van Splunder \& Verguts, 2017). On the other hand, opposition to English(ization) remains relatively strong as it has broad support from various interest groups (students as well as academics) reflecting a long tradition of Flemish identity management and the promotion of the Dutch language. In the last couple of years, the Netherlands witnessed a similar movement to promote Dutch. For instance, Against English (the English title of a book in Dutch by Jensen et al., 2019) argues against the 'excessive use of English' in Dutch higher education. Even though the Englishization of Flemish higher education remains limited when compared with the Netherlands, Flemish academics have argued against the excessive use of English in Flanders, especially in the humanities. In a recent op-ed article, they warned against the 'bad example' of universities in the Netherlands, which have adopted English instead of Dutch as their sole medium of instruction. According to the authors, commercial motives which are detrimental to the quality of education have led to this 'point of no return' in the Netherlands (Deneckere et al., 2020).

While it is true that English is gaining prominence in Flemish higher education, it may not be as dominant as often suggested (van Splunder \& Engelen, 2018). Language practices at universities reveal that both Dutch and English are commonly used, albeit in different contexts. From an external point of view, universities may be perceived to be English-only as most of their research output is in English indeed, but an internal point of view reveals that Dutch remains very much present in Flemish higher education. This is the case, for instance, with the use of Dutch as a medium of instruction, in public activities, internal communication, and daily life in and around the campus (Rys, 2019, pp. 264-268). In comparison with universities in the Netherlands, Dutch remains prominent in Flemish higher education, even though students may have the feeling that they study in English. It should be added that lecturers as well as students have expressed 
concerns over the quality of education in English, and the problems encountered when teaching or studying in a 'foreign' language. This appears to be a particular issue in the social sciences and humanities, in which language and communicative competence play a crucial role. Teaching in English may be more time-consuming, and lecturers may feel that their communicative repertoire is limited (e.g., they are less spontaneous, and they use less humour). Cultural differences can play an important role too, and they may be a challenge in an international classroom. While many students can cope with English very well, for others it is an extra hurdle.

In spite of these challenges, the use of English is widely supported in Flemish higher education, reflecting academic globalization in which English plays a crucial role (e.g., in study materials, writing papers and dissertations). In general, Flemish lecturers and students tend to have positive attitudes towards English and English-medium instruction, even though this is dependent on various parameters, such as age, experience with EMI, and one's language ideology (van Splunder 2016, p. 207). Apart from the older generations, for whom French was the second language, Flemish academics regard English as their second language, and even as their first academic language, as many of them teach and publish in English rather than in Dutch. Most Flemish students grew up with English, which they regard as their second language, while they perceive French and German as foreign languages. Moreover, many students speak other languages, reflecting the internationalization of higher education as well as the ethnic diversity of society.

\section{Conclusion: Multilingualism rather than Englishization}

English has become the de facto second language in Flanders, where it has largely replaced French as the 'other' language in the last decades. In addition, English is of seminal importance in today's higher education, where many courses are taught in English in spite of legal restrictions and conditions imposed by the Flemish government. Yet the Englishization of higher education remains limited in scope when compared to the Netherlands or some of the Nordic countries (Finland in particular).

The Flemish government's top-down language policy aims to ensure the quality of education. Yet the quantitative approach to language use fails to take into account that there is more to teaching in English than having a C1-level. Pedagogical skills, for instance, are not tested. As Flemish universities have to operate within the limits set by their government, 
English-medium instruction remains more limited than in the north of Europe. From an international perspective, this may hinder the appeal of higher education in Flanders. In addition, the government's quantitative approach does not cater for more flexible approaches to language, such as parallellingualism - a key concept in Nordic language policy - which promotes the use of the national or regional language in parallel with another language, usually English (Hultgren et al., 2014, p. 10). In spite of its strict language policies, language practices in Flanders tend to be rather pragmatic. In daily life, English is used spontaneously, and few people are even aware of the strict language policies imposed by the Flemish government.

Multilingualism is a reality in Flanders, despite underlying monolingual language ideologies. The current focus on multilingualism in some higher education institutions implies that languages other than English are important too. For instance, in Brussels or in other urban areas it is an asset if one can speak several languages: English, French, Dutch, and perhaps some other languages too. Higher education should take into account this multilingual reality, and make sure that students graduate as proficient multilinguals. The bottom line is that multilingualism is more than English only. While English(ization) may mean internationalization and access to the world, it should be noted that English does not mean access to the whole world. Moreover, English may be an additional barrier for some students as well as their lecturers, which raises issues of fairness and justice. Unfortunately, the concept of multilingualism has often been reduced to English-only, as French and German have largely disappeared as academic languages in most areas of research in Flanders.

In a Belgian context, English can be used as a 'neutral' language or as a go-between between speakers of Dutch, French, and German, who might feel more comfortable speaking English as a lingua franca. It might even make sense to adopt English as a fourth official language in Belgium. This does not mean that everything should be available in English, but in certain contexts (e.g., announcements on trains from and to the airport) English may be more useful than any of the other three languages. Likewise, Flanders may have excellent opportunities to set up universities which draw on multilingual resources and in which courses can be taught in several languages - that is, not only Dutch or English, but possibly also French and German. Unfortunately, this may not be feasible because of the politicization of the language issue, which has been cemented in complex and rigid language legislation. 


\section{Acknowledgements}

I would like to thank An De Moor as well as the editors and two anonymous reviewers for providing critical feedback on previous versions of this chapter.

\section{References}

Barakos, E., \& Unger, J. W. (Eds.) (2016). Discursive approaches to language policy. Palgrave Macmillan.

Blommaert, J. (2011). The long language-ideological debate in Belgium. Journal of Multicultural Discourses, 6(3), 241-256.

Bonacina-Pugh, F., Barakos, E., \& Chen, Q. (2020). Language policy in the internationalisation of higher education in Anglophone countries: The interplay between language policy as 'text', 'discourse' and 'practice.' Applied Linguistics Review, 13 July 2020. DOI: 10.1515/applirev-2019-0148

Bulté, B., Martens, L., \& Surmont, J. (2020). CLIL in Vlaanderen [CLIL in Flanders]. UCLL.

Communauté française. (2013). Décret définissant le paysage de l'enseignement supérieur et l'organisation académique des études [Decree defining the landscape of higher education and the academic organization of studies]. Retrieved 10 June 2020 from https://www.gallilex.cfwb.be/document/pdf/39681_029.pdf

Deneckere, G., De Wever, B., Maddens, B., Sinardet, D., Vos, H., \& Vrints, A. (2020, January 14). Gelijke kansen? Forget it [Equal Opportunities? Forget it]. De Standaard.

Dewaele, J.-M. (2008). Sociodemographic, psychological and politicocultural correlates in Flemish students' attitudes towards French and English.Journal of Multilingual and Multicultural Development, 26(2), 118-137.

Deygers, B. (2017). Just testing: Applying theories of justice to high-stakes language tests. International Journal of Applied Linguistics, 168(2), 143-163.

Doerflinger, N., \& Knipprath, H. (2018). Jugendliche und junge Erwachsene in Ostbelgien [Adolescents and young adults in East Belgium]. Research Institute for Work and Society.

Duchêne, A. (2019). Multilingualism: An insufficient answer to sociolinguistic inequalities. Social Science Research Council. Retrieved 10 June 2020 from https:// items.ssrc.org/sociolinguistic-frontiers/multilingualism-an-insufficient-answerto-sociolinguistic-inequalities/

Education First. (2019). English Proficiency Index. Retrieved 28 July 2020 from https://www.ef.com/wwen/epi/regions/europe/belgium/

Galloway, N. (Ed.) (2020). English in higher education - English medium Part 1: Literature review. British Council. 
Grover, C. (2019). Learning English in Belgium. Language Issues, 3o(2), 42-44.

Hultgren, A. K., Gregersen, F., \& Thøgersen, J. (2014). English at Nordic Universities: Ideologies and practices. John Benjamins.

Janssens, R. (2018). Meertaligheid als opdracht: Een analyse van de Brusselse taalsituatie op basis van taalbarometer 4 [Multilingualism as a commitment. An analysis of the Brussels language situation based on Language Barometer 4]. Academic and Scientific Publishers.

Jensen, L., Pas, N., Rovers, D., \& van Gulik, K. (2019). Against English:Pleidooi voor het Nederlands [A plea for Dutch]. Wereldbibilotheek.

Moors, S. (2020). Verslag Universiteit Antwerpen [University of Antwerp report]. In K. Rys (Ed.), Staat van het Nederlands (pp. 300-331). Nederlandse Taalunie.

O'Donnell, P., \& Toebosch, A. (2008). Multilingualism in Brussels: 'I'd rather speak English'. Journal of Multilingual and Multicultural Development, 29(2), 154-169. Peters, E., Noreillie, A., Heylen, K., Bulté, B., \& Desmet, P. (2019). The impact of instruction and out-of-school exposure to foreign language input on learners' vocabulary knowledge in two languages. Language Learning, 69(3), 742-782.

Rys, K. (2019). Staat van het Nederlands [The condition of Dutch]. Nederlandse Taalunie.

Seidlhofer, B. (2011). Understanding English as a lingua franca. Oxford University Press.

Sierens, S., \& Van Avermaet, P. (2014). Language diversity in education: Evolving from multilingual education to functional multilingual learning. In D. Little, C. Leung, \& P. Van Avermaet (Eds.), Managing diversity in education: Languages, policies, pedagogies (pp. 204-222). Multilingual Matters.

Taalunie (2020).Jaarverslag 2019 [Annual report]. Den Haag.

ten Thije, J. D. (2013). Lingua receptiva. International Journal of Multilingualism, $10(2), 137-139$.

Van de Craen, P., Surmont, J., Mondt, K., \& Ceuleers, E. (2012). Twelve years of CLIL practice in multilingual Belgium. In G. Egger \& C. Lechner (Eds.), Primary CLIL around Europe: Learning in two languages in primary education (pp. 81-96). Tectum.

Van Parijs, P. (2011). Linguistic justice for Europe and for the world. Oxford University Press.

van Splunder, F. (2014). Negotiating multilingualism in Flemish higher education. In J. W. Unger, M. Krzyżanowski, \& R. Wodak (Eds.), Multilingual encounters in Europe's institutional spaces (pp. 221-242). Bloomsbury.

van Splunder, F. (2015). A tale of two countries: Diverging policies on Englishmedium instruction in the Netherlands and Flanders. In R. Wilkinson \& M. L. Walsh (Eds.), Integrating content and language in higher education: From theory to practice (pp. 89-98). Peter Lang. 
van Splunder, F. (2016). Language ideologies regarding English-medium instruction in European higher education: Insights from Flanders and Finland. In E. Barakos \& J. W. Unger (Eds.), Discursive approaches to language policy (pp. 205-230). Palgrave Macmillan.

van Splunder, F. (2020). Language is politics: Exploring an ecological approach to language. Routledge.

van Splunder, F., \& Engelen, C. (2018). Ruimte voor creatieve oplossingen. Taal in het Vlaamse hoger onderwijs: beleid en praktijk [Room for creative solutions. Language in Flemish higher education: policy and practice]. THeMa, 25(3), 19-23. van Splunder, F., \& Verguts, C. (2017). Testing the test: How politics influenced the reception of an English test for lecturers. Proceedings of the ALTE's 6th International Conference. Learning and Assessment: Making the connections (pp. 51-56).

Vlaamse Codex (2012, 13 July). Decreet betreffende de integratie van de academische hogeschoolopleidingen in de Universiteiten [Decree concerning the integration of academic higher education courses in the universities]. Retrieved 10 April 2020 from https://codex.vlaanderen.be/Portals/Codex/documenten/1022449.html Vlaamse Onderwijsraad (2013). Advies over de implementatie van de nieuwe taalregeling hoger onderwijs [Advice on the implementation of the new language regulation for higher education]. Raad Hoger Onderwijs.

Vlaams Parlement (2019). Anderstalige bachelors 2019-2020 [Bachelor programmes in other languages]. Retrieved 28 July 2020 from http://docs.vlaamsparlement. be/pfile?id=1533878

Vlaams Parlement (2020). Schriftelijke vraag nr. 289 [Written question No. 289], 23 January. Retrieved 2 February 2020 from http://docs.vlaamsparlement.be/ pfile?id=1534129

VLOHRA (2021). Flemish Universities of Applied Sciences and Arts. Retrieved 2 February 2020 from http://www.vlhora.be/indexen.html

Weyts, B. (2019). Beleidsnota Onderwijs 2019-2024 [Policy memorandum Education]. Vlaams Parlement.

Wilkinson, R., \& Walsh, M. L. (Eds.) (2015). Integrating content and language in higher education: From theory to practice. Peter Lang.

\section{About the author}

FrANK VAN SPLUnder holds a PhD in Applied Linguistics from Lancaster University. Currently, he teaches academic writing in a multilingual context at the University of Antwerp. The focus of his research is English as the 
language of globalization and its use in higher education in Flanders and the Netherlands. 


\title{
3 The Englishization of higher education in Estonia and Latvia
}

\author{
Actors, positionings, and linguistic tensions \\ Josep Soler and Kerttu Rozenvalde
}

\begin{abstract}
In Estonia and Latvia, the focus on the domain of higher education as a site of linguistic tension has emerged more powerfully only in recent years. In this chapter, we show how the two sides of the Englishization of higher education (as an opportunity and as a threat) emerge discursively in two public debates that we analyse. Although the issues that are brought up in the debates take a different shape in the two countries, at a fundamental level, similar concerns are discussed. These include language relationships and linguistic hierarchies in higher education, questions on the quality of higher education, and the role of legal measures applied to manage language matters at universities.
\end{abstract}

Keywords: Englishization, higher education, language ideological debates, Estonia, Latvia

\section{$1 \quad$ Introduction}

In Estonia and Latvia, language-related concerns have historically taken a prominent role in the nation-building processes, particularly since their return to political independence in the early 1990s. As such, language policies in education have played a pivotal role in shaping the discourses around the protection, promotion, and development of the state language (Hogan-Brun et al., 2009). In the domain of higher education specifically, language ideological debates remained relatively mild until the mid-2010s. More recently, however, there are signs indicating that the level of linguistic

Wilkinson, Robert, and René Gabriëls (eds), The Englishization of Higher Education in Europe. Amsterdam, Amsterdam University Press 2021 DOI: $10.5117 / 9789463727358 \_$CHO3 
tension may have increased. We posit this may be a result of the consolidated perception of the tension between the 'nationalizing' and the 'globalizing' trends within higher education at present (Rozenvalde, 2018; Soler \& Vihman, 2018), a tension that Englishization, understood as 'the growing use of English as a medium of instruction' (Lanvers \& Hultgren, 2018, p. 1), exacerbates. This seems particularly the case in countries with recent nation-building projects such as the Baltic states (Bulajeva \& Hogan-Brun, 2014).

In the public debates on language in higher education in Estonia and Latvia, the concept of Englishization (ingliskeelestumine in Estonian, anglifikācija or angliskošana in Latvian) is used less than the internationalization of higher education (kõrghariduse rahvusvahelistumine in Estonian; augstākās izglītības internacionalizēšana in Latvian), or as in the case of Latvian state policies, the economic metaphor of higher education export (augstākās izglìtības eksports, cf. Kibbermann, 2017). In Estonia and Latvia, the states still focus their policies on dealing with the outcomes of the Soviet linguistic Russification (Brubaker, 2011; Koreinik et al., 2018). Whereas English is ideologically valued as a language of higher education in state and institutional policies as well as at the grassroots level, state policymakers tend to avoid giving special treatment to English in written policy texts, instead preferring to refer overtly to foreign languages, other languages, or the official languages of the European Union $(E U)$ (in Latvian policy texts) when discussing the use of English in academia (Rozenvalde, 2018). The concepts of the internationalization of higher education or its export are overtly more neutral and seemingly diminish the link between the processes of internationalization and Englishization.

In this chapter we investigate how actors from different backgrounds react to and position themselves vis-à-vis the role and status of the national language and English in the higher education systems of each country. Whereas Russian tends to play a rather prominent role in language ideological debates in Estonia and Latvia in particular contexts (e.g., general education), it does not come up in the discussions on Englishization that we analyse here. Specifically, we conduct a discourse analysis of recent debates that have taken place in the two countries between 2018 and 2020. In our analysis, we underscore that although on the surface, the discussions seem to take a different shape, at a more fundamental level, the core issues are rather similar in both countries. These include the language relationships and linguistic hierarchies in the higher education system, the arguments presented in favour of and 
against the presence of English at universities, and the role of the law and legal measures in order to address the challenges English puts for the national languages in academia. The questions we seek to answer are: (1) Which actors participate in the debates and what positions emerge in them? (2) What arguments are presented in support to the different positions in the debates?

\section{Background}

Today, higher education in Estonia and Latvia mainly functions in the official languages of the states, Estonian and Latvian. Both languages, which regained clear dominance in academia only a few decades ago, are quite strongly supported by the states' language policies, including in higher education (Rozenvalde, 2018). Additionally, as a legacy of the countries' Soviet past, Russian is used to an extent in academia, most visibly as a medium of instruction in the numerous private universities in Latvia (Rozenvalde, 2018). However, the official data by the ministries of education show that the use of Russian as medium of instruction has decreased constantly since the 1990s. The data also indicate that English has been used as a medium of instruction in universities both in Estonia and Latvia since the beginning of the 1990s, but it started spreading at a particularly fast pace only at the beginning of the 2010 s.

In both countries, every 1oth student studies in English (Kreegipuu, 2017, p. 8; Ministry of Education in Latvia, 2019, pp. 71-73). In Estonia, only a few students study in Russian (Selliov, 2018); in Latvia, $6 \%$ of the entire student body is enrolled in Russian-medium programmes (Ministry of Education, 2019), the majority of them in private universities as the state has forbidden teaching in Russian in public universities, except for language and culture studies. Both in Estonia and Latvia, the students who are enrolled in Russian-medium studies are mostly local Russian-speakers. In Estonia, language ideological debates in higher education are mostly centred on the hierarchical position and use of Estonian and English, and the use of Russian in academia is usually not debated publicly as it is used only very rarely as a language of instruction in tertiary education. By contrast, Russian occupies a central role in language ideological debates in higher education in Latvia. Although there are almost twice as many students studying in English, and English is used as a language of instruction at all levels of higher education both in public and private universities, creating policies that deal with Russian continues to be 
important for the state. Recently, state policymakers have paid a great deal of attention to the issues accompanying the Russian-medium private education in Latvia. In the state language policy discourse, Russian is still construed as the main opponent to the thriving of the Latvian language (Ozolins, 2019).

The Englishization of higher education in Estonia and Latvia is easily noticeable as the states collect data on media of instruction. However, Englishization does not only mean the spread of English-medium instruction in academia, and the concept can also be extended to include the often-noted difference in the language choice for $\mathrm{PhD}$ theses. These are written primarily in English in Estonia - more than 90\% of $\mathrm{PhD}$ theses were written in English in 2017 (Klaas-Lang \& Metslang, 2018) - and increasingly in English in Latvia. In 2013, approximately $20 \%$ of $\mathrm{PhD}$ theses were written in English in Latvian universities (Rozenvalde, 2018) but we estimate that the percentage has increased by now. Additionally, the use of English is also spreading in ways that often do not come under public spotlight: for example, English is used more and more for teaching materials, communicating internationally, and for solving administrative issues (Rozenvalde, 2018).

\section{Methodology}

When it comes to discourses around the Englishization of higher education, one relatively well-established finding by now is the existence of two opposing stances, what Hultgren et al. (2014, p. 2) have dubbed the 'internationalist' and the 'culturalist' discourses. On the one hand, those committed to the internationalist stance lay emphasis on the global dimension of higher education and on the importance for universities to be internationally competitive educational institutions. On the other hand, those behind culturalist discourses focus their attention on the national side of universities and on the key role they play as institutions that spearhead the protection, promotion, and development of the national language and culture. These two discourses and the opposition that they entail between English and the national languages are well represented in the Nordic countries (Saarinen, 2020). In that context, the vaguely defined concept of 'parallel language use' has enabled social actors from a diversity of backgrounds to lobby in favour of a specific language-political agenda while remaining relatively ambiguous. In Sweden, for example, 'parallel language use' might be understood sometimes as 'more Swedish', other times as 'more English', depending on the scale and the specific language functions one has in mind (Hult \& Källkvist, 2015). 
As we shall see below, these two discourses, the 'internationalist' and the 'culturalist', are also present in the language debates in Estonia and Latvia, albeit with different degrees of intensity in their opposition.

In terms of method, we develop a discourse analysis of two recent language ideological debates in Estonian and Latvian higher education. We understand language ideological debates as momentary events in which larger scale discourses become instantiated synchronically at a given moment in time via processes of discursive exchange (Blommaert, 1999). As such, these are rich data points when language ideological constructs - that is, beliefs about the value and the function of language(s) in society (Woolard, 1998) - crystallize more explicitly in the public sphere and become more tangible and observable. Our discourse-analytical approach draws inspiration from 'nexus analysis' (Scollon \& Scollon, 2004), in particular its 'Discourses in Place' component. As such, we focus on 'the complex aggregate (or nexus) of many discourses which circulate in the social world and serve to construct it symbolically or materially' (Scollon \& Scollon, 2004, p. 14, as cited in Hult \& Pietikäinen, 2014, p. 7). We analysed the material employing thematic analysis in a flexible way (Clarke et al., 2015). That is, while we did have in mind the categories 'internationalist' and 'culturalist' as two broad discourses, we analysed the data inductively and manually to extract the main themes emerging from the articles, developing in this way an interpretive account of the material.

As far as data is concerned, both for Estonia and Latvia we examine language ideological debates that unfolded themselves in the media, mostly in the form of op-eds in widely circulated newspapers in the two countries. The Estonian debate started in September 2018 and continued until October 2020. In total, we collected 21 newspaper articles, most of them published as op-eds within the period of one year. Many of the articles are concentrated in the December 2018 to February 2019 period; the first few pieces appeared right after the Estonian Culture and Education Congress, held in Tallinn on 23-25 November 2018, in which the rectors of four of Estonia's public universities debated precisely on the topic of the internationalization of higher education from a linguistic and economic perspective. Then, the number of items falls until late October to early December 2019, when Estonian universities (and particularly the University of Tartu) were preparing themselves to commemorate the 1ooth anniversary of Estonian-language teaching at the university (1 December 2019). In spring 2020, against the background of the Covid-19 pandemic outbreak, there was a relatively long period of silence in the 
debate, with the final three pieces in our data-set appearing between September and October 2020, by the time that new legislation was being discussed in parliament affecting access to Estonia's higher education by third-country nationals (e.g., students from Russia, Ukraine, Moldova, etc.).

In the case of Latvia, the language ideological debate on the Englishization of higher education took place in November and December 2019, when various stakeholders (state and university officials, members of cultural elite, etc.) engaged in a discussion on the need for Englishization. The debate gained momentum at the point when the Ministry of Education revealed that it considered making it obligatory to write and defend $\mathrm{PhD}$ theses in English (with some exceptions). Officially, the Ministry was just asking for the opinion of stakeholders as members of its working group had been unable to reach a consensus on the issue. Their initiative, although not final, was met with substantial resistance but it also received support. The debate ended when a parliamentary committee decided that no major changes would be made to the existing regulations on $\mathrm{PhD}$ theses.

In order to make sense of the Latvian debate, we collected 20 written items for the analysis that include, firstly, the concept by the Ministry of Education that initiated the debate; secondly, two public letters written as a reaction to the Ministry's initiative, which were signed by hundreds of people and published in several media channels; thirdly, 13 online newspaper articles, most of them published as opinion pieces; and finally, four press releases (by the Ministry of Education, education societies, and a national political party). The pieces that we analyse in the chapter, for both Estonia and Latvia, are available from the authors upon request.

\section{Analysis and discussion}

\subsection{The debate in Estonia}

A total of 18 participants engaged in the language ideological debate in Estonia. Seven of them are university professors from different fields within the humanities, social sciences, and engineering (this is the most actively engaged group in the debate). Other participants include five university officials (rectors and other members of their offices), and one member each from the Ministry of Education, the Language Inspectorate, and the Estonian Research Agency. Finally, participants include one politician, one artist, and one educational entrepreneur. Out of the 18 participants in 
the debate, seven might be classified as internationalists, while 11 can be counted as culturalists. In line with Hultgren et al.'s (2014) description of which social actors tend to fall in each category, the internationalists in the debate are high-rank university officials (rectors and vice-rectors) as well as representatives of the Ministry of Education, and two professors. On the culturalists' side, we find five professors in total from the humanities, two government officials, one rector, one entrepreneur, one artist, and one politician from a conservative-nationalist party.

In the debate, the main point of confrontation between the two sides revolves around the language(s) of instruction. This seems to be the core of the problem, the centre around which all other themes that emerge from the debate gravitate. These other themes include: (1) the funding system of Estonia's universities; (2) the role of the law and legislative action; (3) the quality and competitiveness of Estonia's higher education; and (4) the position of international students and lecturers. In addition to these main themes, both culturalists and internationalists agree on two basic points: first, that universities have a key responsibility in developing, promoting, and protecting Estonian-language higher education, and second, that it is important for universities to develop English-taught programmes in order to be internationally competitive institutions. What seems more debatable is: in what order and to what extent Estonian and English should both have a presence in Estonia's universities, particularly in the areas of teaching and learning.

Culturalists' point of departure is that universities have all too uncritically assumed the race towards internationalization at all costs, including at the expense of the Estonian language and culture. As they see it, a combination of factors has led to the current situation of a growing presence of English in Estonian universities, particularly in the form of English-taught programmes. First and foremost, there are financial and demographic reasons. Financially, the 2013 higher education reform stipulated that full-time study places in Estonian-medium programmes were to become tuition-free; by that time, though, the number of Estonian students entering university had been decreasing progressively since 2009-2010. This gave rise to universities seeking ways of compensating for the decline in student numbers and for expanding their funding basis. The development of more English-taught programmes, for which tuition fees could be charged and international students could be attracted, seemed only natural. In the piece that sparked the debate, the author notes that 'it is undeniable that universities need internationalization, but the way it is currently done, at the expense of the Estonian language, leaves a strong impression of 
unchained capitalism' (a humanities professor, 24 September 2018) (extracts quoted in this section are our translation from the original in Estonian).

With the above in mind, culturalists argue that this type of funding system for universities should be changed. In their view, taxpayers' money is misused when it goes directly to fund study places in English-taught programmes, most of which are populated with foreign students who, after graduating, will move from Estonia. As one commentator puts it,

More than 80 percent of all foreign students studying in Estonia still receive their higher education in full or in part from Estonian taxpayers' money and without having to learn Estonian. This is not in the interests of Estonian culture, the Estonian state or the Estonian economy. (Education entrepreneur, 28 October 2019)

For culturalists, then, the only way of solving this situation is by means of the law: legislative reforms have to be put in place in order to help find a balance between Estonian and English as languages of instruction in higher education. An argument that emerges repeatedly in the debate from the culturalists' side is that if the primary position of Estonian in higher education is not strongly protected and becomes endangered, this may produce a catalyst effect on other domains, turning Estonian eventually into a simple kitchen language.

The exact proportion of Estonian and English in all programmes is still to be discussed, but some suggest that all English-taught programmes should become bilingual, with an obligatory component within the optional modules of Estonian language and culture. Such an initiative, it is argued, would help international students integrate more smoothly into Estonian society; it would allow them to be able to go on to internships in Estonian companies during their studies, and it would increase their chances of finding a job upon graduation and of seeing a future for themselves in Estonia. This is expressed as follows by one of the contributors to the debate: 'Foreign students should be required to study Estonian language and culture to the extent that they can go on internships and, after graduation, find a job in Estonia and feel part of the local society' (humanities professor, 22 April 2019).

Finally, another group that concerns culturalists from the point of view of their (lack of) language skills in Estonian are international lecturers. With the increase of English-taught programmes and the arrival of more and more foreign students, international lecturers have also become a more visible collective in an increasing number of university departments. There 
is agreement among culturalists that those with a permanent contract at the university should be able to participate from the regular university activities in Estonian by the time of their first performance revision (after three years), and that they should be able to also teach in Estonian by their tenure revision (after five years). A humanities professor makes this point clearly: 'With a permanent contract, the foreigner should, in addition to working in the laboratory and auditorium, take part in all activities of university life' (2 December 2019), the implication being that for all activities of university life, Estonian will be required. Taking inspiration in the guidelines of the recent Nordic Council of Ministers report on parallel language use at universities (Gregersen et al., 2018), some suggest that the language requirements for international lecturers should be part of their contract agreement with the university.

Turning to the internationalists, their main point of concern is with the quality of higher education. For them, the only way for Estonian universities to maintain their level of competitiveness is to continue being internationally visible and to offer attractive programmes, which inevitably means engaging with English substantially, both for teaching and research purposes. Internationalists respond to culturalists' concerns about the misuse of taxpayers' money by saying that international students studying in English-taught programmes generate a decent amount of revenue for the state in both direct (the majority of them via tuition fees) and indirect ways (rent, food, leisure activities, etc.). Importantly, those who do end up staying in Estonia return the state's investment on them within one year of working, and the more time they stay, the more tax revenue they generate. As explained by one high-ranking university official: 'A graduate who goes to work in the IT sector will return the sum invested in him or her to the state in taxes within one year' (28 September 2020).

Internationalists emphasize that a great proportion of foreign students end up occupying jobs for which there is a shortage of qualified workers in Estonia and that, as such, these students should be seen as a highly-skilled imported labour force that the country lacks. Even when considering those students who come from abroad to study free of charge, internationalists argue that a highly-trained international student that ends up staying in the country and contributing to the state for the price of a master's degree is a skilled professional obtained cheaply. And even in the case of foreign students who do not stay in Estonia permanently, internationalists value their training because upon their return to their home countries, they become important critical friends of Estonia, a means of soft power that any small nation needs to value positively. Connecting it to the issue of 
taxpayers' money, one commentator argues that even if such public funds are used, they are well spent, precisely for the above reason: 'Training foreigners (including for taxpayers' money) is not a waste of money, but a projection of the soft power of a small country like Estonia' (social sciences professor, 12 December 2018).

Beyond purely economic matters, for the internationalists, foreign students and lecturers are important because they enrich the university on many different levels. They help raise the bar of teaching and research because there is greater competition for English-taught places than there is for Estonian-taught ones, which means that students in English-language tracks are generally above the average. Foreign lecturers are also an important asset for universities, emphasize the internationalists. Many of them are in the top ranks of their fields of specialization; students being trained under their guidance can take this as a significant opportunity to learn first-hand from the best in their fields. That is why the learning of the Estonian language by teachers and students from abroad is something that should not be forced on them, according to the internationalists, certainly not by law; it should be encouraged and it should be seen as an important added value, but it should not be made a requirement. Indeed, in the internationalists' arguments, there is a clearer recognition of the idea that if universities expect their foreign members to learn Estonian beyond a mere conversational level and within a certain period of time, then proper conditions need to be put in place by the institution, with the necessary resources that that entails, rather than simply expecting foreign staff to learn the language by themselves. One contributor to the debate puts it as follows: 'it is difficult to just put your hands on your hips and demand extra work from foreign lecturers, as many of our foreign lecturers work 60 hours a week in the general underfunding of higher education' (engineering professor, 26 January 2019).

All in all, summarizing the two positions, culturalists see universities as state-national institutions, whose primary goal and most important function is to serve the state. From their perspective, the Estonian language and culture are at the core of the Estonian state. Without its own language and culture, the Estonian state would either not exist at all or it would be meaningless. Internationalists, on their part, see the internationalization of Estonia's higher education as a way to preserve and reinforce the country's university system. Their position places stronger emphasis on the global nature of today's higher education; they do not see universities as first and foremost national institutions at the service of the state. For them, issues of quality and competitiveness are central, 
and to that end, English-medium programmes represent a key structural means through which these two vectors, quality and competitiveness, can be maintained and improved.

\subsection{The debate in Latvia}

The actors who participate in the Latvian debate include, firstly, at the state level, the Ministry of Education, the State Language Centre, and the Higher Education Council; secondly, eight administrators of six universities, and ten members of the academic and research staff of the universities; thirdly, four associations of researchers and education workers, and a political party; and fourthly, journalists from various media channels, and writers. Finally, the debate includes all those who signed the letters to protest against the Ministry's initiative $\left(45^{\circ}+800\right.$ people). The debate revolves around the need for the state's interference in regulating language use for writing and defending PhD theses. Other themes, which are subordinated to the central theme, are: (1) the quality and competitiveness of higher education; (2) linguistic hierarchies in language policies and language practices; and (3) the situation of the Latvian language.

Although going ahead with the Ministry's plan would give English more presence and restrict the use of Latvian in academia, the lines of argumentation presented by actors who either agree or disagree with the plan do not differ much in their stance on English and Latvian but rather in their stance on the state's intervention. In other words, the necessity to use both Latvian and English in higher education is not debated and both parties agree that English is necessary for Latvian higher education and science. During the debate, no opponent to the initiative mentions that $\mathrm{PhD}$ theses should not be written in English, and no proponent of the initiative argues that there is no need for Latvian in academia.

Nevertheless, the internationalist and the culturalist discourses are distinguishable. The culturalist discourse is upheld by state officials whose task it is to focus on the state language, professional linguists, cultural and educational workers, their associations, journalists from the public broadcasting of Latvia and Latvian-minded newspapers, a national political party, and administrations of universities that teach humanities, social sciences, pedagogy and/or art. Although these actors agree with the importance of English in academia, they argue that this should not lead the state to change its political course from maintaining Latvian to overtly supporting the spread of English. According to the culturalists, Latvian and English have to co-exist in academia, but it is the state's task to focus on supporting 
Latvian. For example, an excerpt from a public protest letter, organized by linguists, addressed to the government and signed by 800 people (excerpts provided in this section are our translation into English from the original in Latvian) says:

We ask the government of the Republic of Latvia to follow the state's Constitution and other pieces of legislation and honour the obligations of the state to strengthen and develop Latvian as the official language, instead of damaging its prestige and wrecking its future prospects. (Public protest letter, 28 November 2019)

Indeed, Latvia's language policy has mainly been 'nationalizing' (Brubaker, 2011) with a strong focus on spreading Latvian since regaining independence. As a result, when compared to the debate in Estonia and language policy discourses analysed by Saarinen (2020) in Finland, it seems rather specific to the debate in Latvia that while the culturalists stress the importance of protecting the official language, they do not engage in the critique of the post-national ideal of globalism (Haberland, 2009) and the spread of English. There is nothing new about the Latvian state adopting globalist ideologies in higher education policies, as these have been present in the policy-planning documents already since the beginning of the 2010s (Kibbermann, 2017). However, the Ministry's willingness to include the ideological view of globalism in legislation attracts the attention of the culturalists as language laws have, until now, explicitly stood for maintaining Latvian. Indeed, it is common in language policy discourses in Latvia to construe the state as the main saviour of the national language (Brubaker, 2011).

Furthermore, the culturalists see the Ministry's initiative as threatening the Latvian language at various levels: the greatest number of arguments focus on the status, functionality, and prestige of the language. For example, the authors of the first public protest letter write: 'giving up on the use of Latvian in any domain can influence the general attitude of the society towards Latvian, the prestige of and need for the language' (public protest letter, 20 November 2019), and a professor of literature puts forth a stronger argument, saying that limiting language use in any domain will hinder the development of the entire language and have an effect on all other domains. Its impact will immediately be enormous' (humanities professor, 25 November 2019).

Moreover, the culturalists tend to depict the current Latvian sociolinguistic situation as problematic due to the insufficient Latvian language skills of some minority speakers. For example, a journalist writes in a daily 
that 'almost 30 years after regaining the independence, shop assistants in Daugavpils or Riga might not understand Latvian as they only speak Russian' (20 November 2019). Similarly, some culturalists (e.g., a high-rank state official and a university administrator, 20 November 2019) express a worry about the state sending a wrong message to the large community of minority speakers, whose interest in acquiring and using Latvian would thus wane. Indeed, the Latvian language has still not ensured a dominant position in some spheres of life, for example, shops and cafes, and this is commonly problematized in state language policy discourse (Rozenvalde \& Kḷava, 2021).

In addition, there are also other lines of argument presented to argue against the initiative, but these are not as common as the worries expressed about the future of the Latvian language. Firstly, one argument refers to democracy, for example, 'democracy relies on free choice' (educational association, 6 December 2019). Secondly, other arguments make use of the notion of discrimination, for example, 'if the law forbade writing $\mathrm{PhD}$ theses in Latvian, any Latvian citizen could take this to the court as it entailed blatant linguistic discrimination' (humanities professor, 8 December 2019). More commonly, the culturalists refer to the public interest in having access to research results (e.g., a university administrator, 19 November 2019; a national political party, 3 December 2019).

As for the quality of education, the arguments of the culturalists do not stand against the necessity and opportunity to use English for international communication and cooperation but rather argue that writing in English does not make research of higher quality than writing in Latvian. According to them, firstly, the English language skills of $\mathrm{PhD}$ students in Latvia are not good enough to ensure the high quality of PhD theses, and secondly, the obligation to write in English would affect the range of local research topics covered in PhD theses (a public protest letter, 20 November 2019).

By contrast, the internationalist discourse is supported by the state officials whose task it is to make higher education internationally competitive, natural and technical scientists, including representatives of administrations from universities that teach natural and technical sciences. The internationalists are accustomed to using English extensively in their daily working lives at universities. These actors construe English as an opportunity to make the local higher education more competitive internationally. For example, a high-ranking university official says: 'When we have PhD theses in English, we have more opportunities to find good opponents. So, it's logical that the quality of the theses improves. We have no negative experience with using English' (19 November 2019). 
By no means do the internationalists agree that the spread of English in academia could at some point threaten the linguistic and cultural identity of the local society (e.g., a representative of the Ministry, 25 November 2019; a social scientist, 4 December 2019). Interestingly, the internationalists are far less vocal during the debate, maybe because the idea originates from an authoritative body. However, there is also an exception as one of those who actively participates in the debate and stands clearly against the Ministry's initiative is a professor of chemistry (25 November 2019; 4 December 2019).

Similarly, a great many internationalists agree that Latvian has to be developed but they claim that other means can be used to reach that goal (e.g., a researchers' association, 22 November 2019; a natural scientist, 4 December 2019). According to the Association of Latvian Young Scientists, the Latvian language can be developed at best by well-educated and internationally competitive young scholars, but in order to receive good education and become internationally competitive, they have to write their doctoral theses in English (22 November 2019). The internationalists tend to support their claims that the state's potential pro-English policy on $\mathrm{PhD}$ theses does not have any negative impact on Latvian with the current practices of writing PhD theses in English (e.g., a university rector, 20 November 2019). Therefore, from their perspective it does not make a difference whether the use of English is stipulated by law or simply occurs at the grass-roots level.

What is particularly interesting in the debate, is the heterogeneous nature of the Ministry. Its representatives do not adopt a unified stance on the issue. Their publicly expressed viewpoints range from claims, according to which the initiative stems from below and the Ministry has not made up its mind yet (e.g., 26 November 2019), to globalist claims that give full support to writing and defending PhD theses in English in order to make Latvian higher education more competitive internationally (e.g., 25 November 2019). The Ministry is the only stakeholder at the national level that is - at least to some extent - in favour of the state imposing its pro-English language policy on $\mathrm{PhD}$ theses. The public discussion came to an end when the Ministry officially rejected the idea of the legal Englishization of PhD theses (10 December 2019).

\section{Conclusions}

In this chapter, we have attempted to answer the following questions: which actors participate in the language ideological debates within the higher education systems of Estonia and Latvia, what positions emerge from 
those debates, and what arguments are associated with each position. To summarize our analysis and discussion presented above, the actors that contribute to the debates analysed here include mainly those who conduct their daily working lives at universities, that is, in both cases they mostly represent university administrations, who are in charge of institutional policies and the appropriation (Levinson \& Sutton, 2001) of state-authored policies at universities, and academic and research staff, who appropriate the top-down policies at the grass-roots level. For a century already, it has been customary for the states of Estonia and Latvia to regulate language matters at the state level (Hogan-Brun et al., 20o9), so state authorities also participate in these debates - in the case of Estonia, the state officials add their additional points of view to the debate; in the case of Latvia, the Ministry's actions spark off the entire debate, and the representatives of other state institutions express their standpoints. Moreover, the actors do not only include those who are closely related to creating and appropriating language policies at universities but extend beyond academia and include the general public, which takes a rather keen interest in language matters in society. The interest of the general public in language is nothing extraordinary in these cases as language holds a prominent position in group identity both in Estonia and Latvia (Ehala, 2017).

The standpoints of culturalists and internationalists outlined in the analysis above show that both parties in Estonia and Latvia agree, firstly, that the official language of the country has to be protected, and secondly, that English has to be used in local academia. In both cases, the debate is about the extent to which one or another language should be used, and what position the states and universities should adopt and defend. Whereas the culturalists see language use and policies at universities as affecting language use and ideologies also beyond universities, the internationalists tend to argue that the policies aiming at more qualitative and competitive higher education have nothing to do with maintaining the official languages because this objective can be reached by other means. Consequently, at a more fundamental level, the debates both in Estonia and Latvia revolve around the question of whether language use and policies at universities affect language use and ideologies also in other spheres of life, and whether universities should primarily act to serve the state. So, as in all language ideological debates more generally (Blommaert, 1999), the debates in the context of higher education are also not about language alone (Saarinen, 2020).

However, for all the similarities that can be traced between Estonia and Latvia, with similar core issues that seem to be behind the debates, it is also possible to notice revealing differences between the two cases. 
In the Estonian case, the opposition between the internationalist and the culturalist discourses is strong and clear, and the central point of controversy between them is whether English in higher education does or does not represent a threat for the Estonian language and the Estonian nation. For the internationalists, it does not; for the culturalists, it does. By contrast, in the Latvian case, while this kind of opposition is there in the debate, it is not as fronted as in the Estonian case. Instead, the controversial point in Latvia is whether the state can or cannot take an explicit stance in favour of English in higher education, and in so doing, step away from its historical aim of developing policies for the promotion of the official language. In some sense, then, the higher education language ideological debates in Estonia have moved closer to the debates held in the neighbouring Nordic countries, where the opposition between English and the national languages is more clear-cut and more intense as well.

Inevitably, then, the two cases are context-dependent, and they evolve within their own national and political dynamics. In that regard, we would argue that the sensitization towards English in the Estonian context stems from developments within and outside universities. On the one hand, the significant growth in the number of English-taught programmes has brought with it an increase in the number of international students and staff, making English more readily observable and hearable at university campuses. On the other hand, Estonia has witnessed in recent years a rise of right-wing populism that has re-centred the country politically closer to new-nationalist postulates. As such, what we see in the higher education language ideological debates in Estonia is not entirely different from what Saarinen (2020) describes for Finland, where traditional nationalist discourses are recycled and reused in contexts from where they had historically been absent, thus regaining a renewed impetus. By contrast, the idea of English being an opportunity and a necessity in higher education still enjoys wide currency in Latvia, although the more concerned voices insist on clearly defined hierarchies for Latvian and English, with the former being on top. It will be important, then, to keep monitoring the developments in the two countries and to see whether Estonia continues to move towards the Finnish direction, and whether Latvia follows in the footsteps of its neighbours to the north, or if it takes a somewhat different path, solving the inherent contradictions of the Englishization of higher education in an original way.

\section{Funding}

This work was supported by the European Regional Development Fund and the programme Mobilitas Pluss (grant number MOBJD646). 


\section{References}

Blommaert, J. (Ed.) (1999). Language ideological debates. Mouton de Gruyter.

Brubaker, R. (2011). Nationalizing states revisited: Projects and processes of nationalization in post-Soviet states. Ethnic and Racial Studies, 34(11), 1785-1814.

Bulajeva, T., \& Hogan-Brun, G. (2014). Internationalisation of higher education and nation building: Resolving language policy dilemmas in Lithuania.Journal of Multilingual and Multicultural Development, 35(4), 318-331.

Clarke, V., Braun, V., \& Hayfield, N. (2015). Thematic analysis. In J. Smith (Ed.), Qualitative psychology. A practical guide to research methods (pp. 222-249). Sage.

Ehala, M. (2017). Intergroup communication: The Baltic countries. In J. F. Nussbaum (Ed.), Oxford Research Encyclopedia of Communication (pp. 1-24). Oxford University Press.

Gregersen, F., et al. (2018). More parallel, please! Best practice of parallel language use at Nordic Universities: 11 recommendations. Nordic Council of Ministers.

Haberland, H. (2009). English: The language of globalism. Rask. Internationalt Tidsskrift for Sprog Og Kommunikation, 30, 17-45.

Hultgren, A. K., Gregersen, F., \& Thøgersen, J. (2014). Introduction. English at Nordic universities: Ideologies and practices. In A. K. Hultgren, F. Gregersen, \& J. Thøgersen (Eds.), English in Nordic universities: Ideologies and practices (pp. 1-25). John Benjamins.

Hogan-Brun, G., Ozolins, U., Ramoniene, M., \& Rannut, M. (2009). Language politics and practices in the Baltic States. Tallinn University Press.

Hult, F., \& Källkvist, M. (2015). Global flows in local language planning: Articulating parallel language use in Swedish university policies. Current Issues in Language Planning, 17(1), 56-71.

Hult, F., \& Pietikäinen, S. (2014). Shaping discourses of multilingualism through a language ideological debate: The case of Swedish in Finland.Journal of Language and Politics, 13(1), 1-20.

Kibbermann, K. (2017). Responses to the internationalisation of higher education in language policies of Estonia and Latvia.Journal of Estonian and Finno-Ugric Linguistics, 8(1), 97-113.

Klaas-Lang, B., \& Metslang, M. (2018). Eesti keele kestlikkus kõrghariduses [Sustainability of Estonian in higher education]. Akadeemia, 4(349), 667-688.

Koreinik, K., Siiner, M., \& Brown, K. (2018) Kas keelepoliitika uurimise keskmes peaks olema riik? [Should the state be the only focus of language-policy research?] Keel ja Kirjandus, 1-2, 67-81.

Kreegipuu, T. (2017). Välisüliõpilased Eesti kõrghariduses [Foreign students in higher education in Estonia]. Ministry of Education. Retrieved 27 November 2020 from https://www.hm.ee/sites/default/files/uuringud/valisuliopilased.pdf. 
Lanvers, U., \& Hultgren, A. K. (2018). The Englishization of European higher education: Foreword. European Journal of Language Policy, 10(1), 1-11.

Levinson, B. A. U., \& Sutton, M. (2001). Introduction: Policy as/in practice: A sociocultural approach to the study of educational policy. In B. A. U. Levinson \& M. Sutton (Eds.), Policy as practice: Toward a sociocultural analysis of educational policy (pp. 1-22). Ablex Publishing.

Ministry of Education. (2019). Pārskats par Latvijas augstāko izglītību 2018. gadā. Galvenie statistikas dati. [Overview of higher education in Latvia in 2018. Main statistical data]. Retrieved 27 November 2020 from https://www.izm.gov.lv/lv/ statistika-par-augstako-izglitibu/augstakas_izglitibas_lv_parskats_20181.pdf.

Ozolins, U. (2019). Language policy, external political pressure and internal linguistic change: The particularity of the Baltic Case. In S. Lazdina \& H. F. Marten (Eds.), Multilingualism in the Baltic States: Societal discourses and contact phenomena (pp. 29-55). Palgrave Macmillan.

Rozenvalde, K. (2018) Multi-layered language policy in higher education in Estonia and Latvia: Case of national universities. Summary of doctoral dissertation. University of Latvia Press.

Rozenvalde, K., \& Kḷava, G. (2021, in press). Valodu lietojums dažādās sociolingvistiskajās jomās [Language use in various sociolinguistic domains]. In I. Vìtola (Ed.), Valodas situācija Latvijā: 2016-2020 [Language situation in Latvia. 2016-2020]. Latvian Language Agency.

Saarinen, T. (2020). Higher education, language and new nationalism in Finland. Recycled histories. Palgrave Macmillan.

Scollon, R., \& Scollon, S. W. (2004). Nexus analysis. Discourse and the emerging Internet. Routledge.

Selliov, R. (2018). Õppekeel Eesti kõrgkoolides EHISe andmetel. Statistiline ülevaade [Language of instruction in higher education institutions in Estonia according to the data of Estonian Education Information System. Statistical overview]. Ministry of Education. Retrieved 27 November 2020 from https://www.hm.ee/ sites/default/files/uuringud/oppekeel_eesti_korgkoolides_statistiline_ylev aade.pdf.

Soler, J., \& Vihman, V.A. (2018). Language ideology and language planning in Estonian higher education: Nationalising and globalising discourses. Current Issues in Language Planning, 19(1), 22-41.

Woolard, K. A. (1998). Introduction: Language ideology as a field of inquiry. In B. B. Schieffelin, K. A. Woolard, \& P. V. Kroskrity (Eds.), Language ideologies: Practice and theory (pp. 3-47). Oxford University Press. 


\section{About the authors}

Josep Soler is Senior Lecturer in Applied English Linguistics at Stockholm University. He has published extensively on language policy and the internationalisation of higher education, with Estonia as a focal point of interest. His other research interests include the politics of English as a global language and family multilingualism.

KERTTU ROZENVALDE is a research fellow in language policy at the University of Tartu. Among her fields of research are language policies and higher education policies, particularly in Estonia and Latvia. She is currently conducting research on language use and ideologies in a multilingual university in Estonia. 



\title{
$4 \quad$ EMI in Spain
}

Striving to maintain a multilingual balance

\author{
David Lasagabaster
}

\begin{abstract}
Spanish universities have lately striven to boost English-medium instruction (EMI) programmes, since EMI is viewed as a lynchpin of the internationalization process. Thus, Spanish universities encourage the use of English, which in monolingual regions entails bilingualism as the desired outcome, whereas in officially bilingual regions trilingualism is the aim. Spain is a multilingual country in which some minority languages coexist with Spanish and English in the curriculum and this multilingualism ineluctably generates friction. This chapter analyses how the interaction between Englishization and multilingualism is perceived by society in general and the different university bodies in particular, the reactions encountered as regards the impact of Englishization on the L1, and whether there are differences across disciplines.
\end{abstract}

Keywords: English-medium instruction, higher education, Spain, bilingualism, multilingualism

\section{Introduction}

Countries around the world are dedicating substantial resources to the internationalization of their higher education systems. In a global university context in which Englishization, English-medium instruction (EMI) and internationalization are three processes that are inextricably linked (Dafouz \& Smit, 2020; Doíz et al., 2013a), the lack of competence in English has become a hot issue in Spain. Unlike countries in Central and Northern Europe, Spain is not renowned for the foreign language learning abilities of its inhabitants (as is also the case of, for instance, Italy and France), which is why content

Wilkinson, Robert, and René Gabriëls (eds), The Englishization of Higher Education in Europe. Amsterdam, Amsterdam University Press 2021 DOI: 10.5117/9789463727358_CHO4 
and language integrated learning (also known as CLIL) has become very popular at pre-university level.

As a natural development of this interest in CLIL, English-medium instruction (EMI) is gaining momentum in Spanish higher education institutions. In the Spanish context it is not usual to refer to Englishization, which is usually subsumed under CLIL at pre-university level and internationalization and EMI at university level, as EMI is viewed as the cornerstone of the internationalization process. In fact, the introduction of programmes taught completely in English or, more often, the limited incorporation of some subjects in English in different degrees, is becoming commonplace in the vast majority of Spanish universities (Fortanet-Gómez, 2013; Halbach \& Lázaro, 2015). However, the implementation of EMI programmes in Spain lags behind other European contexts (Wächter \& Maiworm, 2014), the poor command of English among university teachers, students, and administration personnel being one of the main reasons (Arnó-Macià \& Mancho-Barés, 2015).

An issue that should be borne in mind when analysing the Spanish context is that Spain is a multilingual country in which three languages (Basque, Catalan and Galician) hold co-official status with Spanish in six out of the 17 autonomous communities that make up Spain: these six are Catalonia, Galicia, the Balearic Islands, Navarre, the Basque Autonomous Community (BAC), and the Valencian Community. Historically there has been a close tie between language and identity in these regions and one of the main objectives of the Statutes of Autonomy passed in the 1980s was to guarantee that these co-official languages are taught on all the rungs of the educational ladder, from kindergarten to tertiary education. With this in mind, normalization processes have been implemented in the last four decades in order to revitalize Basque, Catalan, and Galician and officially bilingual universities play a key role in this process. In this chapter special attention will be devoted to the linguistic strains caused by Englishization, as some voices consider that the increasing presence of EMI may have a deleterious effect on attitudes and motivation to learn the local languages (Lasagabaster, 2017).

\section{The debate about the role of English in the Spanish educational system}

Broadly speaking, it could be affirmed that to Spaniards Englishization mainly means the increasing presence of English in the curriculum, both as a language subject and as a vehicular language. Since Spain is a multilingual 
country which lacks a foreign language learning tradition and in which minority languages co-exist with Spanish, it does not come as a surprise that EMI has brought about social, political, educational, and linguistic tensions. Since language is at the very heart of both sociopolitical and academic debates about the nation (del Valle, 2020), we should bear in mind that, as Norton (2013, p. 47) bluntly points out, language teaching is not a neutral practice but a highly political one'. This is particularly worth considering in a multilingual country such as Spain which is challenged by recurrent linguistic strains. As a result of the 1978 Constitution, there has been a process of devolution in which minority languages are supported by regional governments with a view to reversing the language shift to Spanish. In this highly sensitive sociolinguistic environment, some voices warn against the Englishization process, perceiving it as a potential Trojan horse that may erode the progress made so far in revitalizing minority languages. Although broadly speaking there is a general positive attitude towards the spread of multilingualism, this multilingual context has sparked debate, especially at pre-university level (in some regions debates have been heated), and to a lesser degree at tertiary level.

However, there has been criticism of the mushrooming of English courses at Spanish universities on the grounds that Spanish is an international language, the third most widely spoken in the world after English and Chinese, that represents a linguistic treasure that needs to be nurtured and promoted. According to Kelly (2017), the concern about how to improve foreign language competence has eclipsed the important asset represented by the Spanish language, which has been overlooked when designing internationalization policies, as it is a great potential attractor not only for those who already speak it as their first language (L1) (more than 460 million speakers), but also for those who want to perfect their Spanish language skills. Some voices (Kelly, 2017; Valdecantos, 2012) predict that implementing English bilingual programmes jeopardizes Spanish's privileged position and would end up impoverishing the Spanish language. Valdecantos (2012) finds it striking that those who have organized unflinching and vigorous campaigns to protect Spanish from the other co-official languages have not spoken out against bilingual education in English. A few of the pundits come from the university system itself (Valdecantos, 2012), but the most salient ones are well-known writers (de Prada, 2013, 2015 and 2019; Marías, 2015). The main concern of campaigners against bilingual education in English is that teachers' mumbling English prevents them from delivering content in an efficient and natural way, which Valdecantos (2012, p. 27) defines as 'verbal destitution in a language mastered by neither the teacher nor the learners' 
that will undoubtedly have a deleterious effect on the learning of content. ${ }^{1}$ De Prada (2013 and 2019) also shares this bleak prognosis and shows his concern about learners leaving school being 'illiterate in two languages' or 'bilingual donkeys', and about politicians' fixation with bilingual education, which he labels as 'utter absurdity'. Needless to say, this author does not provide any empirical evidence to support his opinion and relies on his good judgement and informal conversations with a few teachers. De Prada finds it reasonable that Norwegian and Dutch speakers are in need of a lingua franca, their languages being 'esoteric and irrelevant', but deems incomprehensible that a nation which managed to take its language to the New World has - like an American lackey, due to US global economic and cultural dominance - relinquished it in international fora.

These critical voices are not numerous and their backlash against bilingual education in English is mainly directed at pre-university level (de Prada, 2013, 2015 and 2019; Marías, 2015), whereas few react as violently at tertiary level. As we will see in the next section, both the Spanish Ministry of Education (2015) and the Conference of Rectors of Spanish universities (Bazo et al., 2017) have a completely different approach and agree on the dire need to boost bilingual or multilingual programmes. At university level it is widely believed that offering courses and programmes in English will help to attract international students and international faculty members, to foster more publications in English, to improve local students' English proficiency and their professional future, to be better placed in international rankings, to stimulate educational and research partnerships, and to disseminate Spanish culture. In fact, when university stakeholders are asked about EMI, and despite initial fears and concerns similar to those found in other European contexts (Alfaro-Tanco et al., 2020), they are mostly and overtly positive, which may be the main reason why the teaching in English has not found much opposition in Spanish universities.

In any case, the Spanish Ministry of Education, Culture and Sports (2015) urged Spanish universities not to neglect the role that Spanish - the world's third language in terms of native (L1) speakers and the fourth in terms of the total number of speakers (L1 and L2) - should play when it comes to internationalization. In a document entitled 'Strategy for the internationalization of Spanish Universities 2015-2020' and published by the aforementioned Ministry, the need to find a balance between the increasing presence of EMI and the potential of Spanish as an international language to transmit knowledge in higher education was underscored. 


\section{Englishization in Spanish higher education}

This section revolves around Englishization at the macro level, that is, at the nation-state level, later zooming in on the meso level (university level) through research studies. Although official language policies repeatedly mention the need to spread EMI, the specifications about how this should be carried out are scarce. This policy goes hand in hand with the initiative launched by the Spanish Ministry of Education, which sought to modernize universities in the current knowledge society and expected that one in three degree programmes would be taught in English by 2020 (Spanish Ministry of Education, 2015). This expectation has not been met, as progress on EMI has not been linear, and very few universities have been able to offer $30 \%$ of their bachelor's degrees and $50 \%$ of their master's degrees in English in the 2020/21 academic year. Three main reasons may explain why this objective has not been accomplished: the aforementioned low level of English proficiency among the three university bodies (teachers, students, and administration personnel), the scarcity of support and training to implement EMI, and the lack of incentives.

The second reason mentioned ties in with a survey of 70 European universities in eleven European countries, among which Spain was best represented with 22 universities. When comparing the data obtained, O'Dowd (2018) observed great diversity of EMI training and accreditation procedures. Whereas most institutions offered training in communicative skills, almost half of the universities did not provide any EMI methodological training. When it came to teacher accreditation, the requested proficiency level ranged from $\mathrm{B}_{2}$ to $\mathrm{C}_{2}$, which led the author to conclude that there is a compelling need to reach an agreement on some common guidelines across the European higher education area, including in Spain.

This concern was also shared by the Conference of Rectors of Spanish universities who commissioned a study (Bazo et al., 2017) aimed at establishing common guidelines that would pave the way to a common language policy in Spanish universities. The main objective of this initiative was to pinpoint homogeneous criteria around three main aspects, namely accreditation, training, and incentives. As far as accreditation is concerned, the authors underscore the importance of establishing linguistic requirements for all stakeholders, including not only lecturers (who should be accredited at the $\mathrm{C} 1$ level to be allowed to participate in EMI courses) and students (the B1 level should be the minimum by the end of the degree), but also administrative staff (who should be supported to improve their foreign language skills) with a view to underpinning the internationalization profile of higher 
education institutions. The need to establish common criteria for all Spanish universities is also highlighted. The second aspect addresses the need to equip the three university bodies with the competences to tackle complex academic contents, take part in mobility programmes and provide them with strategies to tackle professional and multicultural contexts, including a number of training activities and courses customized for students, teachers, and administrative staff. The third part proposes the creation of a programme of incentives designed to encourage the three university bodies to take part in the internationalization process. The authors make it clear that this document should not become a checklist but rather a framework to boost coordination between Spanish universities, although each institution should bear in mind its own features and context and apply it accordingly.

Despite this framework document (Bazo et al., 2017), when it comes to research, the number of studies on the Englishization process and teacher development in Spanish universities is rather limited (Ploettner, 2019). Based on questionnaires and interviews, Macaro et al. (2019) looked into what types of accreditation are available in Spain and the beliefs of managers (policymakers, programme coordinators, and internationalizations managers) and EMI teachers as regards professional development and qualifications. Although it is usually taken for granted that EMI teaching staff are highly competent in English, teachers themselves underscore insufficient proficiency as one of the main stumbling blocks for effective EMI implementation, which has led Dimova (2017) to call for the alignment of EMI accreditation. The authors of the study found great variation in beliefs, but widespread agreement on the need to change university teachers' pedagogy. Both teachers and university managers demanded some type of teaching quality-assurance, but they dissented as to what kind of institution or body should award accreditation. However, they concurred that such certification should go well beyond English language competence, as other abilities such as methodological skills should also be considered. However, although there was support for more demanding accreditation, EMI teachers were averse to a more in-depth professional development programme because of difficulties in attending intensive courses that last several weeks.

Ploettner (2019) critically analysed EMI teacher development at a small private Catalan university. The study focused on interdisciplinary collaboration between a language and a content teacher and examined the reformulation of the roles of the participants as defined in the official document. Although the official policy aimed at establishing a relationship of reciprocity and mutual development, the author (researcher and participant in the study) observed that the language specialist claimed superior authority 
in the teacher development process, which led her to acknowledge that a more equal distribution of authority is recommended for this collaborative framework to succeed. Thus, language specialists should not hold the upper hand, because this may cause content teachers to shy away from collaborative experiences designed to underpin EMI teacher development. Two of the main causes for dissatisfaction among teachers are the lack of support and the feeling of loneliness (Doíz et al., 2013b; Fortanet-Gómez, 2010; Lasagabaster, 2018), both causes being repeatedly mentioned by teachers when they are asked about EMI (Alfaro-Tanco et al., 2020; Doíz \& Lasagabaster, 2018; Doíz et al., 2019; Fernández-Costales \& González-Riaño, 2015). That is why it is essential that the collaboration between language and content teachers be carried out on an equal footing and fostering reciprocity, as this seems to be the best way to share experiences and encourage dialogue that leads to reflection and more effective EMI programmes.

There is not much research on teacher collaboration, that is to say, a content teacher and a language specialist working together at university level with a view to paying more attention to language-related issues so that EMI students can more easily grasp the content taught in the foreign language. An interesting study is the one undertaken by Hernández-Nanclares and Jiménez-Munoz (2017), which consisted in boosting the collaboration between a Spanish content teacher in business administration and a fellow economics native specialist and an experienced linguist specializing in EMI. The pre- and post-intervention assessment revealed that this collaboration positively impacted EMI students' foreign language proficiency (more on this study in section 5).

\section{Linguistic and identity strains brought about by Englishization}

In this section I will focus on the linguistic and professional identity tensions caused by teaching in English. Just as in countries such as the Netherlands, which is viewed as a heartland of EMI (Wilkinson, 2018, p. 607), the increasing presence of English in Spanish universities has encountered some resistance, but these critical voices are particularly noticeable in Spanish bilingual regions. Only from a very naive perspective can the learning of English be deemed neutral, as it is a heavily loaded endeavour that usually raises feelings of linguistic imposition, identity loss, and cultural occupation. Although EMI tends to be highly valued by all members of the university community, linguistic tensions tend to generate the most sensitive debate. 
In fact, in a study carried out at the University of the Basque Country, Doíz et al. (2013b) came across a remarkable paradox. On the one hand, some participants regarded English as a predator language that can not only threaten the development and normalization of Basque but also hinder the incorporation of other foreign languages in the curriculum. On the other hand, some (albeit not many) believed that too much effort and too many resources were put into Basque normalization and this impeded the much-needed development of English. Two studies by these same authors revealed that students were more reluctant than administration personnel and teachers to accept compulsory EMI (Doíz et al., 2014), but this was especially the case among those students whose mother tongue was Basque (Doíz et al., 2013c), who were much more concerned about the alleged negative impact of English on Basque - the increasing presence of English being seen as an obstacle for the recovery of the Basque language (e.g., resulting in less resources spent teaching it). However, when students are asked about the importance of English for their future professional lives, all of them - irrespective of their mother tongue - acknowledge that it opens up many possibilities and agree on the fact that the instrumental value of English will keep increasing in the near future (González Ardeo, 2014).

The clash between English and the minority language may jeopardize multilingual language policies in Spanish bilingual regions and, in fact, similar linguistic tensions have also been reported in Catalonia (Llurda et al., 2013) and the Valencian Community (Fortanet-Gómez, 2013), as there is always the underlying fear that English comes to supplant the local languages. Interestingly, strains have also been detected among international students, as they sometimes perceive that the minority language may become an obstacle for their academic objectives and are not always 'appreciative of institutional efforts inviting them to incorporate a new language (i.e. Catalan) into their linguistic repertoire' and prefer to use Spanish or English as the lingua franca in their exchanges with local students (Llurda et al., 2013, p. 219). Atkinson and Moriarty (2012) also observed tensions between different types of language ideology as a result of the commodification of Catalan and an ideology of nation and nationhood, as reflected in the electronic resources designed for mobile students visiting Catalan universities.

With the need to foster linguistic ecology in mind, Doíz et al. (2013b) urge university authorities to articulate language policies that clearly state the objectives to be met for each language by developing the necessary tools and indicators to measure them. The final aim should be to help the university community become functionally multilingual by creating an additive multilingual environment with a view to smoothing out the 
inherent tensions found in multilingual institutions, particularly in the case of officially bilingual universities. This means that English needs to be rolled out in a mature, balanced manner to avoid increasing tensions between those who support more EMI courses and those who advocate greater resources devoted to developing the minority language.

Dafouz (2018) and Doíz and Lasagabaster (2018) delved into how EMI affects teachers' professional identity. Both studies drew on the concept of investment, as investment theory has been successfully applied to the learning of English in very diverse contexts (Barkhuizen, 2016; Norton, 2016). Teachers and learners invest in EMI because they believe it will increase their cultural capital while helping them to play a greater role in the social sphere. In both studies EMI lecturers viewed English as a means for professional and personal growth, since it enables them to foster their international profile. They also agreed on their developing a stronger agency within academic lingua franca practices (Jenkins, 2014) in which the native vs. non-native speaker debate is likely to fade out. In fact, their objective is to communicate in English in a natural and effortless manner, 'whereby native-like competence and flawless production in English is not their goal' (Doíz \& Lasagabaster, 2018, p. 667).

However, Doíz and Lasagabaster (2018) observed significant differences between teachers and students. The former consider that teaching in EMI comes at a high personal cost which, broadly speaking, does not bring economic or institutional rewards, whereas the latter do not see it as such a burden. Two main reasons help to explain these differences: teachers feel more pressed to achieve the ideal EMI teacher they have in mind than students, and the integration of English in students' life comes more naturally than it is the case among teachers, who speak English at work but whose use of English is not so habitual in their private lives (students have incorporated English into many of their daily activities such as watching movies and TV series, or in their social networks). Therefore, teachers think of themselves as part of an imagined professional community, while students contemplate a more holistic imagined community that includes life outside university.

Block (2020) also analysed the emergent identities of three EMI teachers working in Catalonia where English is introduced in a bilingual ecology in Catalan and Spanish. All the participants resisted the English-language teaching gaze and remained loyal to their disciplinary gaze, as they had a strong group/discipline identification. In his study Block finds a strong link between group membership and the notion of disciplinary identities.

Spanish teachers recurrently mention that they feel more insecure in their EMI classes, mainly caused by their inability to tackle language 
problems (Aguilar, 2017; Rubio \& Moore, 2018), as well as more likely to suffer from fatigue due to the additional effort required to prepare their classes in English. All these factors contribute to lower self-esteem and lack of confidence, which is why they demand more training in EMI-related skills that should go beyond the mere improvement of their English proficiency (Doíz et al., 2019). When they talk about language, their interests are focused on grammar, pronunciation, and vocabulary (Block, 2020; Doíz et al., 2019) and appear unconcerned about other language aspects such as pragmatics or discourse. Their disciplinary identity prevents them from paying much attention to language issues, while they recurrently claim that language falls outside their remit because they see themselves as imperfect language users. Whenever they approach language, it is from a 'narrow view of what constitutes language teaching' (Block, 2020, p. 16).

There is no doubt that the discordances found between EMI teachers' professional identities and their language responsibilities while teaching in a foreign language need to be addressed in teacher training programmes, because otherwise this linguistic void may end up negatively affecting the language and content learning process. Although they usually avoid taking on a language teacher role and, therefore, inhabiting an English-language teacher identity (Doíz \& Lasagabaster, 2018; Mancho-Barés \& Aguilar-Pérez, 2020; Moncada-Comas \& Block, 2019), they cannot avoid focusing on language aspects such as vocabulary and, in fact, the majority of language-related episodes (instances in which attention is paid to language) found in EMI classes are initiated by teachers themselves (Doíz \& Lasagabaster, 2021), which is an indication of language awareness on the part of EMI lecturers. In other words, EMI teachers do act as language experts in the case of specialized terminology, whether they like it or not, and irrespective of whether or not they exclusively regard themselves as content teachers. As Mancho-Barés and Aguilar-Pérez (2020) point out after examining EMI teachers' written corrective feedback, their actual teaching practices reveal some provision of language-related feedback and show that they do create opportunities for their students' use of disciplinary English in their classes.

This clearly indicates that teacher training courses should include reflection on teaching practices in order to try to improve language management and not limit it to disciplinary lexis, as the integration of language and content should be an integral part of teacher development programmes. We may agree with content teachers' mantra that their main concern is content (Airey, 2012), but it is hard to comprehend how they will achieve this if they do not also become responsible for how their students deal with 'disciplinary discourse with linguistic appropriateness (mostly in terms of 
technical and specialized vocabulary)' (Mancho-Barés \& Aguilar-Pérez, 2020, p. 21), as it has already been observed that they actually do (Doíz \& Lasagabaster, 2021).

\section{The impact of Englishization on disciplines}

This is undoubtedly one of the areas that deserves further attention, as there is very little in the literature about what influence the Englishization process exerts on particular disciplines. Although I am unaware of any study focused on whether EMI teachers' investment varies according to the importance of English in each discipline, it seems reasonable to conclude that this may well be the case. A quick look at the range of EMI courses reveals that some disciplines such as business studies, economics and engineering are more likely to be taught in English, whereas other areas of study such as physical education, health sciences, history, or art are usually less internationally driven, a trend observable in the vast majority of Spanish universities (Marcos-García \& Pavón, 2018). The impact of globalization has been bigger in some areas such as business studies, which could be put down to the fact that 'a high level of competence in English is viewed as a pre-requisite for all business students in the 21st century of Business Studies and given the globalization of the world' (Dafouz \& Camacho-Miñano, 2016, p. 58), whereas other specializations do not feel so much pressure from Englishization.

As a matter of fact, in Spain all the studies analysing how EMI affects content learning have been undertaken in business administration degrees. What is more, just three studies have actually measured content learning, as the others are based on impressions of either teachers or students, interesting, however not as reliable. This fact is surprising, given the concerns regarding content learning on EMI courses.

The first was authored by Dafouz et al. (2014) and compared degree students enrolled on Spanish-medium and English-medium courses in business administration. The courses were: Financial Accounting I, Principles of Business Financial Management, and Economic History. The two groups had almost identical university access grades, which ensured their comparability. The results of the two groups were very similar in the three subjects with no statistically significant difference between them. The authors found it striking that even in History, a subject in which verbal and linguistic demands are expected to be higher, EMI had no negative impact on students' academic performance. This indicates that EMI students perform 
just as well as students on first language programmes at tertiary level. As for disciplinary differences, both cohorts performed better in History than in Accounting and Finance, which, according to the researchers, could be due to disciplinary discourse distinctions or variation in the way teacher assessment was implemented.

Interestingly, Dafouz and Camacho-Miñano (2016) carried out a longitudinal study in which the grades of the two cohorts of Financial Accounting I were collated during four academic years at the Complutense University of Madrid (where the previous study was also completed). Both cohorts were taught by the same teacher, a teacher with extensive experience in teaching this subject in both languages. The results did not reveal any statistical difference between the EMI and the Spanish-medium students and the assessment format did not have any significant impact either.

Hernández-Nanclares and Jiménez-Muñoz (2017) analyzed content learning in a two-year research project at the Faculty of Economics and Business at the University of Oviedo and the two subjects under consideration were World Economy and World Economic History. The EMI and the Spanish-medium groups had comparable whole group lectures, classroom practice and tutorials, and the cut-off mark for admission was also the same. Unlike in the previous two studies, in this case the non-native EMI teacher collaborated with a fellow economics native teacher in class and a linguist and teacher trainer out of the class. After taking the same exam, the mean scores for both groups showed that EMI students performed better. Thus, whereas the percentage of students with a pass grade was similar in both cohorts, EMI students failed less and their presence in the higher bands or scores was greater. Nevertheless, the top-tier (Matrícula de Honor, or with honours) only included Spanish-medium students, which is why the authors conclude that EMI may have some kind of limiting effect in the realm of excellence due to language-related reasons.

The three studies reviewed in this section would fit in what is known as internationalization at home, since most participants (teachers and students) are learning and teaching in a foreign language in their home university. We can wrap up this section by concluding that these results indicate that not only do EMI students perform as well as their Spanish-medium counterparts, but the former are also developing the specific disciplinary knowledge that will enable them to study and work in an international environment should it be needed or desired (Dafouz \& Camacho-Miñano, 2016, p. 65). However, more research in other disciplines is sorely needed, because those who are skeptical about (and some even dead against) EMI can only be placated by being given reliable and trustworthy data to counter their criticism. In 
addition, the issue of EMI students not achieving the highest distinction grade (Hernández-Nanclares \& Jiménez-Muñoz, 2017) also demands more investigation.

\section{Conclusions}

One of the weaknesses of the Spanish university system is the small proportion of courses delivered in English, which is why the Spanish Ministry of Education (2015) launched an initiative to increase bilingual programmes. Different studies have shown that one of the main stumbling blocks for the success of EMI in Spain has to do with the fact that 'the majority of students signing up for bilingual programmes are locals with limited L2 expertise' (Rubio Cuenca \& Moore, 2018, p. 99). Moreover, language policies are far from fully fledged, as pointed out by Marcos-García and Pavón (2018). They analysed 76 Spanish (50 state and 26 private) universities and observed that, despite the steady yearly increase of credits taught in English, just 18 of those universities had an accessible document setting out their language policy on their webpages.

Although EMI demands a major rethink in terms of pedagogy (Doíz \& Lasagabaster, 2020), Spanish universities have not devoted the necessary means to help teachers transit from Li teaching to EMI and, in fact, most of their official documents make no reference to the methodological changes required when changing to English as the means of instruction (Llurda et al., 2013). Therefore, Spanish higher education institutions should provide support to EMI teachers 'in the form of continuous teacher professional development' (Dafouz, 2018, p. 550), as they regularly feel abandoned to the extent that many of them consider that the success of EMI rests squarely on their shoulders (Doíz \& Lasagabaster, 2018). Although EMI has the potential to foster language learning while content is acquired, it does not substitute the necessary teaching of academic and specialized language, a task that can be best performed by implementing collaborative experiences between language specialists and content teachers (Lasagabaster, 2018; Mancho-Barés \& Aguilar-Pérez, 2020; Roquet et al., 2020).

EMI teachers also complain about the fact that the current English accreditation required in some Spanish universities put too much emphasis on linguistic skills and overlook important issues such as classroom management, the promotion of student interaction, or supra-segmental language skills (Alfaro-Tanco et al., 2020; Macaro et al., 2019). Much work remains to be done in this respect and some common accreditation is needed to ensure 
quality, while Spanish universities should try to avoid operating in isolation and without considering the available empirical evidence (FernándezCostales \& González-Riaño, 2015). Nonetheless, it has to be acknowledged that in the last few years there has been a growing interest in issues such as teacher training, student accreditation, or the internationalization of the administrative staff, as a consequence of which some steps have been taken.

Spanish higher education institutions do not consider that the emergence of EMI programmes may lead to the marginalization of Spanish, as this language enjoys an international status and relies on a large number of speakers that will ensure its attractiveness for mobile students. Nonetheless, the Spanish Ministry of Education (2015) strives to ensure that this linguistic balance is maintained and supports internationalization strategies aimed at this objective. The fact that Spain has the lowest proportion of students enrolled in English-taught programmes in Europe (only 0.3\% of Spanish university students are enrolled in programmes taught fully in English; see Wächter \& Maiworm, 2014) greatly helps university authorities to convey the message that the pressure exerted by EMI is far from being intolerable.

Last but not least, I would like to conclude that the internationalization process entails that multilingualism must become an inherent feature of higher education institutions. In countries such as Spain, wherein foreign language learning has historically not been fostered by authorities, EMI emerges as a potentially powerful means to achieve this aim. However, EMI is fraught with tensions that need to be tackled before they become deep-seated and hard to overcome, and this is especially pressing in those autonomous communities in which a minority language is also spoken. This is the reason why university authorities should bend over backwards to ensure that sound multilingual language policies are cogently implemented while providing the necessary tools (economic support being indispensable) to diminish linguistic tensions and underpin the desired linguistic ecology. If minority language speakers consider that their linguistic rights are being protected, this linguistic security will pave the way to positive attitudes towards the learning of other languages and EMI will not be regarded as a Trojan horse.

\section{Acknowledgements}

This chapter is part of the following research projects: FFI2016-79377-P (Spanish Ministry of Economy and Competitiveness) and IT904-16 (Department of Education, University and Research of the Basque Government). I am grateful to the anonymous reviewers for their insightful comments. 


\section{References}

Aguilar, M. (2017). Engineering lecturers' views on CLIL and EMI. International Journal of Bilingual Education and Bilingualism, 20, 722-735. DOI: 10.1080/13670050.2015.1073664

Airey, J. (2012). 'I don't teach language': The linguistic attitudes of physics lecturers in Sweden. AILA Review, 25, 64-79. DOI: 10.1075/aila.25.05air

Alfaro-Tanco, J. A., Roothooft, H., \& Breeze, R. (2020). Transitioning to English medium instruction in operations management courses taught on Spanish business degrees: Perceptions and diagnosis. Journal of Industrial Engineering and Management, 13(3), 529-545. DOI: 10.3926/jiem.3032

Arnó-Macià, E., \& Mancho-Barés, G. (2015). The role of content and language in content and language integrated learning (CLIL) at university: Challenges and implications for ESP. English for Specific Purposes, 37(1), 63-73. DOI: 10.1016/j.esp.2014.06.007

Atkinson, D., \& Moriarty, M. (2012). 'There is no excuse. Speak Catalan!' The marketing of language acquisition to mobility students. International Journal of Applied Linguistics, 22, 189-204. DOI: 10.1111/j.1473-4192.2011.00303.x

Barkhuizen, G. (2016). A short story approach to analyzing teacher (imagined) identities over time. TESOL Quarterly, 5o, 655-683. DOI: 10.1002/tesq.311

Bazo, P., Centellas, A., Dafouz, E., Fernández, A., González, D., \& Pavón Vázquez, V. (2017). Documento Marco de Política Lingüística para la Internacionalización del Sistema Universitario Español [Towards a language policy for the internationalisation of Spanish universities: A framework of reference]. Madrid: Conferencia de Rectores de Universidades Españolas (CRUE).

Block, D. (2020). Emergent STEM lecturer identities: The shaping effects of EMI in action in an internationalised and Englishised HE context. Language Teaching, 1-19. DOI: 10.1017/So261444820000221.

Dafouz, E. (2018). English-medium instruction and teacher education programmes in higher education: Ideological forces and imagined identities at work. International Journal of Bilingual Education and Bilingualism, 21(5), 540-552. DOI: 10.1080/13670050.2018.1487926

Dafouz, E, Camacho, M., \& Urquía, E. (2014). 'Surely they can't do as well': A comparison of business students' academic performance in English-medium and Spanish-as-first-language-medium programmes. Language and Education, 28, 223-236. DOI: 10.108o/09500782.2013.808661

Dafouz, E., \& Camacho-Miñano, M. (2016). Exploring the impact of English-medium instruction on university student academic achievement: The case of accounting. English for Specific Purposes, 44, 57-67. DOI:10.1016/j.esp.2016.06.001

Dafouz, E., \& Smit, U. (2020). Roadmapping English medium education in the internationalised university. Palgrave Pivot. DOI: 10.1007/978-3-030-23463-8 
de Prada, J. M. (2013). Bilingüismo [Bilingualism]. XL Semanal, 13 October 2013. Retrieved 18 May 2020 from: https://www.xlsemanal.com/firmas/20131013/ bilinguismo-6379.html

de Prada, J. M. (2015). Dinero, demogrescay otros podemonios [Money, demogression and other powerdemons]. Planeta.

de Prada, J. M. (2019). Asnos bilingües [Bilingual donkeys]. XL Semanal, 4 March 2019. Retrieved 18 May 2020 from: https://www.xlsemanal.com/firmas/20190304/ asnos-bilingues-juan-manuel-prada.html

del Valle, J. (2020). Language planning and its discontents: Lines of flight in Haugen's view of the politics of standardization. Language Policy, 19(2), 301-317. DOI: 10.1007/s10993-019-09529-w

Dimova, S. (2017). Life after oral English certification: The consequences of the Test of Oral English Proficiency for Academic Staff for EMI lecturers. English for Specific Purposes, 46, 45-58. DOI: 10.1016/j.esp.2016.12.004

Doíz, A., \& Lasagabaster, D. (2018). Teachers' and students' L2 motivational selfsystem in English-medium instruction: A qualitative approach. TESOL Quarterly, 52, 657-679. DOI: 10.1002/tesq.452

Doíz, A., \& Lasagabaster, D. (2020). Dealing with language issues in Englishmedium instruction at university: A comprehensive approach. International Journal of Bilingual Education and Bilingualism, 23(3), 257-262. DOI: 10.1080/13670050.2020.1727409

Doíz, A., \& Lasagabaster, D. (2021). Analysing EMI teachers' and students' talk about language and language use. In A. Doíz \& D. Lasagabaster (Eds.), Language use in English-medium instruction at university: International perspectives on teacher practice (pp. 34-55). Routledge.

Doíz, A., Lasagabaster, D., \& Sierra, J. M. (Eds.) (2013a). English-medium instruction at universities: Global challenges. Multilingual Matters.

Doíz, A., Lasagabaster, D., \& Sierra, J. M. (2013b). Globalisation, internationalisation, multilingualism and linguistic strains in higher education. Studies in Higher Education, 38, 1407-1421. DOI: 10.1080/03075079.2011.642349

Doíz, A., Lasagabaster, D., \& Sierra, J. M. (2013c). English as L3 at a bilingual university in the Basque Country, Spain. In A. Doíz, D. Lasagabaster, \& J. M. Sierra (Eds.), English-medium instruction at universities: Global challenges (pp. 84-105). Multilingual Matters.

Doíz, A., Lasagabaster, D., \& Sierra, J. M. (2014) Language friction and multilingual policies at higher education: The stakeholders' view. Journal of Multilingual and Multicultural Development, 35, 345-36o. DOI: 10.1080/01434632.2013.874433

Doíz, A., Lasagabaster, D., \& Pavón, V. (2019). The integration of language and content in English-medium instruction courses: lecturers' beliefs and practices. Ibérica, 38 , 151-175. 
Fernández-Costales, A., \& González-Riaño, X. A. (2015). Teacher satisfaction concerning the implementation of bilingual programmes in a Spanish university. Porta Linguarum, 23, 93-108.

Fortanet-Gómez, I. (2010). Training CLIL teachers at university level. In D. Lasagabaster \& Y. Ruiz de Zarobe (Eds.), CLIL in Spain: Implementation, results and teacher training (pp. 257-276). Cambridge Scholars Publishing.

Fortanet-Gómez, I. (2013). CLIL in higher education: Towards a multilingual language policy. Multilingual Matters.

González Ardeo, J. M. (2014). Trilingual identity of engineering students in the Basque Country. International Journal of Multilingualism, 11(1), 23-40. DOI: 10.1080/14790718.2013.816308

Halbach, A., \& Lázaro, A. (2015). La acreditación del nivel de lengua inglesa en las universidades españolas: Actualización 2015 [English Accreditation in Spanish universities: 2015 update]. Madrid: British Council.

Hernández-Nanclares, N., \& Jiménez-Muñoz, A. (2017). English as a medium of instruction: Evidence for language and content targets in bilingual education in economics. International Journal of Bilingual Education and Bilingualism, 20, 883-896. DOI: 10.1080/13670050.2015.1125847

Jenkins, J. (2014). English as a lingua franca in the international university: The politics of academic English language policy. Routledge.

Kelly, D. (2017). Language policy for internationalisation: Spanish as an asset. In A. Pérez-Encinas, L. Howard, L. E. Rumbley, \& H. de Wit (Eds.), The internationalisation of higher education in Spain: Reflections and perspectives (pp. 47-50). Spanish Service for the Internationalisation of Education (SEPIE).

Lasagabaster, D. (2017). Language learning motivation and language attitudes in multilingual Spain from an international perspective. Modern Language Journal, 101, 583-596. DOI: 10.1111/modl.12414

Lasagabaster, D. (2018). Fostering team teaching: Mapping out a research agenda for English-medium instruction at university level. Language Teaching, 51, 400-416.

Llurda, E., Cots, J. M., \& Armengol, L. (2013). Expanding language borders in a bilingual institution aiming at trilingualism. In H. Haberland, D. Lønsmann, \& B. Preisler (Eds.), Language alternation, language choice and language encounter in international tertiary education (pp. 203-222). Springer.

Macaro, E., Jiménez-Muñoz, A. J., \& Lasagabaster, D. (2019). The importance of certification of English medium instruction teachers in higher education in Spain. Porta Linguarum, 32, 103-118.

Mancho-Barés, G., \& Aguilar-Pérez, M. (2020). EMI lecturers' practices in correcting English: Resources for language teaching? Journal of Immersion and Content-Based Language Education, 8(2), 257-284. DOI: 10.1075/jicb.19011.man 
Marcos-García, A. M., \& Pavón, V. (2018). The linguistic internationalization of higher education: A study on the presence of language policies and bilingual studies in Spanish universities. Porta Linguarum, 3 (Special Issue), 31-46.

Marías, J. (2015). Ni bilingüe ni enseñanza [Neither bilingual nor teaching]. El País, 17 May 2015. Retrieved 18 May 2020 from: https:/elpais.com/elpais/2015/05/13/ eps/1431541076_553813.html

Moncada-Comas, B., \& Block, D. (2019). CLIL-ised EMI in practice: Issues arising. The Language Learning Journal. DOI: 10.1080/09571736.2019.1660704

Norton, B. (2013). Identity and language learning: Extending the conversation (Second edition). Multilingual Matters.

Norton, B. (2016). Identity and language learning: Back to the future. TESOL Quarterly, 50, 475-479. DOI: 10.1002/tesq.293

O'Dowd, R. (2018). The training and accreditation of teachers for English medium instruction: An overview of practice in European universities. International Journal of Bilingual Education and Bilingualism, 21, 553-563. DOI: 10.1080/13670050.2018.1491945

Ploettner, J. C. (2019). A critical look at teacher development for English-medium instruction. CercleS, 9, 263-287. DOI: 10.1515/cercles-2019-0016

Roquet, H., Vraciu, A., Nicolás-Conesa, F., \& Pérez-Vidal, C. (2020): Adjunct instruction in higher education: examining the effects on English foreign language proficiency. International Journal of Bilingual Education and Bilingualism. DOI: 10.1080/13670050.2020.1765967

Rubio Cuenca, F., \& Moore, P. (2018). Teacher attitudes to learning in University bilingual education. Porta Linguarum, 3 (Special Issue), 89-102.

Spanish Ministry of Education. (2015). Estrategia para la internacionalización de las universidades españolas 2015-2020. [Strategy for the internationalization of Spanish universities 2015-2020]. Retrieved 11 May 2020 from: www.mecd.gob. es/educacion-mecd/dms/mecd/educacion-mecd/areas-ducacion/universidades/ politica-internacional/estrategia-internacionalizacion/EstrategiaInternacionalizaci-n-ENGLISH.pdf

Valdecantos, A. (2012). El saldo de la lengua [The language balance]. El País, 4 February 2012. Retrieved 18 May 2020 from: https:/elpais.com/diario/2012/02/04/ opinion/1328310012_850215.html

Wächter, B., \& Maiworm, F. (2014). English-taught programmes in European higher education: The state of play in 2014. Lemmens.

Wilkinson, R. (2018). Content and language integration at universities? Collaborative reflections. International Journal of Bilingual Education and Bilingualism, 21(5), 6o7-615. DOI: 10.1080/13670050.2018.1491948 


\section{About the author}

David Lasagabaster is Professor of Applied Linguistics at the University of the Basque Country UPV/EHU, Spain. His research revolves around EMI (English-Medium Instruction), CLIL (Content and Language Integrated Learning), attitudes and motivation, and multilingualism. He has published widely in international journals, books and edited volumes. 



\title{
$5 \quad$ An ambivalent picture
}

\author{
The Englishization of higher education in France
}

\author{
Françoise Le Lièvre
}

\begin{abstract}
In France, English has a hegemonic position in many domains, including education, despite European policy promoting linguistic and cultural diversity to better integrate citizens in democratic processes. In 2013, the Fioraso law modified the Toubon law by allowing French universities to teach in a foreign language. Under the law, the choice of English at the expense of any other foreign language seems to have become practice. However, this practice clashes with long-standing criticism of Englishization in France. In this chapter an ambivalent picture of Englishization in French higher education arises, revealing tensions between criticism and official language policy on the one hand and language practice on the other. Translingual practices in France generate a different view of Englishization in higher education.
\end{abstract}

Keywords: higher education, Englishization, commodification, translingual practices

\section{Introduction}

In an environment that has become extremely competitive as a consequence of globalization, internationalization has become one of the major concerns of institutions of higher education. On a global scale, we are currently witnessing a commodification of education and research as a consequence of free trade agreements on services (Truchot, 2016). Higher education in Europe is torn between the commodification of education and research and the remains of a humanist tradition in academia. This humanist tradition finds its expression in the Humboldtian model of higher education that

Wilkinson, Robert, and René Gabriëls (eds), The Englishization of Higher Education in Europe. Amsterdam, Amsterdam University Press 2021 DOI: 10.5117/9789463727358_CHO5 
places an emphasis not on the learning of knowledge and skills that can be utilitized, but on a process of human development (Bildung). In France, many critics of the Englishization of higher education have the humanist tradition in mind and associate it with issues of quality, identity, and diversity.

The aim of this paper is to explore the way in which the tension between the two perspectives on higher education manifests itself in France. In section 2, I sketch the socio-historical context of the internationalization of higher education through English in France. Section 3 then focuses on the consequences of the commodification of higher education. Section 4 addresses the public debate about the Englishization of French higher education. Next, in section 5 , I will argue that a focus on translingual practices offers an alternative perspective of Englishization that differs from those advanced by proponents and opponents in the French debate. Finally, I conclude by contending that language policies should meet the challenge of combining the centrality of English with the existence of linguistic pluralism.

\section{The internationalization of higher education}

In 1909, in an article devoted to the internationalization of higher education, Leclère questions 'the immobility of the Universities, [...] their excessive nationalization [ ...] (and) their sedentary spirit'. He contrasts his time with the exodus of students which marked Europe in the Middle Ages. This led him to ask: 'Why shouldn't Universities form an international federation?' (Leclère, 1909, p. 429). ${ }^{1}$ This article reminds us that the debates on the internationalization of higher education are not new. However, the internationalization of universities now follows a different star, namely a neoliberal doxa (Giroux, 2014). This doxa is the idea that promoting competition leads to quality improvement and cost reduction. In higher education, this means that universities worldwide compete to attract the best students and researchers so that they score well in the academic competition, that is, rank highly (Sabaté-Dalmau, 2020).

Over the course of the 199os, on the basis of a neoliberal agenda, international organizations such as the World Trade Organization (WTO) and the Organization for Economic Co-operation and Development

1 '[L]'immobilité des Universités, [...] leur excessive nationalisation [...] (et) leur esprit casanier'; 'Pourquoi les Universités ne formeraient-elles pas une fédération internationale?' Translations unless otherwise indicated are by the editors. 
(OECD) triggered reforms in higher education. Since the Bologna process ${ }^{2}$ initiated by the Declaration of the Sorbonne (1998) in particular - even if its primary objectives were favourable to the diversity of languages, cultures, and education systems - we have witnessed a worldwide commodification of the products of research and higher education. According to the OECD (1996), the generation and teaching of academic knowledge plays a key role in the enhancement of the competitiveness of economies and therefore on economic growth ('knowledge economy', OECD, 1996, p. 9). In this conception, knowledge has become assimilated to an economic good, entailing the 'commodification' of higher education. The Lisbon Strategy of the European Union (2000) aimed to define the most competitive and dynamic knowledge-based economy in the world. In the consolidated version of the Treaty on the Functioning of the European Union (incorporating the Lisbon Treaty) (European Commission, 2012), Article 179 concerning 'Research and Technological Development' activities specifies:

The union shall have the objective of strengthening its scientific and technological bases by achieving a European Research Area in which researchers, scientific knowledge and technology circulate freely, and encouraging it to become more competitive, including in its industry, while promoting all the research activities deemed necessary by virtue of other chapters of the Treaties. (Author's emphasis)

In April 2008 the Ministers in charge of Research launched the 'Ljubljana Process' in order to give new impetus to setting up the European Research Area (ERA) and help increase the competitiveness of the European Union (Slovenian Presidency of the EU, 2008). The European strategy consists also of setting up the European Higher Education Area (EHEA) ${ }^{3}$ comparable to that of North America. Freed from public control, institutions of higher education should enjoy a degree of operational autonomy that strengthens their position on the market. The aim is to facilitate the mobility of students and researchers, and to reduce international obstacles to mobility so that the best universities can attract the best students and most talented researchers.

2 This process led to a common architecture of university degrees (licence, master's and doctorate) and to the establishment of a common system of organization on the basis of ECTS (European Credits Transfer System).

3 https://ehea.info/ 
Mobility under internationalization very largely benefits institutions of higher education in English-speaking countries. ${ }^{4}$ In 2018, the top three destinations for international students in the world were the United States, the United Kingdom, and Australia. The United States is continuing to increase its dominance. Germany is in fourth place followed by France. This state of affairs had already been deplored in a report to the Senate about Campus France, 5 a public institution charged with promoting French higher education abroad and welcoming foreign students and researchers to France. The report notes that at a time when 'student mobility at the global level increased by $46 \%$ between 2009 and 2016, France only welcomed $13 \%$ additional foreign students and is losing market share ${ }^{6}$ (Sénat, 2017, p. 23).7 While the Senate report specifies several avenues to become competitive in the higher education market, such as the awarding of scholarships or better communication, ${ }^{8}$ it appears that to be competitive and obtain better visibility in international rankings (such as that of Shanghai in particular), traditional public institutes of higher education are now forced to reorganize to become enterprises that are good at marketing their services: education and research (Gouvernement, n.d.). For instance, since 2009, the University of Strasbourg has been reorganized around a prestigious scientific institution linked to mass institutions that have a cultural vocation. On 1 January 2012, both the University of Aix-Marseille and the University of Lorraine each merged their three universities adopting the status of EPSCP (Établissement public à caractère scientifique, culturel et professionnel). EPSCP are national institutions of higher education and research enjoying pedagogical, scientific, administrative and financial autonomy. A new legal framework ${ }^{9}$ has therefore been gradually implemented in all institutions of higher education, modifying their rules and practices in terms of financial governance and human resources management.

Despite the new legal framework that must offer universities the opportunity to take on global competition in higher education, there is a lack

4 https://ec.europa.eu/eurostat/statistics-explained/index.php/Learning_mobility_statistics 5 https://www.campusfrance.org/en

6 Author's emphasis.

7 '[L]a mobilité étudiante au niveau mondial a augmenté de $46 \%$ entre 2009 et 2016, la France n'a accueilli que $13 \%$ d'étudiants étrangers supplémentaires et perd donc des parts de marché'. 8 According to the 2017 Senate report, African students orient primarily to English-speaking countries $(42 \%)$, then to French-speaking countries (34\%). $18 \%$ of French-speaking students opt for English-speaking countries, while $11 \%$ of English-speaking students opt for French-speaking countries.

9 Law $\mathrm{n}^{\circ}$ 2007-1199 of August 10, 2007 relating to the freedoms and responsibilities of universities, known as the LRU law. 
of the reliable data that is necessary for making good policy. Valid and, above all, shared indicators that can properly inform students and allow a methodologically sound comparison between European universities ${ }^{10}$ are a step in this direction. The lack has, however, gradually been filled with indicators and rankings from other countries, notably China and the United States. The ranking which occupies a prominent position on the international scene and strongly influences the dynamics of the global higher education market is the Academic Ranking of World Universities or Shanghai Ranking. ${ }^{11}$ As Martins (2019) points out, the main criterion of the Academic Ranking of World Universities is the productivity of research, in particular through the number of articles published in journals such as Science and Nature, the citations of articles by researchers ranked by Web of Science or Science and Social Science Citations, the number of professors who have won either a Nobel Prize or a Fields Medal, etc. As the author further points out, these criteria tend to favour old and prestigious Western universities, in particular those which have produced or attracted Nobel laureates. The indicators give high value to publications in English and certain scientific journals of international fame, some of which are published by universities which occupy leading positions in world rankings. While in 2016-2017 only five French universities rose into the top 200 leading universities at the expense of universities in Singapore, Japan and Taiwan, the University of Paris-Saclay, established in January 2020, made a remarkable entry achieving the 14th place in the 18th edition of the Shanghai ranking (2020). France ranks fourth worldwide, just behind the United States, United Kingdom, and China in terms of the number of universities in the top 10o. In this context, many commentators argue that the previous invisibility of French institutions in international rankings was due to the slow reorganization of French higher education and its lack of programmes in English.

\section{Consequences of the commodification of higher education}

As we have just seen, internationalization has become one of the major preoccupations of universities, because it allows them to compete better in the academic market. One of the consequences of the commodification of higher education, in France as in many other European contexts, is to propose courses in English, considered the indispensable lingua franca 
of our globalized world. This is often done without prior research into its real necessity and without appraisal of what students and staff want. The top-down implementation of a language policy promoting Englishization is characteristic of internationalization programmes in various countries (Aizawa \& McKinley, 2020, p. 34; Lanvers \& Hultgren, 2018). The proposal to offer more courses in English is made at a time when several French sociolinguists are making a plea to embrace and give value to linguistic diversity through recognition of regional and minority languages, ${ }^{12}$ now accepted as Langues de France (Languages of France) (Beacco \& Messin, 2010). It is noteworthy that, in line with European directives, France has for several years adopted a plurilingual and pluricultural perspective. During the construction of Europe, the prevailing orientations of the language policies were aimed at founding a European citizenship grounded in linguistic pluralism. The idea is that Europeans, united in diversity, are able to understand and speak languages different from their own.

Despite the European policy to cultivate linguistic pluralism, there is a tendency towards monolingualism based on the Englishization of higher education. English is a language unlike any other in the world. It occupies a vast sociolinguistic space and holds a dominant place on the planet (Bourdieu et al., 2001). No other language has ever reached such a degree of diffusion and speakers. The number of people who master English as a second language nowadays outnumbers the number of native speakers of English (Ethnologue, 2021). The 2017 edition of Key data on teaching languages at school in Europe (European Commission, 2017) reports the very high degree of dissemination of English in Europe, such that in almost all European countries, English is the foreign language studied by the majority of students in primary and secondary education. The percentage of students learning English continues to increase. The change is most marked among the youngest - in primary education. In France, in line with eight other European countries (Croatia, Italy, Cyprus, Malta, Austria, Poland, Liechtenstein, and North Macedonia), most students (over 90\%) learn English from the first grade until school graduation. It should be noted that in France, as in other countries, the learning of a foreign language is compulsory for students from the start of the primary school.

Héran (2013) conducted a survey between 2007 and 2009 on the use of modern languages by the French scholars. In the exact sciences, the use

12 At the end of 1997, the French government began a debate on plurilingualism on the occasion of the establishment of the process which was to lead to France signing of the European Charter for Regional or Minority Languages (see for example Viaut, 2020) 
of French has become marginal, with a low proportion in the human and social sciences, while English occupies a dominant position in all domains of research (see also Le Lièvre, 2017; Le Lièvre \& Forlot, 2014). Publications, meetings or scientific symposia are mainly in English. Héran (2013) also showed that $25 \%$ of the teachers regularly or occasionally teach courses in English in higher education. As Truchot (2016) notes, the use of English as a lingua franca in higher education was first established in the $199 \mathrm{~s}^{13}$ in countries with a 'small distribution' language such as those of Northern Europe and the Netherlands. Countries in Central Europe, Southern Europe, Germany, and finally France followed.

The Englishization of French higher education accelerated in the new millennium, as more and more courses were offered in English, despite the Toubon Law. This law, named after Jacques Toubon who was Minister of Culture and Francophonie under the presidency of François Mitterrand, was passed by the French Parliament on August 4, 1994, and imposed a guarantee on the use of French in the media, at work, in everyday life and in education (Journal officiel, 1994). Article 1 of this law states: 'As the language of the Republic, according to the Constitution, the French language is a fundamental element of France's personality and heritage. It is the language of teaching, work, communication and public services. It is the privileged link between the states forming the Francophone community' (translation from Blattès, 2018, p. 36). In the context of this law, not only was there a quota regulation developed for radio stations to be obliged to play a certain number of French songs, but it was also stimulated to use French words, for instance ordinateur and infox, for English words such as computer or fake news. Blattès emphasizes that the Toubon Law entailed with regard to education 'that teaching, exams, dissertations and theses must be in French, in public and private schools and universities alike' (Blattès, 2018, p. 36). An exception is made for the teaching of foreign languages, special education (i.e., international schools) and visiting professors. There is an interesting mismatch between the spirit of the Toubon Law and the language practice. Even if it is incompatible with the law, since the beginning of this century universities have been offering more courses as a consequence of

13 The project to internationalize higher education began in the late 1960 os in Sweden. As Cabau remarks: 'It was part of the line of internationalization and democratization of Swedish society by relying, among other things, on the introduction of the compulsory learning of English for all students from 1962' ('Il s'inscrivait dans la ligne d'internationalisation et de démocratisation de la société suédoise en s'appuyant, entre autres, sur l'introduction de l'apprentissage obligatoire de l'anglais pour tous les élèves dès 1962') (2014, p. 60). 
the commodification of higher education. It is not surprising that Béatrice Khaiat, Director General of Campus France, remarked (France Culture, 2018):

Today, we no longer have a choice, English is no longer a foreign language. The United States, England and Oceania attract students from all over the world, but there are new players: China, Russia, the Netherlands. In this market, France must urgently catch up. ${ }^{14}$

Due to the focus on the global market of higher education, a decree of April 3, 2020 (Journal officiel, 2020) requires all students enrolled in institutions of higher education wishing to obtain the Licence diploma obtain certification in the English language. Article 10 of the decree specifies:

Specifically with regard to the language skills mentioned [...], the test methods allow the student's progress to be verified between entry into the licence and graduation. A certification of the level he has obtained in the chosen language, defined with reference to the European framework, is issued to the student when he obtains his licence. [...] This certification concerns at least the English language; in this case, it is subject to an external evaluation and is recognized internationally and by the socioeconomic world. The award of the diploma is condition on providing justification of this certification.

In a letter of February 12, 2020, the Office of the Minister for Education specified that:

The English language certification [...] is a choice of the government to better support companies in competitive international markets by allowing each student to certify, at the end of their first cycle of studies, their competence in English. Since English is indeed the language of commercial and scientific exchange, so it is the choice of this compulsory certification that has been retained. ${ }^{15}$

14 'Aujourd'hui, on n'a plus le choix, l'anglais n'est plus une langue étrangère. Les Etats-Unis, l'Angleterre ou l'Océanie attirent les étudiants du monde entier, mais il y a de nouveaux acteurs: la Chine, la Russie, les Pays-Bas. Dans ce marché, la France doit d'urgence rattraper son retard.' 15 The Minister for Education has responded in almost identical words to several députés and senators who had questioned the policy, for example, Assemblée Nationale, question No. 25706 (2020) https:/questions.assemblee-nationale.fr/q15/15-25706QE.htm 
One of the most frequent reasons given for the use of English is that it helps to attract the best students from around the world. Jean-Loup Salzmann, president of the Conference of University Presidents (CPU) and one of the foremost voices, declared in 2013 (Pech, 2013):

In a French medical laboratory, more than half of the people speak only English! Our research evaluations are done in English, our European projects are done in English and when a professor from abroad comes to our universities, we speak to him in English. It has become the international language, no matter what those who are mortified think. ${ }^{16}$

Le Déaut's report ${ }^{17}$ Refonder l'université, dynamiser la recherche, mieux coopérer pour réussir [Rebuilding the university, boosting research, better cooperating for success] (2013), specified, in the same way, that the obligation to restrict the courses offered to foreign students to French-medium programmes had led to them being dissuaded from attending French institutes of higher education, and that the offer of instruction in English, which he called 'a privileged way for the recovery of our competitiveness' (2013, p. 62), 'would on the contrary strengthen our language if accompanied by an attractive offer of French as a foreign language ${ }^{18}$ (Le Déaut, 2013, p. 64). ${ }^{19}$

16 'Dans un laboratoire français de médecine, plus de la moitié des gens ne parlent qu'anglais! Nos évaluations de recherche se passent en anglais, nos projets européens se font en anglais et quand un professeur venu de l'étranger est accueilli dans nos universités, on lui parle anglais. C'est devenu la langue internationale, quoi qu'en pensent les esprits chagrins.'

17 Member of Parliament, first Vice-President of the Parliamentary Office for the Evaluation of Scientific and Technological Choices.

18 Le Lièvre (2017) comments similarly on the regional scheme for higher education and research in Brittany (Schéma régional de l'enseignement supérieur et de la recherche en Bretagne, Regional Council of Brittany, 2013): 'The entry of Breton institutions in the global competition requires continuous improvements which make it possible to strengthen regional attractiveness. [...] This dimension appears essential in a global scientific community where English is the universal language of communication. Proficiency in the English language for our students is essential at this level, and training in English makes it easier to welcome international students. Moreover, in parallel, "French as a foreign language" training should be provided for foreign students' ('Linscription des établissements, des sites bretons dans le concert mondial nécessite des améliorations continues qui permettent de renforcer l'attractivité régionale. [...] Cette dimension apparaît essentielle dans une communauté scientifique mondiale où l'anglais est la langue de communication universelle. La maîtrise de la langue anglaise pour nos étudiants est incontournable à ce niveau, et les formations en anglais favorisent l'accueil des étudiants internationaux. Au demeurant, il convient de développer en parallèle des formations "français langue étrangère" (FLE) pour les étudiants étrangers.')

19 '[Une] voie privilégiée pour le redressement de notre compétitivité'; 'assortie d'une offre attractive de français langue étrangère renforceraient au contraire notre langue'. 
The same thinking permeates the Campus France site. The pages dedicated to courses offered in English and in France promote the slogan: 'French is not a requirement. Start out in English, your French will improve as well.'

It is no surprise that the so-called 'hard' sciences are the most 'Englishized'. One of the most common arguments advanced to motivate Englishization is that students who do not speak the local language do speak English. Under the European Higher Education Area, harmonization through English would allow increased mobility at the same time as it would reduce misunderstandings and conflicts. This is at odds with linguistic diversity, which might constitute a barrier to the harmonization.

Yet until very recently in France, the possibility for institutes of higher education to offer training in a language other than French was hampered by the Toubon Law. However, on July 22, 2013, the Fioraso Law, named after Minister for Higher Education and Research Geneviève Fioraso, was accepted by the French Parliament and expressed a different spirit and opened up a new era in higher education (République française, 2013). She argued: 'India has 6o million computer scientists and only sends us 3,000 students. We must multiply partnerships and, for this reason, have to offer courses in English. Otherwise, we will have five Proust specialists around a table.' She added: 'I love Proust. But sometimes the best weapon to support the Francophonie and our influence is English' (Soulé, 2013).$^{20}$ The Fioraso $\mathrm{Law}^{21}$ proposed 'to authorize teaching in a foreign language when it is provided under an agreement with a foreign or international institution.' The term foreign language did not refer to any language other than English. In addition to objectives relating to student success and the simplification of the higher education landscape, the Fioraso Law aimed to improve the influence of French research in order to increase the attractiveness of France for global elites, in particular students from non-French-speaking countries such as India, Korea, China, and Brazil, among others. Thus the Minister declared in an interview on 30 April 2013 (Gonzague, 2013): 'Ten years ago,

20 'J'aime Proust. Mais parfois la meilleure arme de la francophonie et de notre rayonnement est l'anglais.'

21 In the report to parliament on the use of the French language drafted by the DGLFLF (General Delegation for the French Language and Languages of France) one of the stated objectives of the law is to 'trace a path towards an economy of balanced knowledge, towards beneficial exchanges for France, through knowledge and mobility of students and researchers, through the development of European and global partnerships' ('tracer un chemin vers une économie de la connaissance équilibrée, vers des échanges bénéfiques à la France, par le savoir et la mobilité des étudiants et des chercheurs, par le développement de partenariats européens et mondiaux') (DGLFLF, 2013, p. 34). 
we were third in welcoming foreign students, today we are fifth. Why have we lost so much in attractiveness? Because Germany has set up courses in English and has passed us! We have to catch up'. ${ }^{22}$ Because one of the criteria for internationalization is the percentage of foreign students enrolled in universities, Germany's attractiveness was cited as a model of success. The Fioraso Law should give a boost to internationalization. In the run-up to the adoption of this law, there was a heated public debate about Englishization in higher education in parliament and the media. But even after that, this subject regularly led to public controversies.

\section{The French public debate about Englishization}

English, in France, is much more than a foreign language because of the social and ideological functions that it serves. Due to centuries of cultural, political, and economic rivalry between France and England, in which the names Joan of Arc, Napoleon, and Charles de Gaulle (among others) stand out, English and French are seen as each other's antipodes in shaping a national identity and fulfilling an ideological function (Flaitz, 1988; Gordon, 1978). The related social function is that the national language binds citizens and thus contributes to social cohesion. That is why French is culturally, legally, and institutionally anchored. Regarding culture, the French government protects its own film and music industry from the Americanization associated with English (sometimes referred to as 'cocacolonization'). And with regard to the legal anchoring of French, the Toubon Law and Fioraso Law have already been mentioned. It can also be pointed out that in anticipation of the space that the Maastricht Treaty (1992) would create for the Englishization of the European Union, the then president François Mitterand urged a constitutional amendment. Since 1992, the French Constitution states that French is the language of the republic: 'La langue de la République est le français. L'emblème national est le drapeau tricolore, bleu, blanc, rouge. L'hymne national est la "Marseillaise". La devise de la République est "Liberté, Egalité, Fraternité"' (Article 2). ${ }^{23}$ Institutions such as the Organisation Internationale de la Francophonie (OIF), Académie Française, Alliance Française and

\footnotetext{
22 'Il y a dix ans, nous étions zes dans l'accueil des étudiants étrangers, aujourd'hui, nous sommes 5 e. Pourquoi avons-nous tant perdu en attractivité? Parce que l'Allemagne a mis en place des cursus en anglais et nous est passée devant ! Il faut rattraper notre retard.'

23 'The language of the Republic is French. The national symbol is the tricolour flag, blue, white, red. The national anthem is the "Marseillaise". The motto of the Republic is "Liberty, Equality, Fraternity".'
} 
Institut Français have also made important contributions to anchoring the French language over time.

Against the background of the cultural, legal, and institutional anchoring of French, it is not surprising that the Englishization in general and in higher education in particular has led to fierce public debates in France. Illustrative of this is the public debate that was conducted in the run-up to the Fioraso Law. The proponents and opponents of this law fought each other with fire and sword. The linguist Claude Hagège, an opponent of the Fioraso Law, spoke of a 'projet de loi porteur de cancer' ('cancerous bill'). ${ }^{24}$ In contrast, the Liberation newspaper defended the law with the following front-page headline: 'Teaching in English, let's do it' (Libération, 20 May 2013).

The proponents point out that the Englishization of higher education is necessary if France is not to fall behind in a knowledge-based economy and lose its position of power in the world. Debré, a member of the French parliament, put it this way: 'we are waging an economic war, coupled with a scientific war, the first being supported by the second' (cited in Blattès, 2018, p. 100). By creating space for English-medium instruction programmes, the best students, especially from the BRICS countries, ${ }^{25}$ would be attracted (Truchot, 2016) and thus new markets could be conquered and the influence of France on a diplomatic level would be preserved. It is expected that attracting international students will ultimately contribute to the economic growth of France. In addition, the chances of French students to get a good job in a global economy would be greatly increased with English-taught classes.

Opponents of the Fioraso Law argue that it is good to attract international students, but that this should be done through French as a medium of instruction and that English as a medium of instruction leads to domain loss. Moreover, they argue that the law creates linguistic inequality and undermines cultural diversity and the collective identity. For example, philosopher Michel Serre pointed to the loss of linguistic sovereignty in the face of Anglo-American imperialism' and the Académie française spoke of the 'marginalization of our language' (cited in Salomone, 2016, pp. 72-73).

An issue related to the domain loss that was central in the public debate is the question of what the consequences of the Englishization of higher education are for the Francophonie (i.e., the global community of people and countries that speak the French language). The opponents of the Fioraso Law argue that the Englishization of higher eduation is a threat to the 
Francophonie and undermines the rayonnement (i.e., influence) of France in the world. In contrast, the proponents say that the Fioraso Law will attract international students who learn the French language and culture and thus not only promote the language but also strengthen France's influence.

The defenders of French and the Francophonie use an alarmist rhetoric. For them, the quality of French, faced with the omnipresence of English, would diminish, which would precipitate domain loss. According to the French writer Frédéric Werst, not only is the French language marginalized, but the English spoken in higher education is a 'mediocre Globish' (McPartland, 2013). For this and other opponents of the Fioraso Law, the quality of education suffers from the fact that English-medium instruction in France is not of the same level as in Anglophone countries and students as well as teachers can express themselves more nuanced in French than in English. 'EMI [English-medium instruction] is only deemed legitimate if it is taught by a native speaker and in an Anglophone country' (Blattès, 2018, p. 102).

Besides domain loss, the loss of French influence in the world and the loss of quality as a consequence of Englishization are discussed in the public debate. This concerns the consequences for linguistic equity, cultural diversity, and collective identity. According to the opponents of the Englishization, inequality will only increase, because English is an additional barrier for some to participate in higher education. However, Minister Fioraso defended the law named after her by pointing out that it corrects inequalities. This law would allow all students to take English classes and not just those who attend the business schools and Grandes écoles where many programmes are in English anyway (Salomone, 2016, p. 71).

An argument often used by opponents of the Fioraso Law, such as the organization L'Observatoire Européen du Plurilinguisme, highlighted the fear that the Englishization would undermine linguistic diversity and the cultural diversity based on it. Given the ever-growing position of English in the world, the Organisation Internationale de la Francophonie considers the promotion of English as a threat to linguistic and cultural diversity at the same time. However, several scholars point out that at an international level France advocates a multilingual language policy to build a barrier against English and preserve its own identity, but at the national level promotes monolingualism (Blanchet et al., 1999; Wright, 2006). The latter would be at the expense of minority languages such as Basque, Breton, and Corsican. On the basis of an assimilatory model, these minority languages are often called languages of France (Langues de France). Given this constellation, Blattès (2018, pp. 33-35) speaks of 'monolingualism on the inside, 
multilingualism on the outside' and Coleman (2006, p. 8) of 'adopting a protective multilingualist stance'.

Besides the substantive points of contention in the public debate about the Fioraso Law, there is one issue that is no less interesting, namely the gap between the official language policy and practice. Deneire (2015, p. 67) points out that the official language policy is supported by a small conservative elite, but that the majority of French citizens do not seriously oppose Englishization. De jure there are all kinds of restrictions to the Englishization of higher education, but de facto, as the research by Héran (2013) shows, more and more universities are offering English medium of instruction programmes. Even after the introduction of the Fioraso Law, this has not resulted in resistance to Englishization being silenced. In Le Parisien (June 16, 2019), the collective Langue française turned to President Macron for support in their fight against 'tout-anglais'. Their petition was signed by many worldwide.

\section{$5 \quad$ Translingual practices}

The outline of the public debate about the Englishization of higher education in France provides an ambivalent picture (Le Lièvre \& Forlot, 2014). There is something to be said for both the opportunities and the threats that this process entails. The different views of the proponents and opponents suggest that there is a great contradiction, but things are never as bleak as they seem. This is especially evident from the gap between the official language policy and the current language practice. According to some, the concern about Englishization is of the older rather than the younger generation (Lakehal, 2011, p. 34). Estival and Pennycook underline that the vision of the Académie française is not representative of what all French think about English (Estival \& Pennycook, 2011, p. 338).

The image of the Englishization of higher education in France remains ambivalent as long as no more empirical research is done into the effects of that process. For example, concerning EMI in France, Blattès (2018, p. 24) contends that: 'France is a latecomer in the global EMI trend which makes it an under-researched context. Very few studies have explored EMI in French universities from an empirical perspective.' It is remarkable that no time during the discussions on the Fioraso law, was there any mention of research studies or exploratory surveys on the real benefits that the use of English could represent. As Truchot (2013, p. 87) underlined, 'One would have expected that the foreseeable effects of such a bill would have been 
the subject of preliminary studies and evaluations by the competent public authorities. However, that is not the case. ${ }^{26}$ Due to the lack of such studies in France, it is interesting to look shortly at research abroad.

In 2011 the conference of German university rectors (Hochschulerektorenkconferenz) released a research report reviewing 10 years of Englishization of higher education in Germany. The effects were generally reported to be negative (HRK, 2011). The research report pointed out that most notably the quality of the English proficiency of teachers often leaves much to be desired. In a study carried out in Lausanne University, Usunier (2010) notes the loss of information in the transmission and reception of knowledge. Class interactions are reduced and students show greater passivity, which raises questions concerning didactics. Contrary to the suggestion of the proponents of the Fioraso Law that it promotes French language and culture, when non-Francophone international students study in France, Usunier's study shows that they are not very motivated to learn French language and culture. Finally, concerning costs, a Swiss study by Gazzola and Grin (2013) analysed the costs linked to the different linguistic regimes. Their study shows that the use of translation and interpretation, even if it is not free, remains more effective and more reasonable than a monolingual diet based on the English language alone.

In the reaction to the HRK report (2011), the German university rectors argue in favour of international openness sustained by language policies that aim both to preserve German and guarantee multilingualism. According to them, teaching and being taught in one's own language enables all skills to be fully exercised. They advocate the benefits of immersion in another educational culture for foreign students. Some of the northern European countries which were at the forefront of Englishization are now considering linguistic adjustments. For instance, in Finland the concept of Iinguistic parallelism' (Cabau, 2014, p. 66) has evolved, which consists of promoting the use of other languages in parallel with English as far as possible. In 2008, in Denmark a Centre for Internationalization and Parallel Language Use (CIP) was established at the University of Copenhagen with the aim of offering programmes in English as well as Danish skills for Danish and international students.

As mentioned, despite European recommendations aimed at promoting linguistic diversity in France, English has consolidated its position in many contexts where it seems to be promoted because of its strong 'social' demand,

26 'On aurait pu s'attendre à ce que les effets prévisibles d'un tel projet aient fait l'objet d'études préalables et d'évaluations par les autorités publiques compétentes. Or il n'en est rien.' 
as described by Forlot (2016, p. 110). The different functions and the various statuses that language occupies in education and in several domains of daily life enable different perspectives on language and allow us to recognize what is taken for granted or where firmly held reluctance lies. Depending on the circumstances, each individual can assess and use a language completely differently. Language policies will have to take this into account in one way or another. How they do that is a political matter. Regarding this political issue, Matthey and Fibbi contend (2010, p. 3): 'The political dimension is naturally dependent on economic and social dynamics so that the status of languages is not defined by force [...] but in a more subtle way, through the power and prestige to which mastery of languages gives access. ${ }^{27}$ Thus, the use of English in various domains in France is due not only to the linguistic and economic hegemony of the language but also to language ideologies.

In many domains, English is a language that is taken for granted and this is not without effects. The more the presence of English increases, the less this presence seems to be questioned. To put it another way, the less Englishization is questioned, the more the status of English as 'different' from other languages seems to be implicitly reinforced. In certain domains, the very large place given to English must be considered as a form of 'submission'. The submission is due to the assumption that the Englishization of higher education is indispensable without examining precisely to what extent this meets the different needs of the various stakeholders. This might have been resulted in a divergence between the extent to which English has gained ground and the real need for it. The use of English has consolidated in scientific domains, leading to domain loss of languages with which scientists have previously communicated. In public opinion, the majority is convinced that English should be the language of instruction in educational domains. Due to globalization and the economic power of the United States in particular, English has also occupied a dominant position in economic domains. Finally, English is very present in media domains. However, in all these domains the question can be raised whether it is more closely linked to its status than to real necessities (see also Chaplier, 2014).

In the aforementioned domains, language ideologies often take away from reality, which is more characterized by hybrids, code-switching, and codemixing than by clearly separate and distinguishable language systems. Based on ideology theory (Althusser, 1970; Larrain, 1979), a language ideology can

27 'La dimension politique est naturellement tributaire des dynamiques économiques et sociales de sorte que le statut des langues ne se définit pas par la force [...] mais de manière plus subtile, par le biais du pouvoir et du prestige auxquels la maîtrise des langues donne accès.' 
be defined as a system of (illusory) beliefs about how language functions in a specific domain. Previously it was pointed out that the language ideologies of the proponents and opponents of the Fioraso Law are not evidence-based. Whatever the views expressed in the public debate, they were not based on solid scientific research into the Englishization of higher education in France. Yet the opponents very confidently asserted that Englishization leads to domain loss for the French language and the loss of France's power in the world. With the same confidence, the proponents claimed that EMI would benefit the French language and culture as international students learn to master them when they study in France and then venture out into the world. Blattès (2018, p. 24) delicately points out the following: 'Most researchers who have focused on France have studied attitudes towards English rather than EMI per se.' All in all, this produces an ambivalent picture of the Englishization of higher education in France.

However different the perspectives of the proponents and opponents of the Fioraso Law are, they have one thing in common: they are blind to translingual practices in France. Both assume two language systems (French and English) between which a bilingual individual moves, but do not see that in practice such a person actually appropriates and deploys features from both language systems in order to communicate. Integrating features from two or more language systems is called translanguaging (Vogel \& García, 2017). Williams coined the concept of translanguaging (in the original Welsh: trawsiethu) to refer to bilingual practices characterized by 'the planned and systematic use of two languages for teaching and learning inside the same lesson' (Lewis et al., 2012, p. 643). For example, writing in Welsh and reading in English. Beyond the idea that the language repertoire of an individual consists of two separate domains in the brain that correspond to different language systems, Cummins, based on research into bilingual classrooms (French/English) in Montreal, used the iceberg metaphor to describe the interaction between language systems. That part of the iceberg that rises above the water surface suggests that a bilingual speaker speaks two different languages, but below the water surface there is a 'common underlying proficiency', that is, an amalgam of features of both language systems (Cummins, 1979). According to Wei (2018, p. 24), translanguaging 'challenges the conventional understanding of language boundaries between [...] culturally and politically labelled languages.'

The Englishization of higher education in France implies the creation of spatio-temporal contexts in which students are involved in translanguaging. The translingual practices in higher education are at odds with the ultimately monolingual perspectives of the proponents and opponents of the Fioraso 
Law, which are based on the idea that efficient communication is only possible in a common language, French or English. As English-speaking monolingualism spreads and proliferates, it is important to bear in mind that, contrary to what is widely believed - by politicians and the general public - monolingualism is not the norm in our globalized societies: it is the exception. The development of plurilingual education via translingual practices could curb the instrumentalization of English as a factor of internationalization. A conference on 'Plurilingualism, pluriculturalism and English in globalization: Devices, practices and issues of internationalization in European higher education' held in Angers in October 2015, is illustrative of translanguaging. It aimed to explore various avenues that demonstrate internationalization policies where English is not the ubiquitous lingua franca. Of the many examples presented, the experience of a Franco-Italian master's degree (Brancaglion, 2018) designed between the Università degli Studi di Milano and the University of Avignon and the Pays de Vaucluse testifies to the possibility of creating international courses which allow the national languages to be maintained, especially when it is a question of closely related languages. Similarly, Muñoz and Vieira (2018) report the case of the Universidade Federal da Integração Latino-Americana (UNILA, the Federal University for Latin American Integration) in Brazil which in 2010 received its first intake of students from different countries in Latin America and the Caribbean. As Muñoz and Viera underline, this project, both political and educational, aimed to promote simultaneously integration through bilingualism (Spanish and Portuguese), interdisciplinarity and multiculturality. Moreover, Forlot (2016) has developed the idea whereby English can be seen as a stabilizer or even as a 'booster' of plurilingualism, an idea which consists in 'departitioning language teaching' and considering the role of English within it, so that it can function as a 'bridge language' between French and Chinese for example (pp. 103-105).

\section{Conclusion}

In the case of the Englishization of higher education in France official discourses and actual practices diverge. Illustrative of this, as mentioned, is the gap between what the Toubon Law prescribes and the increase in universities offering EMI programmes. The introduction of the Fioraso Law was intended to close this gap, but it sparked a public debate between proponents and opponents who each maintained their own perspective. However, the proponents and opponents have one thing in common, namely 
that they assume that languages are separate and distinguishable. They have an overly static and monolingual image of language that does not do justice to the translingual practices in higher education in France. These dynamic practices are characterized by hybrids, code-switching, and code-mixing. Although the Englishization of higher education in France is the result of the global commodification of education and research, translingual practices may provide the breeding ground for resistance to the underlying neoliberalism. Even if a kind of globalized English does function as the 'lingua franca' in many academic domains on higher education in France, cases of 'translanguaging' abound. A policy that valorizes plurilingualism, a true parameter of differentiation, would be much more interesting than a policy of blindly chasing Englishization. To achieve real inclusion in times of globalization, it is necessary to design language policies in higher education that would combine the challenge of the centrality of English with that of linguistic plurality. Such language policies would offer attractive paths that differ from those of Anglophone universities.

\section{References}

Aizawa, I., \& McKinley, J. (2020). EMI challenges in Japan's internationalization of higher education. In H. Bowles \& A.C. Murphy (Eds.), English-medium instruction and the internationalization of universities (pp. 27-48). Palgrave Macmillan.

Althusser, L. (1970). Idéologie et appareils idéologiques d'État. (Notes pour une recherche). La Pensée, 151.

Beacco, J.-C., \& Messin, K. C. (2010). Les politiques linguistiques européenne et la gestion de la diversité des langues en France. Langue Française, 167, 95-111.

Blanchet, P., Breton, R., \& Schiffman, H. (Eds.) (1999). Les langues régionales de France: un état des lieux à la veille du XXIe siècle/The regional languages of France, an inventory on the eve of the XXIst century. Peeters.

Blattès, M. (2018). English-medium instruction in French higher education: Competing ideologies, policies and practices [Thesis]. King's College London. Retrieved 10 November 2020 from https://kclpure.kcl.ac.uk/portal/files/104629103/2018_ Blatt_s_Marianne_1171954_ethesis.pdf

Bourdieu, P., de Swaan, A., Hagège, C., Fumaroli, M., \& Wallerstein, I. (2001). Quelles langues pour une Europe démocratique? Raisons politiques, 2, 41-64.

Brancaglion, C. (2018). Internationalisation des études: l'expérience du master francoitalien 'Langues, Littératures, Traduction et Culture'. Heteroglossia, 16, 125-142.

Cabau, B. (2014). Échos nordiques: l'anglais dans l'enseignement supérieur en Suède. Les langues modernes, $1,60-66$ 
Chaplier, C. (2014). Réflexion sur les enjeux et les conséquences de l'utilisation de l'anglais international. Educação, Sociedad \& Culturas, 41, 25-45.

Coleman, J. A. (2006). English-medium teaching in European higher education. Language Teaching, 39(1), 1-14.

Conseil régional de Bretagne (2013). Schéma régional de l'enseignement supérieur et de la recherche en Bretagne, rapport adopté. www.europe.bzh/upload/docs/ application/pdf/2013-11/sresr_version_finale.pdf

Cummins, J. (1979). Linguistic interdependence and the educational development of bilingual children. Review of Educational Research, 49(2), 222-251.

Deneire, M. (2015). Images of English in the French press. In A. Linn, N. Bermel, \& G. Ferguson (eds.), Attitudes Towards English in Europe: English in Europe (pp. 55-70). De Gruyter Mouton.

DGLFLF (2013). Rapport au parlement sur l'emploi de la langue française. Ministère de la Culture et de la Communication.

Estival, D., \& Pennycook, A. (2011). L'Académie française and Anglophone language ideologies. Language Policy, 10(4), 325-341.

Ethnologue: Languages of the World (2021). Retrieved 5 March 2021 from www. ethnologue.com

European Commission (2012). Treaty on the Functioning of the European Union. Official Journal of the European Union, $\mathrm{C}_{32} 6 / 47$.

European Commission (2017). Key data on teaching languages at school in Europe (2017 edition). Retrieved 18 October 2020 from op.europa.eu/en/ publication-detail/-/publication/3b929832-3f61-11e7-ao8e-o1aa75ed71a1

Flaitz, J. (1988). The ideology of English: French perceptions of English as a world language. Mouton de Gruyter.

Forlot, G. (2016). English in the educational expanding circle: Power, pride, and prejudice. In F. Le Lièvre, M. Anquetil, M. Dérivry-Plard, C. Fäcke, \& L. VerstraeteHansen (Eds.), Langues et cultures dans l'internationalisation de l'enseignement supérieur au XXIe siècle (pp. 91-111). Peter Lang.

France Culture (2018). L'université en anglais: soft power ou menace pour le français? Retrieved 18 October 2020 from www.franceculture.fr/emissions/hashtag/ luniversite-en-anglais-soft-power-ou-menace-pour-le-francais

Gazzola, M., \& Grin, F. (2013). Is ELF more effective and fairer than translation? An evaluation of the EU's multilingual regime. International Journal of Applied Linguistics, 23(1), 93-107.

Giroux, H. A. (2014). Neoliberalism's war on higher education. Haymarket Books.

Gonzague, A. (2013). Fioraso: 'Je vois beaucoup d'hypocrisie dans ce débat.' Nouvel Observateur (30 April). Retrieved 10 November 2020 from www.nouvelobs.com/ education/20130430.OBS7733/fioraso-je-vois-beaucoup-d-hypocrisie-dans-cedebat.html 
Gordon, D. C. (1978). The French language and national identity (1930-1975). Mouton de Gruyter.

Gouvernement (n.d.). Le Programme d'investissements d'avenir. Retrieved 5 January 2021 from www.gouvernement.fr/le-programme-d-investissements-d-avenir Héran, F. (2013). L'anglais hors la loi? Enquête sur les langues de recherche et d'enseignement en France. Populations et Sociétés, 501, 1-4.

HRK, German Rectors' Conference. (2011). Language Policy at German Universities, Resolution of the 11th General Meeting of 22 November 2011.

Journal Officiel de la République Française. (1994). Loi no. 94-665 du 4 août 1994 relative à l'emploi de la langue française.

Journal Officiel de la République Française. (2020). Arrêté du 3 avril 2020 relatif à la certification en langue anglaise pour les candidats inscrits aux diplômes nationaux de licence, de licence professionnelle et au diplôme universitaire de technologie. Retrieved 10 December 20202 from www.legifrance.gouv.fr/jorf/ id/JORFTEXToooo41782410/

Lakehal, S. (2011). English hegemony and language diversity in the European Union. Problems and solutions. Stendhal University, Grenoble. Retrieved 5 March 2021 from www.academia.edu/2503834/ELF_and_EU

Lanvers, U., \& Hultgren, A. K. (2018). The Englishization of European education. European Journal of Language Policy, 10(1), 1-11.

Larrain, J. (1979). The Concept of Ideology. Hutchinson.

Leclère, A. (1909). L'internationalisation de l'enseignement supérieur. Revue Internationale de l'Enseignement, 58, 427-437.

Le Déaut, J.-Y. (2013). Refonder l'université, dynamiser la recherche, mieux coopérer pour réussir. Ministère de l'enseignement supérieur et de la recherche. Retrieved 18 October from www.vie-publique.fr/sites/default/files/rapport/pdf/134000040. pdf

Le Lièvre, F. (2017). Quelles motivations et quelles conséquences au choix d'enseigner en anglais à l'université en France? In E. Suzuki, A. Potolia, \& S. CambroneLasnes (Eds.), Penser la didactique du plurilinguisme et ses mutations: politiques, idéologies, dispositifs (pp. 73-84). Presses Universitaires de Rennes.

Le Lièvre, F., \& Forlot, G. (2014). Éducation et plurilinguisme: quel rôle pour l'anglais? Cahiers Internationaux de sociolinguistique, 1(5), 161-117.

Le Parisien (2019, June 16). Défense de la langue française: 100 signatures pour refuser la dictature dur tout-anglais. Retrieved 5 February 2021 from www. leparisien.fr/societe/defense-de-la-langue-francaise-10o-signatures-pour-refuserla-dictature-du-tout-anglais-16-06-2019-8094285.php

Lewis, G., Jones, B., \& Baker, C. (2012). Translanguaging: origins and development from school to street and beyond. Educational Research and Evaluation, 18(7), 641-654. 
Martins, C. B. (2019). L'enseignement supérieur à l'heure de la mondialisation. Socio, 12, 205-227.

Matthey, M., \& Fibbi, R. (2010). La transmission intergénérationnelle des langues minoritaires. Revue Tranel (Travaux Neuchâtelois de linguistique), 52, 1-7.

McPartland, B. (2013). Plan for degree courses in English is deluded. The Local. Retrieved 6 January 2021 from http://www.thelocal.fr/20130417/ university-english-french-werst

Munoz, A. E., \& Vieira, C. (2018). Le plurilinguisme dans le cadre académique et de mobilité MERCOSUR: le cas de l'Université Fédérale d'Intégration LatinoAméricaine. Heteroglossia, 16, 143-16o.

OECD (1996). L'économie fondée sur le savoir. [The knowledge-based economy]. Paris. Retrieved 10 January 2021 from www.oecd.org/officialdocuments/public displaydocumentpdf/?cote=OCDE/GD\%2896\%29102\&docLanguage $=\mathrm{Fr}$

Pech, M.-E. (2013, 13 March). L'université française veut créer des diplômes en anglais. Le Figaro. Retrieved 18 October 2020 from etudiant.lefigaro.fr/les-news/actu/ detail/article/l-universite-francaise-veut-creer-des-diplomes-en-anglais-1420/

République Française. (2013). Loi n 2013-66o du 22 juillet 2013 relative à l'enseignement supérieur et à la recherche. Retrieved 18 October 2020 from www.legifrance.gouv.fr/loda/id/JORFTEXToooo27735009/

Sabaté-Dalmau, M. (2020). Neoliberal language policies and linguistic entrepreneurship in higher education: Lecturers' perspectives. Language, Culture and Society, 2(2), 174-196.

Salomone, R. (2016). The rise of global English: Challenges for English-medium instruction and language rights. In F. Le Lièvre, M. Anquetil, M. DerivryPlard, C. Fäcke, \& L. Verstraete-Hansen (Eds.), Langues et cultures dans l'internationalisation de l'enseignement supérieur au XXIe siècle: (Re)penser linguistiques: anglais et plurilingualisme (pp. 59-9o). Peter Lang.

Sénat (2017). Rapport d'information $n^{\circ} 90$ (2017-2018) de MM. Robert del Picchia et André Vallini sur le contrat d'objectifs de Campus France, déposé le 15 novembre 2017. Retrieved 18 October 2020 from www.senat.fr/rap/r17-09o/r17-0901.pdf

Slovenian Presidency of the EU. (2008). Informal meeting of the Ministers for Competitiveness (Research). Brdo 15 April 2008. Draft summary by the Presidency. Retrieved 10 December 2020 from http://www.eu2008.si/

Soulé, V. (2013). L'anglais enflame les amphis. Libération (20 May). Retrieved 6 January 2021 from www.liberation.fr/societe/2013/05/20/l-anglais-enflammeles-amphis_904358/

Truchot, C. (2013). Enseigner en anglais dans les universités françaises: quels effets prévisibles? Education et Sociétés Plurilingues, 35, 87-9o.

Truchot, C. (2016). Internationalisation, anglicisation et politiques publiques de l'enseignement supérieur. In F. Le Lièvre, M. Anquetil, M. Derivry-Plard, C. Fäcke, 
\& L. Verstraete-Hansen (Eds.), Langues et cultures dans l'internationalisation de l'enseignement supérieur au XXIe siècle. (Re)penser les politiques linguistiques: anglais et plurilinguisme (pp. 427-437). Peter Lang.

Usunier, J.-C. (2010). Un plurilinguisme pragmatique face au mythe de l'anglais lingua franca de l'enseignement supérieur. In A.-Cl. Berthoud (Ed.), Les enjeux du plurilinguisme pour la construction et la circulation des savoirs (pp. 37-48). Éditions ASSH.

Viaut, A. (2020). De 'langue régionale’ à langue de France' ou les ombres du territoire. Glottopol, 34, 46-56.

Vogel, S., \& García, O. (2017). Translanguaging. In G. Noblit \& L. Moll (Eds.), Oxford Research Encyclopedia of Education. Oxford University Press. DOI: 10.1093/ acrefore/9780190264093.013.181

Wei, L. (2018). Linguistic (super) diversity, post-lingualism and translanguaging moments. In A. Creese and A. Blackledge (Eds.), The Routledge Handbook of Language and Superdiversity (pp. 16-29). Routledge.

Wright, S. (2006). French as a lingua franca. Annual Review of Applied Linguistics, $26,35^{-60}$.

\section{About the author}

FranÇOISE LE LIÈvre is Assistant Professor in Language Sciences, focusing on language policy issues in higher education. She is currently in charge of Francophonie at the University of Galatasaray (Istanbul). She is general secretary of Poclande (People, Cultures, Languages and Development), an international network of researchers, experts and practitioners on development issues. 



\title{
6 English in Swiss higher education
}

\author{
The pragmatic way \\ Patrick Studer and Aisha Siddiqa
}

\begin{abstract}
This chapter reviews the current discourses surrounding English in higher education, focusing on the impact Englishization has had on education and language policy-planning in Switzerland. While English is in direct competition with national languages at the obligatory school levels, and the debate about the status of English is evident in national language policymaking, higher education institutes (henceforth HEIs) have taken a pragmatic approach, broadening their educational offerings to include English-medium courses and programmes at all levels. Taking legal, strategy and policy documents as its basis, this chapter discusses themes that impact thinking about language in higher education in a small multilingual nation and reviews how the language question has been addressed by policymakers at the national and institutional levels.
\end{abstract}

Keywords: language policy, English-medium instruction, multilingualism, higher education, Switzerland

\section{Introduction}

Switzerland is an interesting case in the study of Englishization as it is not only highly interconnected with the world but also quadrilingual. With a population of around eight million people, Switzerland has four national languages - German, French, Italian, and Romansh - which sets it apart from most of the European countries that have one overarching national language (e.g., France, Germany, Italy, Spain). Switzerland is made up of 26 cantons of varying sizes but major distinctions can be made linguistically, with areas where German is spoken predominantly (62.1\% of the population)

Wilkinson, Robert, and René Gabriëls (eds), The Englishization of Higher Education in Europe. Amsterdam, Amsterdam University Press 2021 DOI: 10.5117/9789463727358_CHo6 
compared to French (22.8\%), Italian (8\%), Romansh (0.5\%) (FSO, 2018) and bilingual regions (e.g., Bern, Fribourg, Valais). With numerous national and migrant languages present in such a small nation, Switzerland has put considerable effort into creating and maintaining a linguistic harmony through comprehensive policy efforts and measures.

In Switzerland, multilingualism is not only enshrined in the constitution and in day-to-day politics but also finds expression across all domains of public life, especially in education. According to Swiss educational curricula, pupils in public schools are taught through one of the four national languages but are required to learn a second language at an early age. In bilingual regions, pupils may even qualify for bilingual education in two national languages. Despite considerable policy efforts towards language integration, and in spite of the fact that English has no official status in Switzerland, English has, over the past few decades, been increasingly used as a vehicle for communication across language regions and in many professional domains within Switzerland, replacing national languages. Therefore, already at the turn of the millennium, Watts and Murray (2001) wondered whether English had become the fifth national language in Switzerland, and Durham (2016, p. 107) more recently claimed that English had attained the status of a 'de facto' additional language of Switzerland.

According to the Federal Statistics Office population census (FSO 2018), about $40.8 \%$ of permanent residents with a migration background use English at least once a week. The use of English as a lingua franca in workplaces has also increased over time, from $17.2 \%$ in 2012 to about $20 \%$ in 2018 (FSO, 2018). This trend is also visible in education, where the rise of English has repeatedly sparked public controversy and extensive media coverage over the past two decades, at both the national and regional levels. Some cantons, which exercise authority over languages taught in schools, have replaced Swiss second languages by English in the early school curriculum (cf. Demont-Heinrich, 2005; Lüdi, 2007; Pfenninger \& Watts, 2019). While the public debate surrounding English in education has primarily revolved around obligatory school levels, higher education has enjoyed more freedom to explore different policy options, a phenomenon which we will further analyse in the following sections.

The spread of English in Switzerland, especially at HEIs, echoes the global trend towards Englishization. By Englishization, we refer to the shift of medium of instruction in HEIs to English in a context where English is not spoken as the first language (Lanvers, 2018). In the European context, Englishization gained particular momentum in the wake of the Bologna process (Kirkpatrick, 2014). Englishization tends to be the result 
of a top-down policy effort in tertiary level institutes (Lanvers \& Hultgren, 2018), led by 'the imperative of globalization' (Boussebaa \& Brown, 2017, p. 7) and the aim of HEIs to internationalize, attract foreign talent, and increase university rankings and overall visibility. Englishization as a trend has been problematized by various scholars, who claim that it is symptomatic of HEIs following a neoliberal, economic ideology 'pushing the global spread of English' through a 'covert language policy mechanism' (Piller \& Cho, 2013, p. 23; cf. also Studer, 2021a; generally on economic ideology: Akdağ \& Swanson, 2018). Language, in this context, becomes a symbol and object of status allocation in a struggle between elites and counterelites (Barakos \& Selleck, 2019; Cooper, 1989, p. 120; Studer 2021a, p. 18).

In this chapter, we aim to trace the policy approaches in response to Englishization at the macro level and at the meso level in selected Swiss universities, critically analysing its impact on the national language status and the perception of Swiss multilingualism. The chapter then proceeds to summarize research carried out over the past two decades into Swiss multilingualism and English in higher education. Secondly, key languagestrategic and policy documents at the national and institutional levels are analysed and compared across different language regions of Switzerland.

\section{A brief review of language debates and concerns}

A recent study by Pfenninger and Watts (2019) investigated discourses surrounding the teaching of English in Switzerland and highlighted their potential to challenge Swiss national cohesion at the federal level. They claim that in Switzerland two radically dichotomous discourse archives exist concerning the spread of English, especially in the educational context (cf. Foucault, 1972, p. 127 on the notion of discourse archives). The first discourse archive is expressive of a serious concern over the decrease in interest in learning, and interacting in, national languages, considering English a threat to national cohesion (cf. Murray \& Dingwall, 2001, p. 89), while the second, competing discourse archive supports the introduction of English as an optional second language in schools in all cantons (cf. Watts \& Murray, 2001), assuming that learners' efficient linguistic performance in business and industry world will increase their job prospects (Pfenninger \& Watts, 2019).

The results of Pfenninger and Watts' (2019) study echo similar findings in other studies that have been conducted at the European level, corroborating fundamental dichotomies in language policy-planning 
discourses that seem irreconcilable and contradictory (Studer, 2021b; Studer, 2012). Part of the incompatibility between the two discourse archives is rooted in the dichotomy unity in diversity (e pluribus unum, cf. Studer et al., 2010), where unity comes at the expense of diversity (on the unity-in-diversity ideology in Switzerland, cf. also Billigmeier, 1979, p. viii; Stępkowska, 2019, p. 70). The sentiment that national or regional diversity is in danger is clearly expressed in other studies in which voices can be heard advocating for the protection of national languages (e.g., Saarinen \& Taalas, 2017) and warning against domain loss in local languages (Kuteeva, 2019).

While much of the debate surrounding English in the Swiss education system concerned its controversial status as first foreign language in the national school curriculum, the case is different with higher education: Swiss HEIs, like most schools at the obligatory levels, are public institutions. Unlike public schools, where languages have been subject to debate and controversy, Swiss HEIs have been able to largely stay outside public scrutiny and no cantonal language regulations similar to the national school curriculum have been put in place (Dürmüller, 2001; also see Studer, 2021a, p. 24 for further considerations). Possibly as a result of this, English in higher education in Switzerland has received comparatively little attention from sociolinguists. A few early studies appeared at the turn of the millennium. In 2005, Lüdi and Werlen (2005) found that English was used regularly by $40 \%$ of people in HEIs. In another case study, Murray (2001) found that in the University of Bern teaching materials in about $50 \%$ of courses were in English, particularly in natural sciences and biomedical subjects. Dürmüller (2001), moreover, found that the use of English was much less common in universities located in French and Italian regions compared to the German speaking parts. In the absence of more recent surveys on the use of English in Swiss higher education, it is reasonable to assume that the overall trend outlined in these early studies as well as the differences between the language regions and the disciplines are still valid today (cf. Murray \& Ding wall, 1997, on some historical developments).

HEIs in Switzerland, like elsewhere in Europe, have been active in establishing English-taught programmes (ETPs), that is, study programmes entirely taught through English, over the past 20 years (Wächter \& Maiworm, 2002; 2008; 2014). In 2002, out of an estimated total of 600 programmes (Bachelor, Master, $\mathrm{PhD}$ ) offered in numerous Swiss HEIs, only 15 programmes were ETPs. Visible development can be seen in 2008 when out of an estimated total of 1,400 programmes offered by different 
Swiss HEIs, $5^{2}$ programmes were classified as ETPs. In their latest study, Wächter and Maiworm (2014) reported that out of an estimated total of 1,700 programmes offered in different Swiss universities, the number of ETPs stood at 236 , which is about $14 \%$ of all study programmes. More recently, Sandström \& Neghina (2017) looked at the distribution of ETPs at the bachelor's and master's levels and reported that Switzerland, along with the Netherlands, have the highest percentage of HEIs offering ETPs at the bachelor's level, indicating that English-taught bachelor's programmes have become an integral part of Swiss higher eduation. The numbers in Sandström and Neghina (2017, p. 28) suggest a further rise in English-taught programmes from 2014 , with approximately 380 programmes entirely taught through English.

While, as indicated in Wächter and Maiworm's studies and Sandström and Neghina (2017), the number of ETPs has been increasing steadily over the past 20 years, a far more widespread way of implementing English as a medium of instruction is by offering parts of study programmes through English. Zurich University of Applied Sciences (ZHAW), as one case in point, published so-called EMI guidelines already in 2011, outlining four levels of complexity that can be achieved through the partial integration of English into study programmes, ranging from systematic CLIL (Content and Language-Integrated Learning) to EMI or occasional English-taught classes. Within Universities of Applied Sciences, moreover, it has become a common practice to define International Profiles which are exclusively taught through English (Studer, 2018a, pp. 1-5). These profiles commonly consist of one semester's worth of studies in English in study programmes taught through national languages in order to attract foreign students to Switzerland.

Considering the reality outlined above, it may seem surprising that little attention has been paid to date to issues of language policy and planning in Swiss HEIs. Studer (2013), Gautschi and Studer (2017) and Studer (2018b) have dealt with the role of policy stakeholders in Swiss HEIs at some length. While these studies focus on the perceptions, willingness and role of university stakeholders involved in the planning or implementation of EMI programmes in higher education, they do not address the larger policy context within which university stakeholders position themselves at significant length. In the next sections, the policy context of English in Swiss higher education will be outlined in greater detail by reviewing the legal premises and by highlighting and comparing concrete examples across language regions and HEI types. 


\section{Document basis}

For the purpose of the present analysis, relevant strategic and policy documents were collected from seven HEIs including the two federal HEIs (ETHZ, EPFL), four representative cantonal HEIs from different language regions (UZH, UNIFR, UNIGE and USI) and one University of Applied Sciences (ZHAW). Table 6.1 provides an overview of the HEIs analysed in this chapter. In addition to institutional documents, Federal Acts relating to language and multilingualism as well as to higher education were collected. In the following, findings from the analysis of each HEI are presented by their university type and language region, embedding the discussion in the broader national framework.

Table 6.1 HEls analysed in this chapter

\begin{tabular}{|c|c|c|c|c|}
\hline University & $\begin{array}{l}\text { Short } \\
\text { form }\end{array}$ & $\begin{array}{l}\text { Language } \\
\text { Region }\end{array}$ & Canton & University Type \\
\hline University of Zurich & UZH & German & Zurich & Cantonal Tier-One University \\
\hline University of Fribourg & UNIFR & $\begin{array}{l}\text { French and } \\
\text { German } \\
\text { (bilingual) }\end{array}$ & Fribourg & Cantonal Tier-One University \\
\hline University of Geneva & UNIGE & French & Geneva & Cantonal Tier-One University \\
\hline University of Lugano & USI & Italian & Ticino & Cantonal Tier-One University \\
\hline $\begin{array}{l}\text { Federal Institute of } \\
\text { Technology Zurich }\end{array}$ & ETHZ & German & Zurich & Federal Tier-One University \\
\hline $\begin{array}{l}\text { Federal Institute of } \\
\text { Technology Lausanne }\end{array}$ & EPFL & French & Vaud & Federal Tier-One University \\
\hline $\begin{array}{l}\text { Zurich University of } \\
\text { Applied Sciences }\end{array}$ & ZHAW & German & Zurich & University of Applied Sciences \\
\hline
\end{tabular}

\subsection{English as a language of instruction: National and institutional approaches}

Switzerland is small but complex. This is particularly true of its educational system, which is a cornerstone of Swiss identity and pride. If we look back over the past 20 years of research into English as an international language in Switzerland, we notice a thematic development from critical considerations of the role of English in the Swiss multilingual landscape in the face of the country's internal linguistic diversity, to descriptions of English as a reality in Swiss society. This thematic progression largely coincides with public and media attention to the topic, which, particularly 
in the first half of this period, treated English in Switzerland as a topic worthy of public attention and scrutiny. This development also coincides with significant language policy developments which led to legal provisions at different levels. In this section, we will trace these developments in greater detail.

The Federal Council's Act on the National Languages and Understanding between the Linguistic Communities in 2007 (Languages Act) can be considered the first important milestone in the new millennium in that it provided the framework for ensuring internal linguistic harmony in Switzerland. With respect to English, two articles are of interest in the context of this chapter: Article 6(5) specifies that, while official communication with authorities will be conducted in national languages, '(i)n dealings with persons who have no command of an official language, the federal authorities shall if possible use a language that these persons understand.' Thus, the Act leaves open the possibility that residents may communicate in other, non-national languages, including English. A similar flexibility as in the Languages Act 6(5) is expressed in the Ordinance on the National Languages and Understanding between the Linguistic Communities of 2014 (Languages Ordinance) which stipulates explicitly in Article 5 that 'International agreements may be concluded in English' under certain circumstances.

Article 15(3) of the Languages Act, the second article of interest here, expresses an explicit commitment to plurilingualism in education and to the teaching of one additional national language together with a foreign language. The order in which these languages are taught in the curriculum, however, is left to the cantons to determine. Within the scope of this law, cantons may decide to focus their language education more strongly on English than on a second national language within the cantonal school curriculum, whatever seems more suited to the professional or academic outlook of the students. A similar regional approach is encouraged at the higher education level, where no national provision regulates the language of instruction across all university types.

Switzerland has a complex higher education landscape in the so-called tertiary-A sector, consisting of federal institutes, cantonal tier-one universities, cantonal universities of applied sciences and cantonal universities of teacher education. In the Federal Act on Funding and Coordination of the Swiss Higher Education Sector 2011/2020 (Higher Education Act), reference to language is only made in Article 59(2d), which identifies multilingualism in Swiss national languages as an area of national higher education policy interest eligible for federal contributions. In other words, while no overarching 
regulation exists at the federal level concerning the use of languages in all university types, the article clearly supports multilingualism in Swiss national languages. Universities of Applied Sciences (i.e., universities that are traditionally closer to industry) seem to present an exception. Article 2(7) of the Ordinance on the Establishment and Management of Universities of Applied Sciences 1996/2014 (Fachhochschulverordnung) allows English as an additional language of instruction.

No such federal ordinance exists for cantonal tier-one universities but provisions concerning languages of instruction may well exist at cantonal levels. Cantonal tier-one universities and Federal Institutes, however, have no uniform approach to the language in question. We will, in the following, look at some examples in detail.

\subsection{Tier-One Cantonal Universities}

Among the tier-one cantonal universities in German-speaking Switzerland, the University of Zurich (UZH) is prominent and, as the largest Swiss university, plays a major role in shaping the Swiss higher education area. The University of Zurich issued regulations concerning language requirements for students in 2017 (Reglement über die sprachlichen Anforderungen in der Unterrichtssprache), stating, in Article 5, that the languages of instruction of study degree programmes or subjects at the University of Zurich are German and/or English.

In terms of language level, a minimum of $\mathrm{C} 1$ (Common European Framework of Reference, CEFR) is required for enrolment. Article 7 further allows other languages of instruction, depending on the requirements of the study degree programmes (e.g., in language or literature studies). While no mention is made of language in the University Law of the Canton of Zurich (1998), collaboration and coordination with foreign HEIs is laid down in Article 5, underscoring the university's international orientation.

In its Internationalization Strategy 2014-2020, UZH focuses on three strategic goals (among others), which are a) the strengthening of UZH's research profile, b) recruitment and academic career development and c) infrastructure. English is mentioned in two places in this document: Strategic goal I.3 emphasizes the university's continued efforts towards becoming a bilingual university at the level of administrative services:

Information on administrative and study-related procedures is published in German and English. Bilingual communication is taken into consideration for basic procedures concerning enrollment, booking modules, and 
development strategies. The most important university regulations are made available in English. (UZH, 2014-2020, p. 3)

English as a medium of instruction appears secondly as a strategic objective of the university, especially at master's level. Strategic goal III.3 of the current internationalization strategy of UZH states that 'Master's degree programs and PhD programs, except at the Faculty of Medicine, are increasingly offered in English.'

While UZH seems to include English as a strategic point on its internationalization agenda, the further west we move in Switzerland, the more regulated languages of instruction seem to become. One such example is the University of Fribourg (UNIFR). As the seat of the national institute of multilingualism, subsidized by the state, and as a bilingual university, UNIFR is an example of a particularly language-sensitive HEI in Switzerland, more than Zurich or Fribourg's neighbour, the University of Bern. UNIFR's Loi sur l'université (State of Fribourg, 1997/2015, Article 6, Languages) stipulates that French and German are the official languages of the university in teaching and administration but that individual faculties can allow other languages of instruction. Based on this law, the university, in 2007, issued guidelines concerning languages of instruction in which they differentiate between levels and functions of the degree programmes (Article 1). While individual courses in English are permitted within degree programmes, the main languages of bachelor's programmes are French and German. At Master's level, the main languages of instruction are either French and German (with occasional English courses), or ETPs (englischsprachig deklarierte Studiengänge) which are exclusively or predominantly taught through English. At faculty level, these guidelines translate into regulations, such as the Regulations of the Faculty of Economy and Social Sciences (UNIFR, 2014) in which Article 29(1) specifies that the official languages of instruction at bachelor's level are German and French, but at master's level, however, they are German, French, and English.

The Faculty of Arts and Social Sciences, on the other hand, is less explicit on this matter but simply states in its study regulations (Article 1(3)) that it promotes multilingual studies and particularly bilingual studies in German and French. What is striking about UNIFR is the clear separation between language and internationalization policy. In fact, and in comparison to UZH, English seems to be conspicuously absent as part of the mandate and as a strategic topic dealt with by UNIFR's International Relations Office. While in UZH, the International Strategy (2014-2020) clearly promotes English in its effort to contribute towards making the university a bilingual 
German-English institution, the International Relations Office at UNIFR focuses mainly, but not exclusively, on traditional mobility (Reglement über die internationalen Beziehungen, 2004/2009).

The University of Geneva (UNIGE) seems to be the best example for comparison with the University of Zurich (UZH). It is located in the largest French-speaking city and the second largest city of Switzerland. Unlike UZH, UNIGE has developed an elaborate language policy (18 mesures pour une politique des langues à l'Université de Genève, 2012), following the trend set by Fribourg by not only ensuring instruction in French at undergraduate level but also by committing itself to multilingualism. UNIGE, in Article 3 , states that French remains the language of instruction even if classes can be given in English, particularly at bachelor's level ( français comme langue d'enseignement des baccalauréats). The university also commits itself to ensuring the possibility of studying in French for at least one consecutive master's degree following each bachelor's programme. ETPs are permitted if they provide additional language support for students. Most notably, and in contrast to UZH, Geneva encourages bilingual programmes in which at least one third of classes are taught through a language other than the main language of instruction.

Located in one of the most international cities of Europe, international collaboration and mobility, like in the University of Zurich, is part of UNIGE's identity (Loi sur l'université, 2008, Art.4(2) and 4(3); see UNIGE, 2008). UNIGE ranks high in internationalization scores in the Times Higher Education Ranking (9th position in 2019). The core values of UNIGE's Strategy (Plan Stratégique, 2015-2025) include international openness, respect for human rights, sensitivity to cultural diversity, to ethics, humanism and to the tradition of scientific research. This mission provides firm ground for the establishment of links with international institutes and for opening up to other languages and cultures.

Unlike UNIGE or UNIFR, but similar to UZH, the University of Lugano (USI) does not have an overarching language policy that regulates and/ or promotes multilingualism, including the use of English as a medium of instruction. Although according to the University Law (1995) Art. 1(6) (Republic and Canton of Ticino, 1995), Italian is stated as the official language of the university, other languages are not excluded from teaching. In the study regulations at faculty level, further guidance concerning language use is offered, which, however, reveals considerable diversity across the university. The Faculty of Economics, for example, states that while written examinations and bachelor's degree papers are usually written in Italian, they can also be written in German, French, or English, with the teacher's permission (Article 27). Similar directives exist in other faculties (e.g., the 
Faculty of Communication, Society and Culture). In both faculties, the official language of the programmes at Master's level depends on the study plan. The Faculty of Communication, Society and Culture stipulates that in master's programmes where English is used as a medium of instruction, the level $\mathrm{C}_{1}$ in English must be obtained by the time the final thesis is submitted. The Faculty of Informatics is the most liberal faculty regarding English, formally adopting English as its working language. The Academy of Architecture, conversely, presents a more traditional picture, focused on national culture and identity to promote studies 'in an interdisciplinary, multilingual and multicultural perspective' (Accademia di architettura Statuto, USI, 1997/2012, Article 1). In the general study regulations, the Academy further states, following the French-speaking or bilingual universities, that the main language of instruction is Italian but that English may be used as an alternative in parts of the programme.

Being the only Italian-speaking university in the Swiss higher education area, the preservation and promotion of the Italian language forms the basis of USI's internationalization policy. Therefore, most of the bachelor's programmes are offered in Italian, although where possible materials are made available in English and free Italian courses are provided for the entire academic community. English, on the other hand, is not directly mentioned in USI's internationalization policy but the wide range of scientific networks of global partnerships at USI bears testimony to researchers' links with international colleagues from all over the world.

\subsection{Federal Institutes of Technology}

The Federal Institutes of Technology (ETHZ and EPFL) are interesting cases in point that seem to capture the complex debate surrounding languages of instruction at the meso level. This is not surprising given the fact that the Federal Institutes of Technology have a national mandate but operate internationally. At the Federal Institutes of Technology, current regulations resemble, in their level of detail, those of the cantonal universities such as UNIFR and UNIGE. The Languages Article 12 in the Federal Act on the Federal Institutes of Technology 1991/2017 (ETH Act) specifies that

1 The two federal institutes of technology shall provide instruction in German, French and Italian and, depending on usage in teaching and research, English as well.

2 The Executive Board may authorise other languages of instruction. (Authors' emphasis) 
The phrase in italics here, which is counter-balanced by the commitment to Swiss national languages in (2), was inserted after extensive discussion on the subject leading up to the Languages Article in 2004. Part of this discussion is summarized in the Communication on the Partial Revision of the ETH Act of 27 February 2002, in which English as the universal language of research and as an important language of instruction is acknowledged. English is seen to facilitate mobility and international cooperation in higher education. At the same time, the wording in Article 12 is still vague and leaves room for interpretation and implementation.

The two Federal Institutes subsequently issued directives on the use of languages in teaching (Weisung ETH Zurich, 2010; Directive EPF Lausanne, 2014/2017). In these directives, the institutes largely follow UNIFR and UNIGE in that national languages are clearly prioritized at bachelor's level, while English is designated the default language at master's level. At the same time, the Federal Institutes are more specific than UNIFR, defining the volume of courses (in percentage) that can be taught through English at bachelor's and, at master's level, in national languages.

The introduction of English as the standard language of instruction at master's level in the ETH Zurich, at the time, drew public criticism and media attention, as in the article in Switzerland's broadsheet Neue Zürcher Zeitung (26 September, 2010) or in the Sunday paper Sonntag (25 July, 2010). The debate surrounding language of instruction taken up by the newspapers echoed a much broader initiative launched by ETH Zurich a few years earlier: the reform project ETH 2020, which was to develop visions for the institute's future, touching on topics such as Quality of Teaching, Internationalization, and Organizational Structure (cf. Neue Zürcher Zeitung 27 October, 2006). This initiative, however, came to a sudden end after strong objection by the professorate. Only some areas were moved forward, including the language question. The debate surrounding ETH's language of instruction, therefore, must be understood in connection to the overall tendency of the university to advance internationalization. The ETH's internal debate was summarized by Anders Hagström in the daily web-paper ETH Life (2006), where he argued for the introduction of English at both Bachelor's and Master's level for reasons of communicative efficiency and increasing employability:

Firstly, language is a tool for communication. In a multilingual environment, a rational language choice is based on the audience. You speak or write the language in which you can reach the largest group of people. As ETH Zurich wants to internationalize its graduate programmes, there is no question that this language is English. 
Hagström's arguments clearly anticipated the institute's 2010 directive that emphasized a similar utilitarian view of language (cf. Studer, 2021a, for a critique of English as a basic skill).

Since English was determined as language of instruction at Master's level, several measures have been taken to ensure the quality of the use of a foreign language (e.g., online resources to non-native students and staff). ETH's sweeping introduction of English as a 'rational language choice' at Master's level reflects the strong international orientation of the university, consistent with its title of most international university in the world in 2017 and second in 2018, competing for the first position with its francophone counterpart, EPFL (THE, 2017, 2018).

ETH's international orientation and its commitment to multilingualism today is not only visible in its language directive but also in its education policy which emphasizes comprehensive competences as an educational objective for students such as 'interdisciplinary and system-oriented ways of thinking' beyond disciplinary expertise, including the ability to express oneself 'in several languages' (ETHZ Teaching Policy, 2016). A similar approach is found in its francophone counterpart, EPFL.

\subsection{Universities of Applied Sciences}

Universities of Applied Sciences (UAS), the youngest of the HEIs in Switzerland, resemble UZH in approach in that they permit both national languages and English as languages of instruction. Unlike UZH, the right to use English is established at the federal level and applies to all cantonal Universities of Applied Sciences, as outlined above (Fachhochschulverordnung, 1996/2014). Let us briefly look how this plays out, taking ZHAW as a case in point, one of the largest Universities of Applied Sciences, located in the Germanspeaking canton of Zurich. UAS, as young HEIs, are currently building their international profile, while traditional tier-one cantonal universities or federal institutes are in a position to consolidate their international outlook. UAS have an International Relations Office that not only coordinates traditional exchange and mobility activities but that is also engaged in developing and implementing strategies to drive the internationalization of their university. UAS have recently been supported in that endeavour at the state level, through funding programmes such as Internationalization of Swiss Universities of Applied Sciences and Arts, launched by swissuniversities (2014), the umbrella organization of the Swiss universities.

At ZHAW, for example, the Internationalization Strategy (Z-SD-Teilstrategie Internationales, 2016) is directly aligned with the university strategy 
for 2025, defining five areas of activity: (1) Increase student mobility; (2) Full-course enrolment of foreign students; (3) Strategic partnerships with other HEIs; (4) Creation of synergies across schools and service missions; (5) Visibility of ZHAW as an international HEI. In the context of implementing its internationalization strategy, ZHAW developed guidelines for the establishment of so-called International Profiles, which are study options for students wishing to obtain an international certificate as part of their studies (Z-RL-Richtlinie Certificate International Profile, 2019). While no distinction is made between bachelor's or master's level, students enrolling for the CIP (Certificate International Profile) are required to engage in three competence areas, such as foreign language competence, international experience, and intercultural competence. Foreign language competence is defined, primarily, in terms of general language competence as specified by the CEFR $(\mathrm{C} 1)$. While the guidelines leave open which language is meant, it is clear from the wording (p. 3) that any language other than English would be considered exceptional and that, in case of not choosing English, proof of English skills at level B2+ must be provided anyway.

The importance of English is further underscored by the requirement that students also need to enrol in modules given through the foreign language of their choice. While, in theory, such modules may be taken abroad, in practice this means that, in the absence of courses offered in languages other than English, the majority of students enrols in EMI modules at their home institution. Other provisions or guidelines may exist in other UAS, but the general perception and importance of English as a medium of instruction in the context of internationalization is presumed to be very similar across all UAS in Switzerland.

\section{Discussion and conclusion}

This chapter set out to trace Englishization in Switzerland by looking at institutional and federal responses to regulating English language use in higher education. The chapter was divided into two sections, the first presenting an overview of sociolinguistic research into English in Switzerland. In the second section, we reviewed policy approaches and solutions by seven HEIs representing different university types (Cantonal Universities, Federal Universities, Universities of Applied Sciences) and language regions (French, German, Italian). This section will present a synthesis of this analysis and a critical reflection of the common themes running through these policy approaches. 
The policy analysis revealed that while institutions may differ in their international outlook and aspirations, and also in terms of the weight they attribute to national languages, they all have made efforts adapting to a new reality by making space for English in teaching and research, thus trying to create a new linguistic harmony. The paths chosen by the HEIs studied differ considerably, depending on a variety of factors including (a) the type of HEI; (b) their individual tradition; (c) the culture of the language region; (d) the actors inside the HEI responsible for policy-making (university management vs faculty, international relations vs vice-rectorate teaching, etc.); and (e) their management approach (top-down, bottom-up, middle-out).

Firstly, the analysis indicates that English today enjoys greater acceptance at master's level, especially in cantonal universities and federal institutes, where it is either the default language of instruction or 'tolerated' in bilingual programmes alongside national languages. This acceptance of English at the master's level shows, conversely, that education in national languages is considered more important at the undergraduate level.

Secondly, we notice a division between German-speaking Switzerland and French-speaking Switzerland in terms of how institutions conceptualize English vis-à-vis multilingualism and internationalization. Macro-level language-policy considerations concerning the role of English in Swiss society are particularly present in the Suisse Romandie and, to some extent, in Italian-speaking Switzerland. In these HEIs, a tolerance of English as a language of instruction, if visible at all, is embedded in the promotion of national languages and national bilingualism. The bilingual University of Fribourg emerges as the most consistent and vocal example in this context, serving as a model for other universities.

The University of Zurich, on the other hand, can be cited as one HEI at the other end of the spectrum, striving towards institutional bilingualism with English, thus reinforcing monolingualism and internationalism. The Federal Institutes of Technology have steered a middle course in that regional monolingualism has been institutionalized at bachelor's level while English is the default language of the master's level. The preference for regional languages at bachelor's level is echoed in other HEIs of the study, most notably HEIs in the west and south of Switzerland. While language is regulated in some HEIs through institution-wide language policies, it forms part of the internationalization agenda or study regulations in other HEIs, particularly in the German-speaking area, or may be regulated at the faculty or departmental level, such as in the Italian-speaking canton. 
This diversity in policy approach and solutions may seem puzzling to the reader. We are tempted to explain it as a reflection of cultural divides in Switzerland, with HEIs in francophone cantons taking more centralized, top-down approaches to regulating language use, emphasizing national languages, whereas HEIs in Swiss-German cantons seem to pay less attention to the issue but generally welcome and endorse the trend towards English as a reality in internationalized higher education. Such differences in approach have been described with regard to national language policy-planning (e.g., Siguan, 2005).

Another way of explaining the difference is by looking at the policies as the outcomes of two conflicting argumentation rationales. Language, in the francophone HEIs, can then be understood as a value, an expression of culture or identity, whereas language in the German-speaking HEIs can be conceptualized as an object of a utilitarian cost-benefit analysis (see Colombo, 2019; also Domke et al., 1998). The conflict between principle and pragmatism, and the orientation to either pole at the expense of the other, reflects a key balancing act in which language policy actors find themselves (cf., most recently, Studer, 2021a, 2021b). The two rationales are also expressive of different stakeholder expectations towards change: Value-based considerations are built on the premise of stability, whereas utilitarian cost-benefit thinking 'presumes responsiveness to changing circumstances' (Tavits, 2007, p. 153). Following Tavits (2007, p. 152), who investigated voter responses to party policy shifts, we may be tempted to assume that policy shifts on pragmatic issues tend to be more popular than policy shifts on principled issues. This would imply that language solutions that follow a utilitarian cost-benefit approach may be met with greater acceptance and may be implemented in a more informal way than solutions that focus on principles of multilingualism.

Viewing the policy efforts of the seven HEIs from this perspective, their different approaches become more meaningful. If a consequentialist perspective of language is predominant, then language policy efforts are pursued to optimize business or academic prospects. Universities of Applied Sciences illustrate this point well as they are traditionally close to industry and focus on their students' employability. They are the only HEIs in Switzerland that, by default, have two languages of instruction: their regional language and English. The University of Zurich is another interesting case from our corpus, not only because it strives towards institutional bilingualism but also because the language question appears in close connection to the university's internationalization strategy, a domain that is mainly concerned with the practicalities of inter-institutional 
collaboration and exchange. The Universities of Fribourg and Geneva, on the other hand, clearly focus on the maintenance of national languages which is evident in elaborate language policies issued in the form of commitments issued at the university political level. Their approach clearly foregrounds a more value-based vision in favour of Swiss multilingualism. The Federal Institutes, being the only non-regional HEIs, have settled on an apparent compromise. By making the national language the default language of undergraduate programmes and English the default language of postgraduate programmes, their solution seems principled in that it reflects a commitment to English identical in strength to the national language, yet pragmatic in that it addresses the need to institutionalize language use so as to accommodate an international teaching and student body.

Taking a step back from these findings and looking at them from a national perspective, one wonders what they say about Switzerland as a small multilingual nation. Assuming that there are political issues that are 'more principled in nature versus those that are more pragmatic' (Tavits, 2007, p. 153), one wonders where the language of instruction figures on this scale. Clearly, no strong commitment to national languages in higher education as a matter of principle, identity or right can be found at the state level. Apart from the potential financial incentive to implement national multilingualism in HEIs, the state's 'moral voice' seems weak, leaving it to the cantons to define their own policies. In fact, as we have seen, the responsibility for language use can be delegated all the way down from the state to the canton to the institution and, inside institutions, to domains or organizational units. This may not come as a surprise given Switzerland's self-perception as a nation by the will of the people (Willensnation), a nation not founded on ethnicity but on pluri-cultural and ethnical diversity (Maiolino, 2013). Hence, it can be explained that strong international and strong regional orientations may co-exist side by side. This also means that, in Swiss higher education, there will always be patchwork solutions, allowing for extremes in a very small area. These solutions, while reflective of what we would like to call the Swiss pragmatic way, lack a comprehensive and overarching commitment to national languages and national multilingualism as an expression of the nation's culture and identity. English, in this constellation, comes out as the winner: it is not only used as a welcome and efficient tool for communication but may, locally, be elevated to rank side-by-side with national languages. 


\section{References}

Akdağ, E. G., \& Swanson, D. M. (2018). Ethics, power, internationalisation and the postcolonial: A Foucauldian discourse analysis of policy documents in two Scottish universities. European Journal of Higher Education, 8(1), 67-82.

Barakos, E., \& Selleck, C. (2019). Elite multilingualism: Discourses, practices, and debates. Journal of Multilingual and Multicultural Development, 4o(5), 361-374.

Billigmeier, R. H. (1979). A crisis in Swiss pluralism: The Romansch and their relations with the German- and Italian-Swiss in the perspective of a millennium. De Gruyter Mouton.

Boussebaa, M., \& Brown, A. D. (2017). Englishization, identity regulation and imperialism. Organization Studies, $38(1)$, 7-29.

Canton of Zurich (March 1998). Gesetz über die Universität Zürich (Universitätsgesetz). Retrieved 15June 2021 from https://www.zh.ch/de/politik-staat/gesetze-beschluesse/ gesetzessammlung/zhlex-ls/erlass-415_11-1998_03_15-1998_10_01-108.html

Colombo, C. (2019). Principled or pragmatic? Morality politics in direct democracy. British Journal of Political Science, 51(2), 584-603.

Cooper, R. L. (1989). Language planning and social change. Cambridge University Press.

Demont-Heinrich, C. (2005). Language and national identity in the era of globalization: The case of English in Switzerland. Journal of Communication Inquiry, 29(1), 66-84.

Domke, D., Shah, D., \& Wackman, D. (1998). 'Moral referendums': Values, news media, and the process of candidate choice. Political Communication, 15(3), 301-321.

Durham, M. (2016). English as a lingua franca: Forms and features in Swiss context. Cahier de L-ILSL, 48, 107-118.

Dürmüller, U. (2001). The presence of English at Swiss universities. In U. Ammon (Ed.), The effects of the dominance of English as a language of science on the non-English language communities (pp. 389-403). Mouton de Gruyter.

Englisch als Unterrichtssprache (2010, 25 July). Sonntag. No. 29, 4.

EPFL (1 September 2014-1 January 2017). Directive on Teaching Languages at EPFL. The Direction of the Ecole Polytechnique Fédérale de Lausanne.

ETH (2010). Weisung ETH.

ETH (2016). Teaching policy at ETH Zurich.

Federal Council (27 February 2002). Botschaft zu einer Teilrevision des Bundesgesetzes über die Eidgenössischen Technischen Hochschulen.

Federal Council (ETH Act) (4 October 1991-1 May 2017). Federal Act on the Federal Institutes of Technology.

Federal Council (Higher Education Act) (30 September 2011-1 January 2020). Federal Act on Funding and Coordination of the Swiss Higher Education Sector. 
Federal Council (Languages Act) (5 October 2007-1 January 2017). Federal Act on the National Languages and Understanding between the Linguistic Communities. Federal Council (Languages Ordinance) (June 2010-October 2014). Ordinance on the National Languages and Understanding between the Linguistic Communities.

Federal Council (11 September 1996-1 July 2014). Verordnung über Aufbau und Führung von Fachhochschulen (Fachhochschulverordnung, FHSV). Establishment and Management of Universities of Applied Sciences.

Federal Office for Statistics (FSO) (2018). Sprachen (Languages). Retrieved 23 December 2020 from https://www.bfs.admin.ch/bfs/de/home/statistiken/bevoelkerung/ sprachen-religionen/sprachen.html

Foucault, M. (1972). The archaeology ofknowledge. Pantheon Books.

Gautschi, C., \& Studer, P. (2017). The impact of internationalisation on tertiary-level educational social spheres. Bulletin VALS-ASLA $N^{\circ}$ Spécial, 1, 51-62.

Hagström, A. (2006, June 14). The language challenge. ETH Life.

Imhasly, P. (2010, September 26). Dispute about the language of instruction. Neue Zürcher Zeitung.

Kirkpatrick, A. (2014). The language(s) of HE: EMI and/or ELF and/or multilingualism? The Asian Journal of Applied Linguistics, 1(1), 4-15.

Kuteeva, M. (2019). Researching English-medium instruction at Swedish universities: Developments over the past decade. In K. Murata (Ed.), English-medium instruction from an English as a lingua franca perspective: Exploring the higher education context (pp. 46-63). Routledge.

Lanvers, U. (2018). Public debates of the Englishization of education in Germany: A critical discourse analysis. European Journal of Language Policy, 10(1), 37-75.

Lanvers, U., \& Hultgren, A. K. (2018). The Englishization of European education: Foreword. European Journal of Language Policy, 10(1), 1-11.

Lüdi, G. (2007). The Swiss model of plurilingual communication. In J.D. ten Thije \& L. Zeevaert (Eds.), Receptive multilingualism: Linguistic analyses, language policies and didactic concepts (pp. 159-178). John Benjamins.

Lüdi, G., \& Werlen, I. (2005). Le paysage linguistique de la Suisse: Recensement fédéral de la population 20oo. Swiss Federal Statistical Office.

Maiolino, A. (2013). Die Willensnation Schweiz im Spannungsfeld konkurrierender Transzendenzbezüge. In H. Vorländer (Ed.), Demokratie und Transzendenz: Die Begründung politischer Ordnungen (pp. 449-472). Transcript Verlag.

Murray, H. (2001). English als Wissenschaftssprache an der Universität Bern. In H. Murray (Ed.), Die fünfte Landessprache? Englisch in der Schweiz (pp. 85-103). vdf Hochschulverlag.

Murray, H., \& Dingwall, S. (1997). English for scientific communication at Swiss universities: 'God helps those who help themselves.' Babylonia, 97(4), 54-59. 
Murray, H., \& Dingwall, S. (2001). The dominance of English at European universities: Switzerland and Sweden compared. In U. Ammon(Ed.), The dominance of English as a language of science: Effects on other languages and language communities (pp. 85-112). Mouton de Gruyter.

Pfenninger, S., \& Watts, R. (2019). English in Switzerland. In R. Hickey (Ed.), English in the German-speaking world (pp. 315-333). Cambridge University Press.

Piller, I., \& Cho, J. (2013). Neoliberalism as language policy. Language in Society, 42, 23-44.

Republic and Canton of Ticino (3 October 1995). Legge sull'Università della Svizzera italiana, sulla Scuola universitaria professionale della Svizzera italiana e sugli istituti di ricerca. Il Gran Consiglio della Repubblica e Cantone Ticino. Retrieved 15 June 2021 from https://m3.ti.ch/CAN/RLeggi/public/raccolta-leggi/legge/ numero/5·3.1.1

Saarinen, T., \& Taalas, P. (2017). Nordic language policies for higher education and their multi-layered motivations. Higher Education, 73(4), 597-612.

Sandström, A.-M., \& Neghina, C. (2017). English-taught bachelor's programmes: Internationalising European higher education. The European Association for International Education (EAIE).

Siguan, M. (2005). La Europa de las lenguas. Alianza Editorial.

State of Fribourg (19 November 1997-10 September 2015). Loi sur l'université. Le Grand Conseil du canton de Fribourg. Retrieved 15June 2021 from https://bdlf. fr.ch/app/fr/texts_of_law/431.o.1

Stępkowska, A. (2019). Swiss multilingualism: A historical background to language policy. Studies in Logic, Grammar and Rhetoric, 59(72), 69-84.

Studer, P. (2012). Conceptual contradiction and discourses on multilingualism. In P. Studer \& I. Werlen (Eds.), Linguistic diversity in Europe: Trends and discourses (pp. 115-135). De Gruyter Mouton.

Studer, P. (2013). Englisch als Unterrichtssprache in Bachelorstudiengängen der Zürcher Hochschule für Angewandte Wissenschaften (ZHAW): eine Bestandsaufnahme. Winterthur: ZHAW.

Studer, P. (2016). Lecturers' communicative strategies in English-medium instruction: The importance of classroom interaction. In P. Studer (Ed.), Communicative competence and didactic challenges: A case study of English-medium instruction in third-level education in Switzerland (Working Papers in Applied Linguistics 6, pp. 7-18). Zurich University of Applied Sciences: School of Linguistics.

Studer, P. (2018a). Introduction. Bulletin suisse de Linguistique Appliquée, 107, 1-5.

Studer, P. (2018b). English in the age of comprehensive internationalisation: Defining competence guidelines for teachers in higher education. Bulletin suisse de Linguistique Appliquée, 107, 27-47. 
Studer, P. (2021a). Internationalization, quality and multilingualism in higher education: A troublesome relationship. In F. D. Rubio-Alcalá \& D. Coyle (Eds.), Developing and evaluating quality bilingual practices in higher education (pp. 9-30). Multilingual Matters.

Studer, P. (2021b, in press). Common-sense beliefs around language: English-medium instruction (EMI) in applied linguistic research abstracts. European Journal of Language Policy.

Studer, P., Kreiselmaier, F., \& Flubacher, M.C. (2010). Language planning of the European Union: A micro-level perspective. European Journal of Language Policy, 2(2), 251-270.

Swissuniversities (December 2014). Internationalisation of Swiss Universities of Applied Sciences and Arts.

Tavits, M. (2007). Principle vs. pragmatism: Policy shifts and political competition. American Journal of Political Science, 51(1), 151-165.

UNIFR (4 October 2004-3 November 3, 2009). Reglement über die internationalen Beziehungen. Université de Fribourg.

UNIFR (19 May 2014). Reglement über die Organisation of Studiums und der Examina an der Wirtschafts- und Sozialwissenschaftlichen Fakultät der Universität Freiburg. Université de Fribourg.

UNIGE (June 13, 2008). Loi sur l'université. Retrieved 23 December 2020 from https:// www.unige.ch/universite/reglements/

UNIGE (26 March 2012). 18 mesures pour une politique des langues à l'Université de Genève. Université de Genève.

UNIGE (2015-2025). Plan Stratégique. Université de Genève.

USI (13 March 1997-22 June 2012). Accademia di architettura Statuto (The Academy of Architecture). Università della Svizzera Italiana.

UZH (2014-2020). University of Zurich Internationalization Strategy $(U Z H)$. University of Zurich.

UZH (25 April 2017). Reglement über die sprachlichen Anforderungen in der Unterrichtssprache. University of Zurich.

Wächter, B. \& Maiworm, F. (Eds.) (2002). English-language-taught degree programmes in European higher education: Trends and success factors. Lemmens.

Wächter, B., \& Maiworm, F. (Eds.) (2008). English-taught programmes in European higher education: The picture in 2007. Lemmens.

Wächter, B. \& Maiworm, F. (Eds.) (2014). English-taught programmes in European higher education. The state of play in 2014. Lemmens.

Watts, J. R., \& Murray, H. (Eds.) (2001). Die Fünft Landssprache? English in der Schweiz ('The fifth national Language? English in Switzerland'). vdf Hochschulverlag.

Wehrli, C. (2006, October 27). ETH-Schulleitung stoppt 'Zukunftsprozess.' Neue Zürcher Zeitung. 
ZHAW (2011). Englischsprachiger Fachunterricht an der ZHAW. Ein Leitfaden. ZHAW Ressort Internationales.

ZHAW (12 October 2016). Z-SD-Teilstrategie Internationales ZHAW. Ressort Internationales.

ZHAW (15 January 2019). Z-RL-Richtlinie Certificate International Profile. ZHAW Ressort Internationales.

\section{About the authors}

PATrick STUDER has been Professor of Applied Linguistics in ZHAW since 2012 and is a founding member of the association ICLHE (Integrating Content and Language in Higher Education). His research interests include the study of English as a World language. He has published widely on language ideology, EMI and internationalization of higher education.

Dr AISHA SIDDIQA, Research Associate in ZHAW since 2020, completed her PhD in Linguistics (2018, Université Cote d'Azur), focusing on the acquisition of second language pragmatics by young learners of English as a foreign language in France. Her research interests include the interface between pragmatics and second language acquisition, English-medium instruction and internationalization of the curriculum. 


\title{
$7 \quad$ Englishization in Danish higher education
}

\author{
From critical to constructive conceptualizations
}

Slobodanka Dimova, Anna Kristina Hultgren, and Joyce Kling

\begin{abstract}
This chapter offers a longitudinal overview of Englishization in Danish higher education, tracing its conceptualization from critical to constructive. In the initial stages, English was viewed sceptically, with concerns over domain loss, equity, quality of education, and consequences for the national language and culture. Such concerns led to a joint Nordic language policy promoting parallel language use, that is, a balanced use of English and the national language. In Denmark, this concept has been particularly salient, with all Danish universities having some sort of parallel language policy (Hultgren, 2014b). Recently, more constructive stances have replaced the concerns, perhaps recognizing that the continued expansion of Englishization is inevitable. Today, numerous Danish initiatives advance practical solutions to secure a smooth implementation of English medium of instruction.
\end{abstract}

Keywords: Denmark, higher education, multilingual universities, Englishization, English-medium instruction

\section{Introduction}

Concerns about Englishization, here understood as an increasing role of the English language in non-English-dominant contexts, have been pervasive in Denmark. Some concerns have centred on the perceived threat of lexical borrowings to the national language (Östman \& Thøgersen, 2010; Hultgren, 2013), whilst others have focused on a wholesale language shift in

Wilkinson, Robert, and René Gabriëls (eds), The Englishization of Higher Education in Europe. Amsterdam, Amsterdam University Press 2021 DOI: 10.5117/9789463727358_CHO7 
transnational domains, primarily corporations (Lønsmann \& Mortensen, 2018) and academia (Gregersen, 2014). Within academia, our focus in this chapter, Englishization permeates both research and teaching. In research, whilst there is considerable disciplinary variation, $83 \%$ of the total scientific output at Danish universities is in English (Gregersen, 2014; Hultgren, Gregersen, \& Thøgersen, 2014). In teaching, Denmark is second in Europe, just after the Netherlands, in the provision of English-medium instruction (EMI) in higher education (Dimova et al., 2015; Wächter \& Maiworm, 2014). Figures from a Nordic survey suggest that in 2009, $20 \%$ of programmes at Danish universities were delivered in English, with $26 \%$ at master's level and 6\% at bachelor level (Gregersen, 2014; Hultgren et al., 2014, based on Danish Evaluation Institute, 2010). Only eight years later, these percentages had doubled, with $48 \%$ at master's level and $13 \%$ at bachelor university level (Ahlers, 2018), although it should be noted that comparisons across studies are often difficult given different methodological approaches. According to Statistics Denmark, in 2017, 43\% of all master's and 8\% of all bachelor's students in Denmark studied in English (Danmarks Statistik, 2018).

Englishization of Danish higher education is not only evident in the expansion of EMI programmes, but also in the use of English reading materials in Danish-medium programmes (Thøgersen et al., 2014). It should be noted, however, that inclusion of foreign language educational material in higher education is not new in Denmark (Haberland \& Mortensen, 2012). In the (late) 2oth century, it was possible to use texts in languages other than Danish (e.g., English, German, French, and the other Scandinavian languages) because upper secondary school graduates were assumed to be capable of reading texts in these languages. Whilst reading materials in other languages are still used, the decline of students' French and German proficiency, coupled with the increasing market share of English-language publications, means that most texts used in Danish higher education are now in English (Holmen, 2018).

Against this documented presence of English language at Danish universities, it must be borne in mind that practices are often considerably more multilingual than surveys allow us to capture. Observational and ethnographically inspired research on classroom and other practices has shown interactants drawing on a range of linguistic and semiotic resources to enable communication (Hultgren et al., 2014; Mortensen, 2014; Söderlundh, 2012). In the EMI literature, this is reflected in a conceptual shift, notably in the introduction of the term EMEMUS - English-Medium Education in Multilingual University Settings - to recognize multilingualism as intrinsic to EMI (Dafouz \& Smit, 2016, 2020). Multilingualism may manifest itself in 
various ways. For example, students in groupwork in EMI courses in the natural sciences may shift from English to Danish to facilitate both academic and social interplay (Kiil, 2011). The scaffolding resulting from the stakeholders drawing on their linguistic repertoires facilitates comprehension of content in English, while reinforcing both conceptual and comparative understanding in Danish. This acceptance and co-existence of English and Danish, as well as additional shared languages in the EMI context, supports English as a lingua franca (ELF) and, at the same time, enables and perpetuates multilingual communication (Lanvers \& Hultgren, 2018).

In this chapter, we adopt a longitudinal view and consider how debates about Englishization in Danish higher education have shifted over time. Whilst the development should not be seen as linear, we argue that around the turn of the millennium, debates tended to be highly critical, but that this criticism gradually died down, giving way to more constructive approaches that sought to address Englishization pragmatically. This is not to say, of course, that critical and constructivist approaches cannot and do not co-exist. We should clarify from the outset that whilst we do not dispute the increasing prevalence, status, and importance of English in Denmark and other countries across the world, we do not regard Englishization solely or even primarily as an empirical phenomenon. In this sense, our theoretical starting point aligns with American linguistic anthropology and much of contemporary sociolinguistics, which view debates about language as proxies for underlying social, economic, and political anxieties. As Mufwene puts it, language is often only an epiphenomenon of a problem that is fundamentally non-linguistic' (2010, p. 921). We see merit in recent sociolinguistic developments that have sought to move beyond debates about language displacement and language threat by shifting focus to the fluid linguistic practices in which multilingual language users engage (García \& Wei, 2014; Pennycook, 2016). At the same time, we are cognizant that languages in a delineable sense continue to exist at the ideological level and serve important functions for identity, ethnic, political, and other reasons (Hultgren et al., 2014).

We also need to clarify that by viewing Englishization as primarily an ideological construct, we do not thereby condone the underlying factors that drive it. On the contrary, we would argue that by moving the gaze away from language as a threat, we are given the headspace to ponder and tackle the underlying factors - some of which are deeply problematic - of which Englishization is but an epiphenomenon. For instance, it is widely accepted that Englishization in higher education is driven by the emergence of a highly competitive global higher education market and a commodification 
of scientific knowledge in which institutions seek to obtain the greatest possible return from education and research (Hultgren et al., 2015; Marginson, 2006). Many countries across the world offer EMI in order to compete with English-dominant countries and to advance on world university ranking lists (Hultgren, 2014a). In Europe, the implementation of harmonized degree structures as part of the Bologna agreement has also attracted international students and scholars to Denmark and further fuelled the use of EMI in classrooms and lecture halls. Denmark ranks in the top 10 European destinations for higher education exchange programmes (Universitas21, 2020). Likewise, internationalization at home and internationalization of the curriculum is on the rise, in efforts to prepare Danish and guest students for a global labour market and for navigating a complex, globalized world (Kling et al., 2017; Lauridsen, 2020). All these are factors that explicitly or implicitly drive Englishization. Whilst they can and should be subjected to proper analysis and debate, this is not our aim in this chapter. Here we consider how debates about Englishization of higher education have played out in Denmark.

\section{Early critical voices on Englishization}

In Denmark, Englishization started to become a talked-about phenomenon around the turn of the millennium (Danish Ministry of Culture, 2003, 2008; Davidsen-Nielsen, 2009; Harder, 2009). Concerns were voiced about domain loss, the idea that, as a result of the rise of English within a particular domain, the national language would cease to develop, gradually lose status, and eventually not be used at all (Jarvad, 2001; Jensen \& Thøgersen, 2011; Thøgersen \& Airey, 2011). Commentators often portrayed domain loss as having consequences for the nation state. One argument was that the widespread use of English in teaching would hamper the ability of new university graduates to communicate effectively with members of the public when taking up employment in Danish society. The example of veterinarians not being able to communicate with their farmer clients was often invoked. Another argument was framed in terms of threats to equality and the democratization of knowledge, on the logic that if scientific knowledge is mainly disseminated in English, then how will the general public, some of whom do not have sufficiently high levels of English language proficiency, be able to access it? Other arguments centred on threats to Danish cultural heritage and the idea that, faced with language shift, the works of Hans Christian Andersen and other national treasures 
would become inaccessible to future generations (see also Hultgren, 2014b; Hultgren, 2016).

In contrast to what may have been the case in other countries, in Denmark, the main actors in the domain loss debate were members of the intellectual elite, mainly of whom were employed at universities, the Danish Language Council, and other cultural institutions. Robert Phillipson's work on linguistic imperialism (1992) is likely to have been influential too, given that he worked and lived in Denmark. Denmark is a small country with tight networks, which made it possible for domain loss to be placed on the national political agenda. Some of those who had voiced concerns about domain loss served as consultants on key government policy documents that sought to curb the perceived threat of English to the national language (Danish Ministry of Culture, 2003, 2004, 2008; Gregersen, 2014; Gregersen et al., 2018). The domain loss debate was also hijacked by the political far right. Domain loss was the main argument that the Danish nationalist party posed in the parliament in 2006 in order to pass a language law that would guarantee the use of the Danish language at the universities in the country. This proposition led to a heated debate between political blocs on the left and the right in parliament, which lasted until the beginning of 2009. In that period, the debate was largely represented in the media, and the major national newspapers published a number of articles that discussed Englishization both as an opportunity and a threat (Jensen \& Thøgersen, 2011).

In the middle of the public debate, a large survey was conducted at the University of Copenhagen to gauge lecturers' opinions about the positive and negative impact of Danish university Englishization. Results from the survey suggested that the university lecturers' views were not as polarized as expected. Lecturers showed awareness of both sides of the issue: while they saw the importance of English for internationalization, they were aware of the possible impact on teaching and learning (Jensen \& Thøgersen, 2011). Some lecturers with limited English proficiency resisted EMI because of the changes it entailed, such as added scrutiny of their English and threats to their professional identities (Henriksen et al., 2018). Lecturers were also concerned about the extra work and time required to reconceptualize and plan the teaching in a different language. Such concerns are expressed regardless of whether the medium of instruction changes from Danish to English or from English to Danish. For example, Chopin (2015) found that when a faculty at a Danish university established a new language policy that required all bachelor courses to be taught in Danish and all master's courses in English, a number of Danish lecturers, who had taught in the bachelor EMI programmes for a number of years, resisted returning to 
teaching in Danish even though it was their first language (L1). In addition to time and workload, the Danish-speaking lecturers were concerned that the policy would relegate them to teaching mostly bachelor courses whilst leaving the more attractive master's level courses to the non-Danish speaking international lecturers and PhD students. These findings indicate that attitudes to Englishization are complex and not reducible to a simple question of whether you are for or against.

\section{Constructive responses}

In this section, we discuss some responses to the intensified Englishization of Danish universities. These reflect the more constructive and pragmatic approach that has characterized recent time. They include:

1 Parallel language use policy;

2 EMI lecturer certification;

3 English language requirements and support for students.

\subsection{Parallel language use policy}

In Denmark, a string of policy initiatives has been taken to mitigate the rise of EMI (Danish Ministry of Culture, 2003, 2004, 2008; Gregersen, 2014; Gregersen et al., 2018). Such policy initiatives, which have been part of wider Nordic initiatives, have centred on the idea of parallel language use, that is, a balanced use of English and the national language without the former encroaching on the latter. Whilst parallel language use serves an important symbolic function, its vague and imprecise nature has left it open to a range of interpretations in terms of its implementation (Holmen, 2020; Preisler, 2009; Tange, 2012). Hultgren (2014b), for instance, has shown how state institutions have interpreted it as meaning more Danish, whereas universities have tended to use it to legitimize an increase in the use of English through intensified international recruitment and other internationalization strategies (see also Bolton \& Kuteeva, 2012). Nevertheless, despite its fuzzy meaning, the concept has had considerable impetus, and all eight of Denmark's universities have some sort of official parallel language policy in use (Hultgren, 2014b).

Whilst parallel language use may intuitively suggest bi- rather than multilingualism, more recent interpretations view its potential in promoting and normalizing the presence of multiple languages (not only Danish and English) in higher education (Holmen, 2012, 2020). This responds to concerns 
that parallel language use has downgraded the position of other foreign, heritage, and minority languages in higher education (Daryai-Hansen \& Kirilova, 2019; Holmen, 2012). The introduction of English as a language of instruction allows for the recruitment of international students with a range of different first language backgrounds. There are also large numbers of domestic students with minority language backgrounds. This offers opportunities for a more strategic inclusion of other languages beyond English and the national language in higher education. In the EMI literature, translanguaging has often been hailed as a viable way forward (García \& Wei, 2014) because it offers students linguistic tools to draw on to scaffold and support comprehension. However, it should be noted that translanguaging can also exclude some students from participating if they do not share the linguistic resources being drawn on (Kuteeva et al., 2020). Lecturers are also afforded opportunities to draw on students' linguistic repertoires to develop disciplinary knowledge and multilingual proficiency, as well as cross-cultural perspectives that have previously been obscured (Nissen, 2019).

In Denmark, supporting and including additional languages has become part of a national agenda. Examples include specialized study programmes that directly link content instruction to foreign languages (FLs) other than English, such as Roskilde University's Language Profiles and Copenhagen Business School's degree programmes in Business, Language and Culture (SPRØK). These academic programmes are designed from the outset to promote plurilingual teaching and learning. This focused agenda has given rise to the establishment of The Danish National Centre for Foreign Languages (NCFF), a national centre aimed to promote and enhance FL education in more languages than English (NCFF, 2020).

A similar initiative has been taken by the Centre for Internationalisation and Parallel Language Use (CIP), established in 2008, at the University of Copenhagen (UCPH). CIP's mission is to acknowledge multilingualism in the university setting and to assist with the development of staff's and students' proficiency not only in English and Danish, but also in other languages (CIP, n.d.; Dimova \& Kling, 2015; Jürna, 2014; Kling, 2016; Kling \& Stæhr, 2011). As part of this wider mission, CIP developed and administered a five-year, university-wide initiative at the UCPH entitled The Language Strategy: More Languages for More Students. The purpose of this initiative was to identify and address students' FL needs through large student surveys, meetings with academic study boards, and funding for content teachers to conduct pilot projects that addressed students' language needs (Holmen, 2020). The common goal of the pilot projects was development 
of sustainable models for addressing the language needs of students in a specific academic environment. The five-year initiative resulted in a catalogue of innovative approaches designed to support the integration of content and FL in higher education. The FLs covered with this initiative included English, German, French, Spanish, Arabic, Chinese, and Danish as a second language, as well as Latin and Ancient Greek. The purpose of the courses was not to develop general language proficiency, but to offer targeted language domain learning, such as the development of Spanish for fieldwork, the development of German and French reading comprehension strategies, and the integration of support for academic English at Animal Science. The initiative involved around 4,500 students and 170 lecturers across all faculties at the university (Holmen, 2020). NCFF has recently funded a project that furthers the investigation of models of teaching and developing language as an additional competence (i.e., language as integrated in disciplinary learning) in higher education in Denmark (NCFF, 2020). A large percentage of the pilot projects undertaken under the Language Strategy at the University of Copenhagen project focused on meeting the increased EMI academic literacy demands of students at UCPH. Several of these EMI focused projects resulted in raising content lecturers' awareness of the role of language in disciplinary learning, as well as developing students' reading and writing strategies in both Danish and English, also at the undergraduate level in Danish medium courses (Kling et al., 2017).

\subsection{EMI lecturer certification}

In response to concerns about lecturers' ability to teach in English, English certification requirements for EMI lecturers have been implemented at some Danish universities. Certification results are typically used to make decisions regarding the adequacy of lecturers' proficiency to teach in EMI classes (Bazo et al., 2017; O'Dowd, 2018; Verguts \& De Moor, 2019). The lecturers who are not certified may not be allowed to teach until they reach the appropriate proficiency level (see, e.g., van Splunder, this volume). Such a punitive use of EMI lecturer certification may easily lead to power imbalance at the workplace (Dimova, 2020c), and some lecturers who lack proficiency in the local language or do not have a permanent position at the university may feel that their positions in the department are threatened (Dimova, 2017).

In the certification procedures at most Danish universities, lecturers' English proficiency levels do not overshadow their broad academic profiles and professional and disciplinary competences. While there is no national policy for language certification of academic staff, there is great interest in 
supporting English language proficiency development for teachers across the country. Although half of the Danish universities have developed and used certification models (see Dimova \& Kling, 2018), technical manuals and quality analyses are available for only one certification procedure, which is the Test of Oral English Proficiency for Academic Staff (TOEPAS). TOEPAS was developed by CIP in 2009 and is currently used for EMI lecturer certification at the University of Copenhagen and at Roskilde University. Unlike other certification procedures developed for this purpose, from its inception, TOEPAS serves a formative purpose and provides test takers with feedback that could be used for competence development. In developing TOEPAS, all stakeholder groups (e.g., heads of departments, faculty representatives, and even union representatives) were present to support teachers and ensure that implementation of an assessment scheme would address the lecturers' needs (Henriksen et al., 2018). Therefore, TOEPAS was designed to represent a certification model that recognizes content lecturers' competences, professional identities, and educational culture. Its purpose is to:

- identify the lecturers who may need language support to teach EMI courses;

- raise EMI lecturers' awareness about their own English language strengths and weaknesses through an extensive written and oral formative feedback report accompanied by a video recording of their own performance.

TOEPAS is in the form of a simulated lecture, which allows for elicitation of classroom-related language in a controlled setting. The formative feedback is provided in relation to the EMI classroom, which represents the communicative domains of language use. In other words, the formative feedback focuses on the pedagogical functions of language in EMI rather than the grammatical and phonological correctness of lecturers' speech (Dimova, 202ob). Based on a rigorous standard-setting procedure with an international panel, the threshold proficiency needed to teach in EMI was set at B2+ level from the Common European Framework of Reference (Dimova, 2019, 2021). In the newest version of TOEPAS, the native-speaker norm was removed from the assessment scale, and the emphasis was placed on the pragmatic aspects of English language use in an English as a lingua franca setting, where most participants are L2 speakers of English (Dimova, 202ob). Pedagogy is not part of the assessed construct because lecturers who teach in their Lis, including native English speakers, are not scrutinized in this manner for their teaching abilities. Inclusion of pedagogy would thus create inequality. 
At Danish universities, the use of English for teaching is supported by both language experts and pedagogical consultants. Unlike other European countries, where EMI implementation is associated with pedagogical shifts, national requirements for pedagogical competence development training for academic staff in Denmark has been implemented through 'Teaching and Learning in Higher Education' programmes (universitetpcedagogikum) and is offered to all lecturers regardless of the medium of instruction they use. For that reason, discussions about pedagogy are not associated with EMI and are not as strongly considered synonymous with Englishization of education in Denmark.

Given the existing strategies for pedagogical training of lecturers, this push to alter pedagogical behaviours has been limited. To what degree the pedagogical approaches change depends on the course structure and participants. In courses where the student population has remained the same (i.e., enrolment comprises mainly Danish L1 speakers), Danish L1 lecturers often only change the language of instruction to English, but may rely on explanations in Danish to support content instruction (Hultgren, 2013). As noted above, in these situations, student discussions and project work may be conducted in English and/or Danish. Coming from the Danish educational system, the students attending courses are familiar with the educational culture and academic expectations and requirements. However, in courses comprising international students with limited Danish proficiency, and/or courses where the lecturers are themselves Li speakers of other languages, English use becomes more dominant, the curriculum may need to be internationalized, and explicit guidance through the course assignments, exams, and requirements may need to be implemented (Kling, 2017).

\subsection{English language requirements and support for students}

When EMI programmes are implemented at universities in regions where English is not the dominant language, concerns are often raised about the students' English proficiency levels and their ability to learn content material in a foreign language. Danish universities require that domestic and Nordic applicants have completed English B level in upper secondary school for admission to EMI programs (Dimova, 2020a). According to the admission policies outlined in the ministerial orders BEK nr. 107 from 12 February 2018, and BEK nr. 106 from 12 February 2018, domestic students can, but are not required to take international academic English language tests (e.g., IELTS, TOEFL, Pearson), which is usually a requirement that applies to international students (Ministry of Higher Education and 
Science, 2020). Given the challenges that some students face when learning in English, discussions at national, institutional, and departmental levels focus on whether the English language requirements should be adjusted to follow those at British, American, and Australian universities in order to select only the students with adequate English proficiency for admission in EMI programmes, regardless of students' origin. Such discussions assume that established English language proficiency tests would be more valid predictors for academic success than documentation of English proficiency through school-leaving certificates.

Dimova (2020a) explored various political, economic, sociocultural, and academic dimensions within a Danish EMI context in order to build an argument for or against use of international academic English test scores for admission of domestic students in Danish universities. The findings suggested that requiring commercial test scores are a quick solution that may have positive short-term effects, such as cutting down the institution's costs associated with providing language support for students and pedagogical training for teachers. However, imposing additional test score requirements for admission in EMI would have negative long-term societal effects by widening the gap between the students who get access to EMI and those who do not. It may also conflict with institutional policies to increase student intakes. With such extensive EMI course offerings in tertiary education in Denmark, one could also expect that commercial English test preparatory courses would flourish and influence teaching in learning in upper secondary schools.

In principle, this agenda has been sidestepped through governmentmandated English language instruction at the primary and secondary levels. Essentially, if the government allows public universities to implement EMI degree programmes, then it has the responsibility to ensure that the citizens are given the possibility to participate in these degree programmes by offering support (e.g., establishing instruction that integrates content and language) or by changing the English as a foreign language curricula at elementary and high school levels to focus more on preparing students (i.e., help students develop academic English proficiency) for their tertiary education in English. Students enrolling in higher education must rely on English proficiency acquired through mandatory English language instruction that begins in primary school (from grade 1) and continues through upper secondary school (at both vocational and academic institutions). Equal opportunity to receive quality English foreign language instruction is meant to diminish or minimize gaps in accessibility and opportunities in the national educational system. Conceivably, all students are already 
equipped with a threshold level of English language proficiency necessary for academic programmes. Thus, Danish residents are eligible for admission to higher education, and deemed proficient in English for academic purposes, after successful completion of 12 years of formal education (or the equivalent). Without this supposition, some students could feasibly miss out on the opportunity to study in their preferred field because the degree programme may only be available in English even though they have the academic ability to study in the particular field (e.g., master's degree programmes in the Faculty of Science at the University of Copenhagen, Denmark's Technical University, and Copenhagen Business School).

Instead of admission policies based on English screening tests, Danish universities have considered establishing purposeful bridge initiatives to integrate content and language instruction (Kling et al., 2017; Larsen \& Jensen, 2020; Swerts \& Westbrook, 2013). Although the key motivation to implement EMI at national and institutional levels is internationalization through recruitment of international students and lecturers and access to international research (Carroll-Boegh, 2005; Cortes et al., 2016; Hellekjær \& Westergaard, 2003; Thøgersen, 2013), grassroots initiatives have stressed the need to support the teaching and learning through the establishment of courses that integrate content and language, as well as courses in English for academic purposes and English for specific purposes (Dimova \& Kling, 2020; Henriksen et al., 2018; Tange, 2010). These initiatives focus directly on academic literacy skills development such as discipline specific critical reading skills and academic writing for EMI, often linked directly to Danish medium instruction at the bachelor level. These training schemes seek to assist students in recognizing and strengthening competencies developed in Danish medium instruction and emphasize transformation (Larsen-Freeman, 2013, in Hirvela, 2016) of these skills for success in future EMI contexts.

\section{Conclusion}

Reflecting on Englishization in Danish higher education, we have shown how initial reactions were marked with critical discussion regarding domain loss and the consequences for students and teachers of using English as a medium of instruction. As we said at the start, such debates are often linked to underlying tensions about the role of the nation state in our globalized society. We also showed that many of the initial concerns have been or are being addressed through both grassroots initiatives and top-down strategies. 
Early recognition of the need for constructive approaches to mitigate some of the perceived challenges posed by EMI has shifted perceptions of English as a threat to Danish education to the opportunities multilingualism affords society at large. The creation of an academic culture that supports linguistic competence development (i.e., for English, Danish, and other languages) allows for, and in a sense commands, continuous reflection and discussion. The parallel language use strategy in Denmark reflects a context where citizens can mediate and negotiate information in multiple languages. In Denmark, English links strongly to this small country's participating in the global knowledge economy and the development of globally minded graduates who are capable of working across sectors and disciplines in both their first and other languages. For a small nation such as Denmark, these longitudinal goals are non-negotiable. That said, universities continue to be committed to support the needs of the nation state and as such, there continues to be a need to keep the discussion about the balance between languages across the educational system on the agenda. There are also discussions to be had, we believe, about the underlying factors that drive Englishization, whether this is increased competition in the higher education system, international alignment, or commodification of knowledge. These underlying issues are ultimately decisions about what role and function higher education should serve in contemporary policies and societies across the world.

\section{Funding}

Anna Kristina Hultgren acknowledges financial support from UK Research and Innovation (Grant reference: MR/To2150o/1).

\section{Acknowledgements}

We are grateful for comments and advice from reviewers and editors.

\section{References}

Ahlers, T. (2018). Response to question 162. Ministry of Higher Education and Science. https:/www.ft.dk/samling/20171/almdel/ufu/spm/162/svar/1499193/1913887.pdf Bazo, P., González, D., Centellas, A., Dafouz, E., Fernández, A., \& Pavón, V. (2017). Linguistic policy for the internationalisation of the Spanish university system: A framework document. Madrid, CRUE. 
Bolton, K., \& Kuteeva, M. (2012). English as an academic language at a Swedish university: Parallel language use and the 'threat' of English. Journal of Multilingual and Multicultural Development, 33(5), 429-447.

Carroll-Boegh, A. (2005). Internationalisation and teaching through English: A Danish perspective. Educate, 5(2), 19-30.

Centre for Internationalisation and Parallel Language Use (CIP) (n.d.). About parallel language use. Retrieved 16 June 2021 from https://cip.ku.dk/english/ about_cip/about_parallel_language_use/

Chopin, K. (2015). Reconceptualizing norms for language testing: Assessing English language proficiency from within an ELF framework. Current Perspectives on Pedagogy for English as a Lingua Franca, 6, 193.

Cortes, D., Pinborg, A., Teilman, G., Løkkegaard, E. C. L., Andersen, J., Westergaard, H. B., Andersen, S., Kling, J., Jørgensen, F. S., Jørgensen, I. M., Poulsen, J. H., Mola, G., Bergholt, T., Pryds, O., \& Nilas, L. (2016). A new model of paired clinical teaching of international and Danish medical students. Danish Medical Bulletin (Online), 63(7), 1-5. [A5244]. https://pubmed.ncbi.nlm.nih.gov/27399977/

Dafouz, E., \& Smit, U. (2016). Towards a dynamic conceptual framework for Englishmedium education in multilingual university settings. Applied Linguistics, $37(3), 397-415$.

Dafouz, E., \& Smit, U. (2020). ROAD-MAPPING English medium education in the internationalised university. Palgrave Pivot.

Danish Evaluation Institute (Danmarks Evalueringsinstitut) (2010). Engelsksproget undervisning på danske kandidatuddannelser [English as medium of instruction in Danish MA studies]. https://www.eva.dk/sites/eva/files/2017-08/Engelsksproget\%2oundervisning\%2opa\%2odanske\%2okandidatuddannelser.pdf

Danish Ministry of Culture (2003). Sprog på spil-Et udspil til en dansk sprogpolitik [Language at stake - An initiative towards a Danish language policy].

Danish Ministry of Culture (2004). Sprogpolitisk redegørelse [Language Policy Review].

Danish Ministry of Culture (2008). Sprog til tiden [Language in time].

Danmarks Statistik (2018). Nyt fra Danmarks Statistik: Engelsksprogede uddannelser 2018 - Uddannelse og viden [New from Denmark's Statistic: English language education 2018 - Education and knowledge] (No. 107). www.dst.dk/nyt/30250

Daryai-Hansen, P., \& Kirilova, M. (2019). Signs of plurilingualism: Current plurilingual countermoves in Danish higher education. International Journal of Bias, Identity and Diversities in Education (IJBIDE), 4(2), 43-58.

Davidsen-Nielsen, N. (2009). Danish under pressure: Use it or lose it. In P. Harder (Ed.), Angles on the English-speaking world. English in Denmark: Language policy, internationalization and university teaching (pp. 138-140). University of Copenhagen: Museum Tusculanum. 
Dimova, S. (2017). Life after oral English certification: The consequences of the Test of Oral English Proficiency for Academic Staff for EMI lecturers. English for Specific Purposes, 46, 45-58.

Dimova, S. (2019). Linking the TOEPAS with the CEFR: Technical report. TAEC Erasmus+ project (2017-2020). https://cip.ku.dk/english/documents/Alignment_of_TOEPAS_with_the_CEFR.pdf

Dimova, S. (2020a). English language requirements for enrolment in EMI programs in higher education: A European case.Journal of English for Academic Purposes, $47,100896$.

Dimova, S. (2020b). Language Assessment of EMI Content Teachers: What Norms. In M. Kuteeva, K. Kaufhold, \& N. Hynninen (Eds.), Language perceptions and practices in multilingual universities (pp. 351-378). Springer.

Dimova, S. (2020c). The role of feedback in the design of a testing model for social justice. Journal of Contemporary Philology, 3(1), 27-47.

Dimova, S. (2021). Certifying lecturers' English language skills for teaching in English-medium programs in higher education. ASp, 79(1), 29-47.

Dimova, S., Hultgren, A. K., \& Jensen, C. (2015). English-medium instruction in European higher education (English in Europe, Vol.3). De Gruyter Mouton.

Dimova, S., \& Kling, J. (2015). Lecturers' English proficiency and university language policies for quality assurance. In R. Wilkinson \& M. L. Walsh (Eds.), Integrating content and language in higher education: From theory to practice (pp. 50-65). Peter Lang.

Dimova, S., \& Kling, J. (2018). Assessing EMI lecturer language proficiency across disciplines. TESOL Quarterly, 52(3), 634-656.

Dimova, S., \& Kling, J. (2020). Integrating content and language in multilingual universities. Springer.

García \& L. Wei (Eds.) (2014). Translanguaging: Language, bilingualism and education. Springer.

Gregersen, F. (Ed.) (2014). Hvor parallelt: Om parallellspråkighet på Nordens universitet [How parallel: About parallel language at the Nordic University]. Nordic Council of Ministers.

Gregersen, F., Josephson, O., Huss, L., Holmen, A., Kristoffersen, G., Kristiansen, M., Östman, J.-O., Londen, M., Hansen, Z., Petersen, H., Grove, A., Thomassen, E., \& Bernharðsson, H. (2018). More parallel, please! Sprogbrug i internationaliseringsprocesser. Nordisk Gruppe for Parallelsprogligheds afsluttende rapport med 11 anbefalinger til universiteterne om mønsterpraksis for brug af internationale og lokale sprog. Afgivet til Nordisk Ministerråd, oktober 2017. [More parallel please! Language use in processes of internationalisation. Final report of the Nordic group of parallel language use with 11 recommendations for universities about best practice for use of international and local languages]. https:// 
www.sprakradet.no/globalassets/sprakarbeid/forsking-og-hogare-utdanning/ more-parallel-please-.pdf

Haberland, H., \& Mortensen, J. (2012). Language variety, language hierarchy and language choice in the international university. International Journal of the Sociology of Language, 216, 1-6.

Harder, P. (2009). Parallel language use: A case for active social construction. In P. Harder (Ed.), Angles on the English-speaking world:English in Denmark: Language policy, internationalization and university teaching (pp. 109-128). University of Copenhagen: Museum Tusculanum.

Hellekjær, G., \& Westergaard, M. (2003). An exploratory survey of content learning through English at Scandinavian universities. In C. van Leeuwen \& R. Wilkinson (Eds.), Multilingual approaches in university education: Challenges and practices (pp. 65-8o). Valkhof Pers.

Henriksen, B., Holmen, A., \& Kling, J. (2018). English medium instruction in multilingual and multicultural universities: Academics' voices from the northern European context. Routledge.

Hirvela, A. (2016). Connecting reading and writing in second language writing instruction (2nd edition). University of Michigan Press.

Holmen, A. (2012). Does the Nordic concept of parallel language use apply to minority children in Denmark? In K. J. L. Knudsen, H. P. Petersen, \& K. a Rógvi (Eds.), Four or more languages for all: Language policy challenges for the future (pp. 94-108). Novus Forlag.

Holmen, A. (2018). Shaping a multilingual language policy. Gatekeepers and drivers of change. In M. Siiner, F. Hult, \& T. Kupisch (Eds.), Language policy and language acquisition planning (pp. 137-153). Springer. DOI: 10.1007/978-3-319-75963-0_8

Holmen, A. (2020). Integrating content and language: The role of other languages than English in an international university. In S. Dimova \& J. Kling (Eds.), Integrating content and language in multilingual universities (pp. 37-50). Springer.

Hultgren, A. K. (2013). Lexical borrowing from English into Danish in the Sciences: An empirical investigation of 'domain loss.' International Journal of Applied Linguistics, 23(2), 166-182.

Hultgren, A. K. (2014a). English language use at the internationalised universities of Northern Europe: Is there a correlation between Englishisation and world rank? Multilingua, 33(3-4). DOI: 10.1515/multi-2014-0018

Hultgren, A. K. (2014b). Whose parallellingualism? Overt and covert ideologies in Danish university language policies. Multilingua, 33(1-2), 61-87.

Hultgren, A. K. (2016). Domain loss: The rise and demise of a concept. In A. Linn (Ed), Investigating English in Europe: Contexts and agendas (pp. 153-158). De Gruyter Mouton. 
Hultgren, A. K., Gregersen, F., \& Thøgersen, J. (2014). English in Nordic universities: Ideologies and practices (World Language Problems, vol. 5). John Benjamins.

Hultgren, A. K., Jensen, C., \& Dimova, S. (2015). English-medium instruction in European higher education: From the north to the south. In S. Dimova, A. K. Hultgren, C. Jensen (Eds.), English-medium instruction in European higher education (English in Europe, vol. 3) (pp. 1-15). De Gruyter Mouton.

Jarvad, P. (2001). Det danske sprogs status i 199o'erne med særligt henblik på domænetab. Dansk Sprognæevns skrifter 32. Dansk Sprognævn.

Jensen, C., \& Thøgersen, J. (2011). Danish university lecturers' attitudes towards English as the medium of instruction. Ibérica, 22, 13-34.

Jürna, M. (2014). Linguistic realities at the University of Copenhagen. In A. K. Hultgren, F. Gregersen, \& J. Thøgersen (Eds.), English in Nordic universities: Ideologies and practices (pp. 225-249). John Benjamins.

Kiil, L.E. (2011). Danish university students' use of code-switching during Englishmedium instruction: A case study of two English-medium courses at The Faculty of Life Sciences. University of Copenhagen. Serien Studier i Parallelsproglighed, bind $\mathrm{C}_{3}$, Københavnerstudier i Tosprogethed.

Kling, J. (2016). Content teachers engaged in English medium instruction in Denmark. In J. Crandall \& M. A. Christison (Eds.), Teacher education and professional development in TESOL: Global perspectives (pp. 225-239). Routledge.

Kling, J. (2017). English medium instruction and the international classroom. In A. M. Snow \& D. M. Brinton (Eds.), The content-based classroom: Perspectives on integrating language (2nd edition, pp. 216-227). University of Michigan Press.

Kling, J., Larsen, S., \& Thomsen, S. F. (2017). The need for focused literacy training in the medical school curriculum: A cross-sectional study of undergraduate students. Education Research International, 2, 1-6. DOI: 10.1155/2017/7273824

Kling, J., \& Stæhr, L. S. (2011). Assessment and assistance: Developing university lecturers' language skills through certification feedback. In R. Cancino, L. Dam, \& K. Jæger (Eds.), Policies, principles, practices: New directions in foreign language education in the era of educational globalization (pp. 213-245). Cambridge Scholars Press.

Kuteeva, M., Kaufhold, K., \& Hynninen, N. (2020). Introduction: Language perceptions and practices in multilingual universities. In M. Kuteeva, K. Kaufhold, \& N. Hynninen (Eds.), Language perceptions and practices in multilingual universities (pp. 1-24). Palgrave Macmillan.

Lanvers, U., \& Hultgren, A. K. (2018). The Englishization of European education: Foreword. European Journal of Language Policy, 1o(1), 1-11. DOI:10.3828/ejlp.2018.1

Larsen, S., \& Jensen, F. (2020). Acknowledging the role of language in English medium instruction: Experiences from a pilot project intervention at University of Copenhagen. In S. Dimova \& J. Kling (Eds.), Integrating content and language in multilingual universities (pp. 153-166). Springer. 
Lauridsen, K. (2020). It does not happen by osmosis: Creating an internationalized learning opportunity for all students requires careful consideration and specific action. In H. Bowles \& A. C. Murphy (Eds.), English-medium instruction and the internationalization of universities (pp. 205-227). Springer.

Lønsmann, D., \& Mortensen, J. (2018). Language policy and social change: A critical examination of the implementation of an English-only language policy in a Danish company. Language in Society, 47(3), 435-456.

Marginson, S. (2006). Dynamics of national and global competition in higher education. Higher Education, 52(1), 1-39.

Ministry of Higher Education and Science (2020). Admission to Danish higher education for holders offoreign qualifications. Retrieved from https://ufm.dk/ en/education/recognition-and-transparency/recognition-guide/admission-he/ admission-to-danish-higher-education-for-holders-of-foreign-qualifications

Mortensen, J. (2014). Language policy from below: Language choice in student project groups in a multilingual university setting. Journal of Multilingual and Multicultural Development, 35(4), 425-442.

Mufwene, S. S. (2010). The role of mother-tongue schooling in eradicating poverty: A response to language and poverty. Language, 86(4), 910-932.

NCFF (2020). NCFF's mission, vision og verdier [NCFF's mission, vision and values]. https://ncff.dk/om-os/in-english/

Nissen, C. F. R. (2019). Blind spots of internationalization of higher education: Lived experiences of students in three versions of the international classroom [Doctoral dissertation, University of Copenhagen, Faculty of Humanities].

O'Dowd, R. (2018). The training and accreditation of teachers for English medium instruction: An overview of practice in European universities. International Journal of Bilingual Education and Bilingualism, 21(5), 553-563.

Östman, J-O., \& Thøgersen, J. (2010). Language attitudes and the ideology of the Nordic. International Journal of the Sociology of Language, 204, 97-127.

Pennycook, A. (2016). Mobile times, mobile terms: The trans-super-poly-metro movement. In N. Coupland (Ed.), Sociolinguistics: Theoretical debates (pp. 201216). Cambridge University Press.

Phillipson, R. (1992). Linguistic imperialism. Oxford University Press.

Preisler, B. (2009). Complementary languages: The national language and English as working languages in European universities. In P. Harder (Ed.), Angles on the English-speaking world: English in Denmark: Language policy, internationalization and university teaching (pp 10-28). University of Copenhagen: Museum Tusculanum.

Söderlundh, H. (2012). Global policies and local norms: Sociolinguistic awareness and language choice at an international university. International Journal of the Sociology of Language, 216, 87-109. 
Swerts, S., \& Westbrook, P. (2013). Preparing students and lecturers for English medium instruction at the University of Copenhagen. Sprogforum, 56, 71-78.

Tange, H. (2010). Caught in the tower of Babel: University lecturers' experiences with internationalisation. Language and Intercultural Communication, 10(2), 137-149.

Tange, H. (2012). Wars of words: Management policy and employee practice at the international university. Tamara Journal of Critical Organisation Inquiry, $10(4), 5$.

Thøgersen, J. (2013). Stylistic and pedagogical consequences of university teaching in English in Europe. In H. Haberland, D. Lønsmann, \& B. Preisler (Eds.), Language alternation, language choice and language encounter in international tertiary education (pp. 181-199). Springer.

Thøgersen, J., \& Airey, J. (2011). Lecturing undergraduate science in Danish and in English: A comparison of speaking rate and rhetorical style. English for Specific Purposes, 30(3), 209-221.

Thøgersen, J., Josephson, O., Londen, M., \& Salö, L. (2014). Engelsk som undervisningssprog på nordiske universiteter. Hvordan gør man? [English as medium of instruction at Nordic universities. How to do it]. In F. Gregersen (Ed.), Hvor parallelt: Om parallellspråkighet på Nordens universitet [How parallel: On parallel lanuage use at Nordic universities] (pp. 55-123). Nordic Council of Ministers.

Universitas21 (2020). Rankings Raw Data 2020. https://universitas21.com/media/966 Verguts, C., \& De Moor, T. (2019). The policy-imposed C1-Level of English in Flemish universities: A blessing for students, a challenge for lecturers. BAAHE Conference, Ghent, Belgium.

Wächter, B., \& Maiworm, F. (Eds.) (2014). English-taught programmes in European higher education: The state of play in 2014. Lemmens.

\section{About the authors}

Slobodanka Dimova (MA and PhD Purdue) is an Associate Professor in Language Testing and Assessment at the Centre for Internationalisation and Parallel Language Use at the University of Copenhagen. Her work focuses on fairness and justice in language assessment as a policy tool in the internationalized higher education.

Anna Kristina Hultgren (DPhil Oxon, MA Copenhagen, SFHEA, Cert LSE) is UKRI Future Leaders Fellow and Professor of Sociolinguistics and Applied Linguistics at The Open University, UK. Her work centres on uncovering fundamental principles governing language shift in our globalized world by bringing together linguistics and political science. 
JoYCE KLING (PhD Copenhagen, EdM Harvard, MA MIIS) is Geise Foundation Associate Professor at the University of Copenhagen. Her research focuses on English-medium instruction (EMI) and professional development of lecturers, with particular interest in the integration of content and language in multilingual higher education. 


\title{
8 Internationalization vs Englishization in Italian higher education
}

\author{
Reframing the issue ${ }^{1}$ \\ Amanda C. Murphy and Beatrice Zuaro
}

\begin{abstract}
This chapter investigates the concepts of internationalization/ internazionalizzazione and Englishization/anglicizzazione as used by academics publishing research about Italian higher education in English and Italian. We seek to understand whether internationalization is understood principally as Englishization, and to investigate the resonance of the terms in context. Methodologically, three corpora are analysed within a corpus-assisted discourse studies approach. The findings indicate that internationalization is presented in a neutral light, is not construed exclusively as Englishization, which is used invariably as a negative term indicating an invasive process from which Italian academia needs to defend itself. The research suggests reconsidering the role of English as a way of making Italian academic culture more accessible to international audiences, rather than a threat to its identity.
\end{abstract}

Keywords: internationalization, Englishization, CADS methodology, higher education, Italy

1 This paper was devised and written as an entirely joint project. For the sake of the publication norms in the Italian academic system, Sections 1-3 were written by Beatrice Zuaro, 4-6 by Amanda Murphy, and 7 together.

Wilkinson, Robert, and René Gabriëls (eds), The Englishization of Higher Education in Europe. Amsterdam, Amsterdam University Press 2021 DOI: $10.5117 / 9789463727358$ _CHо8 


\section{Introduction}

The internationalization of Higher Education (HE) in Italy has been a sensitive topic for members of the public tuned into education, due to a clamorous court case won in 2018 by 100 professors from the Politecnico di Milano, one of the most prestigious and respected Italian higher education institutions. The academics took the University to court to challenge a decision taken by the Academic Senate to impose English as the medium of instruction in all MA and PhD courses. This enforced Englishization (anglicizzazione or the more rarely used inglesizzazione in Italian) had enraged some Faculty members, and mainstream newspapers gave space to both voices: the Rector of the University at the time defended the University's position, affirming that 'a graduate who can work in English has five times the opportunities of one who can't' (Cavadini, 2014), ${ }^{2}$ while the authoritative national reference point for the Italian language, Accademia della Crusca, defended the importance of upholding Italian as the national language of education and culture (Maraschio \& De Martino, 2013).

It is no novelty to assert, with Haberland and Mortensen (2012, p. 1), that 'there is more to university internationalization than mere Anglicization', and yet it is undeniable that teaching through English is the fastest way of attracting international students to a country (Tira, 2021). Italy has taken this route decisively: by $2015,100 \%$ of private and $82 \%$ of public Italian HE institutions offered degree programmes in English (Broggini \& Costa, 2017, p. 253), and this unstoppable trend may be one of the reasons why the Politecnico case, well documented and discussed in academic research (Molino \& Campagna, 2014, Pulcini \& Campagna, 2015; Santulli, 2015; among others), continues to be cited by dissenters.

The present paper does not intend to go over this well-rehearsed ground, but rather discusses the issue of internationalization by examining how it has been conceptualized, measured and discussed by the Italian academy. We intend to answer the following questions: How is internationalization in Italian HE conceptualized by academics? Does internationalization coincide with Englishization/anglicizzazione? What resonance does 'Englishization/anglicizzazione' have in Italian academic research? To answer these questions, the paper draws on academic research on internationalization regarding Italian $\mathrm{HE}$, and investigates the contexts in which Englishization or its sister term, anglicizzazione, are used. 


\section{The Italian Context}

In order to properly contextualize the present study, a brief account of the Italian linguistic context, as well as of its policies, seems necessary. In fact, Italy has a complex history which represents the inevitable backdrop to discourses around culture, education, and language. On the one hand, the country is characterized by a long tradition of local academia (the University of Bologna being the first founded in the Western world) and Italian is one of the bigger languages in Europe (Ethnologue, 2019), with significant international relevance in certain domains; on the other hand, the country's long history of divisions has resulted in a unique situation of inner linguistic diversity (Tosi, 2004) which has informed national policies and contributed to a certain sensitivity around the topic of language. While it is estimated that no less than 40 languages were traditionally spoken within Italian territory (Coluzzi, 2009), only Italian currently holds the status of official language of the nation, together with 12 minority languages (Law n. 482/1999).

In the context of the aforementioned inner fragmentation, education is deemed to have played a central role in the unification of the country (De Mauro, 1991). It may thus be unsurprising that Italian is the main language in use at all levels of education. This position of prominence relies, among other factors, on the general interpretation of Art. 9 of the Italian Constitution, which safeguards the 'historical and artistic heritage' of the country, including the national language. Nonetheless, in recent years, as internationalization has been establishing itself as an indicator of quality and prestige in global higher education, the debate around language use has been rekindled. As mentioned in the introduction, the strategy of Italian institutions to increase internationalization seems to have largely revolved around the implementation of English-medium degree programmes. Nonetheless, initial available data painted the picture of a country that was 'slow to internationalize its universities' (Costa \& Coleman, 2013, p. 7; see also Wächter \& Maiworm, 2008, 2014). This trend appears to be confirmed by recent research that found the English-medium instruction (EMI) offer to be on a slow increase (Costa \& Mariotti, 2020). A possible reason for this is the overall moderate proficiency of the English language in Italy: indeed, Italy is one of the few countries in Europe where the competences of the local student population in EMI courses appear to be lower than that of foreign students (Clark, 2018; Wächter \& Maiworm, 2014). 
Despite the challenges, there are signs that EMI courses appeal to different stakeholders, for different reasons, including improvement of the institutional profile, better prospects on the job market for students and even aspirations of language improvement (Ackerley et al., 2017; Clark, 2018; Costa, 2017; Costa \& Coleman, 2013; Costa \& Mariotti, 2017; Guarda \& Helm, 2017). However, the clash of needs, motivations, and expectations has in some instances caused much discussion around higher education policies.

Returning to the example of the Milan litigation mentioned in the introduction, it is important to note that the resistance encountered was not towards the idea of any teaching occurring in a foreign language (in this case, English). In fact, as established by the Ministerial Decree 270/2004, the learning of a foreign language is a qualifying educational objective across disciplines in Italian universities. Rather, opposition was made to the exclusive use of a foreign language as the medium of instruction. The verdict to the court case reaffirmed this: the resolution of the Polytechnic was seen as explicitly contradicting Art. 9 of the Constitution and therefore invalidated (see also Pulcini \& Campagna, 2015; Santulli, 2015). Additionally, it should be noted that, given the rather modest command of the language in this country, implementing courses exclusively via English is seen as having the potential to curtail access to education. This scenario can be especially striking vis-à-vis a cultural environment that has traditionally advocated for accessible education, even at higher education level, via free attendance of lectures at public universities (Royal Decree 1592/1933). ${ }^{3}$

Thus, it would be an oversimplification to read these events as a manifestation of resistance to English in HE tout court. As mentioned, there is evidence in the literature to show favorable approaches in Italian academy to the use of English as the lingua franca. The 'bunker attitude' (Baker, 1992) that often finds particular expression in the media may be but one nuance of a multilayered discussion. To fully appreciate the views of different stakeholders in the internationalization debate, we argue for the need to clarify the terms of this discussion. The contribution of the present article to that end is an investigation of how the ideas of 'internationalization' and 'Englishization' are conceptualized and used in academic research about Italian $\mathrm{HE}$.

3 According to the mentioned Decree, lectures are to be considered public, thus anyone is free to attend them, regardless of whether they are enrolled in a programme or not. 


\section{Review of Literature}

Before moving to the details of the present study, we present an overview of how 'internationalization' and 'Englishization' are understood and discussed in the literature.

Since the so-called 'invention' of internationalization as an element of prestige for higher education institutes (HEIs) (Brandenburg \& de Wit, 2011, p. 15), stakeholders in various capacities have contributed to the codification of the internationalization paradigm. Nonetheless, conceptually the idea of internationalization remains somewhat broad, one oft-cited example being the 'working' definition by De Wit et al. (2015, p. 29), whereby internationalization means:

Integrating an international, intercultural or global dimension into the purpose, functions and delivery of post-secondary education, in order to enhance the quality of education and research for all students and staff, and to make a meaningful contribution to society.

By contrast, more recently Hawawini (2016) stressed the need for a definition which, while remaining applicable to a variety of contexts, places emphasis on the beneficial outcomes of the process, clarifying their twofold nature. In fact, if, on the one hand, institutions benefit from becoming a part of the global knowledge construction process, on the other hand, it is the institutions themselves that contribute to this body of knowledge and to its increase. Thus, Hawawini came to the following formulation (2016, p. 5):

Internationalization is an ongoing process of change whose objective is to integrate the institution and its key stakeholders (its students and faculty) into the emerging global knowledge economy.

If defining internationalization theoretically can prove challenging, the difficulty is heightened when one attempts to pin it down into categories that can be measured. The use of language, for example, can be a difficult indicator: while a shared lingua franca seems an effective way of enacting internationalization, its uniform use can raise issues of 'globalization' (Bull, 2012) and 'linguistic hegemony' (Ives, 2006). Given its strengthened position as the de facto lingua franca of academia (Cots et al., 2012), in the last few decades English has thus found itself at the centre of the debate.

At least in some circles, the equation of 'doing things in English' and internationalization has appeared to be consolidated (e.g., Coleman, 2006; 
Cots et al., 2014; Galloway et al., 2020). The use of English as the default language for international courses is a comfortable practice for institutions, in that it merely consolidates what is already perceived to be the status quo (on the 'self-perpetuating' dynamic of the dominance of English, see Lanvers \& Hultgren, 2018a; see also the 'Catherine wheel' described by Earls, 2013). This 'ever-growing use of English' (Lanvers \& Hultgren, 2018a, p. 1) is often addressed in the literature as 'Englishization', with a shift from the original meaning of the term, traditionally used to indicate linguistic adaptation towards English (Lanvers \& Hultgren, 2018a, drawing on McArthur, 1992).

In previous research, the phenomenon of Englishization has been paired up with various types of complications. Many have raised pedagogical concerns (e.g., Aizawa \& McKinley, 2020; Kaur, 2020; Klaassen, 2001; Wang, 2020). Airey and Linder (2007), in particular, showed that not only there are differences in the way students experience lectures in different languages, but also that they appear to be unaware of such differences, which has important pedagogical implications. It has also been reported that, considering the differences in practices and disciplinary literacy goals among disciplines, the idea of a possible uniform use of language is simplistic and fallacious (e.g., Kuteeva \& Airey, 2014). Ethical implications for access to learning and research have also been reported (e.g., Lanvers \& Hultgren, 2018a; Lueg, 2018), especially for contexts where English has made fewer profound inroads in society (e.g., Kuwamura, 2018; Romaine, 2015; Tsuneyoshi, 2005). Additionally, there are indications in the research to show that students from higher classes are more likely to be socialized into reaping the benefits of an English-medium education, perpetrating mechanisms of elitism and social inequality (Lueg \& Lueg, 2015). In previous research Englishization has also been linked to preoccupations of domain loss, diglossia, and general impact on the international dimension of other languages (e.g., Cots et al., 2012; Cots et al., 2014; Earls, 2013; Phillipson, 2006).

As a result of these considerations, it could be argued that, far from simply describing the presence of English in academic environments (cf. Lanvers \& Hultgren, 2018b), the term Englishization carries negative, albeit not yet precisely codified, connotations.

In this chapter we posit that although much research dealing with internationalization inevitably examines it in connection to Englishization, the two phenomena are associated with different discourses, one of which is more dominant. We look specifically at the context of Italian HE to show that, while much research on the country is indeed conducted under the umbrella of English-medium instruction (e.g., Broggini \& Costa, 2017; Costa, 2017; Costa \& Coleman, 2013; Costa \& Murphy, 2018; Doiz et al., 2020; Guarda 
\& Helm, 2017; Murphy \& Costa, 2018; Pulcini \& Campagna, 2015), above all by linguists, there is also a significant amount of research which, conducted within various disciplines, testifies to the multiple manifestations and interpretations of internationalization in the system. We present the details of our dataset and analysis in the next section.

\section{Methodology}

In order to answer the question of how internationalization is understood and researched by Italian academics, and whether it is construed as Englishization, we have adopted a corpus-assisted discourse studies (CADS) approach, enucleated by Partington (2004a) and clearly laid out in Partington et al. (2013). The use of corpora - large quantities of computerized text - for analysing language, language functions, and ideas was pioneered in Europe by John Sinclair (see, for example, Corpus, Concordance, Collocation, 1991). One of the major insights emerging from his work was, as Thompson and Hunston (2006, pp. 11-12) concisely point out, that meanings are not located in single words, but in 'units of meaning' (Sinclair, 1996); consequently, discourse can thus be described and investigated as a series of semi-fixed phrases. Meaning is created also by the regular phraseologies and collocations that frequently occur with certain words. Another important concept which is relevant to the present study is that of semantic prosody: this has been interpreted either as the property of a word (Partington, 2004b), typically indicating a 'positive or negative attitudinal meaning', which is also gradable (Hunston, 2007, p. 250), or as a property discernible through the surrounding discourse.

Corpus linguistics is typically quantitative: if a pattern of words recurs across different texts, then it is significant, both in terms of observing what is said, and in terms of predicting what could be said. It can also be described as an inductive methodology, in that from a series of repeated instances in text, it infers a general law or principle (Partington et al., 2013, p. 8); accumulating evidence of a phenomenon is also a way into deeper knowledge of that phenomenon. What the CADS approach adds to 'pure' corpus linguistics is the combination of observations deriving from a corpus with knowledge from other sources. Methodologically, this can add a qualitative, even sociological slant, which examines the extra-textual contexts and the society in which they are embedded. It also explains the adoption of reference works such as dictionaries and encyclopaedias for assistance in interpreting the findings in a corpus of texts and understanding how 
the meanings of words can change. 'The aim of the CADS approach is the uncovering [...] of what we might call non-obvious meaning, that is, meaning which might not be readily available to naked-eye perusal' (Partington et al., 2013, p. 11).

To this end, a number of corpora were compiled to provide appropriate data for the research questions. Since the research specifically regards academics in higher education, it was decided to examine the text typologies which represent them most, that is, research articles and book chapters. These constitute the prime research outputs for most academics in the 21st century: they reflect systematic research and considered thought more than other text types, such as newspaper articles, for example. While an issue as topical as internationalization may also create waves in the print and online press, newsworthiness is a prime concern for the press, rather than depth of thought. The academic article is a genre in which evidence-based discourse has been distilled, discussions and conclusions are pondered rather than sensational, and where there is a guaranteed audience of a similar type to the writer. Research articles and book chapters have also normally gone through a peer review quality assurance process.

Two corpora were built following objective criteria. The first was compiled by means of the English search words 'internationalis/zation', 'higher education' and 'Italy/ian' using the databases ProQuest, Elsevier Science Direct, Eric, and Google Scholar. Articles in journals and book chapters published in English and reported in these databases were sought over a span of 20 years (1 January 2000 to 31 December 2020) in the disciplinary areas of applied sciences, business, ecology, economics, education, engineering, environmental sciences, international relations, language and literatures, law, political science, psychology, social sciences, social welfare, and social work. The search words had to appear more than once and not be present only in the bibliography of the articles found. This search produced 69 academic articles $^{4}$ from a cross-section of the above disciplines, which adopt a variety of research methodologies and data types, including annual reports, university strategic plans, and national evaluation reports, for example. A second search was made for articles in English the word 'Englishis/zation', using the same databases and in the same 20-year span; but of the four articles found through this search, two were not about higher education, and the other two were already in the internationalization corpus.

4 Articles and book chapters published in this timespan but not registered in the databases were obviously not included, but the two corpora are representative of academic publications that have international visibility and are available online, some through library subscriptions. 
The total amount of text in English, minus the bibliographies and tables which were removed for the corpus research, is 329,401 running words. The corpus INT-EN thus represents scientific research on the topic of internationalization (and Englishization) written in English.

The same criteria were adopted to build a corpus of academic research about internationalization written in Italian called INT-IT. Accordingly, the search words internazionalizzazione and anglicizzazione referring to Italian higher education were sought through Italian databases and journals. This produced a small amount of data, namely seven articles, amounting to just over 31,000 words. 5

Since the two corpora were constructed according to the same criteria (i.e., through key words in academic journals and books), despite their difference in size, they can be compared with due attention to normalization of numbers. Incidentally, the amount of data available in Italian gives an indication of little attention to the issue of Englishization in published Italian research, despite it attracting a certain amount of attention in the national media; alternatively, it could be an indication that research on the topic is published in English.

Given the small amount of data in Italian, it was decided to build a third corpus containing the articles in a book which is known to be precisely about the topic of internationalization and Englishization, because it contains the academic contributions made in a high-profile debate launched by the national Academy for the Italian language, Accademia della Crusca, after the Politecnico court case. The Academy took a public stance opposing the unilateral use of English in the MA and PhD courses at the Politecnico, and the book illustrates the various positions assumed by academics around the country. The title chosen for the book was clearly provocative: Fuori l'italiano dall'Università? (Exclude Italian from the University?). The size of the corpus is approximately 13,000 words, and it was called the CRUSCA corpus. The difference between this corpus and the INT-IT corpus is that the latter was compiled according to objective criteria, so that it is comparable to the INT-EN corpus. The CRUSCA corpus concentrates specifically on the debate linked to the Politecnico case.

The research followed two steps: the consultation of authoritative dictionaries in both languages for definitions of the words internationalization, ${ }^{6}$ Englishization, and anglicizzazione, and the

5 Many articles were found about the internationalization of companies, but not about higher education.

6 The search for words ending in -zation used * to gain occurrences also with -sation. 
examination of the words (and derivations from the same stems), in the three corpora. The free software Antconc 3.5.9 (Anthony, 2020) was used to examine the words in context, their collocates, and repeated clusters of words in which they occur.

Section 5 presents the definitions of the words, while subsections $5 \cdot 1-5 \cdot 3$ present the findings from the three corpora, with initial comments on the textual examples. The findings are discussed in greater detail in section 6 , while conclusions are drawn in section 7 .

\section{Definitions and Findings}

In the Oxford English Dictionary $(O E D)$, an acknowledged authoritative source for the English language, the first thing to note is that 'internationalization' is a general process, not associated necessarily with education, and is defined: 'The action or process of making something international in character, composition, or scope.' 'Englishization', on the other hand, does not exist as a lemma in the dictionary; the closest word is 'anglicization', of which 'anglicizzazione' is a cognate, whose definition (updated in 2008) is:

i. The action or process of making something or someone English (or British) in character; an instance of this. Also: the acquisition of English (or British) character or characteristics.

ii. An English form or version (of a word or name); an adaptation into English. Typically describing a word formed from the pronunciation or spelling of a foreign term rather than by translation of its meaning.

We note in passing that the dictionary equates 'Englishness' with 'Britishness', a contestable feature which seems dated in the present era where regional and national identity is of increasing importance. More relevantly, the division of meaning into two areas, one relevant to 'character, characteristics', the other to 'words or names' is notable. The definition is neutral and indicates no attitude towards this process. ${ }^{7}$

7 For the purpose of comparison, more recently compiled and corpus-based dictionaries, such as the Cambridge Advanced Learner's Dictionary (CALD), and the COBUILD dictionary, were also consulted, but they too lack the word 'Englishization'; the verb 'anglicize' is defined in CALD as 'to make or become English in sound, appearance or character'. The added specification of 'sound' is similar to the second meaning listed in the $O E D$. 
As regards Italian dictionaries, one of renowned authority is the Treccani, and the definition of the Italian equivalent anglicizzare is as follows:

Rendere inglese, adattare agli usi, ai costumi, alla cultura inglesi: $a$. un popolo, una nazione; con riferimento alla lingua, accogliere parole o costrutti della lingua inglese (to make English, adapt to English customs, uses, culture: to Englishize a people, a nation; with reference to language, to incorporate words or constructions from English).

The definition is shared by the verb inglesizzare. We note there is no hint of Britain or British culture.

\subsection{Findings from the INT_EN corpus: Internationalization in Italian Higher Education}

The compilation of the INT_EN corpus revealed first of all that the discourse about internationalization in Italy is distributed across a wide variety of disciplinary areas (see Table 8.1). These range from the more classic fields, like education (also higher education, bilingual education) and language and linguistics, with education occupying half the corpus, to the disciplines within the social sciences, such as politics, sociology, policies and language policy, economics, management, planning, entrepreneurship, informatics, statistics, and technology transfer. There is one exception, which is an article from engineering.

Table 8.1 Disciplinary areas in the INT corpus

\begin{tabular}{lr}
\hline Education (Higher, Bilingual) & 31 \\
Economics, Management, Planning, Entrepreneurship & 18 \\
Politics and Policies (Language), Sociology & 11 \\
Informatics, Statistics and Technology Transfer & 6 \\
Language and Linguistics & 2 \\
Engineering & 1 \\
\hline Total & $\mathbf{6 9}$ \\
\hline
\end{tabular}

The frequency with which the concept is named, also counting the various forms of the verb 'internationali*e (*s, *ed, *ing), is 1.4 per 1,00o words. The strongest lexical collocates ${ }^{8}$ of internationali*ation in this corpus are

8 Collocates were calculated via AntConc (Anthony, 2020) using the T-score function, which also takes into account frequency of occurrence. 
university, education, and academic, which are distributed fairly evenly across the corpus. These collocates merely situate internationalization, in the academy, without adding anything significant about the understanding of the concept. Other collocates, however, indicate examples of a less conventional and more specific interpretation. These are spin-offs, co-authorship, and entrepreneurship. Examples 1-3 illustrate these collocates in context.

1) Our approach differs from existing literature since it explores the coauthorship network to measure internationalization across institutions. In fact, we build a network based on co-authorships and we use it to measure internationalization of Italian Universities.

2) the degree of internationalization of academic spinoffs can be a consequence of the presence of a highly international team due to the international propensity of the parent university.

3) Future studies can address the role of entrepreneurial teams in the internationalization of ventures originating from universities and research institutes.

In these and other occurrences of the collocates, there is no indication of positive or negative semantic prosody. They point to the study of the enactment of internationalization through unconventional measures. There are many other collocates of the term internationalization, but none with very high scores that indicate a prominent theme that dominates the discourse. Apart from co-authorships, academic spinoffs, and entrepreneurship, other ways of interpreting and measuring internationalization that are found in the co-text of 'internationalization' emerge as:

a the percentage of international staff compared to total staff;

b cooperation with departments from other countries for joint programmes and double degrees;

c establishment of branches of universities in other countries;

d partnerships with international institutions and multinational firms;

e virtual educational programmes delivered in other countries;

f the influence of Rectors with international mobility on the development of networks and collaborations;

$\mathrm{g}$ Italian student representation in international political forums and policy-making bodies.

By contrast, the word Englishization appears only twice in the whole corpus, in journals from the areas of education and language policy, where it is 
used to mean 'teaching only through English'. Examples 4 and 5 illustrate these two occurrences:

4) it seems impossible to separate the Bologna Process from internationalisation, and internationalisation from the Englishisation of Higher Education: to that extent, the Bologna Process has indeed undermined the EU's goal of multilingualism.

5) The latest studies in the field of English as a corporate language demonstrate that adopting a global language policy is not easy. It is a radical choice. The benefits of 'Englishisation' (as Hiroshi Mikitani calls it, the CEO of Rakuten, Japan's largest online marketplace, who decided in 2010 that English would be the company's official language for business) are significant, but only a few companies have systematically implemented an English-language policy with sustained results.

And here arises a question: Is the university a company? Is its mission the same as that of an international or multinational corporation?

Obviously not.

The INT-EN corpus, which reflects research on internationalization in Italian Higher Education published internationally, shows no dominant interpretation of the concept, and no particular trend of positive or negative semantic prosody, as well as very limited reference to Englishization. It shows an understanding of the variegated ways in which internationalization can be enacted and an overall neutral stance.

\subsection{Findings from the Italian corpus on Internationalization in Italian Higher Education (INT-IT)}

The Italian corpus contains 7 articles written for an Italian audience, taken from four disciplinary areas, as illustrated in Table 8.2.

\section{Table 8.2 Disciplinary areas included in the IT corpus}

\begin{tabular}{lr} 
Language and Linguistics & 3 \\
Social Psychology & 1 \\
Public Law & 1 \\
Education & 2 \\
Total & 7 \\
\hline
\end{tabular}


The word 'internazionalizzazione' occurs 2.7 times per 1,00o words and is distributed throughout all the articles in the corpus. The noun has three lexical collocates: i) 'casa' (home), which occurs in the expression 'internazionalizzazione a casa' (internationalisation at home); ii) 'discorsi' (discourse about) in the expression 'discorsi sull'internazionalizzazione', which is used exclusively in one article contesting the common association of internationalization with mobility and arguing for 'internationalization at home', and iii) 'atenei' (universities), used exclusively in one article that reflects on the consequences of the legal case at the Politecnico di Milan, particularly on courses in foreign languages. Similarly to the results of the investigation into INT-EN, the first collocates do not indicate an attitude towards the phenomenon of internationalization, but specify its context (universities), or the type of internationalization envisaged (i.e., at home).

The one article where 'atenei/universities' is a collocate of internationalization concludes with the following recommendations: 'ben venga l'internazionalizzazione dei nostri Atenei' ('the internationalization of our universities is more than welcome') as long as the following three conditions are met: resistance to intellectual subservience to the English-speaking world, resistance to cultural subjection to the same world, and the search for alternative ways of internationalizing. This example shows that although the collocate itself is not negative the surrounding text reveals a defensive attitude summed up as 'resistance', indicating that the process can only be considered positive if it does not imply subservience to the English language or culture of the English-speaking world.

The word anglicizzazione occurs 0.2 times per 1,000 words and is distributed over 3 articles ( $42 \%$ of the corpus), rather unevenly. It is invariably used in negative contexts: in example 6, we see anglicizzazione glossed as 'killer language', whereas in the article where it occurs most (6 times), the word is used exclusively in the sense of 'incorporating words or constructions from English' which is seen as a negative process. These are illustrated in examples 6 and 7 :

6) Il fenomeno dell'English as a Medium of Instruction (EMI) nel suo complesso ha portato molti a parlare di anglicizzazione delle università, o addirittura di «killer language» (Coleman, 2006) e «pandemic English» (Phillipson, 2009). (The phenomenon of EMI as a whole has led many to speak about the Englishization of universities, or even of a 'killer language' or 'pandemic English'.) 
7) Per fermare, o almeno frenare, una tale anglicizzazione della lingua italiana, e similmente delle altre lingue, e per renderle la sua purezza, non servirebbero forse delle contromisure come quelle dei francesi? (To stop, or at least slow down, such an anglicization of the Italian language, and in the same way of other languages, and to restore her purity, would we not need some kind of countermeasures like those adopted by the French?)

Comment: Anglicization is seen as a pernicious process that needs to be stopped or slowed down.

In the INT-IT corpus, internationalization is discussed mostly in terms of internationalization at home, which in fact does not need to take place in English, but which can mean internationalizing the curriculum, for example (Leask, 2015). Anglicizzazione is mentioned solely in connection with the negative effect on other languages, which leads to monolingualism and subservience to Anglophone culture.

\subsection{Findings from the CRUSCA corpus}

The articles in the CRUSCA corpus comprise all the contributions to the debate on the use of English as a vehicle of instruction at university, promoted by the Accademia della Crusca in 2012. This corpus is expected to produced negative examples about Englishization, given the heated debate it represents.

The search for 'internazionalizz* produced various forms of the verb 'internazionalizzare' as well as the noun, and 'anglicizzazione', and more various related words, including anglicismo (anglicism), anglicizzat* (anglicized), anglicizzante (Englishizing - adj), anglitaliano (Italish), than in the INT-IT corpus.

Internazionalizzazione or related words occur 5.5 times per 1,000 words, much more than anglicizzazione which occurs 1.8 times per 1,000 words. The top lexical collocates of internazionalizz* are: università (university) and sistema (system), which as in the other two corpora both indicate the context of use, while not revealing anything about how it is conceptualized or positive or negative semantic prosody: internazionalizzazione delle università (internationalization of universities), internazionalizzazione del sistema universitario italiano (internationalization of the Italian university system). Anglicizzazione proved to be more fertile ground in terms of discerning positive or negative semantic prosody, and Table 8.3 illustrates the numbers 
of occurrences of the word and its derivates, and the classification into positive or negative contexts of use.

Table 8.3 Occurrences of words beginning with angl* and their positive or negative contexts in the Crusca corpus

\begin{tabular}{lccc}
\hline & $\begin{array}{c}\text { TOTAL } \\
\text { OCCURRENCES }\end{array}$ & $\begin{array}{c}\text { POSITIVE or } \\
\text { NEUTRAL CONTEXT }\end{array}$ & $\begin{array}{c}\text { NEGATIVE } \\
\text { CONTEXT }\end{array}$ \\
\hline $\begin{array}{l}\text { Anglicizzazione } \\
\text { Englishization } \\
\text { anglismi/o } \\
\text { anglicismi/o }\end{array}$ & $\mathbf{8}$ & 2 & 6 \\
$\begin{array}{l}\text { Anglicisms } \\
\text { anglicizzata/i: }\end{array}$ & $\mathbf{1}$ & 1 & 3 \\
$\begin{array}{l}\text { Anglicized } \\
\text { anglico/ anglicus }\end{array}$ & 3 & 1 & 3 \\
$\begin{array}{l}\text { English } \\
\text { anglicizzante/i } \\
\text { Sounding English } \\
\begin{array}{l}\text { Anglitaliano A language mixture } \\
\text { of English and Italian-Englian }\end{array}\end{array}$ & 3 & 1 & 2 \\
\hline TOTAL & 3 & & 1 \\
\hline
\end{tabular}

Six examples of the co-texts surrounding the words are reported, translated, and briefly commented on here. In examples 8-13, anglicizzazione has a negative semantic prosody, judging from the surrounding co-text. In example 13, the process is seen from two points of view and appears to be neutral.

8) Che francese e spagnolo appartengano a questa categoria, non c'è alcun dubbio. Basta pensare alla tenacia con cui hanno frenato l'anglicizzazione della terminologia del computer. (There's no doubt that French and Spanish belong to this category of 'languages of culture'. It's enough to think of the tenacity with which they put a brake on the anglicization of computer terminology.)

Comment: the use of 'tenacity' and the verb 'brake' (frenare) would indicate that the anglicization process is something negative that has doggedly been stopped.

9) Diversa, naturalmente, è la situazione nelle aree umanistica e giuridica, dove è inaccettabile oltre che un po' ridicolo il principio che le 
pubblicazioni in inglese (p. es. nel settore dell'italianistica!) valgano più di quelle in italiano; ma dove non vedo alcuna minaccia di anglicizzazione dell'insegnamento. (The situation in courses in the areas of Humanities and Law is quite different, where it is unacceptable as well as rather ridiculous that publications in English (e.g. in the sector of Italian studies) should be worth more than those in Italian; but I see no threat of anglicization of teaching)

Comment: the fact that anglicization is seen as a threat confers a negative aura to the process.

10) è molto significativo che anche la Germania, la quale ha affrontato questi problemi prima di noi [...] ed è quindi più avanti nel processo di anglicizzazione, stia ripensando le sue scelte. (it is extremely significant that even Germany, who faced these problems before we did [...] and who is therefore further on than us in the process of anglicization, is rethinking the choices that were made.)

Comment: a country that is more anglicized than Italy is reconsidering the choices it made - this implies that the choices were not good and that therefore anglicization is not a good thing; the mention of 'problems' also confers a problematic aura on the process of anglicization.

11) Ironicamente i nostri avi hanno resistito l'anglicizzazione per $15^{0}$ anni, difendendo l'italiano come acroletto [...] no ai primi decenni del Novecento, ma oggi dobbiamo ammettere che per noi il cambiamento è stato un vantaggio. (Ironically, our ancestors resisted anglicization for 150 years, defending Italian as acrolect... but today we must admit that the change brought us advantages.)

Comment: the use of 'resist' implies that anglicization was not considered a good process, and Italian needed to be defended from it. The coordinated clause introduced by 'but' resets the balance, implying that this point of view is no longer shared, thus neutralizing the negativity.

12) Non si può ignorare che l'applicazione totalitaria dell'anglicizzazione dei corsi anzidetti creerà una netta preselezione sociale e ambientale dei fruitori. (It cannot be ignored that the totalitarian application of the anglicization of the prementioned courses will bring about a precise social and environmental pre-selection of the students.) 
Comment: the adoption of the adjective 'totalitarian' could be a neutral choice, if the adjective is being used just to mean 'total', but its connotations are inevitably negative; moreover the consequences of the anglicization process - that students are preselected on the basis of economic and social grounds - creates negative backlash to the anglicization process and the sentence as a whole.

13) Perché è apparso immediatamente chiaro il rischio da evitare: quello che su un tema tanto delicato e in un momento significativo di svolta (che parte dall'università ma non si limita certo a essa) si determinasse una contrapposizione netta, quasi manichea, tra fautori e oppositori dell'anglicizzazione, tra chi cioè vede nella scelta dell'inglese come lingua veicolare dell'insegnamento il modo migliore, più semplice ed economico per i nostri atenei di aprirsi al mondo e chi invece difende ad oltranza la lingua italiana, appellandosi alla forza e all'autorevolezza della tradizione nazionale. Inglese contro italiano, insomma, in una visione semplificante e fuorviante. (It became immediately clear that a riskneeded to be avoided: that of creating - on a rather delicate issue, which had emerged at a significant turning point (which starts in university but would go beyond it), a distinct, almost Manichean contraposition between the advocates and opponents of anglicization, between those who see the choice of English as a vehicular teaching language as the best, simplest and most economical way for our universities to open up to the world and those who defend Italian all-out, invoking the strength and authority of national tradition. English against Italian, in other words, in a simplistic and misleading way.)

Comment: anglicization is construed as a process that can be seen as a fast, simple, and economic way of opening universities up to the world, or as bad thing because it attacks national tradition. A neutral use of the word.

\section{Discussion}

The findings in the corpus of articles in English (INT-EN) scarcely mention or discuss the concept of Englishization with regards to internationalization, with the word occurring only twice in publications from the areas of language and linguistics in a corpus of 69 articles. Both instances of the search word Englishization occur in negative contexts, implying that the process undermines plurilingual competences and that universities 
should not apply monolingual policies that may characterize companies. On the other hand, the discussions of internationalization in this corpus are embedded in a wide range of disciplinary areas, and their attention is focused on various enactments of internationalization, such as co-authored publications, international, academic spin-offs, entrepreneurship, the presence of international staff, virtual education, and so on. Neither Englishization nor simply English appear as lexical collocates of the noun internationalization, nor do the classic indicators of international mobility and the presence of international students in a university. This is the corpus where debate does not appear to be polarized, where discussion of the topics is broad ranging, and touches on innovative measures of internationalization, such as academic spin-offs and entrepreneurship. The research in this corpus, reported in English, is directed at an international audience, which may influence the more nuanced and multi-layered attitude towards the phenomenon and the lack of a clear polarization around the Englishization process.

In the small Italian corpus on internationalization, INT-IT, the research is produced by scholars from various disciplines, and internationalization is mentioned generally in the form of internationalization at home, with one article encouraging resistance to cultural subservience to the English-speaking world. 'Anglicizzazione' is mentioned in fewer than half the articles in the corpus, and is seen as a process requiring resistance, since incorporating English words into the Italian language attacks its purity, and the adoption of English generally encourages an exclusive, monolingual, and monocultural outlook; a few examples show a balanced attitude towards the process, recognizing that there are good reasons for publishing in English internationally. The third corpus, composed entirely of contributions provoked by the Polytechnic court case, understandably shows the highest frequency of both 'internazionalizzazione' and 'anglicizzazione'; while the first term is used without any noticeable positive or negative connotations, the second demonstrates a predominantly negative semantic prosody, describing the process as a threat needing to be braked or resisted, and a path taken and subsequently regretted by some countries. There is, however, admission of the fact that Englishization is a simple and fast way of opening universities up to the world. Both the INT-IT and CRUSCA corpora are directed at predominantly Italian audiences; the former was compiled through objective criteria and could in theory be for an international (Italianspeaking) audience, but the prosody of anglicizzazione is predominantly negative, as in the CRUSCA corpus, which fulfils expectations of negativity, given the circumstances it represents. 
Overall, the negative connotations of Englishization in these corpora are largely consistent with what has been reported in previous research, which frames it as a de facto monolingual and hegemonic process (e.g., Cots et al., 2012; Cots et al., 2014; Earls, 2013; Ives, 2006; Lanvers \& Hultgren, 2018a, b; Phillipson, 2006). The Italian understanding of internationalization as a wide-ranging phenomenon is also in line with the general paradigm: the focus on its enactments and on the various stakeholders here identified is also a feature of current definitions of internationalization (see De Wit et al., 2015; Hawawini, 2016). Whether, by rejecting Englishization's monolingual model, internationalization inherently comes to signify plurilingualism is not clearly established by the present analysis (and, indeed, see Kuteeva, 2020, for a discussion of 'wishful multilingualism'). Nonetheless, the differences in how Englishization and internationalization are construed in these corpora appear prominently and represent the main finding of the present study.

\section{Conclusions}

The present study aimed to investigate how 'internationalization' and 'Englishization' are conceptualized in research about Italian HE. To that end, academic publications both in Italian and English were analysed with a focus on the use of this terminology, its context, and its nuances. In this section, we provide answers to our original research questions to draw the conclusions of the study.

The investigations conducted here show that, across disciplines, the term 'internationalization' has no prevailing attitudinal undertones and, while its use appears firmly nestled in the context of education, its interpretation remains broad and connected to several indicators. On the contrary, 'Englishization' was shown to be associated with consistently negative semantic prosody, in fact never occurring in a positive light in any of the corpora. In line with what previous research brought to light (see section 3), when Englishization/ anglicization/anglicizzazione does appear in these corpora, it carries connotations of threat, problem, or injustice. This shows that internationalization and Englishization do not coincide in either meaning or use. Furthermore, their distribution was clearly different in the corpora, indicating that, most frequently, internationalization is not discussed in direct association with Englishization.

Overall, we conclude that, in light of its connotations, Englishization is not perceived as a desirable phenomenon in this context. This perception appears to have two nuances (in line with what originally noted for dictionary entries in both languages) investing both language and culture. Nonetheless, we remark that this stance is no indication of attitudes around internationalization itself, 
given the ascertained distinction between the two phenomena. It should be noted, however, that much like the simple introduction of English in education systems is not a reliable indicator of internationalization, similarly not all use of English should be connected to processes of Englishization and its negative connotations. Internationalization achieved through the medium of English can represent a bridge to other cultures and a way of making Italian academic culture more accessible to international audiences, rather than a threat to its identity (Maggioni \& Murphy, 2018). In the future, further research could productively focus on identifying ways in which this accessibility could be enhanced. Fortunately, as our results seem to indicate, internationalization is clearly understood by academics to be much more than Englishization, which is a trend that will hopefully become prevalent.

\section{Acknowledgement}

This chapter gained enormously from the peer-review process. The authors wish to thank the anonymous reviewers for engaging deeply and constructively with the first version of the chapter.

\section{References}

Ackerley, K., Guarda, M., \& Helm, F. (2017). Sharing perspectives on English-medium instruction. Peter Lang.

Airey, J., \& Linder, C. (2007). Disciplinary learning in a second language: A case study from university physics. In R. Wilkinson \& V. Zegers (Eds.), Researching content and language integration in higher education (pp. 161-171). Maastricht University Language Centre.

Aizawa, I., \& McKinley J. (2020). EMI challenges in Japan's internationalization of higher education. In H. Bowles \& A. C. Murphy (Eds.), English-medium instruction and the internationalization of universities (pp. 27-48). Palgrave Macmillan. DOI: 10.1007/978-3-030-47860-5_2

Anthony, L. (2020). AntConc (Version 3.5.9) [Computer Software]. Tokyo, Japan: Waseda University. Available from https://www.laurenceanthony.net/software

Baker, C. (1992). Attitudes and language. Multilingual Matters.

Brandenburg, U., \& de Wit, H. (2011). The end of internationalization. International Higher Education, 62, 15-17.

Broggini, S., \& Costa, F. (2017). A survey of English-medium instruction in Italian higher education. Journal of Immersion \& Content-Based Language Education, $5(2), 238-264$. 
Bull, T. (2012). Against the mainstream: Universities with an alternative language policy. International Journal of the Sociology of Language, 216, 55-73.

Cavadini, F. (2014, 29 July). Corsi in inglese, errore opporsi al TAR [Courses in English, opposing the TAR is a mistake]. Corriere della Sera.

Clark, C. (2018). The case of the non-native English speaker in EMI. Studi e ricerche, $13,563-576$.

Coleman, J. (2006). English-medium instruction in European higher education. Language Teaching, 39(1), 1-14.

Coluzzi, P. (2009). Endangered minority and regional languages ('Dialects'). Modern Italy, 14(1), 39-54.

Costa, F. (2017). English-medium instruction in Italian universities: If we're gonna do it do it right - right? In M. Guarda, F. Helm, \& K. Ackerley (Eds.), Sharing perspectives on English-medium instruction (pp. 77-94). Peter Lang.

Costa, F., \& Coleman, J. (2013). A survey of English-medium instruction in Italian higher education, International Journal of Bilingual Education and Bilingualism, 16(1), 3-19. DOI: 10.1080/13670050.2012.676621

Costa F., \& Mariotti C. (2017). Students' profiles and their reception of Englishmedium instruction in Italian universities, In C. Boggio \& A. Molino (Eds.), English in Italy: Linguistic, educational and professional challenges (pp. 160-181). Franco Angeli.

Costa, F., \& Mariotti C. (2020). EMI students' 'international coexistence' at one Italian university. In H. Bowles \& A. C. Murphy (Eds.), English-medium instruction and the internationalization of universities (pp. 229-258). Palgrave Macmillan. DOI: 10.1007/978-3-030-47860-5_10

Costa, F., \& Murphy, A. C. (2018). Supporting the switch to teaching international classes in tertiary education. In C. M. Coonan, A. Bier, \& E. Ballarin (Eds.), La didattica delle lingue nel nuovo millennio: le sfide dell'internazionalizzazione (pp. 599-613), Edizioni Ca' Foscari - Digital Publishing.

Cots, J. M., Lasagabaster, D., \& Garrett, P. (2012). Multilingual policies and practices of universities in three bilingual regions in Europe. International Journal of the Sociology of Language, 216, 7-32.

Cots, J. M., Llurda, E., \& Garrett, P. (2014). Language policies and practices in the internationalisation of higher education on the European margins: An introduction. Journal of Multilingual and Multicultural Development, 35(4), 311-317. DOI: 10.1080/01434632.2013.874430

De Mauro, T. (1991). Storia linguistica dell'Italia unita [Linguistic history of unified Italy]. Editori Laterza.

De Wit, H., Hunter, F., Howard, L., \& Egron-Polak, E. (2015). Internationalisation of higher education. European Parliament, Committee on Culture and 
Education. Retrieved from http://www. europarl.europa.eu/RegData/etudes/ STUD/2015/540370/IPOL_STU\%282015\%29540370_EN.pdf

Doiz, A., Costa, F., Lasagabaster, D., \& Mariotti, C. (2020). Linguistic demands and language assistance in EMI courses: What is the stance of Italian and Spanish undergraduates? Lingue e Linguaggio, 33, 69-85.

Earls, C. W. (2013). Setting the Catherine wheel in motion. Language Problems and Language Planning, 37(2), 125-150. DOI: 10.1075/lplp.37.2.02ear

Eberhard, D. M., Simons, G. F., \& Fennig, C. D. (Eds.) (2021). Ethnologue: Languages of the world. Twenty-fourth edition. SIL International. Retrieved ${ }_{15}$ February 2021 from http://www.ethnologue.com.ezp.sub.su.se.

Galloway, N., Numajiri, T., \& Rees, N. (2020). The 'internationalisation', or 'Englishisation', of higher education in East Asia. Higher Education, 8o(3), 395-414. DOI: 10.1007/s10734-019-00486-1

Guarda, M., \& Helm, F. (2017). 'I have discovered new teaching pathways': The link between language shift and teaching practice. International Journal of Bilingual Education and Bilingualism, 20(7), 897-913. DOI: 10.1080/13670050.2015.1125848

Haberland, H., \& Mortensen, J. (2012). Language variety, language hierarchy and language choice in the international university. International Journal of the Sociology of Language, 2, 1-6. DOI: 10.1515/ijsl-2012-0036

Hawawini, G. (2016). The internationalization of higher education and business schools. Springer.

Hunston, S. (2007). Semantic Prosody Revisited. International Journal of Corpus Linguistics, 12(2), 249-268.

Ives, P. (2006). 'Global English': Linguistic imperialism or practical lingua franca? Studies in Language and Capitalism, 1, 121-141.

Kaur, J. (2020). Using English for interaction in the EMI classroom: Experiences and challenges in a Malaysian public university. In H. Bowles \& A. C. Murphy (Eds.), English-medium instruction and the internationalization of universities (pp. 129-154). Palgrave Macmillan. DOI: 10.1007/978-3-030-47860-5_6

Klaassen, R. G. (2001). The international university curriculum: Challenges in English-medium engineering education [Doctoral dissertation, Technische Universiteit Delft].

Kuteeva, M. (2020). If not English, then what? Unpacking language hierarchies at university. In M. Kuteeva, K. Kaufhold, N. Hynninen (Eds.), Language perceptions and practices in multilingual universities (pp. 27-55). Palgrave Macmillan. DOI: 10.1007/978-3-030-38755-6_2

Kuteeva, M., \& Airey, J. (2014). Disciplinary differences in the use of English in higher education: Reflections on recent language policy developments. Higher Education, 67(5), 533-549. DOI: 10.1007/s10734-013-966o-6 
Kuwamura, A. (2018). The future of English-medium instruction in Japan. In A. Bradford \& H. Brown (Eds.), English-medium instruction in Japanese higher education (pp. 265-282). Multilingual Matters.

Lanvers, U., \& Hultgren, A. K. (2018a). The Englishization of European education: Foreword. European Journal of Language Policy, 10(1), 1-11.

Lanvers, U., \& Hultgren, A. K. (2018b). The Englishization of European education Concluding remarks. European Journal of Language Policy, 1o(1), 147-152. DOI: 10.3828/ejlp.2018.7

Law/Legge (1999, 20 December). 15 December 1999, n. 482. Norme in materia di tutela delle minoranze linguistiche storiche. (Italy). Gazzetta Ufficiale, (297). Retrieved 15 February 2021 from https://www.gazzettaufficiale.it/eli/ id/1999/12/20/099G0557/sg

Leask, B. (2015). Internationalizing the curriculum. Routledge.

Lueg, K. (2018). The internationalization of higher education in Europe: A discussion of English as a medium of instruction and its implication. Culture, Practice \& Europeanization, 3(1), 47-67.

Lueg, K., \& Lueg, R. (2015). Why do students choose English as a medium of instruction? A Bourdieusian perspective on the study strategies of non-native English speakers. Academy of Management Learning and Education, 14(1), 5-30. DOI: 10.5465/amle.2013.0009

Maggioni, M. L., \& Murphy, A. C. (2018). La lingua o le lingue inglesi oggi: strumento di egemonia culturale o ponte? [The English language or languages today: a means to cultural hegemony or bridge?] In G. Del Zanna (Ed.), La geopolitica e le lingue (pp. 33-44). Maggioli.

Maraschio, N., \& De Martino, D. (2013). Fuori l'italiano dall'università?: inglese, internazionalizzazione, politica linguistica [Exclude Italian from the University?: English, internationalization, language policy]. Laterza.

McArthur, T. (1992). The Oxford companion to the English language. Oxford University Press.

Ministerial Decree/Decreto Ministeriale (2004, 12 November). 22 October 2004, n. 270. Modifiche al regolamento recante norme concernenti l'autonomia didattica degli atenei, approvato con decreto del Ministro dell'università e della ricerca scientifica e tecnologica 3 novembre 1999, n. 509. (Italy). Gazzetta Ufficiale, (266). Retrieved 15 February 2021 from https://www.gazzettaufficiale.it/eli/ $\mathrm{id} / 2004 / 11 / 12 / 004 \mathrm{Go303} / \mathrm{sg}$

Molino, A., \& Campagna, S. (2014). English-mediated instruction in Italian universities: Conflicting views. Sociolinguistica, 28(1), 155-172. DOI: $10.1515 /$ soci-2014-0013 Murphy, A. C., \& Costa, F. (2018). Language and internationalization of the higher education curriculum. In P. Teixeira \& J. Shin (Eds.), Encyclopedia of 
international higher education systems and institutions (pp. 1961-1964). Springer. DOI: 10.1007/978-94-017-9553-1_223-1

Oxford English Dictionary (2021). Retrieved 15 February 2021 from www.oed.com Partington, A. (2004a). Corpora and discourse. A most congruous beast. In A. Partington, J. Morley, L. Haarman (Eds.), Corpora and Discourse (pp. 11-2o). Peter Lang.

Partington, A. (2004b). 'Utterly content in each other's company': Semantic prosody and semantic preference. International Journal of Corpus Linguistics, 9(1), 131-156.

Partington, A., Duguid, A., \& Taylor, C. (2013). Patterns and meanings in discourse: Theory and practice in corpus-assisted discourse studies (CADS). John Benjamins. Phillipson, R. (2006). English, a cuckoo in the European higher education nest of languages? European Journal of English Studies, 10(1), 13-32.

Pulcini, V., \& Campagna, S. (2015). Internationalisation and the EMI controversy in Italian higher education. In S. Dimova, A. K. Hultgren, \& C. Jensen (Eds.), English-medium instruction in European higher education (pp. 89-114). De Gruyter Mouton.

Romaine, S. (2015). The Pushmi-Pullyu of language policy and political economy. In T. Ricento (Ed.), Language policy and political economy (pp. 252-275). Oxford University Press.

Royal Decree/Decreto Regio (1933, 7 December). 31 August 1933, n. 1592. Approvazione del testo unico delle leggi sull'istruzione superiore. (Italy). Gazzetta Ufficiale, (283), 1-156.

Santulli, F. (2015). English in Italian universities: The language policy of PoliMi from theory to practice. In S. Dimova, A. K. Hultgren, \& C. Jensen (Eds.), Englishmedium instruction in European higher education (pp. 269-9o). De Gruyter Mouton.

Sinclair, J. (1996). The search for units of meaning, Textus, 9(1), 75-106.

Sinclair, J. (1991). Corpus, concordance, collocation. Oxford University Press.

Thompson, G., \& Hunston, S. (2006). System and corpus: Two traditions with a common ground. In G. Thompson \& S. Hunston (Eds.), System and corpus: Exploring connections (pp. 1-14). Equinox Publishing.

Tira, M. (2021). Introductory remarks at 'La formazione linguistica quale veicolo di internazionalizzazione degli atenei italiani' [Language education as a vehicle for the internationalization of Italian universities], Conference held online at Università di Venezia Ca' Foscari, 25-26 February 2021.

Tosi, A. (2004). The language situation in Italy. Current Issues in Language Planning, 5(3), 247-335, DOI: 10.1080/14664200408668259

Treccani (n.d.). Retrieved 15 February 2021 from www.treccani.it/vocabolario

Tsuneyoshi, R. (2005). Internationalization strategies in Japan.Journal of Research in International Education, 4(1), 65-86. 
Wang, Y. (2020). The role of English in higher education internationalisation: Language ideologies on EMI programmes in China. In H. Bowles \& A. C. Murphy (Eds.), English-medium instruction and the internationalization of universities (pp. 103-128). Palgrave Macmillan. DOI: 10.1007/978-3-030-47860-5_5

Wächter, B., \& Maiworm, F. (2008). English-taught programmes in European higher education. The picture in 2007. Lemmens.

Wächter, B., \& Maiworm, F. (2014).English-taught programmes in European higher education: The state of play in 2014. Lemmens.

\section{About the authors}

AmAnda C. MurPhy, PhD is Professor of English language at Università Cattolica del Sacro Cuore, Italy. Her interests include corpus-related analyses of language, English as a medium of instruction and the internationalization of higher education. She is the co-editor (with Hugo Bowles) of English-medium Instruction and the Internationalization of Universities (Palgrave 2020).

BEATrice ZuAro is a PhD candidate at the Department of English of Stockholm University. Her PhD project is an investigation of English-medium Instruction (EMI), specializing in the context of Italian Higher Education. Her main research interests encompass language policy and language ideologies, EMI and academic discourse in general. 


\title{
9 The place of English in the Russian higher education landscape
}

\author{
Elena Belyaeva, Lyudmila Kuznetsova, Olga Nikiforova, and \\ Svetlana Suchkova
}

\begin{abstract}
The dissemination of English and the role it plays in Russian higher education are connected with its internationalization - a process that has been gaining momentum over recent decades spurred by a number of top-down and bottom-up initiatives. The role of English in university teaching and research is illustrated by the analysis of open access data on two leading Russian universities and the findings of a survey of teaching staff's perceptions of English in academia. The views of some other stakeholders have been collected from the existing publications on the topic. The term Englishization is inappropriate to describe the Russian context because the use of English in Russian academia is not as far-reaching as the term implies.
\end{abstract}

Keywords: Russian higher education, internationalization, state policy, EMI, university lecturers' challenges, English for research publishing purposes

\section{Introduction}

While there is a considerable body of literature on Englishization and the use of English as a medium of instruction (EMI) in the sphere of education in Europe (Airey, 2020; Airey et al., 2015; Earls, 2016; Kirkpatrick, 2011; Lanvers \& Hultgren, 2018; Macaro et al., 2018, to name but a few), little can be found on the spread of English in Russian higher education (Smolentseva et al., 2018; Trent, 2020). The reasons for this could be the slower process of education internationalization and lower rate of international publication activity of

Wilkinson, Robert, and René Gabriëls (eds), The Englishization of Higher Education in Europe. Amsterdam, Amsterdam University Press 2021 DOI: $10.5117 / 9789463727358 \_$CHo9 
Russian researchers. However, it can also be viewed as an indication of the fact that the increasing dispersion of English as a means of communication - i.e., Englishization - is not such a burning issue in Russia as in some countries of Europe (Gabriëls \& Wilkinson, 2020; Phillipson, 2015; Salomone, 2018; Selvi, 2020).

Russian researchers do note the increasing use of English in education and science (Kurgansky, 2018; Panova, 2018; Zhura \& Rudova, 2017). However, those are Russian linguists who use the term Anglicization (the analogue of Englishization) specifically to describe the influence of English on the Russian language - the penetration of English language elements, such as morphemes, lexical units, and spelling (Boiko, 2014; Bondarenko, 2019; Kushnareva, 2016). In addition, the term Globanglization (Глобанглизация) has been coined to refer to the spread of English and its influence on local languages in the world (Chistova, 2014). The linguists using these terms express concern about the influx of borrowings into the Russian language and culture and the implications it carries for the national identity. Some Russian politicians also share these sentiments (Matvienko, 2015).

We would like to abstain from using the term Englishization, one of the reasons being that Englishization is not part of the professional jargon of Russian educators. In discussions regarding the spread of English in Russian higher education, the most commonly applied terms are internationalization and EMI. There are many facets to internationalization in higher education (HE), provoking ongoing polemics among researchers around the globe (de Wit, 2019; Knight, 2013; Stukalova et al., 2015; Wu \& Zha, 2018). Authors look at this process from different perspectives, their critiques ranging from highly positive to negative (Wihlborg \& Robson, 2018). Distinction is made between such strategies as inbound and outbound, internal and external internationalization, or internationalization abroad and at home (Beelen \& Jones, 2015; de Wit, 2019; Robson et al., 2018; Wu \& Zha, 2018). For the purposes of this paper, we have chosen a general and neutral definition of internationalization viewed as 'the variety of policies and programmes that universities and governments implement to respond to globalization' (Altbach et al., 2009, p. 7). The chapter focuses on certain state policies to make Russian higher education visible globally and steps taken by universities in this direction, one of which is introducing EMI in their educational programmes. The attitudes to these developments of some micro-level stakeholders will also be discussed. 
In this chapter, we seek to provide answers to the following major questions:

1 What forces are behind the spread of English in Russian academia?

2 How much is the English language in demand at Russian universities?

3 What are Russian academics' practices and attitudes to EMI?

We will first provide some background information about the 'mountains' in the Russian higher education landscape, that is, the state policies in this sphere. Then, narrowing the focus, we will centre attention on two of the landscape 'hills' - the universities which are ranked highest among Russian higher education institutions (HEIs): their practices with regard to internationalization and EMI, and academics' opinions about these practices. Further, our general observations of what processes are in motion in Russia, and how they compare with the global trends, will be followed by an invitation to look beyond Englishization.

\section{Some macro-level developments}

From the macro-level perspective, we will confine ourselves to a brief discussion of the Russian state policy of internationalization in the sphere of education. This process has recently been gaining momentum in Russian higher education. However, as the existing statistics indicate, even before the formation of the European Higher Education Area in the 1990s, the USSR was the third after the USA and France in the number of international students in its HEIs (King et al., 2010; quoted in Frumina \& West, 2012, p. 12). The share of international students in Soviet universities constituted $10.8 \%$ of the global total (Patsukevich, 2019). The absolute majority of those students were from the countries of Eastern Europe or developing countries of Asia, Africa, and Latin America who were to learn the Russian language before entering their study programmes. These numbers dropped in the 199os after the disintegration of the Soviet Union and discontinuation of state support of university internationalization programmes.

Since that time, there has been a range of significant changes to the Russian Federation policy in the sphere of higher education. These are:

- its marketization - the emergence of private institutions and fee-paying tuition;

- Russia joining the Bologna process in 2003, which entailed the introduction of bachelor's and master's degree programmes (instead of the 
previous five-year 'specialist' degrees) and the European system of credits;

- $\quad$ rapidly growing academic mobility of students, professors, and researchers (Smolentseva et al., 2018).

Between the 1990s and the first decade of the 21st century, staff and student mobility was to a large extent supported by grants provided by various international organizations, such as the European Erasmus programme, a number of American foundations and societies, and the British Council (Frumina \& West, 2012). The latter and the English Language Office of the American Embassy also supported projects aimed at improving the quality of teaching English at Russian schools and universities. The more recent development is that of universities themselves seeking cooperation and establishing partnerships with HEIs from around the globe.

Although 'Russian HEIs were slow to move towards internationalization of research programs on the same scale as universities in the rest of the world' (Frumina \& West, 2012, p. 15), the competition of universities for higher places in the world rankings, where internationally published research plays a significant role, contributed to the spread of English in Russian academia. To stimulate the publication activity of their research and teaching staff, universities have introduced 'carrots' and 'sticks' - offering bonuses for articles appearing in the Web of Science and Scopus indexed journals and adding in academic staff labour contracts the requirement to annually publish research articles, preferably in reputed international editions (Karmaeva, 2018).

Starting in 2006, the Ministry of Education and Science and the central government implemented a series of reforms intended to re-energize universities' research by supplying subsidies to leading HEIs, by supporting the creation of a group of national research universities in 2008, and by launching in 2013 the Russian Academic Excellence project '5-100' (Dezhina, 2020). The aim of the ' 5 -100' project was to raise international competitiveness of the selected 21 universities, mainly by increasing their publication activity and international research collaboration. ${ }^{1}$ Five of the participating HEIs were expected to enter the list of the world's top 100 universities by the year 2020 (Guskov et al., 2018). The government funding infusion resulted in the rapid development of their research base and international partnerships,

1 Project 5-100 had a highly positive impact on the publication activity and process of internationalization in the participating universities. However, none of them entered the Top 100 of the three world rankings - QS, THE and AURWU (Zhang He, 2020, p. 22) 
leading to exponential growth in their publication output. Universities not included in the ' 5 -100' project also demonstrated a significant increase in the number of academic publications in English (Matveeva et al., 2021). Such measures could not but lead to the rise of English as the lingua franca of research communication in Russia. Most of the '5-100' project universities opened writing centres for their staff and students, to support their publication activity. By 2018, the number of university writing centres reached 15 (Bazanova \& Korotkina, 2017).

The most recent top-down initiative in Russian higher education is the Strategic Academic Leadership Programme announced by the government in summer 2020 (PSAL, 2020). Its stated aim is to support Russian HEIs, enabling them to advance in training highly professional cadre for the national economy and social sphere. According to the Programme, by the year 2030 the Russian Federation should be among the world top 10 countries - leaders in research and development, information technology, and key economic and social indicators. For these purposes, grant support will be given to more than 120 Russian HEIs.

\section{Narrowing the focus}

Currently there are around 720 HEIs in the Russian Federation; more than $55^{\circ}$ of them are located in the European part of the country. The general student cohort is about 4.2 million (Malkov, 2020). After joining the Bologna process, Russian universities underwent a period of turmoil in attempts to adjust and adapt to the internationalization demands. At the institutional (meso) level most Russian HEIs have been struggling to win a higher position in the international university rankings. They are obliged to search for partnerships with universities outside Russia to launch or join international research projects, to increase the number of publications in highly ranked academic journals, to facilitate academic mobility of students and staff, and to increase the number of programmes and courses taught through English in order to attract more international students. The above-mentioned challenges require a sufficient level of the English language proficiency, and thus English has become a 'perceived need'. As English is acquiring its status of the academic lingua franca (Seidlhofer, 2005), Russian university lecturers, researchers, and students start to realize the importance of English in fulfilling their academic and professional needs (Belyaeva \& Kuznetsova, 2018). 
So far there are few Russian universities in some of the top world rankings: Moscow State University, St Petersburg University, Higher School of Economics, Novosibirsk State University, and Tomsk Polytechnic University (Webometrics, 2020 July). From this list, we have selected two universities, St Petersburg University (SPbU) and Higher School of Economics (HSE University), to present a closer look at their institutional policies regarding internationalization and the use of English in their teaching and research practice. By analysing the activity of these two institutions with different histories but similar international recognition, we would like to highlight some characteristics pertaining to their internationalization and EMI policies (Table 9.1).

St Petersburg University (SPbU) possesses a special status as a Federal university, which gives it the right to develop its own educational standards and to confer its own doctoral degrees. SPbU has mostly specialized in teaching and conducting fundamental research in science and humanities. Higher School of Economics (HSE University) is considered to be one of the prominent economics and social sciences universities in Eastern Europe and Eurasia. It is consistently ranked as one of Russia's top universities.

\section{Table 9.1 SPbU and HSE in numbers}

\begin{tabular}{lcc}
\hline & $\begin{array}{c}\text { SPbU } \\
\text { founded in 1724 }\end{array}$ & $\begin{array}{c}\text { HSE University } \\
\text { founded in 1992 }\end{array}$ \\
\hline Overall number of students & $30,000+$ & $44,100+$ \\
Percent of international students (2018-2019) & $0.5 \%$ & (all campuses) 6.37\% \\
Overall number of teaching staff and researchers & 12,000 & 7,000 \\
Number of international faculty and researchers & $10 \%$ & $10.6 \%$ \\
(\% of the total) & & \\
Total of degree programmes & 421 & 278 \\
English-taught degree programmes & 15 & 765 \\
Cooperation agreements (2019) & 485 & 618 \\
Staff mobility (2019): Outbound & 240 & 782 \\
Inbound & 237 & 18,869 \\
Publications in Scopus journals (2016-2019) & 16,635 & \\
\hline
\end{tabular}

Source: https://www.hse.ru/en/figures/; https://spbu.ru/sites/default/files/

As can be seen from the figures in Table 9.1, both universities are highly active in developing international cooperation, concluding partnership agreements with universities abroad and publishing research in internationally recognized journals. Retrospectively, it should be noted that HSE University's participation in the government-supported ' 5 -100' project gave a 
powerful impetus for the institution to develop. The statistics demonstrate that in the year 2006 HSE University had 43 agreements with institutions outside Russia, their number rocketing to 765 in 2019. Significant differences between the two universities can be seen in the figures related to staff and student mobility and English-taught degree programmes. This can be accounted for by the weight of the long-standing traditions in SPbU's administration and structure compared to a younger, more dynamic HSE University.

HSE University was the first university in Russia to open an Academic Writing Centre in 2011. It provides HSE University staff with assistance in preparing publications and conference presentations in English by organizing training courses, seminars, tutorials, and individual consultations. The Centre also helps in developing materials for EMI programmes (https:// academics.hse.ru/en/awc/). SPbU does not have a centre like this as part of its structure, though its library regularly holds webinars on writing for publication for its staff, and its lecturers can take a professional development course in EMI organized each academic year.

In general, these figures demonstrate that:

- high priority governmental projects, offering considerable financial support, are very effective in stimulating Russian universities to internationalize, thus promoting the use of the English language in their administrative and academic departments;

- a traditional classical university, though determined to compete with other HEIs for higher places in the world rankings, may be less prepared to respond to the challenges that globalization in the sphere of higher education puts before it.

Compared with statistics from many universities in Europe (Airey et al., 2015; Gabriëls \& Wilkinson, 2020; Airey \& Kuteeva, 2014), these data expressly demonstrate that even the 'highest hills' in the Russian HE landscape are much lower than their European counterparts in terms of internationalization and use of English. According to the Organization for Economic Cooperation and Development (OECD, 2016), regarding higher education, Russia is far behind such countries as the Netherlands, Switzerland, Belgium, and Austria with regard to the internationalization of its university education. Thus, where there are few international students and teaching staff, and the number of English-taught courses in the highest-ranking universities does not exceed $6 \%$, we can hardly describe the process of the spread of English in Russian HE as Englishization. 


\section{Internationalization of university teaching and research: Voices from the field}

To identify the current trends in the internationalization of teaching and research in Russian HEIs, from October to November 2020 we conducted an online sociological survey through social networks and emailing. We used the 'snowball' method: colleagues, having received the questionnaire, distributed it to their professional contacts. The questionnaire consisted of 31 multiple-choice questions. We divided them into three blocks: (1) general information about respondents, (2) motivation for using EMI and challenges they meet, (3) motivation and challenges of using English for research publication purposes. The major goals were to identify the role of English in Russian universities and academics' perceptions of English in professional contexts.

\subsection{Respondents}

The respondents are 303 Russian-speaking academics. Representatives of St Petersburg University and Higher School of Economics comprise about $22 \%$ and $45 \%$ of respondents respectively. In addition, lecturers from some Russian regional universities make up about one-third of the total number.

The academics' discipline profiles are diverse. Almost half of the whole dataset are linguists and language teachers (47\%). The next group $(23 \%)$ we labelled 'social scientists' included sociologists, political scientists, philosophers, historians, and journalists. Specialists in economics and business management comprise $20 \%$ of the total, and $10 \%$ represent the fields of science and technology.

In terms of their degrees, $56 \%$ of respondents hold the Candidate of Science degree, ${ }^{2}$ about $15 \%$ are Doctors of Science, ${ }^{3} 6 \%$ are $\mathrm{PhD}$ holders from overseas universities; a little over $22 \%$ are bachelor's and master's degree holders. The basis of the sample are professors and assistant professors (67\%), of whom about $11 \%$ are researchers and just above $5 \%$ are junior lecturers.

To the question about the way they acquired English language skills, our respondents replied that they had:

- $\quad$ attended free professional development courses at the university of employment (34\%);

- learned English at a secondary language school (32\%);

2 The Candidate of Science degree is a Russian equivalent of $\mathrm{PhD}$.

3 Doctor of Science is the highest research degree in Russia, which is awarded in recognition of further achievements in research after the Candidate of Science degree. 
- attended fee paying courses of English outside the university (31\%);

- graduated from a pedagogical university with a major in teaching English $(28 \%)$;

- graduated from a university abroad (17\%);

- studied on EMI programmes in a Russian university (15\%);

- learned English on their own (8\%).

Despite the limitations of the method, voluntary participation and limited university representation, snowballing sampling allows to analyse whether the major trends characteristic of the two leading universities can be traced in other universities, too. Assuming that dominant trends emerge in leading universities, we first analysed responses of the representatives of the two universities (SPbU and HSE) and then those of some other regional universities.

\subsection{Lecturers' perception of English}

The vast majority of academics consider English to be very important for their career growth. We found that $90.4 \%$ of all survey respondents agree that a university teacher needs to be proficient in English. Proficiency in English is seen as an instrument serviceable in many spheres of their professional life: research publications $(92 \%)$, teaching $(77 \%)$, applying for international grants $(75 \%)$, cross-cultural communication, internships, reading, paperwork, and so on.

Respondents, who could choose more than a single answer, stated that English:

- contributes to international communication with colleagues ${ }^{4}(27 \%$ : $7 \% / 20 \%)$;

- is required by the employer to be part of the staff (22\%: $15 \% / 7 \%)$;

- is a condition for financial bonuses from the employer (22\%: $15 \% / 7 \%)$;

- provides opportunities for international internships and exchanges (17\%: 10\% / 7\%);

- increases the chances for receiving international grants and participation in international studies (15\%: $10 \% / 5 \%)$;

- offers an opportunity for career growth within the university $(12 \%$ : $7.5 \%$ / $4.5 \%) ;$

- may lead to further employment abroad (10\%: $9 \% / 1 \%)$.

4 Here and throughout this section, the percentages are given for the total data set first, then for the leading universities, and then for regional universities. 
Additionally, about $30 \%$ of all respondents associate English with a hobby or a source of positive emotions and highlight its use in leisure pursuits: travelling, watching films, reading books, communicating with foreign friends, and so on.

\subsection{English for teaching}

The majority of those surveyed (67\%) currently teach their courses in English, among them $55 \%$ are from the leading universities. Interestingly, two-thirds of the remaining $33 \%$ - those who have no experience in EMI - would like to do it when the opportunity arises. These are mainly representatives of the leading universities $(89 \%)$.

To the question about the necessity for EMI lecturers to have a language certificate, $45 \%$ are in favour of international exams certificates; $27 \%$ choose course completion certificates, but $23 \%$ see no value in any kind of formal certification.

We traced two key trends in delivering EMI at the university level. On the one hand, teaching in English is traditionally the domain of linguists, philologists, and language teachers. Such respondents make up about $35 \%$ : $10 \% / 25 \%$. Some of them start teaching discipline courses in English. On the other hand, we found that over the past three years the number of nonlinguists delivering EMI courses has increased dramatically. Having taught in academia for a long time, nearly $40 \%$ of experienced faculty reported that they had started teaching their disciplines in English less than three years ago in response to institutional demands.

Respondents agree that it is the university that is more interested in the increase in the number of EMI courses than academics themselves ( $61 \%$ total, with $38 \%$ of responses coming from the leading universities). Mostly, academics teach courses in English to either Russian students $(29 \%$ : 9.5\% / 19.5\%) or mixed audiences who know Russian (48\%: $31 \% / 17 \%)$. Only $12 \%$ of all respondents state that they teach EMI courses in groups of international students who do not know Russian. In general, academics think that not all disciplines should be delivered in English, ${ }^{5}$ considering Russian-taught courses more effective ( $79 \%: 52 \% / 27 \%)$. This is to a certain extent connected with students' ability to master subjects taught in English.

5 In respondents' opinions, Russia-specific courses, e.g., Russian Literature, Russian Legislation, Russian Culture do not lend themselves to being taught in English. EMI courses included Business and Management, Economics and Social Sciences, followed shortly by IT, STEM (science, technology, engineering, and mathematics) disciplines. 
Among the challenges they face delivering courses in English, respondents mention:

- students' low level of English, which makes classes ineffective (47\%: $27 \%$ / $20 \%)$;

- their own level of English, which does not allow them to teach as successfully as in Russian ( $28 \%: 22 \%$ / 6\%);

- lack of time to update the course with new resources and materials in English (24\%: 14\% / 10\%);

- insufficient teaching skills - i.e., lack of methodology, techniques, and tools for teaching the course in English (15\%: 14\% / 1\%);

- lack of relevant literature in English (8\%: 4\% / 4\%).

\subsection{English for publications}

Having analysed the data regarding academics' publication activity, we obtained the following results. To the question 'Do you write research articles for publication in English?' the overwhelming majority (88\%: 61\% / 27\%) answered 'yes'. One-third of respondents publish articles in local journals included in Russian databases. Respondents mainly focus on research article genre; only $23 \%$ of them write monographs. Many academics aim at high-ranking journals indexed in Scopus and Web of Science (62\%: $51 \% / 11 \%)$, with about $45 \%$ trying to target the first and second journal quartiles; these figures for the leading and regional universities speak for themselves $-40 \%$ and $5 \%$ respectively.

Among the motivation factors that stimulate their publication activity in English, academics indicate that publishing in English:

- is treated as a more significant contribution to the research community ( $55 \%$ : $41.5 \%$ / $13.5 \%)$;

- means increased visibility and readership (40\%: $35 \%$ / 5\%);

- gives financial bonuses which make academics interested in publishing in English rather than in Russian (39\%: $28 \%$ / 11\%);

- realizes their ambition to contribute to world science (30\%: $23 \% / 7 \%)$;

- enables them to rise in scientists' ratings (30\%: $22 \%$ / 8\%);

- is part of the labour contract, which is considered a burden (24\%: $17 \%$ $17 \%)$;

- is a requirement for grant applications (19\%: 14.5\% / 4.5\%).

Some researchers like to write in English, as it is easier for them (11\%: 8\% / $3 \%)$, mainly language teachers. 


\section{Figure 9.1 Barriers to publishing research in English}

\section{Barriers to publishing research in English}

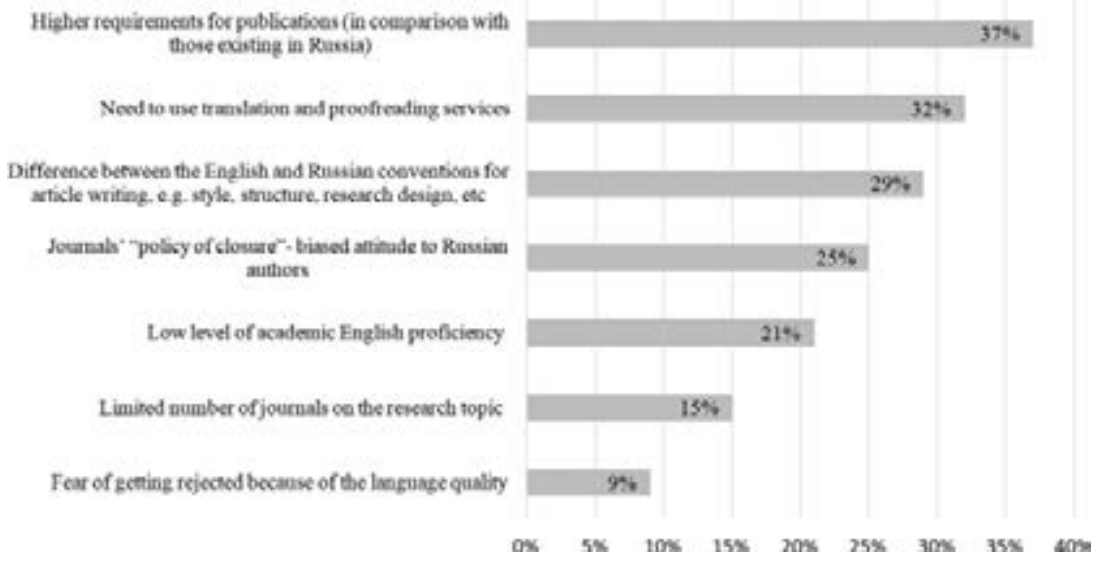

Being motivated, Russian academics, however, face serious difficulties in publishing papers in English, among which they name insufficient level of their language skills and the need to seek the help of translators or English native speakers, cultural differences in requirements and conventions for academic texts, and editors' prejudiced attitude to non-native authors (see Figure 9.1).

To cope with the challenges of writing for publication in English, Russian authors employ different strategies. Some researchers prefer to write with co-authors who are native speakers of English or foreigners who have better command of the language (16\%). Others seek editing help from an English native speaker (36\%) or translate Russian texts into English with the help of colleagues or translation agencies ( $9 \%)$. Some $(15 \%)$ use translation software - the practice which may become increasingly widespread with the further development of information technology. About a third of respondents (31\%), presumably members of HSE University staff, indicate that their universities' Academic Writing Centres provide assistance with preparing articles in English.

\subsection{Suggestions for academics' support}

More than half of the academics (57\%) think that this is the university's responsibility to help employees to master the English language, while $21 \%$ hold the opposite opinion. These autonomous writers $(26 \%)$ are ready to develop their English skills on their own, whereas $49 \%$ will be motivated to learn English only if they are financially stimulated. Respondents would 
appreciate university support performed by means of reducing teaching workload to enable them to develop professionally (57\%); providing methodology courses to help them to teach them in English (57\%); toughening entry requirements for students enrolling on EMI courses (33\%); offering writing for publication courses $(57 \%)$ to overcome the existing barriers to publishing research in English. Short-term training in preparing articles for international journals is also a popular option favoured by $55 \%$ of respondents. Next in popularity come workshops on publication-related topics and meetings with editors - these were chosen by $41 \%$. However, some respondents (12\%) think that Russian researchers favour publishing their research in Russian and would not be motivated to resort to English. In general, about $75 \%$ of university lecturers surveyed mention excessive teaching load and lack of time as the major factors that prevent them from engaging with English development programmes.

More than 300 academics' voices offer revealing insights into the perception of English in Russian academia. Despite the convenience sampling, the survey results demonstrate that the trends, which are traceable for the leading universities, can be observed in regional universities, too. Although our research has obvious limitations, such as the study of just two universities' policies with regard to internationalization and use of English, and the selection of a single group of stakeholders - university lecturers - to explore their perceptions of English in Russian academia, we were able to collect information which can be extrapolated to the analysis of broader contexts. The critical evaluation of the data we obtained was supplemented by information collected from publications by other Russian authors.

\section{Discussion}

Returning to our metaphor of the Russian HE landscape and the questions we have sought to answer, the discussion will unfold around them. It is quite clear that gale-force winds blowing from the lands outside Russia cannot but affect the HE landscape of the country, which seeks to prove to the world that its education and science can rank alongside with the leaders in this sphere. Internationalization of Russian HE and science remains on the agenda of the state policy ${ }^{6}$ and, accordingly, enters universities' development plans and encourages wider use of English.

6 Presidential decree on the national development goals of the Russian Federation until 2030 of July 21, 2020, section 2-b; http://www.kremlin.ru/events/president/news/63728 
If we look back to 1887, Lazar Zamenhof, a resident of the Russian empire, published a book launching an artificial language called Esperanto, which was intended to 'tear down the linguistic barriers between diverse peoples' (O'Keeffe, 2019, p. 1). It so happened that in the century that followed, not a constructed language but English became the lingua franca of the globalizing world - the language of communication across borders and distances. This was to the advantage of those 370 million L1 speakers of English, as well as to the estimated 970 million who speak it as an L2. ${ }^{7}$ In total, they make up 14\% of the world's population. Its advantage for those who speak other languages is that they have the stimulus for personal growth - mastering a foreign language and learning about such things as intercultural communication, etiquette, culture of English-speaking nations, and the ability to explore the enormous informational resources on the internet bringing significant added value to those who have mastered English.

However, as Mortensen (2014, p. 425) points out, 'the widespread belief that university internationalization equals the exclusive use of English is at odds with empirical facts.' This fully accords with the facts reflecting the situation in Russian HE. According to the Statistical Digest published in 2016, in the academic year 2014/15, 54\% of all international students in Russian HEIs came from the former republics of the Soviet Union (Arefiev \& Sheregi, 2016). Stukalova et al. (2015) gives an even higher figure: more than $70 \%$ of international students were Russian speakers or ethnic Russians mostly from Kazakhstan, Belarus, and Uzbekistan. SPbU's internal documents contain the following data: in the year 2019, there were 848 international students of whom only 96 (11.3\%) were studying on EMI programmes. The general situation in Russian HEIs is that students from other countries come to Russia with the aim to study and practise Russian, not English. Thus, even in the centrally located largest universities, the majority of international students come either to study the Russian language and culture or take special subject courses where Russian is the language of instruction.

The results of our survey of micro-level stakeholders - university professors - demonstrate that they consider English both as a powerful tool in their career growth and an obligation imposed by the employer. These results are in line with the survey conducted in HSE University in 2018, which showed that $35 \%$ of 699 HSE faculty referred to teaching their academic subjects in English as an important part of their professional development (HSE University, 2020a). 
Recognizing the importance of English for their careers, subject lecturers, however, face certain challenges with introducing EMI courses and require university support to enhance their English language proficiency and teaching methodology, which some universities may be unable to organize. These challenges are matched by the experience in some other countries. As has been demonstrated by this research and some earlier studies on the role of English in teaching (Belyaeva \& Kuznetsova, 2018; Dearden \& Macaro, 2016; Lourenço \& Pinto, 2019; Macaro, 2019), a discouraging factor for EMI teachers is the insufficient English competence of students enrolled on EMI courses, which does not allow learners to master content complexity. In the ideal world, ICLHE (Integrated Language and Content in Higher Education) could be the most effective way to prepare and conduct subject-specific courses in English. This approach means the involvement of language specialists in syllabus design and course delivery, and team teaching (Gustafsson \& Jacobs, 2013). But this might require system restructuring and resources, in most cases, beyond Russian universities' budgets.

The overall positive attitude of lecturers to the use of English in higher education is not altogether shared by students in Russian HEIs. A number of authors have done research into the level of motivation to learn foreign languages (most commonly English) among students of non-linguistic disciplines. Some researchers describe their motivation level as high (Kaznacheyeva \& Bondarenko, 2016; Khristolyubova, 2017), some others - as moderate or low (Mineyeva \& Liashenko, 2018; Olifirenko, 2019; Tsalikova \& Pahotina, 2015). These studies were conducted in different institutions and cities - Moscow, Nizhny Novgorod, Saint-Petersburg, Tambov, in total involving about 1,00o students. Though dissimilar, one of the authors' main conclusions was that the major factor motivating students - future pharmacists, engineers, economists, managers - consisted in the role a foreign language played in their professional development and future careers. Some of the findings clearly indicate that students' motivation grows towards the end of study in HEIs, when their exposure to the language is wider (Kaznacheyeva \& Bondarenko, 2016; Khistolyubova, 2017).

The sphere in which the spread of English in Russian HE might be described as Englishization is Russian academics' publication activity. Our study has demonstrated that universities, in the race for higher ratings, encourage English-medium publications, financial stimuli being one of the major driving forces in this process. As a result, Russian academics' publishing in English is gaining momentum (Matveeva et al., 2021). Consistent top-down incentive measures lead to an increase in international publication rates. As our survey has demonstrated, Russian researchers 
themselves are also inspired by the prospects of making their findings known to broader circles of specialists worldwide. They are prepared to invest their time in learning or upgrading their English, and to prove its level by taking international tests in the language. We have found no evidence to suggest that academics in Russian universities are threatened by the dominance of English-speaking nations, or that they are concerned about 'linguistic imperialism' (Phillipson, 1992). The reverse is true: both lecturers and researchers appear to be pragmatic and tend to recognize opportunities brought by English, particularly in the domain of research publications.

Significant as the recent progress in Russian researchers' publication activity in English may seem, many more scientific publications appear in the country in its native language. According to eLibrary's statistics (eLibrary, n.d.), early in 2021 there were 69,643 academic journals published all over Russia. However, out of 29,411 titles included into the Russian Science Citation Index (RSCI) and out of 3,241 titles accredited by the State Academic Board, there are only 625 Scopus-indexed and 803 Web of Science-indexed Russian journals, which is a modest share. This statistical evidence reinforces the claim that the Russian language remains the leading language for research publications on the territory of the Russian Federation.

There is one other detail characteristic of the landscape we are describing, which deserves mentioning here - the fact that both universities under study have a number of degree programmes and individual courses taught in languages other than English: German, French, Spanish, Italian, Chinese, and Japanese (HSE University, 202ob; St Petersburg University, 2019). The influence of the Chinese language spoken by $18 \%$ of the world population has been growing slowly but steadily (Gil, 2017) in Russia, too. As reported by the media, Chinese has recently been increasing its presence in Russian HE, taught in more than 180 universities (RIA News, 2019). It is coupled with the growing inflow of Chinese students entering undergraduate and graduate programmes taught in English or Russian. According to the Russian Ministry of Education, between 2007 and 2017 the number of Chinese students in Russian HEIs almost doubled from 13,639 to 26,775 people (Ministry of Education and Science of the Russian Federation, 2018). The growing popularity of Chinese culture and language in Russian society was reflected in the results of an opinion poll conducted recently by the All-Russia Public Opinion Research Centre VCIOM. It was found that $93 \%$ of Russians consider it 'important and useful to learn English', 43\% named Chinese, and $32 \%$ favoured German (VCIOM, 2019). Although Russians 
predominantly value English as the language of international communication, modern global processes may shift the balance in a different direction in years to come.

In our estimation, further developments in computer technology and more specifically, translation software, may condemn to oblivion whatever threat Englishization poses to other languages and cultures. So far there has been little research done into the application of fast developing translation programs in human communication and teaching (Austermuehl, 2013; Dmitrichenkova et al., 2017). However, the recent decades have vividly demonstrated how fast information technology can develop, its products promptly entering our everyday lives. In the near future, whether teachers of foreign languages like it or not, academic subjects might come to be taught in any language and to multilingual audiences, their understanding of the subject matter facilitated by interpreting programs in their cell phones.

\section{Conclusions}

There is still a long way to go to achieve coherence between the national and institutional policies in Russian HE. At the national level, Englishization in Russia has taken the guise of internationalization of higher education that has largely been introduced in a top-down fashion through government acts as well as national projects and initiatives in higher education. The internationalization of Russian HE is primarily aimed at the export promotion of Russian universities and at raising national reputation on the global higher education arena.

Being facilitated by the worldwide trends like globalization and internationalization of scientifıc knowledge, yet higher education in Russia nowadays cannot claim to be becoming bilingual or multilingual. The Russian language clearly remains the prevailing medium of instruction among the local students and among the 'internally international' students as well. The growing numbers of external international students are currently not sufficient to secure for the English language the status of the medium of instruction in higher education in Russia. This is due to the fact that the quantity and quality of EMI clearly depend on the institutional policies that have not been sustainable.

The biggest numbers of EMI (be that double degree programmes or programmes and courses taught in English) are strongly associated with the leading HEIs with extra special privileges and funding. While there is some 
evidence that English is slowly but steadily acquiring the status of a medium of instruction in higher education in the European part of Russia, there is still little evidence to suggest that the other territories of the Russian Federation will be following this tendency, with Chinese becoming more popular in the Far East.

At the micro level, according to the survey discussed above, EMI enjoys generally positive attitude of Russian academics; however, the relatively low number of EMI programmes indicates insufficient English language proficiency among university teachers.

Publishing activity in English has been steadily growing all over the country regardless of HEI status or geographical location. The top-down approach both at national and institutional level is also facilitated by both intrinsic and extrinsic motivation of university faculty at a micro level.

To conclude, English in Russian higher education has established itself as the language of academic publications while the phenomenon of English as a medium of instruction is growing at a moderate rate. There is no convincing evidence of any widespread concerns among Russian academics or any public debate with the English language in focus.

\section{References}

Airey, J. (2020). The content lecturer and English-medium instruction (EMI): Epilogue to the special issue on EMI in higher education. International Journal of Bilingual Education and Bilingualism, 23(3), 340-346. DOI: 10.1080/13670050.2020.1732290

Airey, J., \& Kuteeva, M. (2014). Disciplinary differences in the use of English in higher education: Reflections on recent language policy developments. Higher Education, 67(5), 533-549. DOI: 10.1007/s10734-013-966o-6

Airey, J., Lauridsen, K., Räsänen, A., Salö, L., \& Schwach, V. (2015). The expansion of English-medium instruction in the Nordic Countries. Can top-down university language policies encourage bottom-up disciplinary goals? The International Journal of Higher Education Research,73, 561-576. DOI: 10.1007/s10734-015-9950-2 Altbach, P. G., Reisberg, L., \& Rumbley, L. (2009). Trends in global higher education: Tracking an academic revolution. UNESCO. Retrieved 11 December 2020 from http://unesdoc.unesco.org/images/o018/o01832/183219e.pdf

Arefiev, A. L., \& Sheregi, F. Е. (2016). Экспорт российских образовательных услуг: Статистический сборник [Export of Russian Education]. Ministry of Education and Science of the Russian Federation, 6. Moscow: Sociocentre. Retrieved 17 February 2021 from https://akvobr.ru/po_chislu_inostrannyh_studentov_rossiya_pobila_rekordy_sssr.html 
Austermuehl, F. (2013). Future (and not-so-future) trends in the teaching of translation technology. Revista Tradumatica: tecnologies de la traduccio, 11, 326-337. DOI: $10.5565 / \mathrm{rev} /$ tradumatica.46

Bazanova, E. M., \& Korotkina, I. B. (2017). Российский консорциум центров письма [Russian writing centres consortium]. Higher Education in Russia, $4(211), 50-57$.

Beelen, J., \& Jones, E. (2015). Re-defining internationalisation at home. In A. Curaj, L. Matei, R. Pricopie, J. Salmi, \& P. Scott (Eds.). The European Higher Education Area (pp. 59-72). Springer.

Belyaeva, E., \& Kuznetsova, L. (2018). Implementing EMI at a Russian university: A study of content lecturers' perspectives. Journal of Teaching English for Specific and Academic Purposes, 6(3), 325-439.

Boiko, S. A. (2014). Англицизмы в современном русском языке: лингвоэкологический аспект [Anglicisms in the modern Russian language: linguoekological aspect]. Экология языка и коммуникативная практика [Ekologiya Yazyka I komunikativnaya praktika], 2, 32-43.

Bondarenko, O. R., (2019). Англизация коммуникативного пространства современной России: что дальше? [Anglicization of communication environment of modern Russia: What's Next?]. Vestnik MGLU. Humanities, 3(819), 22-34.

Chistova, E. (2014). Глобанглизация в аспекте лингвистической экологии (англо-русско-китайские параллели) [Globenglishization in the aspect of sociolinguistics (English-Russian-Chinese parallels)]. Ecology of Language and Communicative Practice, $1,182-196$.

Dearden, J., \& Macaro, E. (2016). Higher education teachers' attitudes towards English medium instruction: A three-country comparison. Studies in Second Language Learning and Teaching, 3, 455-486. DOI: 10.14746/sllt.2016.6.3.5

De Wit, H. (2019). Evolving concepts, trends, and challenges in the internationalization of higher education in the world. Вопросы образования [Educational Studies], 2, 8-34.

Dezhina, I. (2020). Научные 'центры превосходства' в российских университетах: смена моделей [Scientific 'centres of excellence' in Russian universities: Changing models]. ECO, 4, 87-109. DOI: 10.3068o/ECOo131-76522020-4-87-109

Dmitrichenkova, S. V., Chauzova, V. A., \& Malykh, E. (2017). Foreign Language Training of IT-students with the Programme 'Translator in the Directions and Specialties of Engineering Faculty'. Procedia Computer Science, 103, 577-580. DOI: 10.1016/j.procs.2017.01.067

Earls, C. W. (2016). Evolving agendas in European English-medium higher education. Palgrave Macmillan. 
eLibrary [Научная электронная библиотека] (n.d.). Retrieved January 11, 2021, from http://elibrary.ru/titles.asp

Frumina, E., \& West, R. (2012). Internationalisation of Russian higher education: The English language dimension. Moscow, The British Council.

Gabriëls, R., \& Wilkinson, R. (2020). Resistance to EMI in the Netherlands. In H. Bowles \& A. C. Murphy (Eds.), English-medium instruction and the internationalization of universities (pp. 49-75). Palgrave Macmillan.

Gil, J. (2017). Soft power and the worldwide promotion of Chinese language learning: The Confucius institute project.Journal of Language and Politics, 17 (6), 907-910. DOI: $10.1075 /$ jlp.18041.lak

Guskov, A. E., Kosyakov, D. V., \& Selivanova, I. V. (2018). Boosting research productivity in top Russian universities: The circumstances of breakthrough. Scientometrics, $117,1053-1080$. Retrieved 26 November 2020 from https://proxy. library.spbu.ru:206o/10.1007/s11192-018-289o-8

Gustafsson, M., \& Jacobs, C. (2013). Editorial: Student learning and ICLHE: Frameworks and contexts. Journal of Academic Writing, 3(1), 1-12.

He, Zhang (2020). Results of Project '5-100'. Positions of leading Russian universities in top 100 of three leading world rankings, Евразийский Союз Ученых (ECУ) [Eurasian Union of Researchers], 10(79), 22-28. DOI: 10.31618/ ESU.2413-9335.2020.8.79.1085

HSE University (2020a). Faculty Survey. Retrieved 26 November 2020 from Faculty Survey at https://cim.hse.ru/en/mpzh_en

HSE University (2020b). Facts and figures. Retrieved 26 November 2020 from https:// www.hse.ru/en/figures; https://www.hse.ru/figures/\#international

Karmaeva, N. (2018). Career aspirations of young academics in Russia. European Education, 5o(3), 283-299. DOI: 10.1080/10564934.2018.1446177

Kaznacheyeva, S. N., \& Bondarenko, V. A. (2016). Специфика мотивов изучения иностранного языка студентами неязыковых направлений Мининского университета [Motivation to learn foreign languages among non-linguistic students of Minin University]. Minin University Vestnik, 3(16). Retrieved 17 February 2021 from https://cyberleninka.ru/article/n/spetsifika-motivovizucheniya-inostrannogo-yazyka-studentami-neyazykovyh-napravleniymininskogo-universiteta

Khristolyubova, T. Р. (2017) Иностранный язык в системе ценностей студентов старших курсов неязыковых специальностей [Foreign language as part of value system of non-linguistic students]. Universum: Psychology and education, 8(38). Retrieved 17 February 2021 from https://cyberleninka.ru/ article/n/inostrannyy-yazyk-v-sisteme-tsennostey-studentov-starshih-kursovneyazykovyh-spetsialnostey 
Kirkpatrick, T. A. (2011). Internationalization of Englishization: Medium of instruction in today's universities. Hong Kong Institute of Education, Centre for Governance and Citizenship. Retrieved 7 August 2020 from https://pdfs. semanticscholar.org/fdaf/d13bo428dgcfa31966f242e1a6416f29c94c.pdf

Knight, J. (2013). The changing landscape of higher education internationalisation - for better or worse? Perspectives: Policy and Practice in Higher Education, 17(3), 84-9o. DOI: 10.1080/13603108.2012.753957

Kurgansky, S. A. (2018) Англоязычные образовательные программы в вузе [English language programmes in higher education]. Izvestiya of Baikal State University, 28(4), 595-601.

Kushnareva, T. I. (2016). Интересно ли студентам неязыкового вуза изучать Иностранный язык? [Is it interesting for non-linguistic students to learn a foreign language?]. Kazan Pedagogical Journal, 4(117), 115-118.

Lanvers, U., \& Hultgren, A. K. (2018). The Englishization of European education: Concluding remarks. European Journal of Language Policy, 1o(1), 147-152. Retrieved 22 August 2020 from https://www.muse.jhu.edu/article/690801

Lourenço, M., \& Pinto, S. (2019). Expatriate and home teachers' beliefs about English-medium instruction at a Portuguese university. European Journal of Higher Education, 3, 252-267. DOI: 10.1080/21568235.2019.1597750

Macaro, E. (2019). Exploring the role of language in English medium instruction. International Journal of Bilingual Education and Bilingualism, 23(3), 263-276. DOI: 10.1080/13670050.2019.1620678

Macaro, E., Curle, S., Pun, J., An, J., \& Dearden, J. (2018). A systematic review of English medium instruction in higher education. Language Teaching, 51(1), 36-76. DOI: $10.1017 /$ So261444817000350

Malkov, P. (Ed.) (2020). Россия в цифрах [Russia in figures]. Rosstat. Retrieved 17 February 2021 from https://rosstat.gov.ru/storage/mediabank/GOyirKPV/ Rus_2020.pdf

Matveeva, N., Sterligov, I., \& Yudkevich, M. (2021). The effect of Russian University Excellence Initiative on publications and collaboration patterns. Journal of Informetrics, 15(1), 1-17. DOI:10.1016/j.joi.2020.101110

Matvienko, V. (2015, June 17) Великий и могучий нуждается в поддержке ['Veliky i moguchy' needs support] Еженедельник 'Аргументы и факты' [Arguments and Facts weekly]. Retrieved 11 December 2020 from https:/aif.ru/society/ opinion/velikiy_i_moguchiy_nuzhdaetsya_v_podderzhke

Mineyeva, O. A., \& Liashenko, M.S. (2018). Исследование мотивации студентов неязыковых специальностей к изучению иностранного языка [Exploring motivation for studying foreign languages among non-linguistic students]. Baltic Humanities Journal, 7(4), 269-273. 
Ministry of Education and Science of the Russian Federation [Министерство Высшего Образования и Науки РФ] (2018, December 17). Количество китайских студентов в России удвоилось за последние 10 лет [Chinese students numbers in Russian universities has doubled over the last 10 years]. Retrieved 26 October 2020 from https://minobrnauki.gov.ru/press-center/news/?ELEMENT_ID=23715

Ministry of Science and Higher Education of the Russian Federation (n.d.). Government Decree No. 211 of 16 March 2013 on measures of government support for leading Russian universities to increase their competitiveness among the world's leading research and education centres. Retrieved 20 July 2020 from https:// www.5top1oo.ru/en/documents/regulations/74083

Ministry of Science and Higher Education of the Russian Federation (2006). Стратегия развития науки и инноващий в Российской Федераиии на период до 2015 года [Strategy for the development of science and innovation in the Russian Federation for the period up to 2015]. Retrieved 17 September 2020 from http://docs.cntd.ru/document/902367266

Mortensen, J. (2014). Language policy from below: Language choice in student project groups in a multilingual university setting. Journal of Multilingual and Multicultural Development, 35(4), 425-442. DOI: 10.1080/01434632.2013.874438

OECD (2016). The internationalisation of doctoral and master's studies. Education Indicators in Focus (39). OECD Publishing. DOI: 10.1787/5jm2f $77 \mathrm{~d} 5 \mathrm{wkg}$-en

O'Keeffe, B. (2019). An international language for an empire of humanity: L. L. Zamenhof and the imperial Russian origins of Esperanto. East European Jewish Affairs, 49(1), 1-19. DOI: 10.1080/13501674.2019.1618165

Olifirenko, S.M. (2019). Перспективные методы формирования мотивации к и зучению английского языка в технических высших учебных заведениях в рамках компетентностного подхода [Competence-based ways of motivating students of technical higher educational institutions to learn English]. World of Science. Pedagogy and psychology, 4(7). ISSN 2658-6282. Retrieved 17 February 2021, from https://mir-nauki.com

Отчет о результатах самообследования Санкт-Петербургского государственного университета за 2019 год [Saint Petersburg State University Self-Survey Results 2019 Report]. Retrieved 26 October 2020, from https://spbu. $\mathrm{ru} / \mathrm{sites} / \mathrm{default} /$ files/

Panova, A. (2018) Foreign language use by the Russian academia. HERB: Topic of the issue: English in Russian Universities: Mind the Gap, 2(16), 21-23.

Patsukevich, O.V. (2019). Международная учебная миграция иностранных студентов на примере России: исторический аспект [International study migration of international students on the example of Russia: Historical aspect]. Bulletin of the Belarussian State Agricultural Academy, 2, 286-289.

Phillipson, R. (1992). Linguistic imperialism. Oxford University Press. 
Phillipson, R. (2015). English as a threat or opportunity in European higher education. In S. Dimova, A. K. Hultgren, \& C. Jensen (Eds.), English-medium instruction in European higher education (pp. 19-42). De Gruyter Mouton.

Presidential decree on the national development goals of the Russian Federation until 2030 of July 21, 2020, section 2-b. Retrieved 20 October 2020, from http:// www.kremlin.ru/events/president/news/63728)

PSAL (2020). Проект постановления о мерах государственной поддержки российских образовательных организаиий высшего образования. [Project of the resolution on measures of state support of Russian organizations of higher education]. Retrieved 17 February 2021, from https://psal.ru/assets/files/ government-docs/2020-10-22-proekt-postanovleniya-psal.pdf

RIA News [РИА Новости] (2019, September 26). Эксперт рассказал, сколько университетов преподают китайский язык в России [Expert gave the number of Russian universities teaching Chinese]. Retrieved 26 October 2021, from https://ria.ru/20190926/1559154845.html

Robson, S., Almeida, J., \& Schartner, A. (2018). Internationalization at home: Time for review and development? European Journal of Higher Education, 8(1), 19-35. DOI: $10.1080 / 21568235 \cdot 2017 \cdot 1376697$

Salomone, R. C. (2018, July). Dutch court defers decision on English in universities. World University News. Retrieved 16 June 2020, from https://www.universityworldnews.com/post.php?story=20180724140627526

Seidlhofer, B. (2005). English as a Lingua Franca. ELT Journal, 59, 339-341.

Selvi, A. F. (2020). Resisting English medium instruction through digital grassroots activism. Journal of Multilingual and Multicultural Development. DOI: 10.1080/01434632.2020.1724120

Smolentseva, A., Huisman, J., \& Froumin, I. (2018). Transformation of higher education institutional landscape in post-Soviet countries: From Soviet model to where? In J. Huisman, A. Smolentseva, \& I. Froumin (Eds.), 25 years of transformations of higher education systems in post-Soviet countries: Reform and continuity (pp. 1-43). Palgrave Macmillan. DOI: 10.1007/978-3-319-52980-6

Stukalova, I., Shiskin, A., \& Stukalova, A. (2015). Internationalization of higher education: A case of Russian universities. Economics and Sociology, 8(1), 275-286. DOI: $10.14254 / 2071-789 X .2015 / 8-1 / 21$

Trent, J. (2020). The positioning of English-medium of instruction. Winners and losers in 'the Game of EMI' at two Russian universities. Journal of Immersion and Content-Based Language Education, 8(1), 5-27. DOI: 10.1075/jicb.18029.tre

Tsalikova I. K., \& Pahotina S.V. (2015). On the issue of forming motivated learning of foreign languages of students at non-philological departments (on the example of provincial higher education institutions). В мире научных открытий. [The World of Scientific Discoveries], 7(67). 
VCIOM (Russian Public Opinion Research Centre) (2019). Аналитический обзор 'Иностранный язык: перспективная инвестиция?' [Analytical review 'Foreign language: A promising investment?']. Retrieved 19 October 2020, from https://wciom.ru/analytical-reviews/analiticheskii-obzor/ inostrannyj-yazyk-perspektivnaya-investicziya

Webometrics (2020, July). Ranking Web of Universities. Retrieved 7 September 2020, from https://www.webometrics.info/en/europe/russian\%2ofederation

Wihlborg, M., \& Robson, S. (2018). Internationalisation of higher education: drivers, rationales, priorities, values and impacts. European Journal of Higher Education, 8(1), 8-18. DOI: $10.1080 / 21568235 \cdot 2017.1376696$

Wu, H., \& Zha, Q. (2018). A new typology for analysing the direction of movement in higher education internationalization. Journal of Studies in International Education, 22(3), 259-277.

Zhura, V. V., \& Rudova, J. V. (2017). Обучение при помощи языка-посредника в российских медицинских вузах [Foreign language medium instruction in Russian higher medical schools: problems and prospects]. Медииинское образование и вузовская наука. [Medical education and university science], 2(10), 73-77.

\section{About the authors}

Elena Belyaeva (MA in Applied English Linguistics, PhD in Pedagogy) is an expert in ELT/EAP/ESP/EMI in higher education. She works as a university teacher/lecturer and a researcher at St Petersburg University (SPbU), Liberal Arts and Sciences Faculty. Since 2018 she has been an EMI teacher trainer for SPbU faculty.

Lyudmila KuZnetsova, MPA (Rutgers University, USA), PhD in Linguistics, Associate Professor, Cambridge ESOL examiner, teaches Effective Professional Communication and Academic English to master's and PhD students at St Petersburg University. She has coordinated the British Council project RESPONSE and co-authored the English for Academics course book series (Cambridge University Press, 2014, 2015).

Olga Nikiforova, PhD in Sociology, Associate Professor at the Department of Economic Sociology and Head of MA programme 'Studies in European Societies', St Petersburg University. Her sphere of scientific and research interests covers such topics as sociology of markets, the labour market and human resource development. 
Svetlana Suchkova, PhD in Linguistics, Associate Professor, teacher trainer, and Cambridge ESOL examiner, is the current director of the Academic Writing Center at the Higher School of Economics, Moscow. She has published a number of EFL coursebooks for Russian university students and researchers, and co-authored the English for Academics series (Cambridge University Press, 2014, 2015). 



\title{
10 Multiple dimensions of English- medium education
}

Striving to initiate change, sustainability, and quality in higher education in Sweden

Magnus Gustafsson and Jennifer Valcke

\begin{abstract}
English-medium education (EME) has traditionally been associated with attracting international students - one-way mobility - in combination with English L1 speaker norms due to the prestige and global hegemony of English. The implications of using EME go beyond mere communication, since they also affect ways of thinking, seeing and practising the disciplines and this has been reflected in public controversies in Sweden. University leadership has to consider the pedagogical, linguistic, and cultural implications of internationalization and the impact of Englishization. This chapter offers a partial governance overview of EME in Swedish HEI and exemplifies EME interpretations with two case descriptions, where one focuses more on EME and the other more on the internationalization of the curriculum.
\end{abstract}

Keywords: English-medium education (EME), Sweden, internationalization strategy, language policy, quality

\section{Context and overview of Englishization in Sweden}

Swedish universities have consistently been at the forefront of the process of Englishization (Hultgren et al., 2014; Hultgren et al., 2015; Wächter \& Maiworm, 2014) over the past three decades. Englishization in Sweden can be conceptualized as a drive towards English as a Medium of Instruction (EMI), alongside it being a subject taught in the curriculum (Hultgren,

Wilkinson, Robert, and René Gabriëls (eds), The Englishization of Higher Education in Europe. Amsterdam, Amsterdam University Press 2021 DOI: 10.5117/9789463727358_CH10 
2018). This chapter specifically addresses how two Swedish universities have engaged with curricular reform as a result of global, national, and institutional internationalization policies to integrate and support teaching and learning through English.

EMI presents both an opportunity and a challenge for Swedish universities today - ranging from a means to enhancing the quality of teaching and learning through to a means of reinforcing social inequalities (Karlsson, 2017). Hult (2012) discusses linguistic hierarchy in Sweden, where English as international language is clearly positioned strongly alongside Swedish, the local language. On the one hand, Swedish is the language recommended for use in administration and legislation, and on the other hand, English is seen as outward-looking and mobile (Ferguson, 2007; Hult \& Källkvist, 2016; Karlsson, 2017; Norén, 2006; Phillipson, 2015). English has thus acquired a preferential position over other languages and has become the language of internationalization (Hult \& Källkvist, 2016; Karlsson, 2017; Liddicoat, 2016; Phillipson, 2015; Siiner, 2016).

The strategic choices made by Higher Education Institutions (HEIs) must remain relevant to our interconnected and interdependent world 'shaped by complex local and global relationships between people and their physical and cultural environments' (Leask, 2020, p. 1388). These choices are addressed by the Swedish inquiry for internationalization (Bladh et al., 2018) which reviews the international aspects of higher education, research, and other activities in Swedish HEIs, including the conditions set out by the government and other public organizations. While the inquiry does not explicitly mention teaching and learning in languages other than Swedish, it does mention that official decision-making in Swedish can hinder non-Swedish speaking persons from taking official positions within HEIs (Båge et al., 2021). Additionally, the inquiry highlights that language is the single most important obstacle for including non-Swedish speaking students in decision-making at HEIs according to student unions (Bladh et al., 2018, p. 341). The inquiry asks HEIs to develop guidelines for which languages should be used in which context, in order to make the choice of language transparent and predictable for all students and faculty. A final recommendation is for HEIs to initiate, design, and provide language courses and language support for students, faculty and administrative staff.

Interestingly, the inquiry recognizes the importance of sustainable development, global dimensions, and intercultural competence as a measure of quality education. In this way, the inquiry aligns with the aim of Internationalization of Higher Education (IHE) 'to make a meaningful contribution to society' as defined by De Wit et al. (2015). The inquiry also raises the 
question of student mobility as being a factor of inequality, where mobility only benefits few students and teachers. It highlights that it is 'necessary for students to acquire international understanding and intercultural competence at home' (Bladh et al., 2018, p. 18). Internationalization at Home (IaH) is, in fact, a Swedish concept coined by Bengt Nilsson (2003) from Malmö University, which lays out possible solutions for the integration of international, intercultural, and global dimensions into the delivery of higher education. Nilsson saw IaH as an antidote to 'vaccinate all our students against the dark forces of nationalism and racism' (Nilsson, 2000, p. 26).

Before we go on to explore how global and local agendas influence language policies in Swedish HEIs, the authors wish to clarify that 'universities need to be committed to articulating policies that can achieve greater social justice, for instance ensuring that any threat from English is converted into an opportunity that does not impact negatively on the vitality of other languages' (Phillipson, 2015, p. 39). The shift towards teaching through English is therefore not a homogeneous one, and when looked at in detail, the standardizing function of English turns out to be more complex and multifaceted than initially expected (Dafouz \& Smit, 2020).

\section{A note on the roles and conceptualizations of English}

Contending with the need of this chapter to present an overarching conceptualization that is both inclusive and equitable, the authors recommend the recently introduced ROAD-MAPPING framework for English Medium Education in Multilingual University Settings (EMEMUS, hereafter EME) by Dafouz and Smit (2020). Drawing on current research and examples from a variety of settings, EME makes a strong case for the dynamic and diverse nature of university contexts both as a methodological tool for researching educational practices and as an analytical guide for examining policies and the continuous professional development of teaching staff. EME thus shifts away from a narrow, monolingual perspective of teaching in English, to an organic view encompassing multilingualism, multiculturalism and interdisciplinarity.

Any understanding and strategic design of EME is reflected in the role users assign to English. However, that role, in turn, is affected by conceptualizations of English. Dafouz and Smit (2020) describe how monolingual or multilingual approaches to English impact the entire EME design and the scaffolding of student learning. A monolingual approach with English as a foreign, second, or even academic language risks limiting the full 
potential of EME as it sidesteps the development of English in the world and misses the point of the shared responsibility for knowledge creation and collaboration as it prioritizes some users over others on monolingual grounds. They suggest that a more inclusive conceptualization of English as a lingua franca (ELF) encourages teachers to challenge preconceived ideas about language standards and norms (Jenkins, 2017; Ur, 2009) in such a way as to promote communicative abilities and open possibilities for different Englishes to co-exist in the classroom (Båge \& Valcke, 2021). In so doing, teachers can deliver effective and inclusive EME (Dafouz \& Smit, 2020), if they are able to reflect on the influence and impact teaching in English has on a teacher's identity.

In this respect, Jenkins (2017) suggests that a fully competent speaker of English as an international language is a speaker with a wide vocabulary, unambiguous grammar, and an easily understood accent, and whose first language (L1) may or may not be English. For university teachers to develop a teaching persona that is inclusive of the heterogeneous language proficiency present in their classrooms, it seems that some myths and preconceptions about language acquisition and language learning need to be debunked. Given that the Nordic countries were early adopters of EME and may have formed their respective conceptualizations of English at a point in time when multilingualism was not yet sufficiently articulated, ELF is not as widely applied in Sweden. Consequently, Swedish EME seems to assume English as a foreign or second language (Kuteeva, 2014). The fact that the Nordic countries also tend to rank high on English proficiency tests (Dafouz \& Smit, 2020) might further suggest the less prominent position for ELF in Swedish higher education in terms of its guiding documents, faculty training, language support for students and staff, or even admissions requirements.

In the next section, we look at different levels of governance that shape the development of EME across the Swedish higher education landscape.

\section{Panorama of policy and ideology in Sweden}

To Sweden, a small export-dependent country, IHE and IaH are seen as particularly valuable (Bladh et al., 2018). Learning through other languages, specifically English, is a gateway to the rest of the world which enables international, fee-paying students to come to Sweden and contribute to its economy in various ways, but also a way to bring international perspectives into the Swedish classrooms. In order to balance realistic expectations and high ambitions, we must remember that strategies that plan clearly 
Figure 10.1 Levels of governance affecting Englishization in Sweden

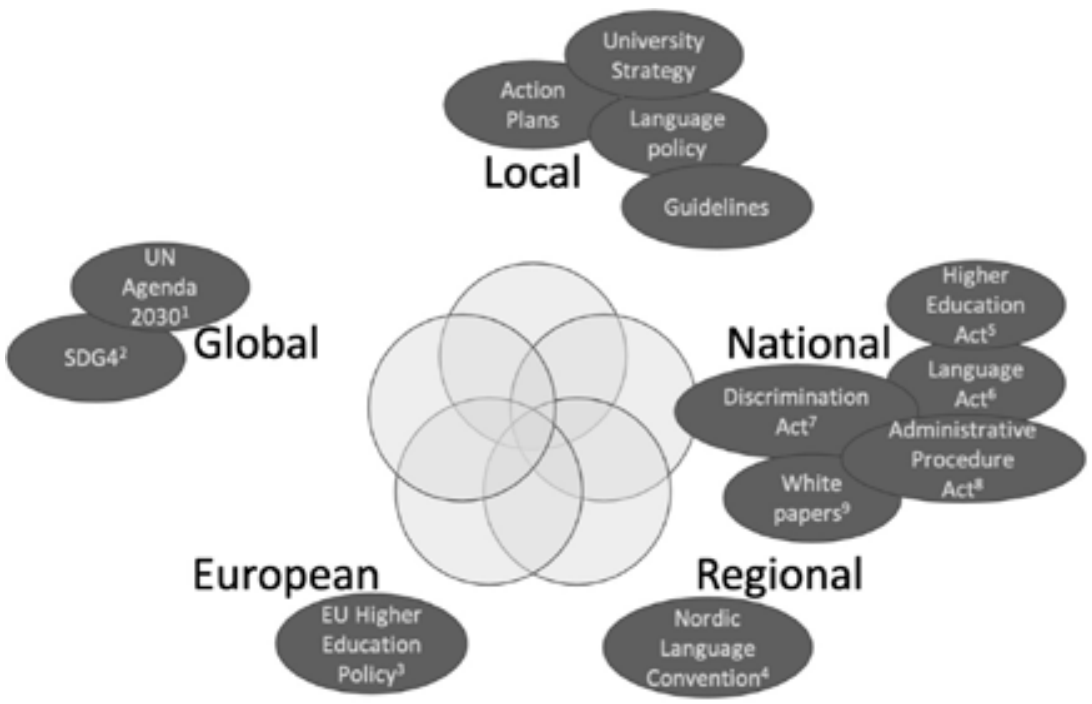

$1 \mathrm{https} / / /$ sdgs.un.org/goals

2 https://sdgs.un.org/goals/goal4

3 https://ec.europa.eu/education/policies/higher-education/about-higher-education-policy_en

$4 \mathrm{https}: / / \mathrm{www}$.norden.org/en/treaties-and-agreements/nordic-language-convention

5 https://www.uhr.se/en/start/laws-and-regulations/Laws-and-regulations/ The-Swedish-Higher-Education-Act/

6 https://www.regeringen.se/contentassets/9e56b0c78cb5447b968a29dd14a68358/ spraklag-pa-engelska

7 https://www.government.se/4a788f/contentassets/6732121a2cb54ee3b21da9c628b6bdc7/ oversattning-diskrimineringslagen_eng.pdf

8 https://www.riksdagen.se/sv/dokument-lagar/dokument/svensk-forfattningssamling/ forvaltningslag-2017900_sfs-2017-900

9 https://www.government.se/48fc30/contentassets/4df6aeabd2bd4f5dbbf69210f786e133/ internationalizationagenda.pdf

for gradual progression towards these goals are essential (Jellinek, 2018). Such strategies might rely on indicators that are measurable or observable, of course, but they also need to address issues of the challenges of aligning efforts among disparate disciplinary or departmental cultural assumptions at the respective institutions.

In order to begin to understand the current state of Englishization in Swedish higher education, we need to first look at the various levels of governance that affect it. Figure 10.1 shows all the relevant documents that regulate education and language of instruction from the local to the global levels. While there is a complex interplay between these documents, the focus of this chapter is mainly on the local and global levels. These combined documents provide either rules to abide by or recommendations 
and guidelines to follow. As we shall see, Swedish HEIs have freedom to choose the degree to which these documents will be implemented or not.

\subsection{Towards inclusive and equitable quality education}

Let us now look at the global level from Figure 10.1 and the UN Agenda 2030 with its Sustainable Development Goals (United Nations, 2015). How do they influence and shape EME internationally and, by extension, how do they inform the Swedish higher education panorama? As we have seen, the understanding of internationalization has shifted from focusing on language for the sake of facilitating mobility, to integrating international perspectives and global dimensions into the curriculum to allow all students to benefit from internationalization (Hudzik \& McCarthy, 2012, p. 2). This shift in emphasis is significant; so, where are we now, where to next, and what are the larger visions for internationalization of education, as well as EME?

In 2015, the United Nations made quality education a top global priority, addressed by Sustainable Development Goal 4 (SDG 4) which specifically highlights that by 2030 nations need to 'ensure inclusive and equitable quality education and promote lifelong learning opportunities for all'. $\mathrm{SDG}_{4}$ Target 7 further includes 'global citizenship and appreciation of cultural diversity' (UNESCO, 2017a, p. 8) as defining characteristics of quality education and recommends this goal be attained through: (a) national education policies; (b) curricula; (c) teacher education; and (d) student assessment (UNESCO, 2017a, p. 48). These indicators for Target 7 do not explicitly mention language. Rather, the ubiquity of language in education pervades and transcends notions of equitable and inclusive relations and communication - concepts which hark back to global citizenship. Global citizenship is mentioned as an indicator for quality education, which requires competencies, skills, knowledge, and values necessary to live in society. The challenge posed by global citizenship must therefore be contextualized locally, since 'inequality coexists with a diversity of ethnicities, languages, cultures, trajectories, circumstances and worlds' (UNESCO, 2017b, p. 15).

There is a clear overlap between global citizenship and research in EME (Dafouz \& Smit, 2020), in that learners are asked to recognize and appreciate the multiple identities inherent to cultures and languages, in order to develop skills for living in an increasingly diverse world. Such a view also overlaps with IHE as a process that inevitably calls for action and is equated with quality education and innovation (De Wit et al., 2015). It is clear that the roles that languages play in academic settings are multi-layered and complex. 
Many Swedish HEIs have therefore tried to support their staff and students by articulating language policies and guidelines.

\subsection{Language policies at Swedish higher education institutions}

There is no national document constituting what a language policy in higher education should cover or address in Sweden, unlike in Norway for example (Jahr et al., 2006). Since there are no overarching guidelines for drafting language policies, it is up to individual institutions to consider their own local context (Liddicoat \& Baldauf, 2008). Universities negotiate their own local practices and processes for areas such as education, research, administration, and promotion strategies in alignment with national regulations, such as those in the Higher Education Act and the Language Act (see Figure 10.1). In this way, HEI language planning becomes an intermediate layer between the national and the local.

Reviewing the language policies of Swedish universities and university colleges, we note, first, that the process of articulating a language policy can be a long one. Table 1 lists Swedish universities in the order in which their current language policies were published. Given the documentation we have studied, the Royal Institute of Technology and the Swedish Agricultural University appear to have been the first universities to articulate and publish their language policies, in 2010. The most recent language policy published as such is that of Uppsala in 2018. Dating the language policies in this heavy-handed manner is risky. Many universities may have had language guidelines integrated in other documents pre-dating the language policies we have found (see also Björkman, 2015, where the language policies of nine universities were analysed; Salö and Josephson, 2014, where they briefly discussed language policies at 15 universities; Soler et al., 2018, who reviewed nine Swedish university language policies and found earlier documents).

Readers of these policies will note a pronounced variation in these documents. The degree of detail is radically different in many ways. Some of the policies read like brief policies and make specific references to supporting document like guidelines and local rules and regulations (Chalmers University of Technology). Other universities have integrated rules and regulations into the actual policy document and some of the policies read as arguments justifying the policies and decisions (Stockholm University). This variation is also the reason why our overview may suffer missing language policy data since some of the relevant information may be published in other documents (Dafouz \& Smit, 2020). Our case studies (see sections 4 and 5) provide examples of this limitation in our language policy data mining 


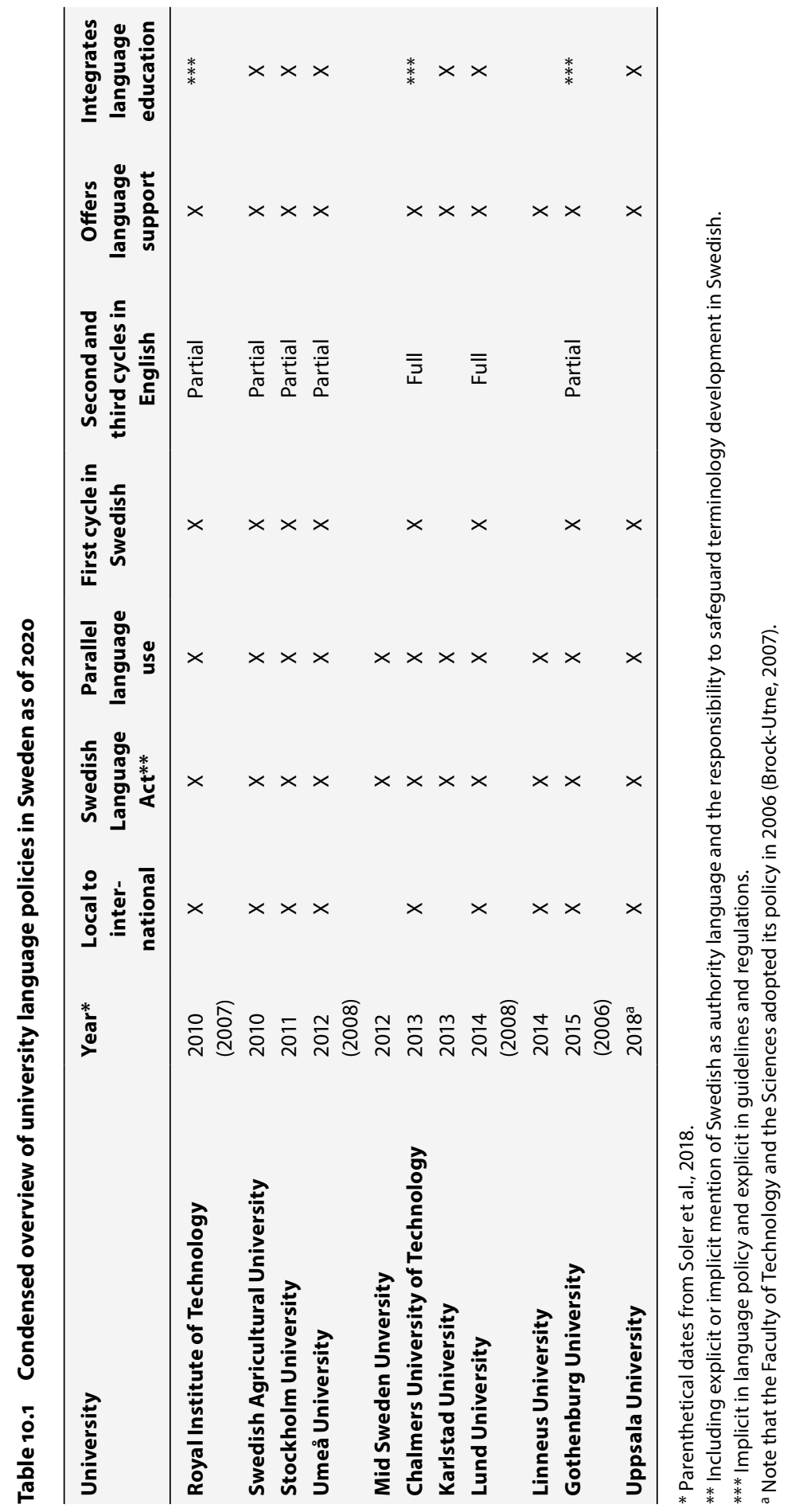


by increasing the resolution for EME and internationalization beyond the policy level for the two universities.

There are several common components in the language policies we have reviewed, and it seems not a great deal has changed since the review by Soler et al. (2018, p. 37). What they all have in common is their reference to the Swedish Language Act of 2009. They tend to refer to two aspects of the Act: (i) that Swedish is the language of agencies and authorities; and (ii) that agencies and authorities have a responsibility to promote the development of Swedish as a language also of science with a focus on building disciplinary terminology. Karlstad and Uppsala make specific references to the corresponding paragraphs in the Act whereas other universities settle for a blanket mention of it. In the context of promoting the development of Swedish as a scientific language, three universities (Chalmers, Lund, Gothenburg) move beyond mere terminology and include phrases to the effect of also developing appropriate discipline-specific rhetorical patterns in Swedish. Another aspect of the Language Act, which all but three institutions make specific reference to, is the use of plain language (Nord, 2018) in formal communication.

A second recurring component in the language policies is how all universities stress the obvious but complex context comprising the local, the regional, the national, and the international. With two exceptions (Mid Sweden and Lund universities), all policies make explicit remarks about being situated in these four spheres of learning and knowledge creation. On the one hand, this context gives rise to comments about internationalization and accommodating international students and staff. On the other hand, the regional might explain why only four universities explicitly refer to the Nordic Council language convention (2007). Technically, the convention affects all Swedish universities, but it seems universities closer to our Nordic neighbours and our oldest universities are more careful to include it in their language policies (Umeå, Karlstad, Lund, and Uppsala).

A third common dimension is the emphasis on embracing parallel language use (Kuteeva, 2014). The international context and the European Union (EU) higher education policy are the obvious drivers for that practice, but only Gothenburg makes that kind of reasoning explicit by referring to their international context. The Swedish Agricultural University states that it is in fact bilingual (English and Swedish), while a university like Umeå has an explicit mission to support and promote two of the minority languages in Sweden (Saami and Meänkeli) and, therefore, highlights that context governs the choice of language. 
A fourth recurring observation in the language policies is what is missing. Only Linneus mentions sustainability. The impact of $\mathrm{SDG}_{4}$ on policies, therefore, is minimal. Then again, while sustainability has been in strategies for the past 10 to 15 years, many language policies pre-date the articulation of the SDGs. More surprising, perhaps, is the fact that only two universities refer to the EU higher education policy or to the Bologna agreement (Royal Institute of Technology and Karlstad). However, this is a particularly weak area in the data collection as many universities may have placed their compliance with the EU policy in their strategy documents or other guidelines (Chalmers University of Technology).

As we begin to look at the impact of the language policies on education and instruction at our institutions, we note that almost all universities make explicit that their undergraduate degrees are taught and assessed in Swedish unless it concerns a language course (an exception here is Karolinska Institutet, where all undergraduate and postgraduate degrees must have at least 7.5 credits taught through English). For the postgraduate and doctoral degrees, the picture is more complex. Five of the institutions mention the partial delivery of their postgraduate and doctoral degrees in English and some also use the policy to make a strategy statement about increasing the amount of EME. Two universities have already implemented, at the level of policy, fully taught English postgraduate and doctoral programmes (Chalmers and Lund). The reasons for implementing this shift to EME are likely multiple: mobility, internationalization away and at home, and EU higher education policy, to name but a few. However, the single most recurring reason offered is the need for two publication languages for postgraduate and doctoral degrees.

With second and third cycles as EME, Swedish universities risk conflicting with the Language Act as it states that citizens have the right to use Swedish in their interaction with the authorities. For universities, this means that students must be allowed to provide answers in Swedish during assessment, for instance. The universities seem to consider Swedish their first and main language for administration purposes. Stockholm is explicit in stating that while documents are translated, it is always the Swedish version that is legally binding. Karlstad and the Swedish Agricultural University mention audience analysis as guiding the choice of language, which suggests that not all documents are translated.

Many of the policies make specific comments about implications for learning in their policies. Five of the universities comment on the centrality of language for learning for instance. On the same note, all universities, except the Mid Sweden University, offer language support, 
but not all of the universities have integrated language education into their programmes. Fewer still have designed a progression of language education components for students as they move from first cycle instruction and assessment in Swedish to second and third cycles as partial or full EME.

What might be surprising given the language debate in Sweden and the Nordic countries is the fact that only one of the language policies mentions domain and capacity loss (Stockholm). On the one hand, the absence of these signal phrases might reflect the corresponding emphasis in the Language Act to promote Swedish as a full language. On the other hand, it might be a reflection that most of the language policies appear as a result of that debate, rather than as arguments for it. The debate on domain loss, after all, was more intensive around the period leading up to the Swedish Language Act of 2009 (Brock-Utne, 2007). Josephson, former head of the Swedish language council, offers a thorough account of this development in Swedish language policy dynamics (Josephson, 2014). A complementary account, not so much of the debate as such but of the parallel language status in Sweden, is provided by Salö and Josephson in their land report (Salö \& Josephson, pp. 265-322). Salö and Josephson point out multiple dimensions of domain loss and parallel language in Swedish higher education. Publication statistics aside, where English dominates, even if there is a domestic scene for Swedish publications, the range of parallel language use variation is pronounced, with English being more prominent is disciplines like physics and computer science and less so in for instance history and law. English is also frequently used at the master's degree level. Salö and Josephson also highlight the tangential discussion of the effects on learning when domain loss or parallel language use results in EME.

\section{The case of Chalmers University of Technology}

The process of Englishization at Chalmers dates back to the 1990s. As a university of technology with strong ties to major Swedish industrial arenas, international collaboration in education was and is a given. There were some 20 isolated international master's programmes delivered partly in English in, for example, management of technology as well as in civil engineering in the early 1990s. While these educational activities offered experience to individual Chalmers faculty, they were not part of, nor the result of a dedicated effort as outlined in vision or strategy documents. 
There was no alignment with other educational strategies and projects, nor was there any organized knowledge transfer within the institution. With the Bologna agreement, however, internationalization and EME were naturally highlighted and coordinated in visions and activity plans in the past.

\subsection{Adjusting educational programmes to EME}

The first step in preparing Chalmers for EME was a project to redesign education to adjust to the three-cycle outcomes-oriented European policy as agreed on in the Bologna agreement (Danielsson, 2010; Räisänen \& Gustafsson, 2006). By 2004, this process was completed at the level of planning and preparation, and postgraduate programmes in English were offered to local, national, and international students by $2007(\mathrm{C} 2005 / 355)^{1}$. As programmes were redesigned, admission rules for all international students needed revising (C2007/957) including, for example, the required number of credits for mobility and language requirements for English proficiency (C2010/1394).

Since the decision to turn to EME postgraduate programmes was communicated, faculty training courses have been offered by the Division for Language and Communication. The battery of courses was largely designed in 2005 and informed by basic constructive alignment principles and the findings from faculty surveys and focus group interviews (Räisänen \& Gustafsson, 2006). A parallel process included reviewing undergraduate programmes to assess to what extent they prepared students for the language swap between the bachelor's and master's levels. In the 199os and the preBologna structure, many of the engineering programmes offered electives in English that were tailored to the programme disciplines (English for electrical engineering or mechanical engineering, for instance). These elective courses were now redesigned and fully integrated into curricula for some of the programmes. However, the process was only at the programme level; no central decisions regarding providing discipline-specific English proficiency in the first three years were communicated. Hence, students arrived at master's level with quite varied chances of meeting the challenge of their new EME context.

1 The C-codes in this chapter are references to the record numbers in the internal library of management decisions at Chalmers. The documents are public but not published externally. By Swedish law, you can request documents like these by contacting the registrar (registrator@ chalmers.se) and using these codes to refer to the exact document. You should then receive the document within 72 hours. 
This redesign process to prepare for EME coincided with the debate about domain loss in Swedish. Concern for Swedish was shared among programme managers and the management of education at Chalmers. Therefore, some programme managers relied on admission requirements for their national students and focused language education on Swedish disciplinary and academic language. This effort to promote Swedish is reflected, for instance, in the instructions for the BSc degree projects (C2019/16o6) that have emphasized Swedish as the language of presentation and assessment since 2007. There are also differences between programmes based on the type of focus they have for undergraduate degrees.

There are two types of engineering education in Sweden; one is a threeyear programme with a focus on application and industry employment, and historically, there is also a longer five-year engineering education with a greater focus on theoretical depth as well as development work. In the Bologna process, that five-year education programme was divided into bachelor's and master's degrees, with only the master's level delivered in English, often inspired by the graduate school emphasis on research preparation. While both these types of engineering profiles require English in their toolboxes, the need is more urgent for the shorter application-focused programmes. They all have EME components in the final year of the Bachelor, whereas there are 'graduate schools' where disciplinary language in English is a learning outcome that only needs to be achieved by the final year. Some of those longer engineering programmes only have elective EME-components at the undergraduate level.

With the adjustment to the Bologna process, educational development for language of instruction and assessment was intensive. Today, the situation has stabilized, but the programme design decisions regarding preparing students for EME remain local rather than central (except for admissions requirements at the formal level, (C2010/1394), and guidelines for the MSc thesis (C2016/o973). The language support and language education that is shared across the university is the battery of elective courses offered by the Division for Language and Communication and the support provided to students via the peer tutor writing centre run by the same division.

\subsection{Internationalization in education at Chalmers}

Much like EME, incidental internationalization dates far back in the Chalmers history but it has intensified and become more coordinated at various points in time. Chalmers does not run an internationally based campus, but it has had a Taiwan office for a decade and established an exchange for 
students. Another activity that provides internationalization both away and at home and might concern a larger number of students is the application of the Conceive-Design-Implement-Operate (CDIO) approach in engineering education at Chalmers. The national and international collaboration through the CDIO initiative generates multiple opportunities for students and staff to interact and collaborate and exchange experience and expertise.

There are also individual projects and interventions on many MSc programmes and many of these are focused on diversity and inclusion (Bergman et al., 2017). Compared to the EME-activities, there are both parallels and differences with the university-wide offer. There is a dedicated faculty training course and there are also integrated activities and workshops delivered by course managers in collaboration with faculty from the Division for Language and Communication. In terms of the number of activities and faculty involved, though, diversity and inclusion activities are still far fewer than the efforts oriented towards disciplinary communication. What is also missing in terms of internationalization is a coordinating office. Today, there is instead an international staff mobility office whose activities and support might indirectly affect internationalization of education.

\section{The case of Karolinska Institutet (KI)}

Like other universities, KI has intentionally prioritized international research collaborations and, to a lesser extent, education, through agreements regarding exchange opportunities. However, when it comes to the content and delivery of its education, this intentionality is less pronounced, and there is a noticeable gap in study programmes that systematically and intentionally integrate internationalization into their curricula.

\subsection{Adjusting educational programmes to EME}

From 2014 to 2018, KI's Board of Higher Education adopted an Action Plan for the internationalization of undergraduate and postgraduate education (Karolinska Institutet, 2014). It had four goals: one dedicated to the integration of Global Health in the curriculum, another to teaching in English and two for increasing mobility and recruitment of international students and staff. The goal addressing teaching in English stated that:

All study programmes are to offer at least one compulsory course delivered in English carrying 7.5 credit points or more by 2018. All students are 
thus to take at least one course that is delivered in English during their academic studies at Karolinska Institutet. (Karolinska Institutet, 2014)

This goal was supported by the provision of English language courses for academic staff whose language proficiency was below $\mathrm{C}$ (diagnosed through an in-house language test), but also two professional development courses integrating teaching in English to other areas related to international education: an online course 'Two2Tango - Teaching in the international classroom" and 'Teaching in the Glocal University'3 (both equivalent to 2 ECTS). An educational developer was tasked with supporting all study programmes and provide workshops, as well as individual consultations. Unfortunately, KI does not have its own language policy and little information was provided to teaching staff on how to carry out the goal described above. To this day, this has meant that study programmes have adopted EME with varying degrees of integration and quality, and with varying degrees of engagement.

Guidelines were therefore necessary and needed to be integrated within a wider approach to IHE. The Board of Higher Education decided to issue recommendations in 2017 (three years after the start of the Action Plan), together with a matrix of internationalized intended learning objectives (ILOs) containing the four dimensions listed below, together with descriptors and rubrics for each dimension. These were:

1 Language skills: reading, listening, writing, presenting, and interacting;

2 Intercultural competence: 'the ability to communicate effectively and appropriately in intercultural situations based on one's intercultural knowledge, skills and attitudes' (Deardorff, 2004, p. 194);

3 Global competence: the ability to engage with global health issues, as well as internationally informed social and/or political issues;

4 International disciplinary learning: the understanding that a given discipline has an international and inter-professional context that is culturally bound.

For courses taught through English, the language of instruction is English and must be used for:

- Course documentation (syllabus, course plan and additional resources/ documents) ;

- Teaching and learning activities (lectures, seminars, workshops, clinical practice, supervision, etc.);

2 https://staff.ki.se/two2tango-tandems-for-teaching-in-english

3 https://staff.ki.se/teaching-in-the-glocal-university 
- Assessment tasks;

- Instruction: the syllabus must state that the language of instruction is English, and students should be told in advance of the course that the medium of instruction will be English.

The presence of international students is not a necessary condition for international courses, but particular attention should be paid to internationalization at home strategies. This will increase the relevance of the use of English, through the incorporation of international, intercultural, and/ or global perspectives.

\subsection{Internationalization of education at KI}

Although the university had centred its action plan on a broad definition of internationalization, the itemization of the goals illustrated how the understanding of this concept focused primarily on EME, mobility, and recruiting fee-paying international students. However, the coordinating team decided that its implementation demanded a new way of understanding and working with internationalization holistically, namely the development of language competence (not only English), intercultural competence, international disciplinary learning, and global engagement. Indeed, if KI were to find a systematic and intentional process for integrating the four dimensions mentioned previously into the content and delivery of the curriculum, it would be able to shift away from an ad hoc approach to internationalization (Båge \& Valcke, 2021). After reviewing and reflecting on the teaching and learning activities resulting from KI's action plan, Båge and Valcke (2021) found that many were isolated and optional, and very few were systematically developed with intentionality and increasing levels of difficulty throughout the curriculum. If KI was to engage sustainably with internationalization, thereby enhancing and sustaining staff motivation, it had to engage in a planned and systematic evidence-based process. In other words, internationalization of education was more likely to succeed at KI if it was embedded in standard university practice, rather than understood as being developed in parallel to regular university operations.

KI faced the challenges of developing a sustainable and integrated approach to internationalization by securing external funding from the Swedish Foundation for International Cooperation in Research and Higher Education (STINT) 
to internationalize the curriculum of five of its study programmes (2017-2020). ${ }^{4}$ The Internationalization of the Curriculum (IoC) is a holistic approach and therefore a dynamic and complex process concerned with ensuring that all students are prepared to work and live ethically and responsibly in a multicultural, multilingual, and globalized world (Leask, 2015). IoC in fact instigated a paradigm shift of KI's conception of quality education by stepping away from haphazard instances of internationalization activities to considering the impact IHE had on its strategic and policy documents, the development of its curricula, the professional development of its teaching staff, as well as its impact on student assessment. This approach also meant expanding the stakeholders involved in IoC from teaching staff and educational leaders, to students, those involved in support services and in quality assurance systems.

\section{Concluding remarks on quality EME}

In Sweden, the convergence of policies and the societal context gives legitimacy to internationalization and its connections with inclusive and equitable education, multilingualism, and multiculturalism. In such a context, IHE lends itself to EME, but in order for university teachers to develop quality EME that is inclusive of the heterogeneous language practices present in their classrooms, it seems that myths and preconceptions about language acquisition and language learning must first be debunked. Teachers need to change their mindset by rethinking the role English plays in their disciplines today and adopt inclusive language practices, where the use of a lingua franca is understood and different varieties of English are embraced. The work on translanguaging and code-switching demonstrates the often-messy practices of everyday life. From this lived experience, we need to learn how to equip our learners with the language skills they need for a multilingual society and help them develop the necessary sensitivity towards the cultural and linguistic needs of their fellow citizens. These are no small tasks and teachers must face these alongside the challenges of scaffolding deep approaches to disciplinary content learning to promote the desired or expected disciplinary expertise.

We believe our two case descriptions exemplify how two very different Swedish HEIs implement and operate EME in ways that are indeed recognizable and in keeping with the Language Act and the Higher Education Act, while placing decidedly different emphases on two aspects of EME. Internationalization

4 To find out more about the project, consult its webpage: https://ki.se/en/collaboration/ internationalisation-of-the-curriculum-ioc 
and inclusion are pronounced at Karolinska Institutet, while the disciplinary discourse aspect of EME is more apparent at Chalmers University of Technology.

What does such variation say about Englishization in Sweden? While the cases might not be mainstream, they do show us that the complex and demanding levels of governance for EME land HEIs in challenging processes and decisions to arrive at balanced EME that meets current conceptualizations and policies. The degree of work that appears to go into EME at these two HEIs, however, also suggests that Swedish HE is onboard and positive to EME, even if a lot of work remains.

We call for evidence-based practices to address a broad range of relevant social, theoretical, and practical issues, to facilitate curriculum development and teacher professional development, as well as student assessment. The further conclusions that can be drawn from the Swedish context is that we must integrate awareness-raising of the different possible uses and roles of English in academia into the continuous professional development of teaching staff. If we can equip teaching staff with a range of multicultural sensitivities, then our classrooms can start to be more inclusive and equitable.

\section{Acknowledgement}

The authors wish to than the editors for their support and excellent advice during the publication process. We are also grateful for the perceptive and constructive feedback we received from the two anonymous reviewers.

\section{Funding}

This research was supported in part by a Strategic Research Grant awarded by the Swedish Foundation for International Cooperation in Research and Higher Education (STINT), 2017-2021.

\section{References}

Bergman, R., Norman, A., Carlsson, C., Nåfors, D., \& Skoogh, A. (2017). Forming effective culturally diverse work teams in project courses. 13th international CDIO conference proceedings CDIO, 18-22 June 2017, Calgary. Vol. $2017(13)$, pp. 508-518. 1796-9964 (eISSN)

Björkman, B. (2015). Attitudes towards English in university language policy documents in Sweden. In A. Linn, N. Bermel, \& G. Ferguson (Eds.), Attitudes towards English in Europe (pp. 115-138). Mouton de Gruyter. 
Båge, K., \& Valcke, J. (2021). From English-medium education to sustainable development goals: The journey of a medical university. In D. Coyle \& F. Rubio Alcalá (Eds.), Developing and evaluating quality bilingual practices in higher education (pp. 73-95). Multilingual Matters.

Båge, K., Gaunt, A. \& Valcke, J. (2021) (in press). Aligning glocal agendas for international education: Using English-medium education to enhance quality education. European Journal of Language Policy.

Bladh, A., Wilenius, M., \& Gaunt, A. (2018). En strategisk agenda för internationalisering - Delbetänkande av utredningen om ökad internationalisering av universitet och högskolor [A strategic agenda for internationalisation - Interim report of the investigation of increased internationalization of universities and university colleges]. Swedish Government Official Reports. Retrieved 12 June 2020 from https://www.regeringen.se/49oaa7/contentassets/2522e5c $3 \mathrm{f}_{4} 424 \mathrm{df}_{4} \mathrm{aec} 78 \mathrm{~d} 2 \mathrm{e}$ 48507e4f/en-strategisk-agenda-for-internationalisering.pdf

Brock-Utne, B. (2007). Language of instruction and research in higher education in Europe: Highlights from the current debate in Norway and Sweden. International Review of Education, 53, 367-388. DOI: 10.1007/s11159-007-9051-2

Dafouz, E. \& Smit, U. (2020). ROAD-MAPPING English-medium education in the internationalised university. Palgrave.

Danielsson, H. (Ed.) (2010). IMPACT - Strategic development of Chalmers master's programmes. Chalmers University of Technology. https://research.chalmers.se/ en/publication/115021http://publications.lib.chalmers.se/records/fulltext/115021. pdf

Deardorff, D., K. (2004). The identification and assessment of intercultural competence as a student outcome of international education at institutions of higher education in the United States. Raleigh: North Carolina State University.

De Wit, H., Hunter F., Howard L., \& Egron-Polak E. (Eds.) (2015). Internationalization of higher education. European Parliament. http://www.europarl.europa.eu/ RegData/etudes/STUD/2015/540370/IPOL_STU(2015)540370_EN.pdf

Ferguson, G. (2007). The global spread of English, scientific communication and ESP: Questions of equity, access and domain loss. Iberica, 13, 7-38.

Hudzik, J. K., \& McCarthy, J. S. (2012). Leading comprehensive internationalization: Strategy and tactics for action. Washington, D.C.: NAFSA.

Hult, F. M. (2012). English as a transcultural language in Swedish policy and practice. TESOL Quarterly, 46 (2), 230-257.

Hult, F. M. \& Källkvist, M. (2016). Global flows in local language planning: articulating parallel language use in Swedish university policies. Current Issues in Language Planning, $17(1)$, 56-71.

Hultgren, A. K. (2018). The Englishization of Nordic universities: What do scientists think? European Journal of Language Policy, 10(1), 77-95. 
Hultgren, A. K., Gregersen, F., \& Thøgersen, J. (Eds.) (2014). English in Nordic universities: Ideologies and practices. John Benjamins.

Hultgren, A. K., Jensen, C., \& Dimova, S. (2015). Introduction: English-medium instruction in European higher education: from the North to the South. In S. Dimova, A. K. Hultgren, \& C. Jensen (Eds.), English-medium instruction in European higher education (pp. 1-16). De Gruyter Mouton.

Jahr, E. H., Salvanes, A. G. V., Walløe, L., Haugland, K., Sandøy, H., Glasser, R., \& Kvåle, G. (2006). Framlegg til ein språkpolitikkfor universitet og høgskolar i Noreg. Oslo: Universitets- og høgskolerådet.

Jellinek, N. (2018). Sustainability and the teaching context: the role of university educators. In K. Iwinska, M. Jones, \& M. Kraszewska (Eds.), Widening interdisciplinary sustainability education (pp. 31-43). Collegium Civitas.

Jenkins, J. (2017). The future of English as a lingua franca? In J. Jenkins, W. Baker, \& M. Dewey (Eds.), The Routledge handbook of English as a lingua franca (pp. 594605). Routledge.

Josephson, O. (2014). The Swedish Language Council and English as a Lingua Franca. Sociolinguistica: Internationales Jahrbuch fuer Europaeische Soziolinguistik, 28(1), 105-122. DOI: 10.1515/soci-2014-0010

Karlsson, S. (2017). Språkpolitik vid Svenska universitet och högskolor [Language policy at Swedish universities and university colleges]. Reports from the Institute for Language and Folklore 8. Språkrådet.

Karolinska Institutet (2014). Action Plan for the Internationalization offirst-and second-cycle education 2014-2018. Stockholm: Board of Higher Education. https:// ki.se/sites/default/files/handlingsplan_internationalisering_0216.pdf

Kuteeva, M. (2014). The parallel language use of Swedish and English: the question of 'nativeness' in university policies and practices. Journal of Multilingual and Multicultural Development, 35(4), 332-344. DOI: 10.1080/01434632.2013.874432

Leask, B. (2015). Internationalizing the curriculum. Routledge.

Leask, B. (2020) Embracing the possibilities of disruption. Higher Education Research \& Development, 39(7), 1388-1391. DOI: 10.1080/07294360.2020.1824211

Liddicoat, A. J. (2016). Language planning in universities: Teaching, research and administration. Current Issues in Language Planning, 17(3-4), 231-241.

Liddicoat, A. J., \& Baldauf, R. B. (2008). Language planning in local contexts. In R. B. Baldauf \& A. J. Liddicoat (Eds.), Language planning and policy (pp. 3-17). Multilingual Matters.

Nilsson, B. (200o). Internationalising the curriculum. In P. Crowther, M. Joris, M. Otten, B. Nilsson, H. Teekens, \& B. Wächter (Eds.), Internationalization at Home: A position paper (pp. 21-28). European Association for International Education (EAIE). 
Nilsson, B. (2003). Internationalization at Home from a Swedish perspective: The case of Malmö. Journal of Studies in International Education, 7(1), 27-40. DOI: $10.1177 / 1028315302250178$

Nord, A. (2018). Plain language and professional writing: A research overview. Language Council of Sweden. The Institute for Language and Folklore. https:// www.isof.se/download/18.74fcba02165cbdce76bef271/153995215546o/Plain\%20 language\%2oand\%2oprofessional\%2owriting.pdf

Nordic Council (2007). Declaration on a Nordic Language Policy. Nordic Council.

Norén, K. (2006). Universiteten väljer språk [Universities choose languages]. Språkvård, 1, 26-29.

Phillipson, R. (2015). English as threat or opportunity in European higher education. In S. Dimova, A. K. Hultgren, \& C. Jensen (Eds.), English-medium instruction in European higher education (pp. 19-42). De Gruyter Mouton.

Räisänen, C., \& Gustafsson, M. (2006). More than medium of instruction: The Bologna process and teaching in English. C-SELT report. https://research. chalmers.se/en/publication/53223

Salö, L. \& Josephson, O. (2014). Landrapport Sverige: Parallellspråkighet vid svenska universitet och högskolor [Country report Sweden: Parallel language use at Swedish universities and university colleges]. In F. Gregersen, O. Josephson, S. Godenhjelm, M. Londen, J.-O. Östman, A. P. Kristinsson, H. Bernhardsson, U. Røyneland, G. Kristoffersen, M. Kristiansen, J. Thøgersen, \& L. Salö. Hvor parallelt: Om parallellspråkighet på Nordens universitet. [How parallel: About parallel languages at the Nordic universities] (pp. 261-322). Nordisk Ministerråd. DOI: $10.6027 / \mathrm{TN2} 214-535$

Siiner, M. (2016). University administrators as forced language policy agents. An institutional ethnography of parallel language strategy and practices at the University of Copenhagen. Current Issues in Language Planning, $17(3-4), 441-458$. DOI: 10.1080/14664208.2016.1204058

Soler, J., Björkman, B., \& Kuteeva, M. (2018). University language policies in Estonia and Sweden: Exploring the interplay between English and national languages in higher education. Journal of Multilingual and Multicultural Development, 39(1), 29-43. DOI: 10.1080/01434632.2017.1307844

United Nations (2015). The United Nations Sustainable Development Goals Knowledge Platform. https://sustainabledevelopment.un.org/sdgs

UNESCO (2017a). Education for Sustainable Development Goals Learning Objectives. Paris: UNESCO.

UNESCO (2017b). Conclusions from the Latin America and Caribbean Regional Network Meeting on Global Citizenship Education, October 23-24, Santiago: UNESCO. 
Ur, P. (2009). English as a lingua franca and some implications for English teachers.

Handout. https://www.tesol-france.org/uploaded_files/files/Collog-Ur_Plenary_Handouts.pdf

Wächter, B., \& Maiworm, F. (Eds.) (2014). English-taught programmes in European higher education: The state of play in 2014. Lemmens.

\section{About the authors}

Magnus Gustafsson is an Associate Professor at the Division for Language and Communication, Chalmers University of Technology, Gothenburg. His work focuses on academic and disciplinary discourse for faculty and students. In his educational development work, he strives to promote seamless integration of communication-oriented learning activities to enhance disciplinary expertise.

JENNIfER VAlCKe is an Educational Developer for the unit for Teaching and Learning at Karolinska Institutet (KI) in Stockholm, Sweden. Her role includes teaching, training and advising on issues related to curricular integration, sustainable education, international education, intercultural education and English-medium education (EME); and she also provides support for educational leaders to implement educational strategies. 


\title{
11 Englishization of Dutch higher education
}

\author{
Divergent language policies and practices \\ Robert Wilkinson and René Gabriëls
}

\begin{abstract}
The Netherlands is one of the countries where the Englishization of higher education is most evident. The percentage of bachelor's and master's programmes at Dutch universities through the medium of English is among the highest in Europe. This chapter addresses the concern and public controversy generated by the preponderance of English. It illustrates how language policy encapsulates the changes in Dutch universities and the impacts these have on stakeholders and compares these with a study of students' perceptions of EMI. The analysis contends that Englishization can only be understood in the light of the impact of neoliberalism on academia, highlighting the incongruity between the critical voices in the public controversy and the discourse of university administrators.
\end{abstract}

Keywords: Englishization, Dutch universities, language policy, public controversy, student perceptions, neoliberalism

\section{Introduction}

The Netherlands is one of the countries where the Englishization of higher education is most pronounced. In 2019, the percentage of bachelor's and master's programmes offered at Dutch universities through the medium of English was one of the highest in Europe, with 30\% of all bachelor's programmes and $76 \%$ of master's programmes in English, and only an additional $15 \%$ and $10 \%$ respectively where students could choose between

Wilkinson, Robert, and René Gabriëls (eds), The Englishization of Higher Education in Europe. Amsterdam, Amsterdam University Press 2021 DOI: 10.5117/9789463727358_CH11 
a Dutch and English variant (VSNU, ${ }^{1}$ 2020a). Correspondingly, the change in the percentage of Dutch-medium bachelor's programmes in the past four years is striking, showing a decline from $70 \%$ in 2016 to $55 \%$ four years later (VSNU, 2020a).

Dutch education has changed a lot in the past half-century. In the middle of the 2oth century, students entering university would have been expected to be proficient in Dutch and three foreign languages: German, French, and English (Schuyt \& Taverne, 2000/2011, pp. 316-317). Such a situation gradually changed in the last quarter of the century with French and German in sharp decline. English is now the only compulsory language that all Dutch secondary school students learn (Wilhelm, 2018, p. 20). Universities naturally have noticed this trend. Since the end of the 2oth century, they have felt obliged to internationalize to cope with pressures such as those imposed by national policy in the light of globalization. Thus, in this century they have extensively recruited international students at both bachelor's and master's level, with numbers more than doubling from 2006 reaching 62,000 in 2019 - that is, over $20 \%$ of the university student population (Nuffic, 2020). In all 13 Dutch research universities, ${ }^{2}$ at least $10 \%$ of their student population and a quarter of their academic staff come from abroad. If we assume that these figures present a measurable fact of the Englishization of Dutch higher education, they raise many questions and give rise to concern (Ministerie van Financiën, 2019). Most notably, how did such a change develop so rapidly in the country? What are the consequences? Does the change privilege certain stakeholders? Are some excluded? What effect does this have on Dutch culture and society? To what extent are the values held by the Dutch government and more widely in the European Union (EU) being supported or violated?

This chapter unpacks the changes in Dutch university education, leading to a pivotal public controversy around a court case on Englishization in 2018, when a campaign group took two universities to court on the grounds that

1 Vereniging van Universiteiten (Dutch Universities Association).

2 We include the 13 research universities in the Netherlands: University of Amsterdam (UvA), Vrije Universiteit Amsterdam (VU), Delft University, Eindhoven University, University of Groningen, Leiden University, Maastricht University, Radboud University Nijmegen, Erasmus University Rotterdam, Tilburg University, University of Twente, Utrecht University, and Wageningen University. We have excluded the non-research universities, the Dutch Hogescholen (known in English as Universities of Applied Sciences). Although these institutions teach mainly in Dutch, they attracted 28,156 international students in 2018 (6\% of total student numbers) (Vereniging Hogescholen, 2020). We have also excluded the Dutch Open Universiteit (Open University) from this study. It mainly provides part-time online higher education for Dutch-speaking students in the Netherlands and Flanders. Almost all its programmes are in Dutch (www.ou.nl). 
they were breaking the law for failing to provide education in Dutch for Dutch students. The chapter describes how language policy encapsulates the changes in the Dutch university and the impacts these have on stakeholders. The chapter limits itself to three groups of stakeholders whose perceptions of Englishization may be expected to differ, critics of Englishization in the public debate, university administrators responsible for authorizing English-medium programmes as evidenced in official documentation, and students following English-medium university programmes who may perceive advantages and disadvantages. The discussion weighs up the benefits and drawbacks.

\section{Characterization of Englishization}

Before it became fashionable to use the term verengelsing (the Dutch word for Englishization) to indicate developments in higher education, it was used to denote everyday practices in which loan words were increasingly used (Christenhuis, 2002). Van der Sijs attributed the increasing use of English loanwords mainly to the influence that American culture gained on Dutch culture after the Second World War (Van der Sijs, 1996).

The word verengelsing is also used to indicate the increasing use of English in the business world (see Rys et al., 2017). Of course, this applies especially to companies that do business abroad. But the term Englishization also refers to shops and restaurants in tourist cities where the de facto language is English and not Dutch. According to the media, this often leads to annoyance among citizens (Dixon, 2019; Rovers, 2019)

In the Netherlands, the discussion about Englishization is not just about higher education. Primary and secondary education is also at stake here (Onderwijsraad, 2011). Verengelsing or Englishization, though, has relatively recently been used to describe developments in higher education, especially the increasing number of bachelor's and master's programmes offered in English. Yet proponents usually refer to this development in terms of internationalization, where internationalization is often cast as a neutral process (Knight, 2008). In essence, internationalization processes do not specify any specific language, and can thus camouflage what happens in practice. In contrast, opponents of the process refer not to internationalization but speak consistently of Englishization. As a result, Englishization is used by opponents to give a negative connotation to the increase in English-medium instruction (EMI) programmes. In this way, the concept of Englishization serves as a tool to politicize this development. This is evident from the 
public controversy that intensified after 2017 about the increase in EMI programmes in the Netherlands. We define Englishization as the process of the English language increasingly gaining ground in social practices where a different language was previously used. We focus on higher education.

\section{Trends}

Dutch university education has gradually displayed features of Englishization over the past half-century. Universities have long offered incidental courses in English, especially when visiting scholars from abroad gave classes or ran workshops. The same applied to newly appointed staff from outside the Netherlands, who would be obliged to learn Dutch often as a condition of tenure. By the start of the 199os, several universities had initiated programmes or part-programmes through the medium of English, notably the technical universities of Delft, Eindhoven, Wageningen, and Twente, as well as Erasmus University and those at Maastricht and Groningen (Haines, 2020), especially at master's level. The success of English-medium programmes in business and economics at Maastricht University coinciding with the highly Europhile trend following the 1992 Maastricht treaty stimulated a noticeable expansion of EMI in other faculties at Maastricht and at other Dutch universities (see Wilkinson, 2013).

Englishization has tended to occur less through an explicit policy decision and more through force of circumstance. For example, as faculties at these Dutch universities found themselves recruiting more and more international students, they faced a choice of either extensive investment in Dutch language training or allowing communication to function in English or any other common language. In most cases, the desire to recruit 'excellent' students and staff from everywhere led to English becoming the dominant language (see for example Van Parijs, 2011, but also Kruse, 2016). Investment in Dutch was limited, and international students were usually not required to learn the local language. Thus, universities found themselves obliged to translate or rewrite relevant regulations and ensure that administrative staff could cope with student encounters in English. Signposting became bilingual, and was sometimes supplied only in English (Bronkhorst, 2019; Edwards, 2016). These trends forged ahead after the implementation of the Bologna Declaration in Dutch higher education (2002) and in the last decade they have accelerated. Furthermore, a joint report in 2018 from the Vereniging Hogescholen and VSNU forecast an expected $7 \%$ decline in the total number of Dutch students but a significant 
increase in international students to over $26 \%$ of all university students (16\% of all students in Dutch higher education) by 2029/30, underpinning the associations' concern for the future quality of Dutch education (Vereniging Hogescholen \& VSNU, 2018; see also Ministerie van Financiën, 2019).

\section{The public debate}

To elucidate the public debate, the database of Dutch media was searched for documents relating to 'verengelsing' (Englishization), 'hoger onderwijs' (higher education) and 'universiteit' (university), resulting in 1,331 articles, of which more than half were syndicated copies. The search terms evidently do not identify relevant articles that do not mention the terms. However, this is unlikely to be a problem given the broad coverage of the debate in the newspaper corpus.

Although the use of English loanwords and expressions has been criticized for some time, it is the increase in the number of EMI programmes at Dutch universities that has precipitated a much broader critique of Englishization. Most saliently, English has become the main language in many areas of higher education and scientific research at the expense of Dutch. Another concern raised is the increasing use of sources (literature, etc.) from the Anglophone world in place of sources from Dutch and other cultures. The surge of English within higher education also has spill-over impacts on Dutch culture, which are also linked to tourism. In shops, hotels, and restaurants in cities with a university and many tourists, English often displaces Dutch as well.

The periodic criticism of Englishization did not initially precipitate widespread public controversy. That changed in 2018, when many in the media publicly expressed concern about, among other things, the future of Dutch as an academic language, the quality of education and the cultural identity of Dutch due to Englishization.

The public debate was triggered by the association Beter Onderwijs Nederland (BON [Better Education Netherlands], 2018a). ${ }^{3}$ According to the association, the massive increase in EMI programmes would harm the quality of education and the Dutch language proficiency of graduates. In

3 BON is a Dutch pressure group arguing for high quality education at all levels. The number of members is not reported on its website. At least 6,ooo people signed its petition against 'overwhelming Englishization' ('de doorgeslagen verengelsing', BON, 2018a). 
2018, BON took the University of Twente and Maastricht University to court, because they regarded these institutions as exemplars of the Englishization of higher education in the Netherlands.

According to BON, neither university complied with the Higher Education and Scientific Research Act (Wet op het hoger onderwijs en wetenschappelijk onderzoek, WHW), which states that higher education must be aimed at 'promoting expressions skills in Dutch'. Under article 7.2., education must be given in Dutch unless the necessity for education in another language can be demonstrated. However, the District Court of Utrecht ruled that the two universities had complied with the law, because they had good reasons to offer EMI programmes. The court added, though, that universities 'must show the necessity of a language other than Dutch as the working language of study programmes' (BON, 2018b; our italics). A subsequent investigation by the Education Inspectorate, ordered by the court, concluded that university language policies often do not comply with the law (Inspectie van het Onderwijs, 2018).

Shortly before the Inspectorate's report, the Minister of Education, who is also formal head of the Education Inspectorate, presented an amendment of the WHW aimed at ensuring the quality and accessibility of higher education for Dutch students and Dutch as an academic language (van Engelshoven, 2019a). BON was satisfied with the proposed amendment's prescription that institutions of higher education must give reasons if they want to deviate from Dutch as medium of instruction. However, the association was vexed that the law would no longer indicate that institutions have to demonstrate the necessity to deviate from Dutch. Because the amendment replaces the word 'necessity' with 'interest', BON feared that the door would be opened to further Englishization (BON, 2019a).

The fear that the amendment to the language policy, adopted by the Tweede Kamer (lower house of the Dutch parliament) on 19 December 2019, would not create a barrier against further Englishization, was shared by 194 eminent professors, writers, and representatives of the cultural sector in a national newspaper. Under the title 'Government must protect Dutch at universities', they voiced their concern that 'by not appreciating Dutch, they [the universities that embrace the Englishization] are ignoring its important role in shaping our national identity and traditions' (BON, 2019b). The signatories also feared that Dutch as an academic language would disappear and that the budget for higher education spent on international students as a result of Englishization could reduce students' access to Dutch programmes. 
In addition to the 194, numerous others publicly opposed the consequences of the Englishization of higher education after the lawsuit. For instance, in the book Against English. Pleidooi voor het Nederlands (Plea for Dutch), professors, writers, and intellectuals complained about the widening gap between academia and society due to Englishization (Jensen et al., 2019). The title of the book, however, is misleading, because the various authors are not against English, but believe that embracing EMI programmes has gone too far at the expense of Dutch language and culture.

Since the adoption of the amendment by the Dutch lower house, neither Englishization nor the debate have stopped. The fact that English became the official language in education, research, and administration at the Universities of Eindhoven and Twente from 1 January 2020 led to public indignation and criticism. At the time of writing, the new higher education law was still awaiting approval from the Dutch Senate.

\section{Method}

We were interested in how Dutch research universities responded to the controversy concerning verengelsing and EMI, and whether the claims in the controversy reflected the perceptions students had of the issues. To do so, we used two different methods: first, documentary analysis of the publicly available annual reports of the universities, and second, a quantitative survey of students as one of the key groups of stakeholders.

For the documentary analysis, the annual reports of the 13 Dutch research universities were downloaded and screened for reference to 'taalbeleid' (language policy) and 'internationalisiering' (internationalization) and related terms. All annual reports were in Dutch. While we also accessed language policies where available, we chose to analyse annual reports reasoning that the annual report highlights what has happened in the view of the university board, whereas the language policy, which may be dated, expresses a vision of what is expected to occur. Our analysis supplements Edwards' (2020) recent analysis of university language policies at 12 of these universities regarding instructional language. She found that less than half the universities had updated their policies in the last five years.

For the quantitative analysis, we recruited 237 students following the same optional course in 2018 and 2019 at the Faculty of Arts and Social Sciences at Maastricht University. We observed few significant differences between the 
cohorts and so combined the data. The questionnaire covered 78 items on a range of topics, plus a number of background items. Respondents indicated the extent to which they agreed or disagreed with a statement on a 5-point Likert-type scale. A 'not applicable' option was also given. The questionnaire was implemented electronically and the data incorporated in SPSS by the university data and information management centre MEMIC. For this study, we selected seven items that reflect perceptions of Englishization from the 2018 and 2019 cohorts (see Table 11.2 below). These items explicitly reflected claims voiced during the public debate. Analysis was performed using chi-square in SPSS 25 since the data are non-dichotomous and ordinal (Field, 2018).

\section{Findings}

The following subsections report findings concerning the documentary analysis of annual reports and the analysis of student perceptions of claims voiced in the public debate.

\subsection{Institutional language policy}

Dutch universities use their annual reports, at a public level, to demonstrate their internationalization policy and by extension how they enact language policy. Yet while there are considerable differences between the universities, it is important first to set the legal context.

As indicated in section 4 above, the national language policy is enshrined in Article 7.2. WHW, currently being amended. The article prescribes that a language other than Dutch may be used if the teaching is provided in the context of a guest lecture by a non-Dutch-speaking lecturer, or if the specific nature, organization or quality of the teaching or origin of the students so requires. As Edwards (2020) highlights in her study of universities' language policies (incorporated in institutional gedragscodes, codes of conduct), universities use a range of discoursal practices and arguments, sometimes circular, to justify their provision of EMI programmes. For example, the international profile of the university warrants the offering of programmes in English (Edwards, 2020, p. 11) or the presence of international students leads to the need to offer EMI programmes (p. 13). Edwards characterizes the arguments as chicken-and-egg. Moreover, Dutch government policy encourages internationalization in Dutch universities, reaffirmed by the Minister of 
Education (van Engelshoven, 2019a), but at the same time aims to safeguard the position of Dutch language and culture. The WHW and its amendment are sufficiently vague to allow universities to continue to offer and expand EMI programmes, providing they can demonstrate sufficient documentary justification ('more administrative hoops', Edwards, 2020, p. 16, concludes) for such a provision.

We examined the 2019 annual reports (in Dutch, jaarverslagen) of the 13 Dutch research universities. Besides reflecting institutional language policy, the universities' annual reports are insightful for two more reasons, both of which relate to Englishization. The first concerns the adoption of English words and expressions to describe the institution. In their Dutch-language annual reports, all Dutch universities use English terms extensively to label job positions, faculties, and departments, even buildings, policy, and strategy committees, research programmes, and many more, for example 'de Erasmus community' (Erasmus), 'Dean Talent Development' (Groningen), 'innovatie in teaching en learning' (Leiden), 'het Continuing Professional Development-programma' (Maastricht), 'het Managementteam Education and Student Affairs' (Radboud). The University of Twente even includes long quotes in English in the middle of the Dutch text, with no attempt to provide a translation. The pervasiveness of English terms likely stems from the adoption of a university structure based on New Public Management (Pollitt et al., 2007). The structure appears partly modelled on British and American universities, as reported by Dekker (2015, p. 109), and originates in the changes under the Reagan and Thatcher administrations in the USA and the UK respectively (Lorenz, 2012, pp. 603-604).

The second reason concerns the very nature of the university annual report, which has become a visible sign of 'audit culture' (Shore \& Wright, 2000). The university annual report in the Netherlands, at the behest of a government pursuing New Public Management, as in many countries, resembles that of business firms who have to report to shareholders (Coy et al., 2001) where academic language is 'replaced with corporate and business language' (Parker, 2011, p. 441). In this light, Dutch universities' annual reports demonstrate the subservience of the academic to private sector corporate philosophies (Parker, 2011, p. 448) emanating from Anglo-American accounting practices, which is also a facet of Englishization.

Our main contention, however, is the evidence of language policy as observed in Dutch universities' annual reports. The first salient observation is that six universities do not mention language policy (Erasmus, Delft, Tilburg, Utrecht, Amsterdam [UvA], and Wageningen), although 
they vicariously refer to the number of international students and aspects such as the international classroom. Two universities (Eindhoven and Radboud) only give scant mention with little of substance. Unsurprisingly, both Twente and Maastricht, as the defendants in the 2018 court case, report extensively on language policy. The Vrije Universiteit also reports at some length, most likely in reaction to the adverse press coverage of the closure of Neerlandistiek (Dutch studies) at the university in early 2019. With the exception of a brief mention of concurrence in the supervisory board's report, the university's annual report passes over the ending of Neerlandistiek in silence. Only Leiden and Groningen contain moderately detailed reports on language policy that do not seem engineered by external forces.

Both Twente and Maastricht highlight the impending changes to the legislation on the language of instruction by stressing how international they are already ('the most international university in the Netherlands'4 - Maastricht; '64 different nationalities' among the students, and international staff increasing to $26 \%$ of staff - Twente). However, the policy reactions of the universities differ. Twente uses the argument to defend its position to opt for English-only as both instructional language and institutional language. The latter is demonstrated by the amount of English in the annual report, which must be in Dutch as required by law. Maastricht in contrast emphasizes its position in a multilingual Euregion, which underpins what it calls a 'balanced vision' for both Dutch and English medium education for employability and personal competence. For students, Maastricht spotlights its free language courses in Dutch, French, and German, even if the number of places for French and German is quite limited. The courses are aimed at increasing the 'stay-rate' (international students remaining in the region after graduation) and employability in the region. Staff, too, are required to demonstrate competence in both Dutch and English. Despite its English-only policy, Twente insists on the 'crucial role of Dutch' for international students and staff with regard to their 'embedding in Dutch society', 5 thus underscoring the employability argument. Both universities strive to impress how they are meeting the implications of the prospective legislation. Maastricht also claims that its policy already goes a long way to meet the calls made in a recent Ministry of Finance study which, among other matters, raises concern about

4 '[D]e meest internationale universiteit van Nederland'.

5 '[D] e cruciale rol van Nederlandse taalvaardigheid [...] voor hun inbedding in de Nederlandse samenleving'. 
the possible decline of Dutch as an academic language and questions the sustainability of Dutch internationalization policy (Ministerie van Financiën, 2019). Both Maastricht and Twente depend heavily on a steady intake of international students (currently $55 \%$ and $30 \%$ of their students respectively, VSNU, 202ob).

While making no mention of the closure of Dutch studies, the Vrije Universiteit defends its language policy by emphasizing inclusion and 'bilingualism'. As is the case for Maastricht and Twente, it highlights the numbers of international students taking Dutch courses, data that arguably serve to demonstrate how the university is promoting Dutch language and culture. However, the university justifies the increase of EMI programmes by claiming that this makes them accessible to both Dutch-speaking and non-Dutch-speaking students.

One may conclude from this brief analysis that language policy does not play a prominent role in the perceptions of university management except where Englishization has led to a perception of detriment to Dutch language and culture, eliciting serious negative publicity. Where risks to internationalization policies are demonstrated (Ministerie van Financiën, 2019; Vereniging Hogescholen \& VSNU, 2018), so far, universities seem set to continue on their current Englishization path and thus to expand the provision of EMI. The provision of Dutch language courses to establish universities' credentials as promoters of Dutch language and culture may appear a rather meagre investment when set against that for EMI programmes.

\subsection{Students as stakeholders}

As one key stakeholder in the higher education spectrum, students form an important group whose opinion merits notice. The argument over Englishization in the Netherlands concerns cultural effects in particular. We were curious to see whether Dutch students held different opinions from international students. Table 11.1 shows selected background characteristics of the students surveyed in 2018-2019. Just over half were female, and one-fifth spoke Dutch as their first language (L1). Of more than half the students both parents had a higher education qualification. Over $80 \%$ of the students had experienced at least one period of residence abroad of more than three months, while more than one in six had done so at least three times. 
Table 11.1 Selected background characteristics of the students

A. Dutch speaker

\begin{tabular}{c|c|c} 
Dutch L1 speaker & Dutch L2 speaker & Not Dutch-speaking \\
\hline $20.3 \%(48)$ & $15.6 \%(37)$ & $64.1 \%(152)$
\end{tabular}

B. Parental level of education

\begin{tabular}{c|c|c} 
Both parents university & $\begin{array}{c}\text { One parent university; one } \\
\text { parent hogeschool }\end{array}$ & Total with higher education \\
\hline $37.1 \%(88)$ & $18.1 \%(43)$ & $55.3 \%(131)$
\end{tabular}

C. Number of residences abroad of three months or more (non-vacation)

\begin{tabular}{c|c|c|c}
$\begin{array}{c}\text { Never resided out- } \\
\text { side home country }\end{array}$ & $\begin{array}{c}\text { One residence abroad } \\
\text { of 3 or more months }\end{array}$ & $\begin{array}{c}\text { Two residences } \\
\text { abroad }\end{array}$ & $\begin{array}{c}\text { Three or more } \\
\text { residences abroad }\end{array}$ \\
\hline $18.1 \%(43)$ & $40.1 \%(95)$ & $24.9 \%(59)$ & $16.9 \%(40)$ \\
\hline
\end{tabular}

$N=237$; Female 55.3\% [131]; percentages [numbers in brackets]

We asked this group of students to give their opinion of seven items relevant to Englishization in the Netherlands that reflect the claims advanced in the public debate (Gabriëls \& Wilkinson, 2020, p. 59) (see Table 11.2). The vast majority of the students agreed that EMI results in dominance of knowledge in English, and they were evenly divided over whether a single lingua franca undermines cultural diversity. But nearly two-thirds of the respondents considered the use of more resources from non-Anglo-American literature would benefit the quality of teaching. When considering the effect of research, only a third considered that Dutch society as a whole loses out if research is reported in English and that researchers should disseminate their findings in Dutch. However, a plurality feared that under EMI, Dutch will disappear as an academic language. This was the only item to show a significant difference between Dutch L1 and L2 speakers and non-Dutch speakers, $\chi^{2}(10, \mathrm{~N}=237)=34,168$, $\mathrm{p}=.000$. Dutch L1 speakers agreed much more than expected, compared with both Dutch L2 speakers and non-Dutch speakers, who were evenly divided. Nearly two-thirds of the respondents favoured the provision of Dutch courses at both bachelor's and master's levels. The item, however, does not differentiate as to whether content courses should be available in Dutch, or whether Dutch language and culture courses should be offered. Nevertheless, it indicates a significant groundswell among the students for universities to promote more Dutch. 
Table 11.2 Student perceptions on Englishization

\begin{tabular}{|c|c|c|c|c|}
\hline Item & $\begin{array}{l}\text { Response } \\
\text { (N) }\end{array}$ & Disagree & Neutral & Agree \\
\hline $\begin{array}{l}\text { EMI leads to dominance in knowledge in the } \\
\text { English language }\end{array}$ & 235 & $\begin{array}{c}7.2 \% \\
17\end{array}$ & $\begin{array}{c}12.3 \% \\
29\end{array}$ & $\begin{array}{c}80.4 \% \\
189\end{array}$ \\
\hline $\begin{array}{l}\text { The quality of teaching in an EMI programme } \\
\text { would improve if more resources were taken } \\
\text { from non-Anglo-American literature }\end{array}$ & 235 & $\begin{array}{c}10.2 \% \\
24\end{array}$ & $\begin{array}{c}28.9 \% \\
68\end{array}$ & $\begin{array}{c}60.9 \% \\
143\end{array}$ \\
\hline $\begin{array}{l}\text { Cultural diversity will be undermined if there } \\
\text { is only one lingua franca }\end{array}$ & 235 & $\begin{array}{c}38.3 \% \\
90\end{array}$ & $\begin{array}{c}23.4 \% \\
55\end{array}$ & $\begin{array}{c}38.3 \% \\
90\end{array}$ \\
\hline $\begin{array}{l}\text { The use of English in teaching and research } \\
\text { means that the general population has less } \\
\text { access to research results }\end{array}$ & 233 & $\begin{array}{c}47.6 \% \\
111\end{array}$ & $\begin{array}{c}18.9 \% \\
44\end{array}$ & $\begin{array}{c}33.5 \% \\
78\end{array}$ \\
\hline $\begin{array}{l}\text { Researchers have an obligation to dissemi- } \\
\text { nate their research findings to Dutch society } \\
\text { in Dutch }\end{array}$ & 226 & $\begin{array}{c}30.1 \% \\
68\end{array}$ & $\begin{array}{l}38.9 \% \\
88\end{array}$ & $\begin{array}{l}31.0 \% \\
70\end{array}$ \\
\hline $\begin{array}{l}\text { Dutch as an academic language will } \\
\text { disappear if a lot of teaching is conducted in } \\
\text { English }\end{array}$ & 229 & $\begin{array}{c}31.9 \% \\
73\end{array}$ & $\begin{array}{c}24.5 \% \\
56\end{array}$ & $\begin{array}{c}43.7 \% \\
100\end{array}$ \\
\hline $\begin{array}{l}\text { The university should offer courses in Dutch } \\
\text { at both the bachelor's and master's levels }\end{array}$ & 232 & $\begin{array}{c}9.1 \% \\
21\end{array}$ & $\begin{array}{c}26.7 \% \\
62\end{array}$ & $\begin{array}{c}64.2 \% \\
149\end{array}$ \\
\hline
\end{tabular}

Note: responses 'disagree' and 'strongly disagree' are combined as are 'agree' and 'strongly agree'. Not applicable responses are excluded. Total $\mathrm{N}=237$.

In their 2019 appeal to the Dutch parliament, 194 eminent scholars and intellectuals had argued that the verengelsing of higher education was turning universities into 'gated enclaves for privileged citizens and foreigners ${ }^{6}$ (BON, 2019b). The claim implies that 'ordinary' Dutch students are being excluded from the universities. The argument of 'privilege' may be relevant. Table 11.1 shows that a majority of the students in our study came from highly educated family backgrounds and had resided extensively abroad. To an extent, we may characterize a salient proportion of them as evolving 'global nomads' who may attempt to remain detached from sedentary societies that are focused on the nation-state, such as the Netherlands (see Kannisto, 2014, p. 224). However, the exclusion of Dutch students might not be a justifiable conclusion, since the VSNU data reported earlier suggests little increase in the number of them eligible to go to university (VSNU, 2020a) and future numbers are expected to fall (Vereniging Hogescholen \& VSNU, 2018). 


\section{Discussion}

Englishization, as shown in our analysis of the public controversy in the Netherlands, should not be reduced to the increase in EMI programmes in higher education. The controversy mainly concerned the loss of quality of education due to an alleged shortage of language proficiency, the increasing use of sources from the Anglophone world at the expense of sources from other cultures, and the decline of Dutch as an academic language. But a not unimportant aspect of Englishization concerns the non-academic world. This reflects the increase of English not only in business and commerce, especially due to economic globalization, but also in everyday life through tourism and popular culture (Schuyt \& Taverne, 2004).

There is an incongruity between the arguments voiced during the public controversy about Englishization and the discourse of the university administrators. The voices of those who intervened in the public debate were hardly taken seriously by the university administrators. This follows from our analysis of the language policies of Dutch universities as presented in their annual reports. University administrators must de jure comply with the national language policy. The legislation, however, offers university administrators so much discretionary space that they can thereby de facto always legitimize their language policy. For example, Twente and Maastricht legitimize contrariant language policies with a reference to the same legislation. The ease with which the universities do so shows that national language policy offers universities sufficient leeway to serve their own interests. Insofar as they pay explicit attention to language policy in their annual reports, they do not express concern about the future of Dutch as an academic language, let alone the consequences of Englishization - in their vocabulary 'internationalization' - for Dutch culture and society.

This incongruity between the views of university administrators on the one hand, and the eminent scholars and intellectuals who are concerned about the consequences of Englishization for Dutch culture and society on the other, is perhaps not surprising. Administrators in Dutch universities, as in many countries, manage according to the guidelines of the neoliberal New Public Management (NPM), as a result of which they defend interests other than those held by the stakeholders who question Englishization in the public sphere. The Englishization of higher education can be understood in the light of the impact neoliberalism has on academia (Breeze et al., 2019; Gupta et al., 2016; Pack, 2018). Neoliberalism, which proliferated around the world in the 1980s, entailed not only the deregulation and flexibilization of the markets, but also a different policy for government. Modelled according 
to the market, the government's services would arguably become better and cheaper. NPM, developed in the 1980s and 1990s, illuminated the way to do this. Proponents of NPM such as Peters and Waterman (1982) argue that the lesson from companies that perform excellently is that bureaucratic organizations must transform themselves into entrepreneurial organizations.

Universities were not spared the ideas of NPM (Lorenz, 2008). By modelling universities on the lines of companies, they would not only be better armed against the cut-throat competition in higher education but would also be enabled to achieve excellence (Münch, 2007). In a few decades, higher education has become a global market where universities compete to get the best possible return from education and research. Rankings have become the most important indicator of a university's market position. The ranking system has largely cultivated the Englishization of higher education. For instance, the number of EMI programmes is an indicator of whether or not a university ranks highly. Because the number of publications in so-called 'high-impact' international journals, which are predominantly Anglophone, also determines the ranking, the incentive to publish in a language other than English is diminished (Boussebaa \& Brown, 2017, p 11).

The discharge of NPM, which is responsible for Englishization, entails that the interests of some stakeholders are well represented and those of other stakeholders scarcely at all. Englishization meets the interests of university administrators and students who consciously choose EMI programmes. Gabriëls and Wilkinson (2020) show that although students do not complain about the quality of education, they are well aware of the impact that Englishization has on culture. According to a majority of the students, the quality of education is not negatively affected by Englishization, but EMI does result in Anglo-American cultural dominance. The present findings suggest that the students generally agree that EMI has deleterious effects on Dutch culture, as the critics of EMI claim. Englishization in higher education, it might be argued, leads to a perception of change in Dutch society that is not widely welcomed.

Our research suggests that the students, who have consciously chosen for EMI programmes, belong to an elite group, given the level of education of the parents and their degree of mobility. This gives rise to two issues. Firstly, do students who opt for EMI programmes displace students who want to follow Dutch-medium programmes? Apart from the Vereniging Hogescholen and VSNU (2018) report, which suggests a decline in the number of Dutch students, little is known. More research is needed into the possibilities and limitations of both Dutch and international students. Secondly, do foreign students contribute to the Dutch economy? This concerns ordinary citizens, 
who are also stakeholders. Many foreign students leave the Netherlands after their studies at a Dutch university. Their working stay-rate is seen as an indicator of their potential contribution to the Dutch economy. Approximately $25 \%-30 \%$ of international students remained working in the Netherlands seven years after graduation (EP-Nuffic, 2016, p. 10). ${ }^{7}$

In addition, many stakeholders are concerned about the future of Dutch as an academic language and its impact on Dutch culture, as language is important for social cohesion. Research by the Sociaal en Cultureel Planbureau (SCP, 2019) showed that the majority of Dutch people regard language as the most important element of their culture. Culture is, after all, a medium through which citizens express what is of value to them, and it might be expected that language policy therefore embodies those values. It is worth observing Dutch government practice regarding language policy and that of the EU.

On 2 September 2019, during a speech on the occasion of the opening of the academic year at the University of Leiden, the Minister of Education emphasized the firm place of the Dutch language in higher education and therefore the need to control internationalization (Van Engelshoven, 2019b). To reduce Englishization, the minister required that universities must present good arguments to demonstrate the added value of EMI programmes. Yet the amendment to the law that she proposed after her speech offers universities the opportunity to continue Englishization as they wish.

Article 165 (and elsewhere) of the Consolidated Treaty on the Functioning of the European Union emphasizes respect for 'the Union's rich cultural and linguistic diversity' (European Union, 2008). To promote cultural and linguistic diversity, a key objective of EU language policy is that every European citizen should master two other languages in addition to their mother tongue. Here too, reality is far removed from the multilingual values defended by the European Union. Few people master so many languages. While our research suggests that a large proportion of students have the required number of languages, this is not the case for the majority of Europeans. Moreover, the Dutch case illustrates that Englishization in practice, such as the universities of Eindhoven and Twente show, even implies embracing monolingualism.

Legislation and the associated language policy in the EU and the Netherlands enable many stakeholders to avoid concerning themselves about Englishization. They have an interest in ensuring that the increase

7 The current stay-rate yields a positive balance to the Dutch treasury of $€ 1.57$ billion annually. Each additional $1 \%$ adds approx. €6o million (EP-Nuffic, 2016, p. 20). 
in EMI programmes at Dutch universities is not politicized. However, the public debate about Englishization in the Netherlands has revealed many stakeholders who do politicize the increase in EMI programmes. For them, scientific knowledge should not be a commodity, but a common good, and Englishization should not lead to monolingualism. They are not against EMI programmes in higher education but are concerned about their predominance and the consequences for Dutch culture and society.

\section{Acknowledgement}

We are very grateful to the anonymous reviewers for their insightful comments and suggestions.

\section{References}

BON [Beter Onderwijs Nederland] (2018a). Jaarverslag 2017 [Annual Report 2017]. Retrieved 30 January 2021 from https://www.beteronderwijsnederland.nl/ verenigingsstukken/

BON (2018b, 6 July). Vonnis: rechter legt bal bij minister en Onderwijsinspectie [Decision: judge puts ball in the minister's and Education Inspectorate's court]. Retrieved 2 August 2019 from https://www.beteronderwijsnederland.nl

BON (2019a, 29 January). Reactie BON op voorgenomen wetswijziging taal in hoger onderwijs [Bon's reaction to proposed law change regarding language in higher education]. Retrieved 3 August 2019 from https://www.beteronderwijsnederland. $\mathrm{nl}$

BON (2019b, 29 March). Oproep aan de Tweede Kamer van 194 prominenten: volledige tekst [Appeal to the Senate from 194 eminent people: full text]. Retrieved 3 August 2019 from https://www.beteronderwijsnederland.nl

Boussebaa, M., \& Brown, A. D. (2017). Englishization, identity, regulation and imperialism. Organization Studies, 38(1), 7-29.

Breeze, M., Taylor, Y., \& Costa, C. (Eds.) (2019). Time and space in the neoliberal university: Futures and fractures in higher education. Palgrave Macmillan.

Bronkhorst, X. (2019, December 18). Wordt Engels de voertaal aan Nederlandse universiteiten? [Will English be the instructional language in Dutch universities?]. DUB (Utrecht University). https://www.dub.uu.nl/nl/nieuws/wordtengels-de-voertaal-aan-nederlandse-universiteiten

Christenhuis, E. (2002). Engelse leenwoorden in het Nederlands: Ergerlijke verengelsing? [English loan words in Dutch: Worsening Englishization]. Universiteit Utrecht: Wetenschapswinkel Letteren. 
Coy, D., Fisher, M., \& Gordon, T. (2001). Public accountability: A new paradigm for college and university annual reports. Critical Perspectives on Accounting, 12(1), 1-31.

Dekker, R. (2015). The road to ruin. Dutch universities, past, present and future. Panchaud Amsterdam.

Dixon, S. (2019, August 19). Dutch language out of stock: Why employers are switching to English speakers. Dutch Review.

Edwards, A. (2016). English in the Netherlands. Functions, forms and attitudes. John Benjamins.

Edwards, A. (2020). Language policy and the law: How Dutch universities legally justify English-medium instruction. Dutch Journal of Applied Linguistics [online]. DOI: 10.1075/dujal.19028.edw

EP-Nuffic (2016). Analyse stayrate van internationale afgestuurden 2007-2014 [Stay-rate analysis among international graduates]. Nuffic. https://nuffic.nl

European Union (2008). Consolidated version of the Treaty on the Functioning of the European Union. Article 165 (ex Article 149 TEC). https://eur-lex.europa. eu/legal-content/EN/TXT/?uri=CELEX\%3A12008E165

Field, A. (2018). Discovering statistics using IBM SPSS statistics (5th edition). Sage.

Gabriëls, R., \& Wilkinson, R. (2020). Resistance to EMI in the Netherlands. In H. Bowles \& A. C. Murphy (Eds.), English-medium instruction and the internationalization of universities (pp. 49-75). Palgrave Macmillan.

Gupta, S., Habjan, J., \& Tutek, H. (Eds.) (2016). Academic labour, unemployment and global higher education: Neoliberal policies of funding and management. Palgrave Macmillan.

Haines, K. B. J. (2020). Policy, principles and practices for the international classroom at a university in the Netherlands: How do we support the lecturers? In D. Gonzáles-Álvarez \& E. Rama-Martínez (Eds.), Languages and the internationalisation of education (pp. 61-79). Cambridge Scholars.

Inspectie van het Onderwijs [Education Inspectorate] (2018). Nederlands of niet: Gedragscodes en taalbeleid in het hoger onderwijs [Dutch or not: Codes of practice and language policy in higher education]. Ministerie van het Onderijs, Cultuur en Welzijn.

Jensen, L., Pas, N., Rovers, D., \& van Gulik, K. (Eds.) (2019). Against English. Pleidooi voor het Nederlands [Plea for Dutch]. Wereldbibliotheek.

Kannisto, P. E. (2014). Globalnomads: Challenges of mobility in a sedentary world. [Dissertation, Tilburg University]. Ridderprint. Retrieved accessed 7 December 2020 from pure.uvt.nl/ws/portalfiles/portal/3511053/Kannisto_Global_18_06_2014.pdf Knight, J. (2008). Higher education in turmoil: The changing world of internationalization. Sense. 
Kruse, J. (2016). Maxi-Min language use. A critical remark on a concept by Philippe van Parijs. Acta Univ. Sapientiae, European and Regional Studies, 9, 63-70.

Lorenz, C. (2008). De universiteiten en het New Public Management [Universities and New Public Management]. In C. Lorenz (Ed.), Ifyou're so smart, why aren't you rich (pp. 165-196). Boom.

Lorenz, C. (2012). If you're so smart, why are you under surveillance? Universities, neoliberalism, and New Public Management. Critical Inquiry, 38 (3), 599-629.

Ministerie van Financiën (2019). IBO Internationalisering van het (hoger) onderwijs [Internationalization of (higher) education]. Inspectie der Rijksfinanciën/Bureau Strategische Analyse.

Münch, R. (2007). Die akademische Elite: Zur sozialen Konstruktion wissenschaftlicher Exzellenz [The academic elite: On the social construction of academic excellence]. Suhrkamp.

Onderwijsraad (2011). Weloverwogen gebruik van Engels in het hoger onderwijs [Well-considered use of English in higher education]. Onderwijsraad.

Nuffic (2020). Regions and universities. Retrieved 13 November 2020 from https:// www.nuffic.nl/en/subjects/facts-and-figures/regions-and-universities

Pack, J. (2018). How the neoliberalization of academia leads to thoughtlessness: Arendt and the modern university. Lexington Books.

Parker, L. (2011). University corporatisation: Driving redefinition. Critical Perspectives on Accounting, 22, 434-450.

Peters, T., \& Waterman, R. (1982). In search of excellence: Lessons from America's best-run companies. Harper \& Row.

Pollitt, C., van Thiel, S., \& Homburg, V. (2007). New public management in Europe: Adaptation and alternatives. Palgrave Macmillan.

Rovers, D. (2019, November 20). We gaan toch niet die kuttaal praten? [We won't talk that crap language anyhow?]. De Groene Amsterdammer.

Rys, K., van der Meulen, M., Hinskens, F., Van der Gucht, F., De Caluwe, J., Heeringa, W., \& van der Peet, M. (2017). Staat van het Nederlands. Over de taalkeuzes van Nederlanders en Vlamingen in het dagelijks leven [State of Dutch. On the language choices of the Dutch and Flemish in daily life]. TaalUnie/Meertens Instituut/Universiteit Gent.

Schuyt, C.J.M., \& Taverne, E. (2000/2011). 1950. Welvaart in zwart-wit [Welfare in black-and-white]. SDU https://www.dbnl.org/tekst/schuo6gwelvo1_o1/ schuo69welvo1_01_0014.php

Schuyt, K., \& Taverne, E. (2004). Dutch culture in a European perspective: 1950, prosperity and welfare. Royal Van Gorcum/Palgrave.

SCP [Sociaal en Cultureel Planbureau] (2019). Thinking of the Netherlands. SCP. 
Shore, C., \& Wright, S. (2000). Coercive accountability. The rise of audit culture in higher education. In M. Strathern (Ed.), Audit cultures: Anthropological studies in accountability, ethics and the academy (pp. 58-89). Routledge.

Van der Sijs, N (1996). Leenwoordenboek. De invloed van andere talen op het Nederlands [Loan word book. The influence of other languages on Dutch]. SDU Uitgevers.

Van Engelshoven, I. (2019a, September 6). Kabinetsreactie op het interdepartementaal beleidsonderzoek Internationalisering van het (hoger) onderwijs [Cabinet reaction to interdepartmental policy research on Internationalization of higher education]. The Hague: Ministerie van Onderwijs, Cultuur en Welzijn.

Van Engelshoven, I. (2019b, September 2). Toespraak van minister Van Engelshoven bij de opening van het academisch jaar [Minister Van Engelshoven's speech at the opening of the academic year]. Universiteit Leiden. https://www.rijksoverheid.nl/ documenten/toespraken/2019/o9/o2/toespraak-van-minister-van-engelshovenbij-de-opening-van-het-academisch-jaar-aan-universiteit-leiden

Van Parijs, P. (2011). Linguistic justice for Europe and for the world. Oxford University Press.

Vereniging Hogescholen (2020). English. www.vereniginghogescholen.nl/english Vereniging Hogescholen \& VSNU (2018). Internationaliseringsagenda hoger onderwijs [Internationalization agenda for higher education]. Vereniging Hogescholen \& VSNU.

VSNU (2020a). Opleidingstaal universiteiten [Instructional language at universities]. Retrieved 13 November 2020 from https://vsnu.nl/taal-en-opleiding.html

VSNU (2020b). Feiten en cijfers [Facts and figures]. Retrieved 22 November 2020 from https://vsnu.nl/nl_NL/feiten-en-cijfers.html

Wilhelm, F. (2018). Foreign language teaching and learning in the Netherlands 1500-2000: An overview. The Language Learning Journal, 46(1), 17-27.

Wilkinson, R. (2013). English-medium instruction at a Dutch university: Challenges and pitfalls. In A. Doíz, D. Lasagabaster, \& J. M. Sierra (Eds.), English-medium instruction at universities: Global challenges (pp. 3-24). Multilingual Matters.

\section{About the authors}

ROBERT WILKINSON is a visiting Research Fellow in the Department of Philosophy at Maastricht University (Netherlands) and conducts research on English-medium instruction (EMI) and multilingualism. He previously worked at Maastricht University's Language Centre, and earlier in Scotland, Czechoslovakia and France. He is currently chair of the ICLHE Association. 
RENÉ GABRIËLS is a lecturer in philosophy at Maastricht University (Netherlands). His research concerns social philosophy, sociolinguistics, philosophy of language and sociology of stratification. He focuses on democracy, inequality, human rights, linguistic justice, poverty and the relation between semantics and pragmatics, with current research on English-medium instruction (EMI) at universities and on food banks. 



\title{
12 The Englishization of Polish higher education
}

\author{
Agnieszka Cierpich-Koziet and Elżbieta Mańczak-Wohlfeld
}

\begin{abstract}
In Poland, Englishization is subsumed under the concept of internationalization, which is considered a nationwide tendency of the development of the higher education sector. It is highly recommended to use English as a lingua franca of research and scientific communication, and it is common to implement programmes using English as a medium of instruction (EMI). Therefore, one of the key aspects discussed in this paper concerns the equalization of the status of Polish and English as languages of instruction. Other 'tangible' exponents of this English-Polish 'alliance' are to be seen in the area of job competition procedures, which have to be stated in both Polish and English. Emphasis is also placed on the development of English versions of university websites.
\end{abstract}

Keywords: internationalization, Englishization, research and scientific communication, educational offer, EMI

\section{Introduction}

In Poland, as in other European countries, Englishization is subsumed under the concept of internationalization, which is considered a nationwide tendency of the development of the higher education sector, whether stateowned or public. Universities in Poland are generally geared towards the internationalization of their research as well as their teaching process. This process started with the decline of communism, followed by the political and economic transformation of 1989. The lifting of the Iron Curtain opened

Wilkinson, Robert, and René Gabriëls (eds), The Englishization of Higher Education in Europe. Amsterdam, Amsterdam University Press 2021 DOI: 10.5117/9789463727358_CH12 
Poland to the West economically, socially, culturally, and linguistically. The foundation for the modern higher education (HE) system in Poland was originally set out in the Law on Higher Education (1990), passed on September 12, 1990 (Ustawa o szkolnictwie wyższym z 12 września 1990 roku $)^{1}$ (see below concerning a new law, the so-called Constitution for ScienceKonstytucja dla Nauki of 2018).

The chapter is divided into five parts, consisting of a short note on Polish language policy followed by an exploration of the use of English in diverse aspects of higher education. One of the most salient areas in which Englishization is prominent is that of academic publications, which we discuss in section 3. While less prominent, Englishization is further evident in teaching and learning as the increase in English-medium programmes demonstrates (section 4). The last two sections address the role of English in job competition procedures, and the development of English versions of university websites. As a result, the chapter aims to establish a twofold perspective of Polish HE. On the one hand, it is a system that lags behind some of the highly internationalized European HEs; on the other, it is a system that initiated radical moves towards internationalization, encouraged by recent national policies, and actions taken by Polish universities.

\section{Polish language policy}

The Polish language policy relates to the protection of the Polish language as the first language of $98 \%$ of the Polish population, the policy towards minority languages or dialects, and finally the policy of promoting the study of other languages. The origin of Polish language policy goes back to the 14th century, and thus prior to its recognition as a fully-fledged academic field of research (see Kuźniak \& Mańczak-Wohlfeld, 2016, who discuss a historical overview of Polish language policy). It is evident that in the history of the development of Polish, it has been influenced by a number of different languages including Latin, Greek, Czech, French, German, Italian, and Russian (to name but a few), and more recently English. Therefore it is no surprise to observe, both in the past and nowadays, concerns about language purity, which in 1996 led to the creation of The Council for the Polish Language (Rada Języka Polskiego), working under the auspices of

1 Retrieved 25 July 2020 from http://prawo.sejm.gov.pl/isap.nsf/download.xsp/ WDU19900650385/U/D19900385Lj.pdf. 
the Polish Academy of Sciences. Its aim has been to advise on and describe (rather than prescribe) linguistic behaviour among Polish language users, and the work of this legislative body led to the creation of the Polish Language Act in 1999. Its purpose, however, has been to protect Polish rather than to purify it, and also to minimize foreign influences rather than to eradicate them. A few amendments to the Language Act were introduced in 2004 and 2005. These appeared to be motivated by Poland's accession to the European Union (EU). The wording of the amendments places an emphasis on the promotion of bilingualism in certain formal communicative contexts and intends to appreciate the role of regional dialects or languages within Poland:

- the possibility of using a language other than Polish in commerce and in employment contracts (The Amendment to the Polish Language Act of 2 April 2004);

- the possibility of using minority and ethnic languages in local administration in districts where the users of the regional variant number more than 20\% (The Ethnic and National Minority Act of 6 January 2005).

The practical implications of the Act on the Polish language are naturally manifold and have been discussed in terms of actions undertaken both by governmental and non-governmental organizations and by individuals empowered with relevant prerogatives under the Act in question (Kuźniak \& Mańczak-Wohlfeld, 2016).

\section{The use of English in scientific publications written by Polish scholars}

Nowadays English is an unquestionable language of international communication and it is also used as a lingua franca in scientific publications and communication. In Poland it is a topic frequently debated by academics as well as by the media (among others, PAUza Akademicka, ${ }^{2}$ an electronic weekly of the Polish Academy of Arts and Sciences, and Gazeta Wyborcza, ${ }^{3}$ one of the most influential Polish daily newspapers).

2 PAU-za Akademicka. Tygodnik Polskiej Akademii Umiejętności. Retrieved 2 July 2020 from www.pauza.krakow.pl/502_2020.pdf.

3 Gazeta Wyborcza. Retrieved 3July 2020 from https://www.google.com/search?client=firefox-b$\mathrm{d} \& \mathrm{q}=$ gazeta+wyborcza. 
The use of English is always driven by international research cooperation. According to a report on the internationalization of Polish research and its visibility in the world (Kwiek, 2019), collaboration patterns in Poland and in other countries are not uniform, but depend on the scientific fields analysed (cf. Abramo et al., 2009; Lewis, 2013; Lewis et al., 2012). The most internationalized research areas in Poland are physical and mathematical sciences as well as life and medical sciences, which accurately reflects the state of affairs in other European countries (Rostan et al., 2014, pp. 133-136, cited in Kwiek, 2019, p. 45). While Polish researchers specializing in physical and mathematical sciences can boast a level of internationalization equal to their European colleagues $(\mathbf{1 2 0} \%),{ }^{4}$ all others, however, lag behind the European average. In life and medical sciences, the ratio of internationalization is $54.8 \%$, in social sciences and humanities only $47.5 \%$ (Kwiek, 2019, p. 45). Social sciences and humanities in particular are opposed to the use of English as a language of scientific communication for reasons such as:

- an inability to express oneself in a foreign language as well as in one's first language;

- the fact that matters specific to one's culture do not need to be written in English or any other foreign language.

Publication patterns in the social sciences and humanities (SSH) in different European countries were analysed by Kulczycki et al., (2018), who compared print patterns that occur across SSH publications in the Czech Republic, Denmark, Finland, Flanders (Belgium), Norway, Poland, Slovakia, and Slovenia. The data was collected on the basis of publications registered in national databases between 2011 and 2014; hence the results are no longer up to date. Nevertheless, it is worth quoting them here: 'In Poland, publications written in English constitute the smallest share of all SSH publications from all the analysed countries [...] Our findings show that Polish SSH scholars are comparatively less internationally oriented in their publication patterns in terms of writing in English' (Kulczycki et al., 2018, p. 481). More recently, Warchał and Zakrajewski (forthcoming) investigated publication practices in the SSH at the University of Silesia (Poland) and traced the share of multilingual publications in particular SSH disciplines. The survey among academic staff at the Faculties

4 The productivity ratio of researchers publishing their articles internationally to the ones publishing locally, in their mother tongue. The research embraced a three-year publishing period. 
of Humanities, Social Sciences, Law and Administration, and Arts and Educational Science yielded a response of 156 questionnaires. Warchał and Zakrajewska underline that:

With regard to the preferred languages of publication, the results, unsurprisingly, demonstrate that the two languages most frequently used for publication purposes in all disciplines are Polish and English, with virtually no disciplinary variation in the social sciences, where almost all the respondents reported using both.

The survey indicated that within the social sciences, $95 \%$ of the academics interviewed publish in Polish and $92 \%$ of them in English as well. In the humanities, $96 \%$ of the respondents report using Polish for publication purposes, while only $77 \%$ of them report publishing in English. Nevertheless, there appears a greater diversity of the foreign language texts published within the humanities: 'there are scholars, especially in linguistics and literary studies (traditionally multilingual disciplines in Poland), who choose to publish in other languages, especially in Russian, German, and French' (Warchał \& Zakrajewski, forthcoming).

For the purposes of this chapter, however, another question from the survey seems of utmost importance. When the respondents were asked about their main language of publication, $67 \%$ of them indicated Polish, followed by English, which was the most frequent language of publication for $22 \%$ of the participants. These results largely tally with the findings of Kulczycki et al. (2018) and Kwiek (2019), and lead to the rather pessimistic conclusion that the level of Englishization of the Polish SSH publications is by no means substantial. Additionally, the research conducted by Warchat and Zakrajewski (forthcoming) demonstrated that publications in languages other than Polish constitute the smallest part of the output of the prevailing majority of law and history scholars. The authors assert that this underlines the centrality of local problems and the commitment to local audiences in these research areas.

Thus, it follows that, if a linguist is concerned with, for instance, grammatical gender distinction in Romanian, it would be preferable to discuss it in Romanian rather than in English. The same holds true for other branches of modern languages. Yet, if the linguist is interested in more general matters, it is certainly worthwhile to write and present them in English. For example, the list of publications of the greatest Polish linguist, Jan Niecisław Baudouin de Courtenay, comprises about one thousand items, but most were written in Polish with a few exceptions in German, French, Russian, Italian, or 
Slovenian. The result was that, despite his intellectual prowess, he had little impact on Western linguistics (cf. Baudouin de Courtenay, 1908). This is unfortunate since he discovered various trends or made observations which were later put forward by other linguists, such as de Saussure's claim concerning the social character of language.

A similar observation could apply to specialists dealing with Polish culture or literature, as well as to historians concerned with Polish history. It is clear that certain facts related to any national culture, literature or history are of interest to the representatives of that nation and in most cases they should, and in fact are written in the national tongue. However, again there are exceptions, for example the history of Poland which has been popularized by Norman Davies' $(1972,1981)$ books which were written in English, or by Timothy Snyder's publications on the contemporary Polish political situation. Thus, the conclusion is the same as in the case of modern languages: research concerning more general matters or of potential interest to an international audience rather than a local one, would better be written in English to avoid sharing the fate of Baudouin de Courtenay.

All in all, it must be underlined that if researchers do not want to be isolated from scientific communication, they will have to use English at least now and in the foreseeable future. Obviously, it is not known whether English will remain the sole international language of science, as it is worth remembering that in the past first Latin, and later French and German, played the same role in academia that English now enjoys.

We would argue that Polish should only be used in scientific discourse in the few exceptional cases enumerated above. Many scholars will disagree with such a standpoint, as they oppose the dominant role of English in academia (see the above-mentioned debates in the media). A more modest proposal was made by Kokowski (2014) who, along with others, considered abstracts alone should be written in the congress languages, languages which apart from English include French, German, and Russian as well as Spanish and that the best scientific works within the social studies and humanities should be translated into these languages. Kokowski is aware that publications in, as he calls them, 'techno-bio-info' are in English anyway.

Despite our conviction of the necessity of using English as the lingua franca of science, we recognize an opposing view that favours a plural language policy within science, namely that of $\operatorname{Hamel}(2007)$ :

I have elsewhere argued in favour of a plurilingual enrichment model for Spanish as a language of science that might help to avoid a zero sum 
game and the 'either-or' dichotomy present in approaches that assume the unrestricted defence of a given language and foster monolingualism. Plurilingualism entails a view of intercultural communication where ones' own position or academic standpoint recognizes that other perspectives and procedures are also part of the possible world knowledge; or, to put it another way, that other valid positions and knowledge bases exist that may be formulated in terms of different languages, discourse structures and cultural models that define research paradigms. (Hamel, 2007, p. 67)

Hamel is not the only linguist who opposes the so-called scientific monolingualism (see Durand, 2001, 2006; Ehlich, 2001; or Phillipson, 2003). However, if we observe the present-day state of science, it seems that these views may be considered 'wishful thinking' (Mańczak-Wohlfeld, 2017).

Let us now turn to a consideration of some more general statistics.

\subsection{Publications in English}

The data in this subsection come from the Polish Ministry of Science and Higher Education ${ }^{5}$ which provided reports outlining the Englishization of the Polish HE. The data were retrieved from POL-on, The Integrated System of Information on Science and Higher Education, a central nationwide ICT system, and the PBN, that is Polish Scholarly Bibliography, which is one of the units of POL-on.

Table 12.1 below, provided by the Ministry of Science and Higher Education, presents a quantitative comparison of articles, books, and book chapters published in Poland both in total ${ }^{6}$ and in English, in the years 2015 to 2019 . The data were collected in the PBN which constitutes a basic source of information regarding academic achievements of Polish academic staff and institutions (Rozkosz, 2013, p. 2). In the PBN statistics, two criteria must be met in order to classify any publication as one published in English: a) the author(s) must have specified the language of the publication (English), and b) at least one of the authors registered in the PBN held Polish citizenship. Additionally, in the table, there are cases when the authors did not specify the language used. The data are included in order to provide a full picture of the issue in question, although they are not included in the percentage calculations, since there has been no possibility of identifying the language of the publication.

6 That is, in Polish and in other languages. 
Table 12.1 Articles, books and book chapters published in Poland in the English language

\begin{tabular}{|c|c|c|c|c|c|}
\hline PUBLICATION TYPE & 2015 & 2016 & 2017 & 2018 & 2019 \\
\hline ARTICLES (total) & 115655 & 114172 & 114472 & 104056 & 75791 \\
\hline Articles in English & 59942 & 63214 & 63778 & 63111 & 54416 \\
\hline $\begin{array}{l}\text { Percentage of English- } \\
\text { language articles }\end{array}$ & $52 \%$ & $55 \%$ & $56 \%$ & $61 \%$ & $73 \%$ \\
\hline $\begin{array}{l}\text { Articles with no language } \\
\text { specified }\end{array}$ & 64 & 84 & 217 & 149 & 371 \\
\hline BOOKS (total) & 13056 & 13103 & 11208 & 10104 & 7171 \\
\hline Books in English & 1817 & 1747 & 1621 & 1508 & 1055 \\
\hline $\begin{array}{l}\text { Percentage of English- } \\
\text { language books }\end{array}$ & $14 \%$ & $13 \%$ & $14 \%$ & $15 \%$ & $15 \%$ \\
\hline $\begin{array}{l}\text { Books with no language } \\
\text { specified }\end{array}$ & 41 & 38 & 39 & 17 & 20 \\
\hline BOOK CHAPTERS (total) & 68206 & 65701 & 58931 & 50663 & 31283 \\
\hline Book chapters in English & 17139 & 16787 & 15204 & 15762 & 10329 \\
\hline $\begin{array}{l}\text { Percentage of English- } \\
\text { language book chapters }\end{array}$ & $25 \%$ & $26 \%$ & $27 \%$ & $31 \%$ & $33 \%$ \\
\hline $\begin{array}{l}\text { Books chapters with no } \\
\text { language specified }\end{array}$ & 135 & 83 & 99 & 86 & 54 \\
\hline
\end{tabular}

The data in Table 12.1 yield a range of observations within the five-year period with reference to articles, books, and book chapters published in English. In general, our findings confirm those of Kulczycki et al. (2018, p. 464), who demonstrated that in different European countries, including Poland, the share of articles and the share of publications in English is on the rise. In 2015, more than half of Polish authors had invariably chosen to write their articles in English, and in 2019 almost three-quarters of them followed this trend. As Kulczycki et al. (2017) note, this accords with science policy in Poland, since recent regulations for the performance-based research funding system provide incentives for publishing in English.

When the issue of books written in English is taken into account, the figures are much lower and remain at approximately the same level (between $13 \%$ and $15 \%)$. Finally, the number of book chapters printed in English demonstrate the growing trend in the last five years (between $25 \%$ and $33 \%)$. It can be concluded that during the years 2015 to 2019 the rate of English-language publications in Poland increased substantially, particularly among the authors of articles. While there is also a general upward tendency 
in writing book chapters in English, monographs published in English, however, maintain a rate below one-fifth of the total number.

\subsection{International research collaboration}

In the Peer Review of Poland's Higher Education and Science System (2017, pp. 158-171), the so-called internationalization imperative is discussed. Among the key indicators which highlight the internationalization of $\mathrm{HE}$ and science in Poland, international research collaboration is enumerated. According to the report (2017, p. 164), in this respect, Poland underperforms compared to the EU average: 'Poland's international scientific co-publications per million inhabitants grew from 173.6 in 2010 to 254 in 2016, at the level of Latvia, and above Bulgaria and Romania, but clearly lagging behind the EU average of 463.' This is confirmed in studies conducted by Kwiek (2018, 2019), who notes (2019, p. 5) that, in 2017, the international publication co-authorship rate in Poland was $34.7 \%$ which was low in comparison to both $\mathrm{EU}_{15}(58 \%)$ and $\mathrm{EU}_{2} 8^{7}(56 \%)$. All in all, as far as international research collaboration is concerned, Poland's performance shows room for improvement.

To improve this state of affairs, the Polish governmental agencies support research development and have placed an increased emphasis on its internationalization that is manifested in the mandatory use of English. Their programmes are accessible to both Polish and foreign scientists, and their websites are in Polish and English. The widest variety of research project calls are offered by the following institutions:

1 The National Centre for Research and Development ${ }^{8}$ (NCBR: Narodowe Centrum Badań i Rozwoju). Among its main tasks there are management and execution of strategic research and development programmes, which lead directly to the development of innovativeness, as well as the support of commercialization of scientific research results.

2 The National Science Centre ${ }^{9}$ (NCN: Narodowe Centrum Nauki) supports basic research, defined as empirical or theoretical endeavours undertaken to gain new knowledge of the foundations of phenomena and observable facts, without any direct commercial use.

7 The term EU-15 refers to the 15 Member States of the EU prior to the accession of 10 candidate countries in 2004. The EU-28 was the abbreviation of the EU which consisted of 28 countries, until Brexit in 2020.

8 https://www.ncbr.gov.pl/en/

9 https://ncn.gov.pl/o-ncn/zadania-ncn?language=en 
3 The National Programme for the Development of the Humanities (Narodowy Program Rozwoju Humanistyki) which main aim, among others, is to financially support the translation into English of the best Polish works from within social studies and the humanities into English.

\section{The use of English in the teaching process}

\subsection{The legal perspective}

The issue of implementing foreign languages in the teaching process was first highlighted in Article 6 (1a) of the Law of Higher Education (1990), which states, 'all educational classes and knowledge or skills tests as well as diploma exams can be conducted in a foreign language.'

Poland's accession to the European Union in 2004 marked a landmark achievement for Polish higher education and since that time it has developed within the broader context of European education models. Gądek (2016, p. 7) highlights that the need to undertake education reforms in European Community countries has always been connected with rapid transitions in all areas of social life, brought about by globalization processes, advancement of technology, and mass communication, as well as by certain negative factors such as economic crises, unemployment, unwanted migration or international conflicts. The author concludes that under such circumstances it was essential to achieve comprehensive system solutions that would tackle these problems, accelerate development and enhance overall welfare. The starting point was a change in Member States' policies consisting in building competitive, knowledge-based societies and in adjusting the European education systems to the needs of both a modern economy and human personal development. Among the commitments made by EU members there was the consolidation of their education policies. Consequently, Poland followed the Bologna Process of creating the European Higher Education Area and joined the gradually emerging European Research Area (Kwiek, 2007, p. 87). Additionally, Poland has become a beneficiary of EU cohesion policy, investing in people's knowledge, skills, and competencies, which are crucial for both ensuring the long-term competitiveness of Europe and for helping all citizens to benefit from more and better jobs offer. ${ }^{10}$ For the Cohesion Policy in 2014-2020, it is education and training that constitute

10 Retrieved 27 July 2020 from https:/ec.europa.eu/regional_policy/en/policy/themes/ education-training/. 
one of the eleven priorities. ${ }^{11}$ In the Peer Review of Poland's Higher Education and Science System (2017, p. 10), an independent panel of experts comment on the condition of the Polish HE during past few years:

Poland is continuing its transition towards an open and globally competitive economy. It is aiming to reinforce its position on a European scale as a large and growing knowledge-based economy. An efficient higher education (HE) and science system is at the nexus of knowledge creation, education, innovation and economic growth. Despite past efforts to transform Poland's HE and science system, its performance and innovation outcomes remain sub-optimal. The government has therefore embarked on a new process of reform, the successful implementation of which is a prerequisite to achieving the country's goals. Designing and implementing these reforms successfully will require one or two decades of continuous and consistent efforts.

To remedy the above-mentioned condition of higher education, the Law on Higher Education and Science (Prawo o szkolnictwie wyzszym i nauce) was brought into force in 2018. It was the latest step towards the internationalization of Polish HE, introducing a change of the approach to education as well as conducting research and university governance. In 2020, the 120-page document was translated into English in order to facilitate and develop international cooperation in the manner asserted by the Ministry. In the Act, there are several explicit references to using foreign languages in general as well as the mandatory use of English while running higher education institutions.

\subsection{English and university enrolment}

In Poland, a certain proficiency level in a foreign language is commonly requested for higher education enrolment. At Polish academies, a pass at the Matura exam (A-levels), taken at the end of secondary school education, is required. The Matura exam comprises three compulsory exams, including one selected modern language. As reported by The Polish Central Examination Board ${ }^{12}$ (Centralna Komisja Egzaminacyjna), in 2019, out of 247,230

11 Retrieved 27 July 2020 from https:/ec.europa.eu/regional_policy/en/policy/how/priorities.

12 Centralna Komisja Egzaminacyjna. Sprawozdanie ogólne z egzaminu maturalnego 2019. [Matura examination 2019: The general report]. Retrieved 29 July 2020 from https://cke.gov.pl/ images/_EGZAMIN_MATURALNY_OD_2015/Informacje_o_wynikach/2019/sprawozdanie/ Sprawozdanie\%202019\%20-\%20Og\%C3\%Blne.pdf. 
graduates, 93.5\% sat their exam in English. German (4.4\%) and Russian (1.5\%) were the next languages of choice. This substantial discrepancy demonstrates both the popularity of the English language and an urgent need to have a command of it, to be able to function efficiently on the labour market, as well as within the globalized and digitalized societies of citizens of Europe.

Within 'the world's ranking of countries and regions by English skills' (2020), ${ }^{13}$ Poland ranks 14th in Europe, with a high rating on the EF English Proficiency Index, behind the Netherlands, Denmark, and Portugal but before Switzerland, the Czech Republic, and Italy. Secondary school graduates possibly contribute to this outcome.

\subsection{English as a medium of instruction (EMI) at Polish universities}

As far as the teaching process is concerned, internationalization of HE is evinced both in the English-language educational offer and in the number of foreign students in Poland. Before a detailed description of the varied English-language programmes, we present a brief overview of the incoming students. Firstly, it is not only the performance of the Polish science that remains sub-optimal. Until 2012/13, the ratio of the number of foreign students in Poland to the total number of students was exceptionally low and the weak activity of universities in acquiring students concerned all studies except for medical ones (Janczyk-Strzała \& Tomaszewski, 2013, p. 68). At present, there is still a lower percentage of foreign students than in the most developed OECD ${ }^{14}$ countries, including in the neighbouring countries like the Czech Republic, Hungary, Slovakia, or Lithuania (Perspektywy Education Foundation, 2021), not to mention Germany. On the other hand, though, a rapid increase in the internationalization ratio has been observable during the last 15 years, with 10,092 foreign students in 2005/06, 29,172 in 2012/13, and 78,259 in 2018/19. This upward trend proceeds from the wider EMI offer and its accessibility, attained partly via English versions of websites developed by most Polish universities (see section 6). In the academic year 2018/19, the dominant group of foreigners were students from Ukraine $(39,203)$ and Belarus (7314), Indians (3,571) ranking third, and Spaniards $(2,131)$ fourth. According to the Study in Poland Programme (2021), these numbers are steadily increasing and there are also more students coming from Turkey $(1,928)$, the Czech Republic (1,655), Germany $(1,315)$, China $(1,259)$ and Taiwan (917), as well as from several Asian and African countries. India and Kazakhstan 
are said to be the most prospective markets for Polish universities (Study in Poland Programme, 2021). These numbers lead to the conclusion that from year to year, the Polish student community is becoming increasingly open and multicultural, which seems to be a promising educational landscape.

The Englishization of academic programmes fosters the development of human capital which is key for knowledge-based economies. Therefore, in Poland, candidates are offered English-language programmes of ist (undergraduate), 2nd (graduate) and long cycle ${ }^{15}$ in humanities, social, exact, natural, and technical sciences, as well as numerous interdisciplinary programmes which combine knowledge and skills in various fields. ${ }^{16}$ The issue of English and other foreign languages within HE can be viewed from various perspectives. On the one hand, there are modern language studies, where students explore the language, literature, history, and culture of other countries. On the other, there are EMI programmes where a foreign language serves as a tool for acquiring specialized knowledge. In order to provide a broader picture of the internationalization of Polish HE, Cierpich and Sieradzka-Baziur (2020, p. 91) present the following data accessed from the Ministry of Higher Education and Science ${ }^{17}$ specifying: a) the number of modern language programmes and other programmes conducted in foreign languages, offered by 113 public and 233 non-public universities (Table 12.2) and b) the division of these programmes according to the language of instruction (Table 12.3). The latter table enables us to juxtapose the popularity of English with the popularity of other foreign languages.

Table 12.2 Modern language programmes vs EMI programmes

\begin{tabular}{lcc}
\hline University type & $\begin{array}{c}\text { Number of modern } \\
\text { language programmes }\end{array}$ & $\begin{array}{c}\text { Number of EMI } \\
\text { programmes }\end{array}$ \\
\hline $\begin{array}{l}\text { Public } \\
\text { (113 out of 130 such institutions in } \\
\text { academic year 2017/18) }\end{array}$ & 181 & 476 \\
\hline $\begin{array}{l}\text { Non-public } \\
\text { (233 out of 267 such institutions in } \\
\text { academic year 2017/18) }\end{array}$ & 109 & 273 \\
\hline TOTAL & & \\
\hline
\end{tabular}

15 Uniform Master's studies for selected majors.

16 See, for example, University of Warsaw: https://en.uw.edu.pl/education/ degree-programmes-1st-2nd-and-long-cycle-studies-bachelor-and-master/

17 The data presented in Cierpich and Sieradzka-Baziur (2020) reflected the beginning of the academic year 2018/19. 
Table 12.3 Foreign language programmes: Language of instruction

\begin{tabular}{lllll}
\hline University & Programme type & English & $\begin{array}{l}\text { English \& } \\
\text { Polish }\end{array}$ & $\begin{array}{l}\text { Other foreign } \\
\text { languages }\end{array}$ \\
\hline \multirow{2}{*}{ Public (state-owned) } & Modern language studies & 10 & 20 & 149 \\
& Other studies & 190 & 253 & 35 \\
\hline \multirow{2}{*}{ Non-public (private) } & Modern language studies & 19 & 23 & 67 \\
& Other studies & 35 & 220 & 18 \\
\hline TOTAL & & $\mathbf{2 5 4}$ & $\mathbf{5 1 6}$ & $\mathbf{2 6 9}$ \\
\cline { 2 - 5 } & & $\mathbf{1 0 3 8}$ & & \\
\hline
\end{tabular}

To sum up, in 2018, there were 290 modern language programmes and 749 EMI programmes. The widespread popularity of English can be easily discerned by comparing the number of programmes designed in English (254) and in both Polish and English (516), with the number of programmes studied in other foreign languages (269). Thus, out of 1,038 programmes with a foreign language of instruction in Poland, a vast majority of them, $770(74 \%)$, incorporated the use of English and $269(26 \%)$ preferred other foreign languages.

Let us consider the most popular BA and MA English-language programmes. In another report provided by the Ministry of Higher Education and Science (August 2020), it was possible to trace the most popular 1st, 2nd, and long cycle programmes with EMI. In the 2019/20 academic year, a total of 1,161,620 students were enrolled and 45,377 (4\%) chose English-only programmes. Table 12.4 lists the 15 most popular majors.

In Poland, apart from English-only programmes, there are at least three different educational models employing the contemporary lingua franca (Cierpich \& Sieradzka-Baziur, 2020, p. 90):

a programmes implemented both in English and in Polish;

b programmes run in Polish, with selected courses carried out in English as the language of instruction (EMI);

c programmes undertaken in Polish, blended with obligatory courses of English for professional purposes.

Additionally, Polish students are frequently obliged to complete foreign language courses. According to the latest official statistics (Statistics Poland [GUS], 2019, p. 32), in the 2018/19 academic year, $89 \%$ of students chose to learn English. 
Table 12.4 Most popular 1st, 2nd, and long cycle EMI programmes in Poland

\begin{tabular}{llc}
\hline $\begin{array}{l}\text { Position according } \\
\text { to the popularity }\end{array}$ & Programme & $\begin{array}{c}\text { Number of } \\
\text { students enrolled }\end{array}$ \\
\hline 1. & Medicine & 7676 \\
2. & Management & 6346 \\
3. & Computer Science & 3819 \\
4. & Finance and Accounting & 1849 \\
5. & Internal Security & 1261 \\
6. & Dentistry & 1227 \\
7. & Architecture & 943 \\
8. & Economics & 1054 \\
9. & International Relations & 1478 \\
10. & International Economic Relations & 851 \\
11. & Psychology & 638 \\
12. & Electronics and Telecommunications & 541 \\
13. & Construction and Building Systems Engineering & 540 \\
14. & Mechanical Engineering & 523 \\
15. & Veterinary Science & 444 \\
\hline
\end{tabular}

\section{Job competition procedures}

A few articles of the Law on Higher Education and Science rigorously enforce the use of English. Among others, the regulation pertains to job competition procedures, which has been stated as follows:

Art. 119 (4) Information on the competition shall also be available in English on the European Commission's website on the European portal for mobile researchers, designed for the publication of vacancies for researchers, within 30 days before the competition.

The Ministry of Science and Higher Education offers a nationwide 'Base of adverts of vacancy for scientific, academic and management of science positions in Poland. ${ }^{18}$ This English-language online service gathers information such as: name of the institution, position offered, voivodship (administrative subdivision in Poland), city, research area, and due dates. It also provides links to specific job offers. We have scanned ${ }^{19}$ the first 200 offers announced in September 2020. Interestingly, fluency in English was often one of the

18 http://www.bazaogloszen.nauka.gov.pl/en/

19 The date of our search was 1 October 2020, screening the first five pages. We analysed 200 out of 424 offers uploaded. 
formal requirements within the recruitment process, which follows the prevailing trend on the Polish job market. However, only 44 out of 200 $(22 \%)$ advertisements were published in English. Although there are certain native-language-specific programmes (e.g., Polish Studies), there are no reasons why other faculties or research units (e.g., medical, biochemical, or even modern language studies) should ignore the requirement to translate their job offers. The evident conclusion is that as far as the internationalization of job competition procedures is concerned, there is still much to be improved in Poland.

\section{Developing English versions of university websites}

For this chapter, we have screened (4-8 August 2020) the websites of all academic institutions in Poland, registered and supervised by the Ministry of Science and Higher Education, by the Ministry of Health (in the case of medical universities), by the Ministry of Marine Economy and Inland Navigation (in the case of maritime universities) and by the Ministry of Culture and National Heritage (in the case of higher schools of arts). In the record, there are, as mentioned above, two main types of academies: the public and the non-public ones, registered in the 2019/20 academic year. ${ }^{20}$ Among the public institutions, the following categories are differentiated: universities (18), universities of technology and higher schools of technology (18), universities of economics and higher schools of economics (5), universities and higher schools of pedagogy (5), universities and higher schools of agriculture (6), higher schools of sport (6), higher schools of theology (1), higher vocational schools (34), ecclesiastical Catholic universities and higher schools (7), medical universities (9), maritime universities (3) and higher schools of arts (20).

An in-depth analysis of all the higher education websites demonstrates that in the academic year 2019/20, out of 132 state-owned academies, a substantial majority (127, over 96\%) offer English versions. Most of them provide access to English versions of their university websites with oneto-one Polish equivalents, passing on information in an exhaustive and comprehensive manner. In this group, only seven institutions confined their English-language websites to guidelines for incoming/Erasmus students,

20 The totals of both public and private universities have changed in comparison with the academic year 2017/18. Interestingly, the number of latter has dropped significantly over the last three years (from 267 to 232 ). 
as well as some basic information about the academy. At the time of the research being carried out, the remaining five institutions (3.8\%) did not provide their online services in English.

As far as non-public institutions are concerned, 146 out of 232 (almost $63 \%$ ) run their websites in both languages in question. Similarly, the majority of them presented their educational profile in Polish and English counterparts. A smaller group possess an English language link; here, however, most attention is also focused on incoming/Erasmus students. Finally, the remaining group of non-public higher education schools (37\%) fail to present their educational offer in English.

Considering the research results, it seems significant to acknowledge that in Poland, although there are fewer public universities than private ones (132 and 232), this proportion is reversed when the issue of Englishization in the whole higher education system is evaluated. First of all, almost all state-owned schools (96\%) attract their candidates with English websites. Consequently, both Poles and foreigners are welcome to read in English, gain available information about a particular school, and compare various syllabuses. ${ }^{21}$ Secondly, $63 \%$ of private institutions duplicate the above illustrated model by providing the English language websites with announcements, notices, guidelines, and so on. All in all, the total number of higher education institutions that attract worldwide internet surfers with English version websites is 278 (out of 364 ). Hence, the conclusion is that the substantial majority $(75 \%)$ of Polish universities have followed the Law on Higher Education and Science where English language usage is encouraged.

\section{Table 12.5 English versions of university websites in Poland}

\begin{tabular}{ll}
\hline University type & English versions of university websites, August 2020 \\
\hline Public (state-owned) & 127 out of $132(96 \%)$ \\
Non-public (private) & 146 out of $232(63 \%)$ \\
\hline TOTAL & 273 out of $364(75 \%)$ \\
\hline
\end{tabular}

21 Among the documents we browsed, one of the most professional was the PDF booklet for international candidates prepared by Wrocław University of Science and Technology (2019/20). It provides detailed descriptions of all BA and MA programmes, including the specification of each semester, as well as the so-called entry information and job prospects descriptions. The file is available here: https://rekrutacja.pwr.edu.pl/fcp/DGBUKOQtTKlQhbxo8SlkTVQVQX208DAoHNiwFE1xVTnVBGıgnBVcoFW8SETZKHg/_users/code_LLl4ZIwVVYWQXwYtGAIUVwQCBDpiCAkXRzUN/dokumenty/prospectus_2019np.pdf 
In contrast, when we take into account universities with no English website $(24 \%)$, a variety of reasons may be suggested to justify this evidence. Some universities may have no intention of creating such English online services since they address their education offer to the local residents rather than foreigners. Another possible explanation is that fewer and fewer students are admitted to private colleges due to either the declining birth rate or avoiding tuition payment (state-owned schools are free of charge). Besides, there are possibly more prestigious colleges in nearby areas that propose similar profiles, as a result, fewer foreigners are interested in choosing these centres.

Finally, Englishization is also noticeable on the Polish versions of the university websites. It manifests itself in some advertising buzzwords attracting the Polish candidates. This phenomenon follows the general trend of selecting Anglicisms and English phrases in the genres of advertising in Poland. For example, the Polish Naval Academy (Akademia Marynarki Wojennej) employed the catchphrase 'It is your force, use it at AMW'.

\section{Conclusions}

In this chapter, we have presented a general overview of the state of Polish science and higher education in terms of Englishization. Firstly, some opening remarks were made on Polish language policy. Secondly, the Englishization of Polish research was discussed, predominantly with regard to publishing practices. As mentioned above, universities in Poland are generally geared towards the internationalization of their scholars' achievements by the requirement to publish valid and successful works in English, at least in the form of the resumé enclosed with the book or article if these are originally composed in a non-English language. We evidenced that in terms of publishing in English, Polish scholars specializing in exact sciences, natural sciences, and technical sciences are internationally oriented, unlike social sciences and humanities (SSH) researchers who remain comparatively less open to internationalization. Hence, it is advisable that the prominent SSH works be translated into the lingua franca of contemporary science. More to the point, we demonstrated that in Poland, the general share of publications in English is on the rise which proceeds from the national science policy, and accordingly, from the policies of the national agencies enhancing research. Thirdly, the Englishization of the teaching process stems mainly from Poland's EU membership. It is manifested by the consistent extension of the educational offer in the English language (inter alia English-only programmes, a wide variety of courses of English for professional purposes, English versions of 
university websites) which result in the greater competitiveness of Polish graduates on the job market.

The reported findings lead to the conclusion that English is of considerable, though not yet of cardinal importance within the dimensions of Polish HE discussed. During the last decade, Englishization has been the focal point of the changing educational landscape, but still, the scope of the phenomenon appears to be limited in comparison with some Western European countries.

\section{Acknowledgements}

We would like to thank the anonymous reviewers for their careful reading of our manuscript and their insightful comments and suggestions.

\section{References}

Abramo, G., D'Angelo, C. A., \& di Costa, F. (2009). Research collaboration and productivity: Is there correlation? Higher Education, 57, 155-171.

Baudouin de Courtenay, J. N. (1908). Ojęzyku pomocnicznym międzynarodowym. [On an international auxiliary language]. Drukarnia Literacka.

Cierpich, A., \& Sieradzka-Baziur, B. (2020). Specjalistyczna edukacja bilingwalna w szkolnictwie wyższym [Specialized bilingual education in higher education]. Wydawnictwo Naukowe Ignatianum.

Davies, N. (1972). White Eagle, Red Star: The Polish-Soviet War, 1919-20. Macdonald. Davies, N. (1981). God's Playground. A History of Poland. Oxford University Press.

Durand, C. (2001). La mise en place de monopoles du savoir [The establishment of intellectual monopolies]. L'Harmattan.

Durand, C. (2006). If it's not English, it's not worth reading! Current Issues in Language Planning, $7(1)$, 44-60.

Ehlich, K. (2001). Wissenschaftskomparatistik [Comparison in scientific research]. In K. Ehlich (Ed.), Mehrsprachige Wissenschafteuropäische Perspektiven - Eine Konferenz im Europäischen Jahr der Sprachen [Multilingual Science European Perspectives - A conference in the European Year of Languages] (pp. 7-10). Iudicium, 1.

Gądek, A. (2016). Koncepcje innowacyjnego ksztatcenia w reformujacym się szkolnictwie wyższym. Firma symulacyjna jako metoda dydaktyczna na studiach o profilu praktycznym [Concepts of innovative teaching methods in the changing higher education environment. Tourism industry simulation - a practice-oriented teaching method for the new profile specialization at a Higher Vocational School]. Wydawnictwa Państwowej Wyższej Szkoły Zawodowej w Tarnowie. 
Hamel, R. E. (2007). The dominance of English in the international scientific periodical literature and the future of language use in science. Association Internationale de Linguistique Appliquée, 20, 53-71.

Janczyk-Strzała, E., \& Tomaszewski, J. (2013). Aspects of internationalization of Higher Education Institutions in Poland. Perspectives of Innovations Economics and Business, 13(4), 67-73.

Kokowski, M. (2014). Podstawowe błędy mechanizmu oceny parametrycznej jednostek naukowych. Aspekt naukoznawczy [Basic mistakes in the parametric evaluation procedures of the research centres. A scientific approach]. PAUza Akademicka. Tygodnik Polskiej Akademii Umiejętności 246. Retrieved 2 July 2020 from: pauza.krakow.pl.

Kulczycki, E., Engels, T. C. E., Pölönen, J., Bruun, K., Dušková, M., Guns, R., Nowotniak, R., Petr, M., Sivertsen, G., Istenič Starčič, A., \& Zuccula, A. (2018). Publication patterns in the social sciences and humanities: Evidence from eight European countries. Scientometrics, 116 , 463-486.

Kulczycki, E., Korzeń, M., \& Korytkowski, P. (2017). Toward an excellence-based research funding system: Evidence from Poland. Journal of Informetrics, 11(1), 282-298.

Kuźniak, M., \& Mańczak-Wohlfeld, E. (2016). Language planning activities and policy: The case of Poland. Glottodidactica. An International Journal of Applied Linguistics, 43(2), 63-83.

Kwiek, M. (2007). The emergent European educational policies under scrutiny. The Bologna process from a Central European perspective. In V. Tomusk (Ed.), Creating the European area of higher education. Voices from the periphery (pp. 87116). Springer.

Kwiek, M. (2018). International research collaboration and international research orientation: Comparative findings about European academics. Journal of Studies in International Education, 22(2), 136-16o.

Kwiek, M. (2019). Umiędzynarodowienie badań naukowych i widzialność polskiej nauki w świecie. Raport I. [Research internationalization and visibility of the Polish Science abroad. Report I]. Seria raportów. Centrum Studiów nad Polityką Publiczną UAM.

Law on Higher Education (1990). (Ustawa o szkolnictwie wyższym z 12 września 1990 roku). Retrieved 25July 2020 from http://prawo.sejm.gov.pl/isap.nsf/download. xsp/WDU19900650385/U/D19900385Lj.pdf.

Law on Higher Education and Science (2018). Retrieved 2 August 2020 from: https:// www.gov.pl/web/science/constitution-for-science-in-english.

Lewis, J. M. (2013). Academic governance: Disciplines and policy. Routledge.

Lewis, J. M., Ross, S., \& Holden, T. (2012). The how and why of academic collaboration: Disciplinary differences and policy implications. Higher Education, 64, 693-708. 
Mańczak-Wohlfeld, E. (2017). Is English a lingua franca of scientific discourse in modern times? In B. M. Ilič \& V. Lopčič (Eds.),Jezik, Književnost, Vreme:Jezička Istraživanja (pp. 487-498). University of Niš.

Ministry of Higher Education and Science (2020). Report on the most popular BA and MA English-language programmes. [Report delivered for the purposes of this chapter.]

Peer review of Poland's higher education and science system 2017. Horizon 2020 Policy supportfacility. European Commission. Retrieved 28 July 2020 from https://rio. jrc.ec.europa.eu/sites/default/files/report/PSF-Peer_review_Poland_FINAL\%20 REPORT.pdf.

Perspektywy Education Foundation (2021). Study in Poland: Foreign students in Poland 2019. Retrieved 30 January 2020 from http://www.studyinpoland.pl/en/ nasze_moduly/view_full_guide/2019/82.pdf\#

Phillipson, R. (2003). English-only Europe? Challenging language policy. Routledge.

Rostan, M., Ceravolo, F.A., \& Scott Metcalfe, A. (2014). The internationalization of research. In F. Huang, M. Finkelstein, \& M. Rostan (Eds.), The internationalization of the academy: Changes, realities and prospects (pp. 119-144). Springer.

Rozkosz, E. (2013). Polska Bibliografia Naukowa - fakty i oczekiwania [Polish Scholarly Bibliography - facts and expectations]. Biuletyn EBIB [online]. Retrieved 15 July 2020 from: http://open.ebib.pl/ojs/index.php/ebib/article/view/124.

Statistics Poland, Statistical Office in Gdańsk (2019). Higher Education Institutions and their Finances in 2018. Retrieved 29 September 2020 from http://stat.gov.pl/ obszary-tematyczne/edukacja/.

Warchał, K., \& Zakrajewski, P. (forthcoming). Multilingual publication practices in the social sciences and humanities at a Polish university: Choices and pressures. DOI: 10.13140/RG.2.2.17059.99367/1

\section{About the authors}

Agnieszka Cierpich-KozieŁ, PhD, is an Assistant Professor at the Institute of Modern Languages of the Jesuit University Ignatianum in Kraków. She holds a master's degree in English Studies and German Studies and a PhD in linguistics. Her research interests lie in the fields of sociolinguistics and contact linguistics. She is a freelance interpreter.

ElżBieta MAŃCZAK-WOHLFELd is a full professor of English linguistics at the Jagiellonian University in Kraków. She has published over 140 papers and books. Since 2006 she has edited the journal Studia Linguistica Universitatis Iagellonicae Cracoviensis. Her academic interests concern contact linguistics, 
the influences of English on Polish and other European languages and English-Polish contrastive studies. 


\title{
13 Englishization 'under the radar'
}

\author{
Facts, policies, and trends in Austrian higher education \\ Monika Dannerer, Martina Gaisch, and Ute Smit
}

\begin{abstract}
Based on statistical information and policy texts, this chapter provides an overview and evaluation of the use and roles of English in traditional research universities and universities of applied sciences in Austria. While internationalization is interpreted and realized in different ways by different institutions, English functions as a central element. A factor supporting the widely unquestioned use of English might be found in the socio-economically strong position that German still enjoys in business, work-life, and higher education in Europe. This predominance is also noticeable in the utilitarian relevance awarded to both German and English in Austrian higher education, thereby failing to recognize the multi-layered relevance multilingualism could have in implementing internationalization policies that would go beyond Englishization practices.
\end{abstract}

Keywords: Austria, research universities, universities of applied sciences, language policy, internationalization

\section{Introduction}

English has made it into Austrian higher education institutions (HEIs), and it is here to stay. As one of many recent newspaper articles describes it:

Auf Englisch zu setzen, bringt für alle Beteiligten Vorteile. [...] Heimische Studenten können so während der Ausbildung einen Grundstein für eine Auslandskarriere legen. Aber auch die jeweilige Hochschule profitiert: Nicht nur Studierende aus anderen Ländern werden angelockt, sondern auch Gastprofessoren und Forscher. Das verschafft zusätzlich Renommee.

Wilkinson, Robert, and René Gabriëls (eds), The Englishization of Higher Education in Europe. Amsterdam, Amsterdam University Press 2021 DOI: 10.5117/9789463727358_CH13 
(The decision to use English is beneficial for everyone involved. [...] Local students can thus establish a foundation for careers abroad, but the respective universities also benefit: not only can they attract students from other countries, but also visiting professors and researchers. This also provides additional prestige.) ('Die Weltoffenheit vor der Tür', 5 April 2017, p. 4)

While such a welcoming and supportive evaluation of English-medium higher education (HE) might not be a surprising statement for 21st century Europe, it is noteworthy when put into a historical perspective. Upon its drastic rebirth after the First World War, Austria was founded as a largely monolingual country and, by acknowledging only the regional language rights of autochthonous minorities, has remained so ever since. Despite the increase of immigrant minorities and the thus growing societal multilingualism especially in urban areas, German has not only remained the main national language, but also the almost exclusive medium of all levels of education (De Cillia \& Vetter, 2013). On the tertiary level, for instance, the University of Vienna prides itself on being the oldest German-medium university in the world that still offers all its bachelor-level programmes in German (see 4.3. below). Despite this continuing self-image of a mainly German speaking nation, the political developments of the 1990s, especially joining the European Union and the Bologna process, made Europeanization and internationalization into a tangible force that impacted noticeably on language policies (LPs) and language practices. Instead of an originally envisioned European multilingualism made possible through mobility and language proficiency in the respective local languages (Haberland et al., 2013), general developments moved towards an entrepreneurial understanding of education and of knowledge as a marketable good (De Costa et al., 2019) where English-medium instruction is increasingly considered common place. With such a consumerist and utilitarian view of language inherent in Austrian policies, this has led to a present-day situation of widespread 'globalized bilingualism', combining German with English as main additional language in education, but also in other spheres of public and private life (Smit \& Schwarz, 2020).

For HE, this means that, even if German is still the dominant language, some form of Englishization is noticeable, in the sense that English now has an 'increased presence, importance and status' (Lanvers \& Hultgren, 2018, p. 1) in Austrian HEIs, so that we can speak of 'monoglossische[r] / monovarietäre[r] Habitus plus Englisch' ('a monoglossic/monovarietal 
habitus plus English') (Dannerer \& Mauser, 2018, p. 21). While this fact as such is typical of European countries in the 21st century - if it was not, we would not have this very volume - the question that is still open, and yet largely unattended to, is what Englishization looks like in Austrian HEIs. How is it identified and characterized? What realizations of Englishization can be found in different HEIs? How are these realizations perceived by different social actors? And what regulations have been put in place?

In view of the situated nature of all educational phenomena, it is the aim of this chapter to approach these questions in a context-sensitive and methodologically comprehensive manner, which is made possible by recent conceptualizations of LP research. In addition to the original focus on top-down language regulations, LPs are understood 'as a multilayered social and discursive process that involves interconnected texts, discourses and practices' (Bonacina-Pugh et al., 2020, p. 5). This implies that LPs need to be investigated within their respective ecologies, as they are not only made up of policy regulations, but also encompass the social players involved and how they see, think of, and enact their language choices. In other words, and as first clarified by Spolsky (2004), LPs combine language management, the social actors' beliefs regarding their languages and how they should be used where and when, as well as the actual language practices they engage in. Not surprisingly, such a multi-dimensional understanding also recognizes and aims to cater for conflict, competition, or controversy implicated in or resulting from the various forces involved (Dannerer, 2020; Darquennes et al., 2020; Johnson, 2013).

While a comprehensive LP coverage of Englishization of HE in one country would certainly go beyond the scope of a single paper, this chapter aims to apply such an ecologically sensitive LP approach when analysing the Englishization policies of the two main HE sectors, that is, traditional research universities and universities of applied sciences (UAS). Drawing on facts gathered from HEIs and their websites as well as from previous publications, section 4 offers insights into the present Englishization of selected traditional research universities, while section 5 does the same for UAS. Based on this factual information, section 6 argues for policy trends and discusses the roles and functions of English in Austrian HE. Beforehand, however, we will first provide an overview of Austrian HE LP in the context of internationalization and sketch the HE sector from a historical perspective. 


\section{Language policies and internationalization in Austrian HE}

While only one of many regular comments on Englishization in the Austrian HE sector (see Schwarz \& Smit, 2018), the newspaper article quoted in the introduction is prototypical of the public discourse on the internationalization of $\mathrm{HE}$ (IoHE) in more ways than the generally positive evaluation of using English for HE: it positions English as a prerequisite for student and staff mobility, thus expecting high levels of English language proficiency and, at the same time, reinforcing the widely held ideology of the utilitarian market value of English (Bonacina-Pugh et al., 2020; Liddicoat, 2016). Furthermore, it refers to this educational practice via the language as instrument - 'English medium' - rather than by identifying it as the process of Englishization. Although the latter point can be understood as reinforcing the instrumental ideology attached to languages, the absence of a German equivalent of this nominalized process is also indicative of the terminological preferences we find in Austria. Except for few cases of academics translating the English term, an Internet search for 'Englischisierung' led to no hits referring to the use of English in educational contexts: an unexpected result in view of the socio-political recency and topicality of the educational process. ${ }^{1}$

Revealing in its absence, there seem to be two reasons for this finding, one semantic and the other discourse-related. On the semantic side, 'Englischisierung' comes with clearly negative connotations as shown in the online search: instances of German being used in a supposedly Englishized way are usually evaluated critically. Such a negative semantic prosody obviously clashes with the generally positive reception of English-medium education. This semantically sound reason for avoiding the nominalization, however, also reverberates well with the general IoHE discourse. In a nutshell, if language features at all in Austrian internationalization policy texts, it does so infrequently, being marginalized to its perceived role as a means to an end. While such an 'invisibility of English' in the IoHE has been noted in other contexts as well (Dafouz \& Smit, 2020; Saarinen \& Nikula, 2013), one aggravating factor in the Austrian case is that, most likely caused by the

1 A Google search on 16 February 2021 for 'Englischisierung' resulted in 140 hits overall and 4 hits when combined with 'site:at'. The Austria-related hits deal almost exclusively with examples of what is identified as Anglicized German. Additionally, one blog entry criticizes Austrians for being surprisingly keen on Anglicisms (https://www.2stroke-tuning.com/moped-forum/ topic/54943-warum-fahren-\% 3 CB6sis-eig-so-auf-die-englische-sprache-ab/?tab=comment s\#comment-602214), while a few hits refer to German-medium academic texts that introduce the search term as a translation of Englishization in the context of higher education. 
monolingual ideology mentioned above, LPs are generally not attended to in the form of explicit language regulations (De Cillia \& Vetter, 2013). Instead, Austrian HEIs provide very general Development Plans that sketch their goals and steps required to reach them for the upcoming three years in all domains of the institution. While such documents reveal internationalization strategies as regards education, research and administration, they might - or, more often, might not - topicalize what linguistic resources should be used when engaging in any of these core HE activities (see sections 4 \& 5 below).

Such sidelining of language matters is also noticeable when turning to (wider) HE networks, two of which will be briefly touched upon here: the associations of research universities (called UNIKO) and of universities of applied sciences (called FHK). UNIKO has made internationalization into one of its main topics over the last few years (see https://uniko. ac.at/), discussing ways of developing and implementing matters such as international research cooperation, staff and student mobility, internationalized master's and $\mathrm{PhD}$ programmes, the international attractivity of Austrian HEIs, or dimensions of Europeanization, including trans- and interculturality. The roles and functions of language(s) in these strategies, however, are not topicalized at all. Instead, the relevance of language is downsized to a handful of instances when particular HEIs introduced specific changes in their official language use, such as when new English-medium master's programmes were started at the University of Life Sciences in Vienna (Annual Report, $2017)^{2}$ or when a new campus received bilingual labelling in German and English (Internationalisierungspanorama, 2013). ${ }^{3}$ In a similar vein, the current development and financing plan of the Austrian UAS sector ${ }^{4}$ puts little emphasis on language topics. In the section 'internationalization', the word 'English' only occurs once, namely regarding the increase of English-medium instruction (EMI). The rest is about internationalization at home, enhanced mobility, fair and transparent recognition of study periods abroad, and internationalization of the curricula. Moreover, the FHK Festschrift published on the occasion of the 25th anniversary of the UAS sector contains no reference to the roles of language(s). What is foregrounded with regard to internationalization are international

2 https://uniko.ac.at/organisation/jahresberichte/organisation/jahresberichte/dokumentation/

3 https://uniko.ac.at/modules/download.php?key=3074_DE_O\&f=1\&jt=7906\&cs=140A

4 https://www.bmbwf.gv.at/Themen/HS-Uni/Hochschulgovernance/Steuerungsinstrumente/ FH-Entwicklungsplan.html 
networks of the sector, student mobility, and the support services provided by international offices (FHK, 2020).

Such unitary and infrequent mentions of explicit language regulations elucidate the general laissez-faire approach taken to LPs in Austrian HE, which stands in stark contrast with the recommendations issued by the European Language Council (2013) for all HEIs to develop their detailed language regulations. These should 'determine the relative status and use of the languages employed in the institutions [...] [including] official language(s) [...] language(s) of communication [...] language(s) of instruction [...] [in relation to their] stakeholders / target audiences' (p. 2).

Having sketched the present LP in Austrian HE as generally reflecting a 'monoglossic habitus plus English', let us now zoom in on the matter by, firstly, outlining relevant recent historical developments in this educational sector in the next section before turning to the role and functions English fulfils first in traditional research universities and then in UAS institutions.

\section{Higher Education in Austria - a historical perspective}

During the 1990s, numerous European countries (e.g., the Netherlands, the UK, Finland, Germany) started to gradually implement a binary HE system consisting of research-intensive universities and more vocationally-oriented institutions, frequently referred to as university colleges, polytechnics, second-tier HEIs or UAS (Gaisch \& Aichinger, 2018). The latter focused primarily on teaching activities, graduate employability and their direct relevance to the local economy. Hence, they were centred on knowledge production, applied knowledge transfer and the formation of professionals (Gaisch \& Aichinger, 2018; Kohoutek et al., 2017) and less involved in basic scientific research (Kyvik \& Lepori, 2010). In 1993, Austria followed this trend and expanded its traditional HE system by implementing a UAS sector. The three main educational drivers for this development were diversification, deregulation, and increased permeability of the educational system (Beerkens, 2003; Gaisch \& Aichinger, 2018).

This contribution sheds light on the two major sectors in Austria, namely research universities and applied HEIs. Figure 13.1 provides a short overview of the 22 Austrian research universities, their intake of almost 270,000 students, 1,125 programmes and wide range of fields of study. 
Figure 13.1 Overview of Austrian Research Universities
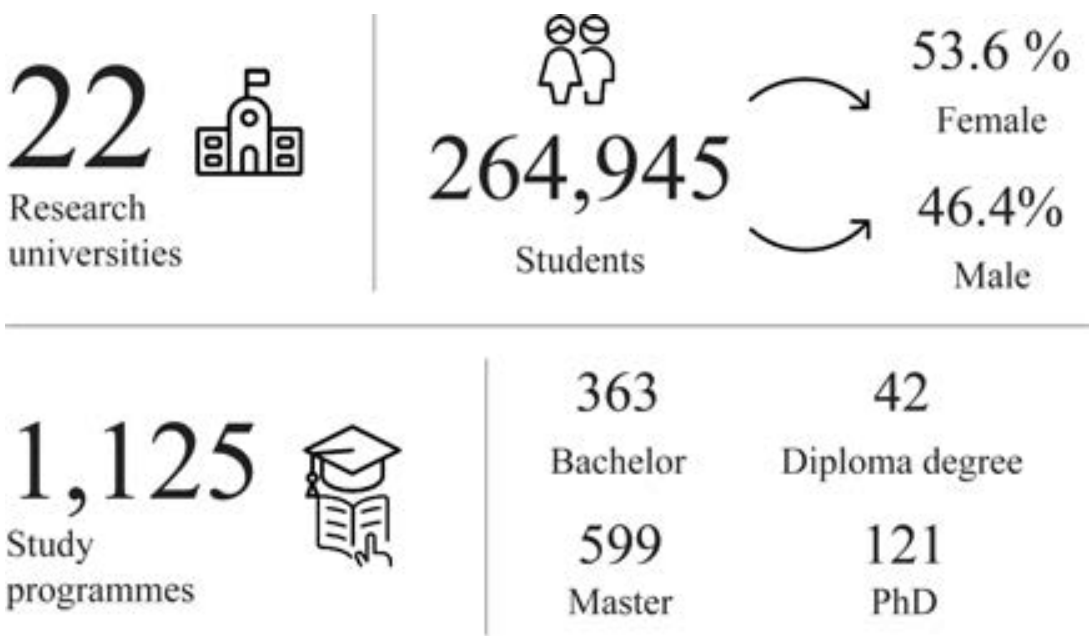

\section{Fields of study}

$\begin{array}{ll}\text { Humanities } & 25.8 \% \\ \text { Natural sciences } & 17.1 \% \\ \text { Engineering } & 16.4 \% \\ \begin{array}{l}\text { Social and } \\ \text { economic sciences }\end{array} & 14.6 \% \\ \text { Law } & 11.8 \%\end{array}$

$\begin{array}{ll}\text { Human medicine } & 4.7 \% \\ \text { Natural resources } & 3.5 \% \\ \text { Art } & 2.9 \% \\ \text { Mining engineering } & 1.4 \% \\ \text { Theology } & 0.8 \% \\ \text { Veterinary medicine } & 0.5 \%\end{array}$

Adapted from Statistik Austria and BMBWF, 2020

When zooming in on the Austrian UAS sector, it becomes apparent that it has steadily grown over the past 25 years since its establishment. Currently, 21 UAS institutions offer nearly 500 study programmes at 45 locations in 32 towns, with nearly as many bachelor's and master's degrees. Figure 13.2 illustrates the breadth of the UAS sector in more detail.

In sum, although small in size, Austria has a highly diversified and multifaceted system of HE, characterized by an above-average share of both new and old institutions (Niederl et al., 2014). In the academic year 2019/20, 376,050 students were enrolled at Austrian HEIs, of which 265,000 were at research universities and 55,000 at UAS. The remaining 
Figure 13.2 Overview of Austrian UAS sector

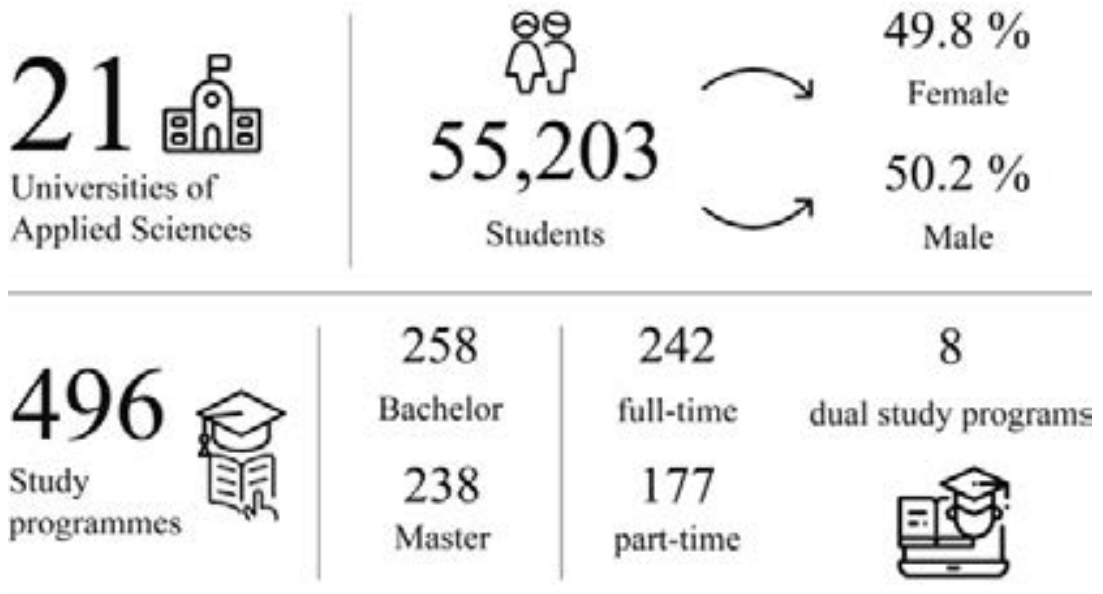

\section{Fields of study}

$\begin{array}{llll}\text { Economis } & 38 \% & \text { Social sciences } & 7 \% \\ \text { Engineering } & 37 \% & \text { Design and art } & 2 \% \\ \text { Health sciences } & 15 \% & \begin{array}{l}\text { Natural sciences, } \\ \text { military and security }\end{array} & 2 \%\end{array}$

Adapted from FHK, 2020

$5^{6,000}$ students study at private universities or teacher training colleges (Statistik Austria ${ }^{5}$ ).

The following two sections will provide an overview of the presence of English in both sectors. While this overview relies on a selection of the 'old' institutions, the 'young' UAS sector will be dealt with in its entirety.

\section{English at research universities}

Of the 22 Austrian research universities, we selected six institutions on the basis of purposive sampling. Three are traditional, comprehensive universities of different sizes and geographical situations: the University of Innsbruck ('Innsbruck'; 27,00o students) in the west, the University of Salzburg ('Salzburg'; 17,000 students) in the centre and the University of 
Vienna ('Vienna'; 89,00o students) in the east of Austria. Additionally, we included specialized universities: the Medical University of Vienna ('MED'; 8,000 students), the Technical University of Graz ('TEC'; 13,00o students) and the Vienna University of Economics and Business ('ECO'; 21,000 students). For this paper, we refer mainly to facts and figures that are available on the homepages of the universities.

\subsection{Development plans}

Research universities integrate remarks on their LP into the Development Plan (DP), a text of approx. 70-180 pages, which is renewed every three years and functions as the basis for negotiating public funding. Therefore, the addressee of these DPs is primarily the national Ministry of Education, but as the DPs are published also on the university homepages, the public must be considered a relevant addressee as well. While none of the universities treats the role of languages for research, teaching and administration with great emphasis, in a detailed manner or in a dedicated section, they do play a role in all DPs, except for the one of MED (DP-MED, 2017), where languages are not mentioned at all.

Although all DPs see English in the context of internationalization (DPInnsbruck, 2017, p. 56f., V; DP-Salzburg, 2018, pp. 22, 98; DP-TEC, 2017, p. 55; DP-ECO, 2017, pp. 44, 48), they foreground four different aspects of the relation:

a Mobility and exchange: English master's and $\mathrm{PhD}$ programmes are expected to make the universities attractive for incoming students and staff and facilitate the exchange of researchers and teaching staff as well as students (DP-Innsbruck, 2017, p. 56f.; DP-TEC, 2017, p. 98f.; DP-ECO, 2017, p. 28).

b Internationalization at home: master's programmes in English are also seen as part of an internationalization at home strategy (DP-Salzburg, 2018, p. 98; DP-TEC, 2017, p. 98) without considering any other languages for this purpose. Innsbruck is the only university to briefly mention Italian besides English as an important language in the 'Euregio' Tyrol - South Tyrol - Trentino (DP-Innsbruck, 2017, p. $\left.5^{2}\right){ }^{6}$

c Employability: Although this aspect is not foregrounded, English is seen as important for preparing students for the (international) job market (DP-Vienna, 2018, p. 126; DP-TEC, 2017, p. 97f.), for improving future career steps for young as well as senior postdoctoral researchers

6 While German and Italian are indeed official languages of this region, English does obviously not have such a regional anchoring. 
(DP-TEC, 2017, pp. 16, 42) and finally also for the present situation for academic and non-academic staff (DP-ECO, 2017, p. 43f., p. 48).

d Administration: A connection to administration is mainly drawn by ECO, mentioning central documents and circulars in English and trainings for different groups of employees (DP-ECO, 2017, pp. 19, 44, 48). TEC refers to English in the context of the library without going into details (DP-TEC, 2017, p. 111).

It is noteworthy that almost all DPs refer to either English or 'language' without specifying which language(s) are in focus. Only Salzburg mentions explicitly a 'breitgefächerte[s] Sprachenangebot[s] [broad offer of languages]' in the context of internationalization and speaks of a 'englischbzw. mehrsprachige[s] forschungsgeleitete[s] Lehrangebot [English resp. multilingual teaching/courses]' (DP-Salzburg, 2018, pp. 22, 98, 103). But even Salzburg's DP shows clearly that languages (beyond English) and language political issues are not consistently linked to internationalization: neither the interests of philological departments nor the offering of language courses are systematically mentioned. Instead, the use of English as an academic lingua franca is tacitly assumed (DP-Salzburg, 2018, pp. 97-99).

\subsection{Students}

In their official web-based documents, the universities usually give only the numbers of Austrian vs. international students. Information about the students' L1s is not available. In the academic year 2019/20 the percentages of international students lie between $23 \%$ (TEC) ${ }^{7}$ and $44 \%$ (Innsbruck ${ }^{8}$ ). ${ }^{9}$ Many of them come from Germany (in Innsbruck also from Italy, mainly from the German speaking part of the population in South Tyrol), thus they do not automatically stand for linguistic plurality. ECO is the only HEI investigated that makes available their students' countries of origin, which shows that a quarter of the internationals come from Germany, followed by students from Hungary, Italy (including South Tyrol), Bulgaria (each 5-6\%), Romania, Russian Federation, Serbia, Slovakia, Croatia, Poland (3-4\% each, with a declining percentage). ${ }^{10}$

7 https://online.tugraz.at/tug_online/StudierendenStatistik.html

8 https://www.uibk.ac.at/universitaet/profil/dokumente/uni-in-zahlen-2020.pdf

9 Salzburg gives only the percentage (33.5\%) and indirectly the numbers of students (PLUS Report, 2020, pp. 84, 87, 96).

10 https://www.wu.ac.at/fileadmin/wu/h/structure/about/publications/aktuelle_Broschüren/ Facts-Figures_web.pdf 
Figure 13.3 Numbers of bachelor's and master's programmes at focal HEls
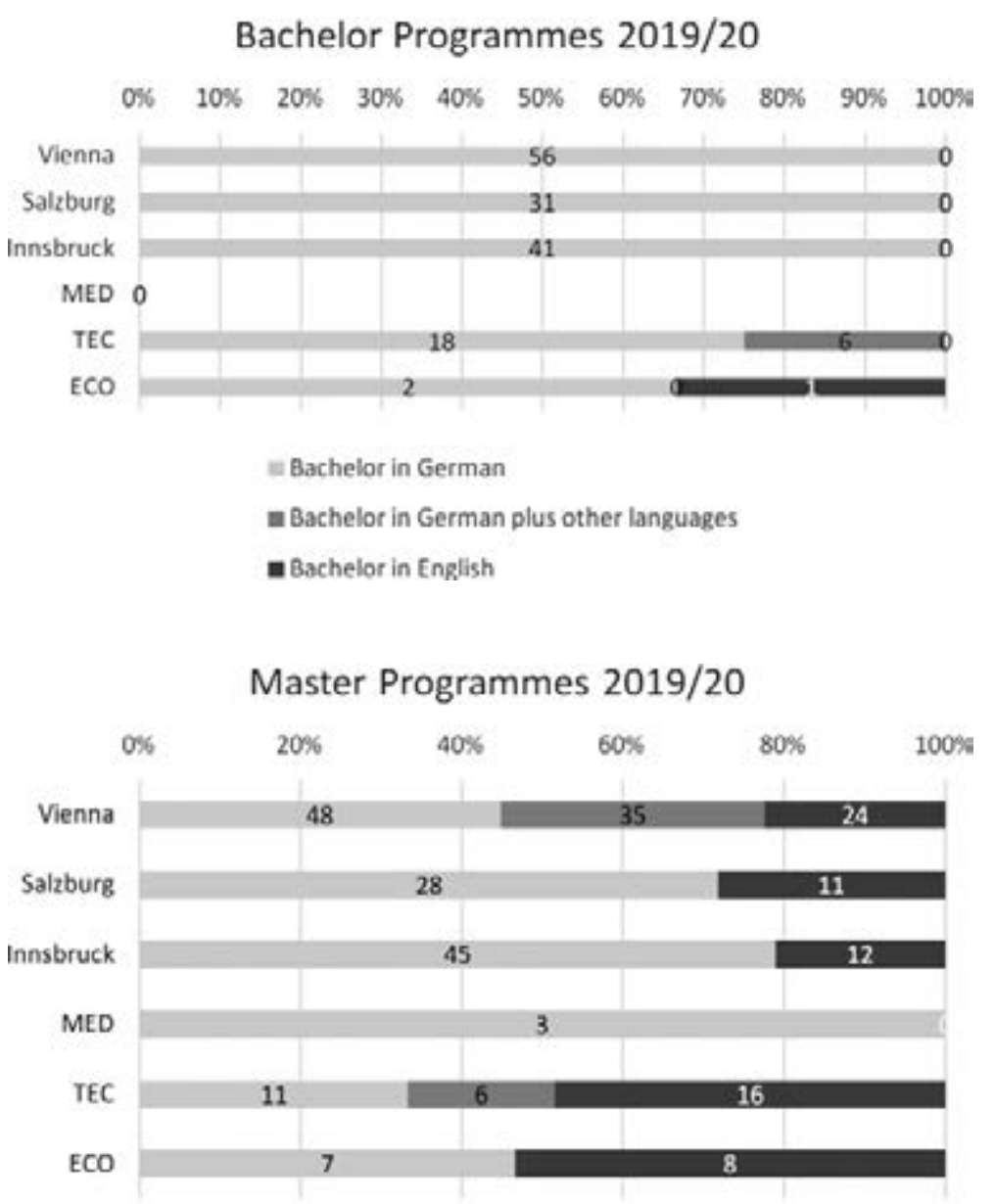

Easter in German = Master in German plus other languages master in English

\subsection{Teaching}

In teaching, the role of English clearly differs between bachelor's and master's programmes (see Figure 13.3). At the bachelor's level, only ECO offers one programme entirely in English. ${ }^{11}$ TEC has some programmes where English is explicitly required because 'some' or 'many' courses are taught in English. Except for MED, where English programmes are restricted to the $\mathrm{PhD}$ level, all universities run a certain percentage of their master's studies 
in English or indicate explicitly that some programmes require language skills other than German - either for courses taught in English, or for the different philological studies. There are seemingly no relations between the percentages of international students and the percentages of master's programmes in English.

The percentages of master's programmes entirely in English range between $21 \%$ and $22 \%$ (Innsbruck, Vienna) ${ }^{12}$ and $28 \%$ (Salzburg) ${ }^{13}$ for the full universities but $48 \%$ (TEC) and even $53 \%$ (ECO) for the specialized universities. TEC plans an increase to $60 \%$ by 2024 (DP-TEC, 2017, p. 57), which aligns well with their high percentage of publications in English (see next section) and the fact that all their PhD programmes are in English (DP-TEC, 2017, p. 6).

\subsection{Research and publications}

The DPs, just like LP documents (Darquennes et al., 2020, p. 29), do not give information about the expected languages for research-related activities, as they result from publication contexts and traditions of the specific fields. Except for MED, all universities provide the number of their yearly publications on their website, most of the time combined with the language of publication. ${ }^{14}$ In 2019 the percentage of publications in English lies between $43 \%\left(\right.$ Salzburg $\left.{ }^{15}\right)$ and $49 \%$ (ECO) on the one hand and $55 \%\left(\right.$ Vienna $\left.^{16}\right)$ and even $84 \%$ (TEC) on the other. For all universities, publications in languages other than German and English are quantitatively of almost no importance, ranging from $1 \%$ to $3.6 \%$.

For TEC and ECO, the available overview of the development of languages of publication over time shows how differently Englishization has gained in relevance in the various domains. Whereas TEC shows a massive growth of publications in English after 2010 (from 69\% to 84\%), the situation at ECO is stable during this time with English nearly as frequently used as German.

\footnotetext{
12 https://studieren.univie.ac.at/studienangebot/masterstudien/fremdsprachige-studien/

13 https://www.uni-salzburg.at/index.php?id=210369, and Plus Report (2020, p. 84).

14 ECO provided us with information on request; Innsbruck informed us that they do not collect the languages of publication systematically.

15 https://uni-salzburg.elsevierpure.com/en/publications/

16 https://ucris.univie.ac.at/portal/de/publications/search.html?search=\&uri=\&advanced= true \&organisations $=16849$ \&organisation Name $=$ Universit $\% \mathrm{C}_{3} \% \mathrm{~A} 4 \mathrm{t}+\mathrm{Wien} \&$ language $=\% 2 \mathrm{Fd}$ k\%2Fatira\%2Fpure\%2Fcore\%2Flanguages\%Figzure2Fen_GB\&publicationYearsFrom=2019\& publicationYearsT
} 


\section{English at universities of applied sciences (UAS)}

Just like the Austrian research universities, UAS institutions are not bound to any LPs. A website analysis of all 21 institutions (Gaisch \& Rammer, 2020) revealed that no significance was attached to either LP strategies or their implementation. Although it was found that importance was attributed to cultural variety and international and cross-border exchange, a commitment to linguistic diversity was not provided.

\subsection{Language policy}

Despite the lack of official LPs, the language of instruction policy and its practical implementation seem to be clear. English, by far the most frequently employed foreign language, is used as a lingua franca for all international programmes that seek to address a more (linguistically) diverse student population. This is particularly true for institutions of higher learning that are situated in urban areas. Traditionally, the majority of programmes in UAS institutions that are located in remote and rural regions are offered in German to cater for the needs of a (mainly) regional student body.

At the same time, there is little doubt that German will remain the major language of instruction in the future, not least because one substantial founding mandate of the sector was to open up HE to underrepresented (predominantly locally based) target groups (Gaisch \& Aichinger, 2018). In addition, further education and lifelong learning opportunities for adult and professionally qualified learners lie in the DNA of the UAS sector and are likely to be offered in German-medium instruction, also in the future.

Further arguments that may favour German as a medium of instruction are in line with the strong ties to local industries and the location of many UAS. Since a number of Austrian campuses are situated in rather remote places, they may not have the same broad appeal for internationally mobile students as traditional universities, which are mostly located in bigger cities.

\subsection{Students}

Given that the internationalization of programmes and student recruitment have become the new form of entrepreneurialism (Stromquist, 2007), also the UAS sector seeks to increase the number of international degree-seeking students. Overall, 10,000 or $18.1 \%$ of all students at the 21 Austrian UAS institutions come from abroad to complete their studies entirely in Austria 
(FHK, 2020). In contrast, $11 \%$ of all Austrian UAS students benefit from a study period abroad within the framework of a funded mobility programme, which totalled 6,052 students in the academic year 2018/19. During the same period, 3,902 international students completed a funded mobility stay at one of the Austrian UAS degree programmes (FHK, 2020).

Like research universities, the UAS sector hosts a high number of international students from Germany and South Tyrol, where 65\% of the population speaks German as an L1.

\section{$5 \cdot 3$ Teaching}

Figure 13.4 offers a general overview of English-taught study programmes in the Austrian UAS landscape.

In total, the Austrian UAS sector offers 8o programmes in English, which appears rather small in view of the large total number of study programmes (496). They are furthermore limited to the bachelor's and master's level, as the UAS sector does not have the right to award doctorates - a privilege still reserved for research universities.

Of the 20 bachelor's degree programmes in English, there are 15 full-time study programmes, mainly in the field of business administration. The English-taught part-time bachelor's degrees are provided in Business Administration, Banking, Innovation, Tourism, and Leisure Management. What is noticeable is the large number of master's study programmes in the STEM field (science, technology, engineering, and mathematics) - 26 compared to only four on the bachelor's level. Generally, the master's programmes can be divided in the broad categorizations of business administration (25), STEM (26) and Sports (4). Of the 55 master's programmes, 33 are offered full-time, 18 part-time and one as a dual study programme. In addition, there are five programmes of a hybrid nature, combining distance learning and part-time studies in the areas of business and STEM. When comparing these figures to the sum total of UAS study programmes (see Figure 13.2), there are two important comments to make: firstly, English-medium programmes amount to $16 \%$, and secondly, they fall mainly into the two areas of business studies and STEM.

It generally seems that the main benefits for the Austrian UAS sector in concentrating their internationalization efforts on EMI are similar to those of the UAS in the Netherlands (de Haan, 2014): providing international experience and knowledge to the local students and creating an international environment largely derived from an intensified recruitment of internationally mobile students (also see Gaisch, 2016; Wächter \& Maiworm, 2014). 
Figure 13.4 English-taught programmes at all Austrian UAS

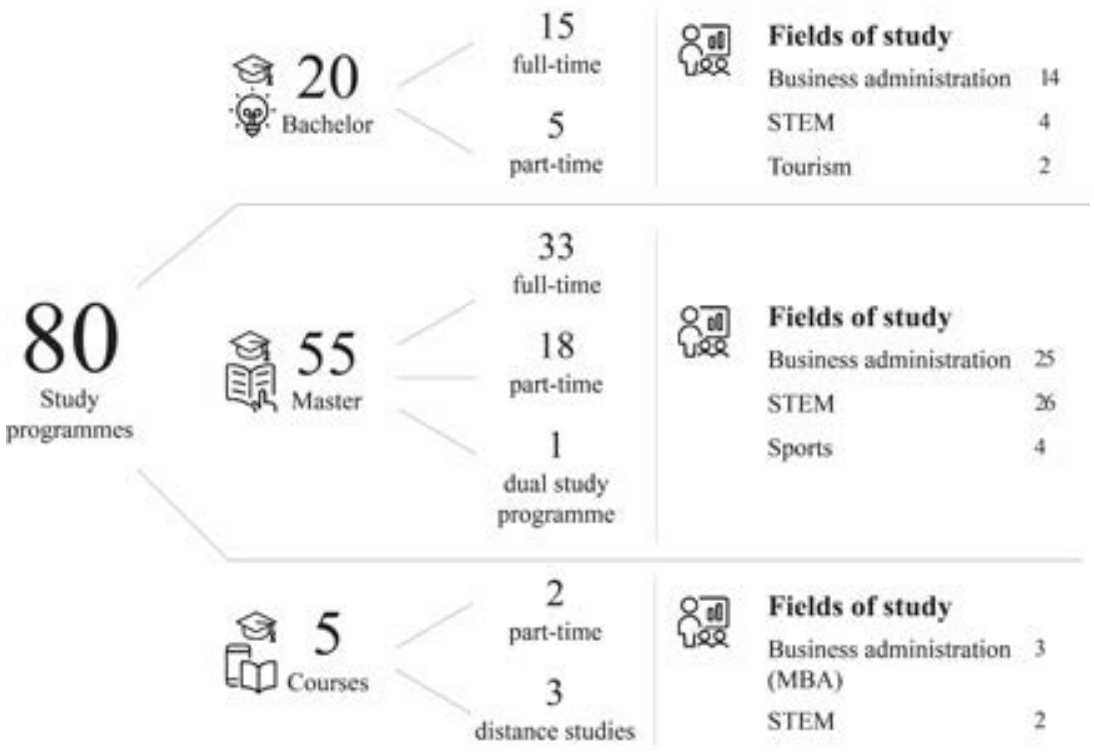

Adapted from https://www.fachhochschulen.ac.at/.

In addition, it is expected that university-level students are proficient in English, as they often find themselves in linguistically and culturally heterogeneous groups (Smit \& Dafouz, 2012). In the UAS sector, it is therefore the lecturer's responsibility to convey the content in ways that students are sufficiently prepared for a professional future in an international setting (Gaisch, 2014). In other words, content teachers need to teach through the medium of a second language, mostly without additional or accompanying English training. Their motivations were found to go beyond the mere use of the English language. Rather, they sought to gain an intercultural understanding of an international classroom setting and train their cognitive and mental flexibility (Earls, 2016; Gaisch, 2014).

\section{$5 \cdot 4$ Research}

At Austrian UAS institutions, (applied) research has become a crucial factor for internationalization work as it often offers added value or can even be the starting point for cooperation with cross-border partners.

Despite the regional embeddedness and practical orientation of Austrian UAS institutions in terms of student recruitment, curriculum content, and structure, some institutions of higher learning draw also on a broad 
international research community and have a very high research affinity, in terms of acquisition of third-party funds as well as the accompanying research output (nearly exclusively in English). With regard to the EU framework programme Horizon 2020, there are currently 18 participating UAS institutions. As stated in the language regime of Horizon 2020, communication with experts and applicants only takes place in English and most documents are only available in English. A further financial source for UAS is the European Regional Development Fund with 29 UAS participations and from the various Interreg programmes (e.g., Austria-Bavaria 2014-2020 with nine projects, or Austria-Czech Republic 2014-2020 with six projects; see Sabbatini \& Kastner, 2020).

With regard to Interreg programmes, it needs to be underlined that only those projects whose activities have a clear cross-border impact on the programme area will be supported. Frequently, these programmes draw on plurilingualism and seek to encourage linguistic diversity. For these purposes, documentation, dissemination, and research output are provided in both German and Czech. Given that there are 21 institutions at 45 locations in 32 towns, many of which are close to a cross-border region, this programme is particularly popular in the UAS sector.

\section{A critical account: Englishization 'under the radar'}

The overview of language-related facts and figures for Austrian HEIs provides us with a suite of insights:

a Practically all HEIs position themselves as (strongly) internationally oriented. While 'internationalization' can be interpreted differently, it is intrinsically combined with the use of English.

b Language in general and English more particularly are rarely topicalized in policy or strategy papers, except in the context of internationalization efforts or activities.

c Although there is no information on students' L1s, it can be assumed that the majority of local and international students are German-speaking, followed by L1 speakers of neighbouring languages.

d The majority of study programmes are offered in German, especially at the undergraduate level. While there are also more German-medium graduate programmes overall, English-medium master's programmes predominate at certain HEIs. Additionally, some multilingual master's programmes require more languages than English and German. 
e English-medium master's and $\mathrm{PhD}$ programmes cater for relatively small groups of students and, depending on the type of HEI, prepare for internationally oriented academic or professional expertise.

f Research is published, and presumably undertaken, in a range of languages, although English accounts for the largest proportion, with German a strong second. When split by discipline, German is preferred in some areas, such as law, theology, and elements of the humanities. In the natural and life sciences and technical disciplines, on the other hand, English is clearly in the lead.

g Individual multilingualism, while widely spread amongst all stakeholders, is not given any visibility at institutional level. Like individual language proficiency, it is not considered to be part of the institutional remit.

Reflecting the aim of our analysis, these points allow us to elaborate on what Englishization seems to amount to in Austrian HE. While internationalization and its local manifestations do not form the main concern of this paper, it certainly represents a fitting starting point as it is the main driving force of our HE language-scape, widened from its monolingual past to an officially recognized largely bilingual present. Irrespective of whether internationalization is associated with student and staff mobility, with research collaboration or with increasing professional employability, the respective endeavours are understood as also necessitating the use of English. The word 'also' is crucial in this context, as this generally unquestioned linguistic realization of internationalization has added English to institutional functions previously fulfilled by German exclusively. As evidenced in the facts collected from six traditional research universities and all 21 UAS, both English and German play crucial roles in financing and undertaking research and reporting its findings, in providing graduate and to a lesser extent undergraduate education, and in communicating HEI internally and, more noticeably externally (e.g., via websites). Looked at from a bird's eye perspective, Austrian HE thus engages in bilingual practices, reflecting the globalized bilingualism identified as characteristic of Austrian de facto LP more generally (Smit \& Schwarz, 2020).

When zooming into the subject matter, however, the situation becomes less clear-cut and more diversified. Starting with administration as the least visible aspect of HE activities, legal communication is restricted to German, official exchanges within international research groups and English-medium programmes rely on English, while online communication with the internet-based public takes place in both languages, representing one of the few instances of parallel language use. Third mission activities 
(e.g., knowledge and technology transfer, social engagement and the socio-economic development of the region) as the third pillar of HE next to teaching and research are predominantly carried out in German (Gaisch et al., 2019).

Such a mosaic of language choices is also noticeable in the educational activities reported above, employing German, English, and other languages in diverse constellations. German as the predominant medium of instruction at undergraduate level is complemented by English at the graduate levels, responding in varying degrees to disciplinary expectations as well as student constellations. Reflecting the socio-economic status of German in Europe, it comes with an added value, even to international students who may not be (very) proficient in it. This means that in addition to disciplinary preferences for using either English and/or German, both languages can also play a role for international students, some of whom already have or want to gain (some) proficiency in one or both languages.

When turning to research, publications come in a range of languages, depending on various factors, such as the authors' language repertoires and intended audiences, but, more importantly, the conventions and expectations of the disciplines in question. Nevertheless, no language besides English and German plays a quantitatively relevant role. While German was once the world's most important scientific language (Ammon, 2005), Austrian HEIs nowadays show different grades of Englishization in different research fields (see e.g., Dannerer, 2008). As the longitudinal analysis at TEC and ECO have shown, the technical fields seem to have moved to English almost exclusively over the last decades; business studies, however, combine both English and German. Clearly, such linguistic differences in academic publishing form a hurdle to a common Englishization strategy in this regard.

Perhaps more importantly, the meso-level overview of language choice has revealed a fundamentally utilitarian approach, in which either German or English is picked for engaging in research or education depending on perceived expectations and communicational needs. Such a pragmatically motivated language selection precludes a conscious decision for using both in, for instance, graduate programmes or research undertakings, thus reflecting a fundamentally monoglossic habitus, which draws on English in addition to German as locally established language (Dannerer \& Mauser, 2018). While this ideology has traditionally privileged German over all other languages, the same now holds true for German and English, thereby making way for an increasing Englishization of certain disciplines.

Such an ideology is arguably made possible by the general absence of explicit LPs. Thus, instead of clarifying their institutional language-related 
visions, Austrian HEIs miss the chance to guide language practices systematically and constructively. Development Plans remain vague as to when English or other languages should be employed, by whom, and for what. Consequently, all our analysis has brought to light are individual and somewhat haphazard references to medium of instruction or language proficiency levels, the former simply stated as a given for the respective degree programmes. Concerning the latter, the language skills of students are sometimes tested or, at least, required when entering study programmes, but they are not further developed systematically. The skills of teachers, on the other hand, are neither tested nor required before they begin to offer courses in English. Although there are English language courses for students, academic, and administrative staff, they are mainly voluntary and so limited in number that they could not support any widespread policy.

Languages besides English and German are present at universities as far as language competences of students and staff are concerned, but they are widely neglected for all programmes outside of philological studies (Dannerer, 2018, 2020). Thus, linguistic and cultural plurality in Austrian HE is not considered an asset that brings added value in terms of institutional diversity or internationalization at home. Interestingly, this holds true for both the traditional foreign languages in Austria, like French, Spanish, or Italian, as well as for frequent Lis of students, like Turkish or Bosnian/ Croatian/Serbian. This circumstance is all the more remarkable as a large linguistic knowledge base may have the potential to cater to the needs of a globalized employment market and also serve the purpose of enhanced graduate employability.

Apart from few language-related regulations, the absence of LPs also reveals that Austrian HEIs fail to acknowledge the crucial role languages play in and for research, education, and knowledge construction more generally (Ehlich, 2005). The assumption that teaching in English (or any other foreign language) simply requires the use of a different linguistic medium is persistent, particularly among content teachers (Gaisch, 2014). Awareness of the manifold effects EMI can have on educational practices is only sharpened in the event of substantial cultural misunderstandings (e.g., misconceived humour, different value structures and cognitive styles, face-threatening acts, various levels of hierarchy and formality, or lacking interactions). Only when such issues arise and are perceived as problematic - such as when cohorts suffer from severe student dropout rates - does the realization follow that there is so much more to teaching in another medium than language proficiency alone (Gaisch, 2014). Such localized insights into the complexity of inter-/transcultural education, however, have so far not 
had an impact on the Austrian HE landscape more generally: similar to 'language', questions of 'culture' have been largely sidelined in the context of internationalization and limited to vague statements, such as on the importance of 'international and intercultural skills' (BMBWF, 2020, p. 9). In other words, both 'culture' and 'language' are reduced to necessary and integral elements of internationalization. Except for individual moments of identifiable language-related trouble, the issue of language in general, and English in particular, remain 'under the radar' and thus out of sight. The lack of awareness of the importance of languages as well as the lack of discussion about language political issues allows for a 'non-addressed conflict' (Dannerer, 2020) between German and English, as well as a lack of awareness that EMI may undermine the status of other Lis.

This combination of positioning language as of little relevance in itself but as integral to the internationalization process shows that Austrian HEIs seem to buy into the widely held belief that language is a tool that is simple to use, leads to clearly identifiable results, and therefore does not need any further consideration. It is highly unfortunate that this one-sided view of language can also be detected in European papers on multilingualism and HE that most likely inform HEIs (Studer, 2021), since it fails to give full credit to the constitutive role language and languages fulfil in the educational and research practices we all engage in.

\section{Conclusion}

This chapter has focused on a selection of Austrian HEIs, six traditional research universities and all 21 UAS, with the aim to provide a critical account of the dynamically developing process of Englishization. In the absence of explicit LPs, English and other language practices are unreflectively steered by (perceived) communicative needs, thus underlining a fundamentally utilitarian approach to language that consistently downplays the constitutive role of language in education (Fairclough, 1993). Indicative of this commodified ideology, language matters are touched upon in other documents, such as Development Plans, and positioned as a means to an end, with the 'end' mainly being internationalization towards Europeanization: the global development towards a knowledge society that increasingly focuses on international dimensions in HE, and within Europe towards a Europeanization of HE policy (Huisman \& Van der Wende, 2004). This change of focus is a shift from a political to a more economic rationale where cost efficiency, international marketing, and student recruitment have been increasingly 
foregrounded (Gaisch, 2016). Reflecting Austria's geopolitical position, such endeavours can be undertaken advantageously by drawing on English and German, thus providing a marketable reason for why German will remain profitable and the Austrian HE sector will not Englishize completely.

\section{References}

Ammon, U. (2005). Welche Rolle spielt Deutsch als Wissenschaftssprache neben Englisch? [What role does German play as scientific language next to English?] In M. Motz (Ed.), Englisch oder Deutsch in Internationalen Studiengängen? (pp. 67-86). Lang.

Beerkens, E. (2003). Higher education in Austria. Country report. Center for Higher Education Policy Studies.

BMBWF (=Austrian Federal Ministry of Education, Science and Research) (2020). National mobility and internationalisation strategy for higher education 2020-2030. Retrieved 20 December 2020 from www.bmbwf.gv.at

Bonacina-Pugh, F., Barakos, E., \& Chen, Q. (2020). Language policy in the internationalisation of higher education in Anglophone countries: The interplay between language policy as 'text', 'discourse' and 'practice.' Applied Linguistics Review, 2020. DOI: 10.1515/applirev-2019-0148

Dafouz, E., \& Smit, U. (2020). ROAD-MAPPING English medium education in the internationalised university. Palgrave Macmillan.

Dannerer, M. (2008). Die Wissenschaft spricht Englisch. Und Deutsch?! [The scientific world speaks English. What about German?!]. In M. Nicolini (Ed.), Sprache, helldunkler Ort. Sprache im Dienst des Verstehens (pp. 59-68). Braumüller.

Dannerer, M. (2018). Mehrsprachigkeit als Programm. Mehrsprachigkeit wider Willen? Universitäre Mehrsprachigkeit zwischen Verpflichtung und Unwissenheit [Plurilingualism as program. Plurilingualism unintentionally? University plurilingualism between obligation and ignorance]. In M. Dannerer \& P. Mauser (Eds.), Formen der Mehrsprachigkeit. Sprachen und Varietäten in sekundären und tertiären Bildungskontexten (pp. 421-440). Stauffenburg.

Dannerer, M. (2020). The university as a terrain for hidden language conflicts? German, English and the silence beyond them. In J. Darquennes, J. Soler, \& T. du Plessis (Eds.), Multilingualism in higher education (Sociolinguistica 34) (pp. 131-154). De Gruyter.

Dannerer, M., \& Mauser, P. (2018). Innere und äußere Mehrsprachigkeit in Bildungsinstitutionen - vom Nutzen einer übergreifenden Perspektive. [Internal and external plurilingualism in educational institutions: The benefits of an extensive perspective.] In M. Dannerer \& P. Mauser (Eds.), Formen der 
Mehrsprachigkeit. Sprachen und Varietäten in sekundären und tertiären Bildungskontexten (pp. 9-26). Stauffenburg.

Darquennes, J., Soler, J., \& du Plessis, T. (Eds.) (2020). Multilingualism in higher education (Sociolinguistica 34). De Gruyter.

De Cillia, R., \& Vetter, E. (Eds.) (2013). Sprachenpolitik in Österreich: Bestandsaufnahme 2011 [Language policy in Austria: Review 2011]. Peter Lang.

De Costa, P. I., Park, J., \& Wee, L. (2019). Linguistic entrepreneurship as affective regime: Organizations, audit culture, and second/foreign language education policy. Language Policy, 18(3), 387-406.

De Haan, H. (2014). Internationalization: Interpretations among Dutch practitioners. Journal of Studies in International Education, 18(3), 241-26o.

Die Weltoffenheit vor der Tür [Open-mindedness right on your doorstep]. (2017, April 5). Kurier, 4.

DP-ECO (2017). Entwicklungsplan der Wirtschaftsuniversität Wien [Development plan of the Vienna University of Economics and Business]. Retrieved 6 December 2020 from https://www.wu.ac.at/fileadmin/wu/h/structure/servicecenters/hr/Mitteilungsblatt/Juli_2017/Entwicklungsplan_web.pdf

DP-Innsbruck (2017). Entwicklungsplan 2019-2024 [Development plan 2019-2024]. Retrieved 6 December 2020 from https://www.uibk.ac.at/zentraler-rechtsdienst/ entwicklungplan-aenderung-stand-03.11.2020.pdf

DP-MED (2017). Entwicklungsplan der Medizinischen Universität Wien 2019-2024 [Development plan of the Medical University of Vienna 2019-2024]. Retrieved 6 December 2020 from Microsoft Word -14_MB_20171220 MB Entwicklungsplan 2019-2024.docx

DP-Salzburg (2018). Entwicklungsplan 2019-2024 Paris Lodron Universität Salzburg [Development plan 2019-2024 of the Paris Lodron University Salzburg]. Retrieved 6 December 2020 from Entwicklungsplan_der_Universität_Salzburg_2019-2024_Version_2.pdf

DP-TEC (2017). Entwicklungsplan 2018plus [Development plan 2018plus]. Retrieved 6 December 2020 from https://www.tugraz.at/fileadmin/public/Studierende und_Bedienstete/Information/TU_Graz/Entwicklungsplan/Entwicklungsplan. pdf

DP-Vienna (2018). Universität Wien 2025. Entwicklungsplan [University of Vienna 2025. Development plan]. Retrieved 6 December 2020 from https://www.univie. ac.at/rektorenteam/ug2002/entwicklung.pdf

Earls, C. W. (2016). Evolving agendas in European English-medium higher education: Interculturality, multilingualism and language policy. Palgrave Macmillan.

Ehlich, K. (2005). Deutsch als Medium wissenschaftlichen Arbeitens [German as a medium for scientific work]. In M. Motz (Ed.), Englisch oder Deutsch in Internationalen Studiengängen? (pp. 41-51). Lang. 
European Language Council (2013). Higher education language policy. Retrieved 20 December 2020 from http://www.celelc.org/activities/Working_groups/ Concluded-Working-Groups/Resources_Working_Groups/HE_Language_Policy_-_Final_2013_w_summary.pdf

Fairclough, N. (1993). Critical discourse analysis and the marketization of public discourse: The universities. Discourse \& Society, 4(2), 133-168.

FHK (= Österreichische Fachhochschulkonferenz) (2020). Sie haben doch keine Ahnung von Fachhochschulen. 20 Jahre Fachhochschulen [You don't have a clue about Universities of Applied Sciences. 20 years of Universities of Applied Sciences]. Retrieved 16 December 2020 from https://www.fhk.ac.at/wp-content/ uploads/2020/08/FHK-Zahlen-Daten-Fakten-12.Maerz-2020.pdf

Gaisch, M. (2014). Affordances for teaching in an international classroom. A constructivist grounded theory [Unpublished doctoral dissertation, University of Vienna]. Retrieved 16 December 2020 from http://othes.univie.ac. at/36432/1/2014-12-09_8860295.pdf

Gaisch, M. (2016). Internationalisation strategies of higher education institutions: A look at universities of applied sciences in Austria. Forschungsforum der Österreichischen Fachhochschulen 2016, Vienna, Austria. Retrieved 16 December 2020 from http://ffhoarep.fh-ooe.at/bitstream/123456789/642/1/115_208_Gaisch_FullPaper_en_Final.pdf

Gaisch, M., \& Aichinger R. (2018). Second-tier higher education institutions and the diversity challenge: Structural components adopted through a Germanic lens. In R. Latiner Raby \& E. Valeau (Eds.), Handbook of comparative studies on community colleges and global counterparts (Springer International Handbooks of Education) (pp. 217-233). Springer. DOI: 10.1007/978-3-319-50911-2_7

Gaisch, M., Noemeyer, D., \& Aichinger, R. (2019). Third mission activities at Austrian universities of applied sciences: Results from an expert survey. Publications, 7(57), 1-14. Retrieved 16 December 2020 from https://www.mdpi.com/2304-6775/7/3/57/ htm

Gaisch, M., \& Rammer, V. (2020). Wie Profilbildung und Vielfaltsmanagement ineinandergreifen: eine Website-Analyse des österreichischen FachhochschulSektors [On how profile formation and diversity management are intertwined: a website analysis of the Austrian sector of Universities of Applied Sciences]. Zeitschrift für Hochschulentwicklung, 15(3), 259-280.

Haberland, H., Lønsmann, D., \& Preisler, B. (Eds.) (2013). Language alternation, language choice and language encounter in international tertiary education. Springer.

Huisman, J., \& Van der Wende, M. (2004). The EU and Bologna: are supra- and international initiatives threatening domestic agendas? European Journal of Education, 39(3), 349-357. 
Johnson, D. C. (2013). Language policy. Palgrave Macmillan.

Kohoutek, J., Pinheiro, R., Čábelková, I., \& Šmídová, M. (2017). Higher education institutions in peripheral regions: A literature review and framework of analysis. Higher Education Policy, $30(4)$, 405-423.

Kyvik, S., \& Lepori, B. (Eds.) (2010). The research mission of higher education institutions outside the university sector: Striving for differentiation. Springer.

Lanvers, U., \& Hultgren, A. K. (2018). The Englishization of European education: Foreword. European Journal of Language Policy, 10(1), 1-11. DOI: 10.3828/ejlp.2018.1

Liddicoat, A. J. (2016). Language planning in universities: Teaching, research and administration. Current Issues in Language Planning, 17(3-4), 231-241. DOI: 10.1080/14664208.2016.1216351

Niederl, A., Bonaccorsi, A., Lepori, B., Brandt, T., De Filippo, D., \& Schmoch, U. (2014). Mapping the European higher education landscape: New insights from the EUMIDA project. In A. Bonaccorsi (Ed.), Knowledge, diversity and performance in European higher education (pp. 1-13). Edward Elgar Publishing.

PLUS Report (2020). PLUS Report 2020. Retrieved 20 December 2020 from https:/ www.uni-salzburg.at/fileadmin/multimedia/PR_Kommunikation/documents/ Plus-Report_2020.pdf

Saarinen, T., \& Nikula, T. (2013). Implicit policy, invisible language: Policies and practices of international degree programmes in Finnish higher education. In A. Doiz, D. Lasagabaster \& J. M. Sierra (Eds.), English-medium instruction at universities: Global challenges (pp. 131-150). Multilingual Matters.

Sabbatini, G., \& Kastner, J. (2020). Forschung \& Entwicklung an Fachhochschulen in Österreich: Leistung und Erfolgsgeschichte trotz herausfordernder Rahmenbedingungen? [Research \& development at Universities of Applied Sciences in Austria: Performance and success story despite challenging circumstances?] Elektrotech. Inftech, 137, 3-10. DOI: 10.1007/s00502-019-00775-8

Schwarz, M., \& Smit, U. (2018, October 26). English in Austria and how it is topicalized in newspaper discourse. 44th Conference of the Austrian Linguistic Society, Innsbruck, Austria.

Smit, U., \& Dafouz, E. (2012). Integrating content and language in higher education: An introduction to English-medium policies, conceptual issues and research practices across Europe. AILA Review, 25(1), 1-12.

Smit, U., \& Schwarz, M. (2020). English in Austria: Policies and practices. In R. Hickey (Ed.), English in the German-speaking world (pp. 294-314). Cambridge University Press.

Spolsky, B. (2004). Language policy. Cambridge University Press.

Statistik Austria (2020). Retrieved June 2020 and adapted from https://www. statistik.at/web_de/statistiken/menschen_und_gesellschaft/bildung/hochschulen/index.html 
Stromquist, N. P. (2007). Internationalization as a response to globalization: Radical shifts in university environments. Higher Education, 53(1), 81-105.

Studer, P. (2021). Internationalization, quality and multilingualism in higher education: A troublesome relationship. In F. D. Rubio-Alcalá \& D. Coyle (Eds.). Developing and evaluating quality bilingual practices in higher education (pp. 9-30). Multilingual Matters.

Wächter, B., \& Maiworm, F. (2014).English-taught programmes in European higher education. The state of play in 2014. Lemmens.

\section{About the authors}

MONIKA DANNERER is professor of German Linguistics at the University of Innsbruck, Austria. Her research in Applied Linguistics and Sociolinguistics is currently focused on first and second language acquisition and language attitudes, as well as multilingualism and repertoires in higher education and tourism.

MARTINA GAISCH is professor of English, Intercultural Competence and Diversity Management at the University of Applied Sciences Upper Austria, Austria. As an applied linguist working at a school of informatics her research focus is at the interface of educational sociology, higher education research and sociolinguistics.

UTE SMIT is professor of English Linguistics at the University of Vienna, Austria. Her applied linguistic research focuses mainly on English in, and around, education. Besides involvement in various international research projects, Ute is a board member of ICLHE (Integrating Content and Language in Higher Education). 



\title{
14 Englishization of Croatian higher education
}

\author{
Conceptualizations, manifestations, and implications \\ Branka Drljača Margić
}

\begin{abstract}
The perceived benefits of English-medium instruction (EMI), such as greater competitiveness of universities, are the reasons why meso- and macro-level stakeholders in Croatian higher education (HE) seek to implement it. Nevertheless, the overall adoption of EMI has been rather slow, resulting in only $3 \%$ of study programmes in English. Such a small number has sparked no public or scholarly resistance to this aspect of Englishization. On the micro level, however, the introduction of EMI has provoked a range of different reactions, from favourable attitudes to concerns over the quality of education and the status of Croatian in academia. Evidence for these views were gleaned from the studies conducted at the University of Rijeka, Croatia.
\end{abstract}

Keywords: English-medium instruction, higher education, Englishization, Croatia, attitudes

\section{Introduction}

Today, the internationalization of higher education (HE) is closely intertwined with English-medium instruction (EMI). English-taught programmes enable the exchange of international teaching staff and students, while the internationalization of HE prompts the use of English as an academic lingua franca. The implementation of EMI, the Bologna Process and the creation of the European Higher Education Area are mutually conditioned and have laid the foundation for academia as we

Wilkinson, Robert, and René Gabriëls (eds), The Englishization of Higher Education in Europe. Amsterdam, Amsterdam University Press 2021 DOI: 10.5117/9789463727358_CH14 
know it today. Present-day universities are oriented towards (economic) competition and boosting rankings more than ever before (Lasagabaster et al., 2013). They also seek to gain greater visibility and collaboration, better intercultural understanding, and higher quality of education (De Costa et al., 2020). In the process, the Englishization of HE is inevitable (Macaro et al., 2018). In Croatia the term Englishization generally relates to the presence of English in Croatian language and context. It primarily carries negative connotations, implying the saturation of Croatian language and culture with English words, expressions, and behavioural patterns. In this paper, in relation to HE, the term Englishization is used with two meanings, both supported by research findings: the first neutrally referring to the presence and use of English in a milieu that was until recently almost entirely dominated by the Croatian language, and the second negatively perceiving this presence through the prism of brain drain and domain loss. The former view is, to an extent, accompanied by perceived challenges and concerns, although unrelated to Croatian language and culture. The latter attitude is sporadically expressed, as reported in sections 3 and 4 .

\subsection{Interface between internationalization and EMI in Croatian HE}

Aware of the pressing need to follow modern academic trends, HE institutions in Croatia are changing their goals and practices and have undertaken reforms and issued policy documents that pave the way for the internationalization of HE (Šćukanec, 2013).

In 2005, Croatia joined the Bologna Process, and universities across the country stated the internationalization of $\mathrm{HE}$ as one of their key strategic goals (Dujić \& Lučin, 2007). In 2009-2010, the leading public universities signed the Erasmus Charter for Higher Education. The importance of integration of Croatian HE education into a common European HE framework is also underlined in the national-level document Strategy for education, science and technology (2014), and is believed to give national universities a competitive edge on the European scene.

In the beginning, however, internationalization was not explicitly associated with the development of study programmes in English. The first study on EMI (Drljača Margić \& Žeželić, 2015), for example, revealed that the inclination towards internationalization was not necessarily accompanied by the openness towards EMI, and that the tight connection between the two was not entirely grasped (cf. Zhang, 2018). In addition, the respondents largely considered international students and teachers to be a prerequisite 
for the establishment of study programmes in English, disregarding the fact that EMI is more of a precondition for their presence than a response to their influx.

\subsection{EMI in Croatia: Current state of affairs}

Croatian HE space is comprised of 131 (primarily public) HE institutions. The backbone of the public sector, which includes $99 \%$ of the student population, consists of eight universities. They are not fully integrated, and their constituent institutions are independent legal entities with their own administration.

As for EMI, only $3 \%$ of study programmes are taught in English. Out of 56 programmes in English, the majority are offered at six public universities, particularly at the University of Zagreb (28), where the first EMI programme, in medical sciences, was launched in 2003 , followed by the University of Rijeka (UNIRI) (6), the University of Split (6), the University of Pula (2), the University of Osijek (1), and the University of Zadar (1) (Drljača Margić \& Vodopija-Krstanović, 2020). Although EMI constitutes an important strategic aim, there is no national or university policy or action plan regarding EMI, nor is there an explicit language policy on language requirements, support, and use.

While public education is fully subsidized by the Ministry of Science and Education as long as students fulfil all the requirements in a timely manner, English-taught programmes are not tuition-free. Hence, for many people education in English is not easily attainable, if at all. EMI seems to be yet another aspect which reflects inequalities between people and their opportunities to achieve certain goals. In addition, it points to inequalities between countries and their potential to implement a wide scale of internationally accessible study programmes. On the other hand, some see no point in paying for education if the equivalent programmes in Croatian are tuition-free. Additionally, by some the quality of English-medium programmes has not been perceived to be better (Drljača Margić \& Vodopija-Krstanović, 2017), and they do not want to pay for something they can get for free. Those who opt for EMI are primarily motivated by an envisaged increase in English language proficiency and the fact that EMI represents something new, prestigious, and modern.

Since systematic and comprehensive research on EMI in Croatia has only been conducted at UNIRI, this paper primarily focuses on EMI-related activities and research findings obtained here with the aim of analysing the conceptualizations, manifestations, and implications of EMI at this medium-size Croatian university. 


\section{Internationalization and Englishization of a Croatian university}

Despite the strategic goal of UNIRI, according to which the number of study programmes in a foreign language should have increased to 20 by 2020 (Strategy of the University of Rijeka, 2014), to date, only four programmes $(2.55 \%)$ are offered in English: one bachelor's and one master's programme at the Faculty of Economics (launched in 2011 and 2014 respectively), an integrated bachelor's and master's programme at the Faculty of Medicine (2017), and a doctoral programme at the University Physics Department (2018). Two additional English-taught programmes started in the academic year 2020/21 - at the University Mathematics Department and the University Biotechnology Department.

When it comes to research projects focusing on EMI, UNIRI has been involved in multiple EMI-related research projects, within which comprehensive research was conducted, workshops for teachers were held and the research-informed 'Language Support for Teachers in EMI (EJVIN)' programme was launched (for more about the programme see Drljača Margić \& Vodopija-Krstanović, 2018). Participation within the international project 'Transnational Alignment of English Competences for University Lecturers (TAEC),' with UNIRI as a partner, yielded the TAEC literature database report (2020), the TAEC EMI handbook (2019), and a technical report on linking a locally developed scale for oral English proficiency (TOEPAS) with the CEFR (Dimova, 2018).

\section{$3 \quad$ Teachers' and students' viewpoints}

Research into teachers' and students' viewpoints, the results of which are presented in this and the following section, was conducted at UNIRI among non-EMI teachers and students, who are not (yet) involved in EMI, as well as among those already engaged in English-taught programmes. The research included a sample of 311 non-EMI teachers, 262 non-EMI students, 37 EMI teachers and 2o EMI students. These numbers represent the totals of the participants taking part in the studies conducted at UNIRI. The results were obtained by means of questionnaires comprising open- and closed-ended questions, semi-structured individual and focus group interviews, and classroom observation followed by stimulated recall interviews. This section reveals the stakeholders' perceptions of Englishization through EMI, from neutral/positive attitudes to the 
perceived challenges and the perception of threat to the Croatian language.

\subsection{Non-EMI teachers: Openness to EMI affected by its negative implications}

Regarding non-EMI teachers, around $80 \%$ consider the introduction of EMI feasible and are willing to embark on EMI, for this would improve their English proficiency and enhance their own and their institutions' international visibility, co-operation, mobility, and competitiveness. Around $60 \%$, however, expect certain preconditions to be fulfilled.

Their main worry is that limited financial resources would not suffice to hire new teaching staff, organize professional and language support, and acquire teaching materials and technical equipment. Another point of concern is teachers' and students' English language proficiency and their ability to maintain the quality of education and achieve learning outcomes in English. Thirdly, teachers, who already work over and above their workload, fear that engagement in EMI would additionally take time away from research and publishing their work - the main prerequisite for their professional advancement. Another complaint voiced by the teachers whose institutions are in the process of implementing EMI is that they are not sufficiently informed about different aspects of the future EMI implementation, and that timely and adequate information provision, thorough preparation of teachers, and setting language and educational standards are largely neglected in the drive to follow suit and flaunt English-taught programmes. It has also been noted that the number of international students is insufficient to justify the adoption of EMI, and that home students would be reluctant to study in English. Teachers also, although rather sporadically, worry that EMI would exacerbate the problem of brain drain Croatia has been increasingly facing for the last two decades (cf. Dujić \& Lučin, 2007). In other words, they think that higher English language proficiency, developed through EMI, will additionally stimulate people to leave the country and look for better private and professional opportunities abroad. At the same time, they say, EMI could render foreign lecturers more desirable, as well as those who are less qualified, but more proficient in English. Finally, a rather small number of teachers frowns upon EMI because it could lead to Croatian losing ground to English in HE. They note that EMI could consequently have a negative impact on students' L1 proficiency and their ability to discuss their field of expertise in Croatian. 
Around $70 \%$ of teachers advocate for students in English-taught programmes to take a Croatian for academic purposes course, and that international students should receive Croatian language training. The teachers are also open to occasional translanguaging in EMI classes, primarily to familiarize students with Croatian terminology. Overall, they argue for raising scholarly and public awareness that EMI is inevitable and necessary, but hold that certain actions should be taken to protect the Croatian language (Drljača Margić \& Tulić, 2018; Drljača Margić \& Velčić Janjetić, in press; Drljača Margić \& Vodopija-Krstanović, 2017, 2019, 2020).

\subsection{Non-EMI students: Appraisal of EMI permeated by misgivings}

Around $80 \%$ of non-EMI students would not be willing to enrol on study programmes that are entirely taught in English and do not regard their introduction as feasible. The principal reason for their reluctance to participate in EMI is students' and teachers' insufficient knowledge of English, followed by their worry that studying in English would be more time-consuming and possibly have a negative impact on their academic achievement. Some students fear that EMI would negatively affect the future of the Croatian language (Drljača Margić \& Vodopija-Krstanović, 2017, 2020; Drljača Margić \& Žeželić, 2015).

Given that inadequate English language proficiency has been underscored as one of the key challenges of EMI, it seems useful to briefly reflect on English language teaching and the position of English in Croatia. For the vast majority of students, English is the first foreign language and a compulsory subject in primary and secondary education in the country, although children usually start learning it before the first grade through the media and various pre-school language learning programmes. Content and language integrated learning programmes, however, are rare and not necessarily confined to English as a medium of instruction. English courses for specific purposes are taken at universities. In addition, English is widely acquired in private foreign language schools. Overall, young people in Croatia are largely exposed to English and have been learning English for years, so one might be puzzled about the insecurity and disquiet EMI triggers among students. They, however, think that their EFL (English as a foreign language) education has been insufficiently oriented towards the requirements of tertiary education in English, involving academic interaction, writing, presenting, analysing, and critical thinking in the language (cf. Evans \& Morrison, 2011; Wilkinson, 2008). Similarly, misgivings about teachers' ability 
to teach and discuss content in a fluent, accurate, and natural way stem from students' perception that publishing and presenting in English might lead one to overrate their English. Teaching back-to-back classes comprises much more than the reproduction of what was prepared ahead; it also involves classroom discussion, answering student questions, elaborating, managing group work, improvising, and telling anecdotes, that is, impromptu language use requiring language fluency and versatility. It seems fair to say that quality teacher preparation is important, but cannot compensate for limited language skills and lack of practice. What is more, overpreparation often results in contrived, uniform, and unengaging teacher-fronted lectures.

\subsection{EMI teachers: Positive feelings about EMI tinged with concerns}

Around $90 \%$ of EMI teachers acknowledge benefits of EMI similar to those mentioned by non-EMI teachers, have positive attitudes towards its implementation, and are willing to pursue it. What they also underline is that without EMI, HE institutions risk isolation. They describe positive feelings aroused by participation in EMI, such as excitement, satisfaction, sense of belonging to a larger academic community, and higher self-esteem. However, the actual EMI classroom experience is reported to also evoke anxiety, stress, and exhaustion, particularly by those who have language-related difficulties, which make them overly focused on language and negatively impact teaching, teachers' spontaneity, and professional status. Moreover, the findings obtained from classroom observation, as well as from an investigation into students' views and perceptions of EMI in practice, indicate that between a number of Englishand Croatian-taught classes there is a considerable disparity in classroom interaction, flow of the lesson, and teacher expressiveness, clarity, and coherence.

Although teachers seem to accept EMI as a standard in modern-day academia, only $10 \%$ think that all teachers and students should be involved, while none hold that Croatian-taught programmes that have English-medium counterparts should be discontinued. As long as study programmes in Croatian are offered alongside those in English, the overwhelming majority of the teachers do not fear for the future of Croatian as an academic language, nor do they think that this primarily instrumental role of English will have a greater impact on Croatian identity and culture. Nevertheless, they maintain that care for Croatian should involve planning and concerted actions ensuring students' academic literacy in both languages (Drljača Margić \& Vodopija-Krstanović, 2017, 2019, 2020). 


\subsection{EMI students: Inclination towards EMI tinted with criticism}

As for EMI students, they report being rather successful at meeting the requirements of EMI. Although occasionally they mention the feelings of anxiety and distraction, excitement and enjoyment prevail. They feel more self-confident than their teachers and say that engagement in EMI boosts their self-esteem. Their main motive for studying in English is the improvement of English language skills, which in turn is perceived to increase their opportunities to study abroad and their competitiveness on the global market. It is also praised for giving them an opportunity to study in an intercultural environment and broaden their intercultural understanding. Like their colleagues who are not involved in EMI and who fear that teachers' language proficiency would not be up to the task, EMI students tend to be rather critical of some teachers' language production and their shifting to Croatian as a compensation strategy. They expect their teachers to be language role models, and not divert student attention away from content by struggling with language. Their criticism is directed towards the institution, which started the programme with teachers who are not highly proficient, as well as towards the teachers who decided to undertake EMI without adequate language skills.

The students also reflected on the knowledge, use, and status of the Croatian language. They regret not being familiarized with the disciplinary discourse in their native language, and see it as a potential barrier to functioning on the local market. According to them, there should be more English-taught programmes offered alongside their Croatian-taught equivalents, and the majority of students should be involved at least to some extent. Nevertheless, they argue for students being required to take an academic Croatian language course. The students are generally not worried about the effect of EMI on Croatian identity, culture and language. However, none of the students studying in English see themselves in Croatia in the future (Drljača Margić \& Vodopija-Krstanović, 2017, 2020).

\section{How Englishization of HE is manifested and conceptualized}

\subsection{The concept of Englishization}

As already mentioned, in Croatia, the term Englishization or, in Croatian, anglizacija, has had rather negative connotations and it has referred to the spread and impact of English world-wide resulting in an import of numerous 
loanwords of English origin into Croatian and other languages. The criticism has primarily been directed at so-called unnecessary expressions and words, which have not entered Croatian to accompany innovations but because they appear more modern, attractive, and prestigious than their Croatian equivalents. It has also been directed towards the influence on Croatian culture and everyday life, implying to an extent the equation of imposing the English language with imposing cultural and social values (cf. Phillipson, 2006). As such, Englishization has stirred up debates and prompted open letters, purist-oriented writings on the topic, TV shows educating about Croatian replacements for English expressions, and contests for the best domestic replacements for words of English origin (Drljača Margić, 2012).

On the other hand, the spread of English in Croatian HE, as indicated in section 3, has been very rarely perceived as Englishization in the negative sense, implying a menace to Croatian language and society. The reason why the spread of English in HE is only very occasionally perceived to potentially lead to domain loss or the marketization of HE (Wilkinson, 2018) probably lies in the fact that the development of EMI here has been rather sluggish. Such a slow pace of EMI implementation has led to no public or scholarly debate or criticism about this aspect of Englishization (unlike that described in, for example, Wilkinson, 2018; Zhang, 2018) - or to public support, for that matter. EMI has extremely rarely been perceived as a threat to Croatian language, culture, and identity, and there has not been a situation which would spark resistance, like the one at the Politecnico di Milano in which the management was sued by teachers and researchers for introducing an English-only policy in their master's programmes (Santulli, 2015). In fact, in Croatia no study programme in English has resulted in the discontinuance of the equivalent study programme in Croatian. Several new study programmes have been launched in English only, but they have not evoked negative emotions either. On another note, bilingualism with English is regarded extremely important and promoted in different sections of the society. Hence, any path to language proficiency, including the one involving immersion in the language, is generally welcomed.

These rare negative attitudes and concerns about detrimental implications the spread of English in HE can have on Croatian have been a matter of individual considerations of the stakeholders concerned and have only been uncovered through research into the subject, that is, elicited by focused questions on the challenges of EMI. In other words, the findings discussed in section 3 show that unfavourable attitudes and worries exist among stakeholders, but they have seldom been directed towards the potential adverse impact of EMI on Croatian as a carrier of academic knowledge. Rather, they 
revolve around undue attention given to the very implementation of EMI programmes and its effect on teachers, students, and teaching/learning. What primarily imbues teachers with rather intense and contradictory emotions is their losing face due to English language insufficiency and its negative implications for their authority, academic performance, and self-esteem. Students can be rather judgemental when it comes to teachers' language proficiency and their failure to satisfy students' expectations and quality standards. They expect their teachers to be proficient in the language. Needless to say, the same expectations come from teachers' (more proficient) colleagues and their institutions (Drljača Margić \& Vodopija-Krstanović, 2017, 2020). Moreover, teachers are not guided by an established (transnational) language-in-education policy or adequately informed on EMI (cf. Doíz et al., 2019), nor are they stimulated to develop their linguistic, pedagogical, and intercultural skills for work in a different environment, as they are too often taken for granted (Drljača Margić \& Velčić Janjetić, in press).

\subsection{The impact of Englishization on teachers' freedom of choice}

Although students tend to denounce teachers' decision to participate in EMI without necessary language skills, it would be wrong to say that this is entirely the teachers' decision. They are usually asked whether they feel competent to teach in English, and are not tested on their language proficiency or required to have prior experience of EMI (Drljača Margić \& Tulić, 2018; Drljača Margić \& Vodopija-Krstanović, 2017). However, although a number of teachers do not want to engage in EMI, advance arguments against its implementation (before certain prerequisites have been met), and/or have worries regarding the stakeholders' language proficiency, motivation, and workload, as well as the institution's aptness to undertake this innovation, they almost always agree to involve themselves in EMI. They do it as a result of the status English has today as an academic lingua franca, which puts teachers under certain pressure to fulfil expectations, accept EMI as an inevitable HE practice, and accommodate it. In addition, teachers are aware that institutions are compelled to adopt EMI to compare with their peer institutions and attract international teachers and students. They understand that they themselves are expected to be on board, and that enquiries into their readiness to join in are to an extent a pro forma procedure. They are also cognizant that the realization of EMI principally relies on them, as hiring new teaching staff has been largely hampered by a lack of money, and are afraid that the external financial and administrative support for bringing in guest lecturers would be purely nominal in character. 
In other words, their freedom of choice regarding participation in EMI seems to be somewhat illusory, and their decisions are often insufficiently informed and influenced by EMI as a fact of life in HE (Mauranen, 2010), as well as, to an extent, by the presentation of English as the best option for modern education and a crucial commodity for professional success (Phillipson, 2006). Under such circumstances, teachers cannot do much but take certain actions themselves and attempt to induce the stakeholders at meso (university) and macro (ministry) levels to help them overcome barriers, so not to undermine the quality of education. This is important as Croatian HE, albeit still lingering behind other European HE contexts, is making greater strides in implementing EMI. The last several years have witnessed increased cognizance of and discourse on the internationalization through EMI, and at many HE institutions EMI implementation is at least discussed.

\subsection{Discrepancies and paradoxes associated with Englishization}

To make it easier for teachers and ensure the quality-based introduction of EMI, human, financial, and logistic prerequisites should be fulfilled, as should the existing conditions be critically reflected upon. EMI calls for quality assurance policies and procedures that would dispel teachers' and students' doubts about the efficiency of the methods, and their misconception of quality assurance for quality control. Their scepticism and fear of leaving a 'wrong' impression make both management and teachers resistant to classroom observation as an effective method of getting valuable insights into EMI in practice. The paradox is that they are willing to grant access in return for language support, but allow only proficient teachers to be observed (Drljača Margić \& Vodopija-Krstanović, 2017), which does not form a basis for identifying problems, providing language assistance, and working towards optimal solutions.

Furthermore, inter-institutional communication should be improved, so that newcomers to EMI can learn from EMI insiders' experiences and best practices, and possibly avoid ambiguities and challenges. Similarly, intra-institutional interaction should be better, and management should consult teachers and teacher trainers, and involve them in the decision making itself. Communication between teachers and students should not only be content- and assessment-related but also involve discussions on the challenges of EMI practices (cf. Drljača Margić \& Tulić, 2018). In Croatia, teachers' discontent with quality assurance and information flow also accompanied the introduction of the Bologna Process (Dujić \& Lučin, 2007). 
Teachers undertake innovations full of questions and qualms caused by the new challenges as well as unresolved issues from previous ventures. This calls for more careful consideration of problems that (might) occur when educational innovations are implemented and there is a temptation to jump on the bandwagon.

Gaps between requirements and provisions can bring the quality of EMI implementation into question. Earlier, there was a slight discrepancy between the attention given to the internationalization of $\mathrm{HE}$ and the importance attributed to the implementation of EMI as the main avenue for its realization. Now, there is a discrepancy between the increasing implementation of EMI and the insufficient care that EMI teacher proficiency and their training receive (cf. Bamond Lozano \& Strotmann, 2015). In Croatia, for example, there is only one language support programme (EJVIN), initiated by two teachers from the UNIRI Department of English, with an insight into EMI (Drljača Margić \& Vodopija-Krstanović, 2018). Initially, the programme was financed by the University, for 20 UNIRI teachers per year. Although it was highly praised by the participants and recognized as an invaluable asset by the University management, and although teachers greatly appreciate this kind of (university-financed) support, after three years it was decided that the programme should be self-funded.

\subsection{Discipline-related differences in the stance on Englishization}

As for distinctions between scientific disciplines regarding conceptualizations of English and EMI, research conducted at UNIRI shows that physics teachers consider English a no-brainer and have rather condescending attitudes towards discussions on language, language support, and testing in EMI (Drljača Margić et al., 2019). Their counterparts from other disciplines, namely medicine, economics, and engineering, are more concerned about their own and their students' readiness to teach and study in English, and the impact of language proficiency on their professional image and the quality of instruction (Drljača Margić \& Tulić, 2018; Drljača Margić \& Velčić Janjetić, in press; Drljača Margić \& Vodopija-Krstanović, 2017, 2019). In addition, physics teachers readily admit the use of Croatian as a more spontaneous and natural choice with students who understand the language. This difference in attitude and confidence is probably due to the fact that physics teachers have a stronger international outlook and richer experience of education and work abroad (Drljača Margić et al., 2019). Additionally, physics is a hierarchical knowledge structure discipline, particularly oriented towards 
English and international disciplinary community (cf. Kuteeva \& Airey, 2014).

Hence, on the one hand, we have: management, determined for HE institutions to engage in EMI; language proficient teachers, who are largely not bothered by the lack of language support; and students, who often have the necessary automaticity in English deriving from their frequent contact with the language from an early age. On the other, there are a number of teachers who do not run away from EMI and perceive its benefits, but for whom language and other challenges are the current reality (cf. Aizawa \& Rose, 2019). This is corroborated by Zhang (2018), who observes that language management and language ideology often diverge from language practice because the latter is determined by language proficiency.

\section{Concluding remarks}

The implementation of EMI generally meets with approval of EMI insiders and non-EMI teachers, and to a lesser extent of non-EMI students. The last group is the least open to EMI probably because they are less familiar with the spread of EMI worldwide, less internationally oriented, and to a smaller extent in contact with English as an academic lingua franca. They also anticipate troubles with language proficiency, content acquisition, and academic achievement (Drljača Margić \& Žeželić, 2015). However, non-EMI students' worries about students' language command have proved largely groundless (especially in the case of home students), which is opposite to the findings obtained by, for example, Doíz et al. (2019) and Zhang (2018). EMI students do not seem to have major problems with their language proficiency or fulfilling learning outcomes, which is also due to work in smaller groups, which itself enables a more student-centred approach. EMI students have stronger motivation and aim to continue studies and find a career abroad. Teachers are also much less critical of their students' language proficiency than vice versa (Drljača Margić \& Vodopija-Krstanović, 2017).

Regarding the two groups of teachers, their main difference in perceptions is that those still outside EMI put much stronger emphasis on increased international collaboration, visibility, mobility, and better university ranking than EMI insiders, which indicates that it takes time, appropriate funding schemes and administrative support to capitalize on EMI (Drljača Margić \& Vodopija-Krstanović, 2017). 
Regardless of their inclination towards EMI, nobody thinks that Englishtaught programmes should replace Croatian ones, or that engagement in them should be an obligation, rather than an option or an opportunity. Along these lines, both teachers and students show greater openness to EMI when asked whether they are willing to participate in EMI than when asked whether EMI should be adopted. The latter to an extent implies top-down implementation strategies, which tend to run into resistance (Drljača Margić \& Vodopija-Krstanović, 2017).

Apart from concerns about the future status of Croatian in HE, expressed by the small minority of teachers and students, as well as occasional voices by teachers and scholars that EMI will additionally spur brain drain, in Croatia the Englishization of HE has not come under heavier criticism regarding its impact on Croatian language, identity, and society. Among teachers and students who are worried about Croatian are those who are willing to take actions to safeguard the language, but also those who do not feel responsible for its development and expect others to take on the task, or count on the language tending itself. The large majority of the respondents do not regard Croatian to be in any kind of jeopardy, and some are even indifferent to the potential domain loss in favour of English, seeing no point in cherishing a small language (Drljača Margić \& Vodopija-Krstanović, 2017).

What meets with stronger disapproval is the preparation for EMI and its very realization, particularly among teachers, who to an extent feel expected or even urged to undertake this educational innovation notwithstanding the absence of support, guidelines, and policies. Therefore, it is time for EMI to receive greater attention and be critically examined concerning its postulates, outputs, resources, and benchmarks. Moreover, EMI requires constant monitoring and communication with the stakeholders, at least in the initial stages of its implementation. The absence of such measures could decrease teachers' motivation and commitment, necessary for any educational practice to be effective and quality-based. EMI, which has entered mainstream HE and is expected to spread further, should not only be manifested in the number of study programmes in English but also in their quality (cf. Aizawa \& Rose, 2019; Galloway et al., 2020). Although EMI is often presented as a promoter of the quality of $\mathrm{HE}$, insights into practice as well as into teachers' and students' perceptions and experiences worldwide clearly indicate that the mere introduction of EMI cannot be a booster of educational excellence. Besides, the quality of education and its assessment should not be based solely on the achievement of learning outcomes. In other words, the classroom practice and the whole educational experience should be satisfactory and count just as much as the product itself. 


\section{Recommendations}

Although some recommendations have already been offered in the previous two sections, as part of discussions on paradoxes and discrepancies associated with Englishization and of the analysis of quality assurance necessary in EMI, here we recapitulate on what is needed to reap EMI's best fruits.

The success of an educational innovation to a large extent depends on the conditions favouring it, the commitment demonstrated by teachers, and the competences they have (Mellion, 2008). It can be deduced that in Croatia the conditions in terms of socio-political and scholarly support exist, while those related to financial and logistic support require further consideration and effort. EMI in Croatia has not been faced with stronger oppositions, and to keep it that way, it is necessary to pay careful attention to teachers' concerns and requirements. Micro-level stakeholders (teachers and students) should be better informed about their responsibilities and rights. The first English-taught programmes at UNIRI were started without the necessary language support, and only after the organization of a number of informative workshops and EJVIN did teachers become fully aware that different types of language support could and should be provided to them, whereupon management had to start taking that into account and act accordingly, although still to an insufficient extent. Furthermore, what is too often neglected is that EMI does not only involve the change of the language of instruction. It also involves different pedagogy, more student-centred, collaborative, and problem-based - if teachers have not already adopted such an approach in their L1 classes - as well as a greater use of different scaffolding techniques. Furthermore, it requires teachers' intercultural competence to be open to and capable of dealing with a multicultural classroom, adjusting, and finding compromises (cf. Wilkinson, 2008). For example, teachers traditionally used to teacherfronted classes with no classroom interaction have had to or will have to accommodate somewhat different practices and expectations of their international students, who often ask questions and request additional explanations throughout the class. Finally, national and local interests should be protected by maintaining Croatian-taught study programmes, developing student Croatian language proficiency, but also opening English-medium programmes to both international and home students. Care should be taken, however, not to infringe international students' rights by using Croatian in EMI classes or by reducing their equality of opportunity to learn other languages, in addition to the official language of the host country (cf. Earls, 2016). 
The endeavour to protect other languages, however, is increasingly arduous and questionably fruitful with the rapid spread of English across HE and the potential development of a diglossic relationship between English and other languages (cf. Altbach, 2004; Coleman, 2006; Drljača Margić \& Vodopija-Krstanović, 2017), that is, a linguistic hierarchy with English at the top and small national languages at the bottom (cf. Earls, 2016).

One of the problems with today's implementation of EMI is that stakeholders at the meso and macro levels ignore some risks in the drive to internationalize HE, somewhat duck responsibility, and do not provide micro-level stakeholders with sufficient information; or else they give unclear guidelines, resulting in teachers and students not knowing how to behave or inconsistently interpreting the directions (cf. Aizawa \& Rose, 2019). Moreover, they are poorly informed about different aspects and challenges of EMI, and thus cannot properly think through the innovation and assist those at the micro level. On the other hand, teachers' commitment and competences to a great extent rely on the existence of specific conditions and explicit guidelines. Specifically, to develop their competences, teachers need training and guidance, and commitment fades if it is not reciprocal and continually reinforced.

In Croatia, Englishization through EMI is very rarely perceived as a threat, but scepticism and concerns can adversely affect EMI realization. Its efficient introduction is primarily dependent on micro-level stakeholders' positive attitudes, competences, and motivation. In order for these to blossom, an explicit language-in-education policy should be established, support should be provided and information flow should be improved.

\section{Acknowledgements}

I would like to thank the anonymous reviewers for their insightful comments and constructive suggestions.

\section{References}

Aizawa, I., \& Rose, H. (2019). An analysis of Japan's English as medium of instruction initiatives within higher education: The gap between meso-level policy and micro-level practice. Higher Education, 77, 1125-1142. DOI: 10.1007/ s10734-018-0323-5

Altbach, P. G. (2004). Globalisation and the university: Myths and realities in an unequal world. Tertiary Education and Management, 10, 3-25. DOI: 10.1023/B:T EAM.ooooo12239.55136.4b 
Bamond Lozano, V. M., \& Strotmann, B. (2015). Internationalizing higher education: Language matters. TESOL Quarterly, 49(4), 847-857. DOI: 10.1002/tesq.251

Coleman, J. A. (2006). English-medium teaching in European higher education. Language Teaching, 39(1), 1-14. DOI: 10.1017/So26144480600320X

De Costa, P. I., Green-Eneix, C. A., \& Li, W. (2020). Problematizing EMI language policy in a transnational world. English Today, 1-8. DOI: 10.1017/So26607842000005X Dimova, S. (2018). Linking the TOEPAS with the CEFR: Technical report. TAEC Erasmus+ project (2017-2020). Retrieved 28 July 2020 from https://cip.ku.dk/ english/documents/Alignment_of_TOEPAS_with_the_CEFR.pdf

Doíz, A., Lasagabaster, D., \& Pavón, V. (2019). The integration of language and content in English-medium instruction courses: Lecturers' beliefs and practices. Ibérica, 38, 151-176.

Drljača Margić, B. (2012). Stavovi govornika prema zaštiti hrvatskoga jezika od utjecaja engleskoga i promicanju hrvatskih zamjena za anglizme [Speakers' attitudes towards the protection of Croatian from the influence of English and towards the popularisation of native equivalents to anglicisms]. In M. Turk \& I. Srdoč-Konestra (Eds.), Peti hrvatski slavistički kongres - zbornik radova 1 (pp. 387-394). Faculty of Humanities and Social Sciences in Rijeka.

Drljača Margić, B., Meštrović Štajduhar, I., \& Vodopija-Krstanović, I. (2019, April 4-5). English in an EMI doctoral programme in physics: From a no-brainer to an overkill [Conference presentation]. EMI Practices in Europe, Copenhagen, Denmark.

Drljača Margić, B., \& Tulić, I. (2018). Teaching staff's critical perspectives on Englishmedium instruction: The case of a Croatian higher education context. In M. Brala-Vukanović, \& A. Memišević (Eds.), Language in research and teaching (pp. 73-84). Peter Lang.

Drljača Margić, B., \& Velčić Janjetić, E. (in press). What it takes to successfully implement English-medium instruction: A case study. In M. Matešić \& A. Memišević (Eds.), Meaning in language: From individual to collective. Peter Lang.

Drljača Margić, B., \& Vodopija-Krstanović, I. (2017). Uncovering English-medium instruction: Glocal issues in higher education. Peter Lang. DOI: 10.3726/b10418

Drljača Margić, B., \& Vodopija-Krstanović, I. (2018). Language-development for English-medium instruction: Teachers' perceptions, reflections and learning. Journal of English for Academic Purposes, 35, 31-41. DOI: 10.1016/j.jeap.2018.06.005

Drljača Margić, B., \& Vodopija-Krstanović, I. (2019). (Micro)teaching through the medium of English: University content teachers' practice and learning. In M. Brala-Vukanović \& A, Memišević (Eds.), Language and its effects (pp. 29-41). Peter Lang.

Drljača Margić, B., \& Vodopija-Krstanović, I. (2020). The benefits, challenges and prospects of EMI in Croatia: An integrated perspective. In S. Dimova \& J. Kling 
(Eds.), Integrating content and language in multilingual universities (pp. 75-96). Springer.

Drljača Margić, B., \& Žeželić, T. (2015). The implementation of English-medium instruction in Croatian higher education: Attitudes, expectations and concerns. In R. P. Alastrué, \& C. Pérez-Llantada (Eds.), English as a scientific and research language (pp. 311-332). De Gruyter Mouton.

Dujić, Ž., \& Lučin, P. (Eds.) (2007). OECD thematic review of tertiary education: Country background report for Croatia. Retrieved 10 June 2020 from http://www. oecd.org/education/skills-beyond-school/38802218.pdf

Earls, C. W. (2016). When English just is not enough: 'Multilingualism with English' in contemporary European higher education. International Journal of Applied Linguistics, 26(3), 329-347. DOI: 10.1111/ijal.12114

Evans, S., \& Morrison, B. (2011). Meeting the challenges of English-medium higher education: The first-year experience in Hong Kong. Englis h for Specific Purposes, 30, 198-208. DOI: 10.1016/j.esp.2011.01.001

Galloway, N., Numajiri, T., \& Rees, N. (2020). The 'internationalisation', or 'Englishisation', of higher education in East Asia. Higher Education. DOI: 10.1007/ s10734-019-00486-1

Kuteeva, M., \& Airey, J. (2014). Disciplinary differences in the use of English in higher education: Reflections on recent language policy developments. Higher Education, 67, 533-549. DOI: 10.1007/s10734-013-966o-6

Lasagabaster, D., Cots, J. M., \& Mancho-Barés, G. (2013). Teaching staff's views about the internationalisation of higher education: The case of two bilingual communities in Spain. Multilingua, 32, 751-778. DOI: 10.1515/multi-2013-0036

Macaro, E., Curle, S., Pun, J., An, J., \& Dearden, J. (2018). A systematic review of English medium instruction in higher education. Language Teaching, 51(1), 36-76. DOI: $10.1017 /$ So261444817000350

Mauranen, A. (2010). Features of English as a lingua franca in academia. Helsinki English Studies, 6, 6-28.

Mellion, M. J. (2008). The challenge of changing tongues in business university education. In R. Wilkinson \& V. Zegers (Eds.), Realizing content and language integration in higher education (pp. 212-227). Maastricht University.

Phillipson, R. (2006). English, a cuckoo in the European higher education nest of languages? European Journal of English Studies, 10(1). 13-32. DOI: $10.1080 / 13825570600590846$

Santulli, F. (2015). English in Italian universities: The language policy of PoliMI from theory to practice. In S. Dimova, A. K. Hultgren, \& C. Jensen (Eds.), Englishmedium instruction in European higher education (pp. 269-29o). De Gruyter Mouton. 
Strategy for education, science and technology 2014-2020 (2014). Ministry of Science and Education of the Republic of Croatia. Retrieved 10 October 2019 from http:// novebojeznanja.hr/strategija/visoko-obrazovanje/12

Strategy of the University of Rijeka 2014-2020 (2013). University of Rijeka. Retrieved 1 December 2019 from http://www.biotech.uniri.hr/files/Dokumenti/ Strategija_UNIRI_2014_2020_HR.pdf

Šćukanec, N. (2013). Overview of higher education and research systems in the Western Balkans. Country report: Croatia. Retrieved 14 May 2020 from http://www. herdata.org/public/HE_and_Research_in_Croatia_FINAL.pdf

TAEC EMI handbook (2019). TAEC Erasmus+ project (2017-2020). Retrieved 19 July 2020 from https://cip.ku.dk/english/projects-and-collaborations/taec/ TAEC_Handbook_FEB_2020_NoEdit.pdf

TAEC literature database report (2020). TAEC Erasmus+ project (2017-2020). Retrieved 29 July from http://taec.ffri.uniri.hr/assets/files/TAEC\%2oDatabase $\% 20$ Report_26o6.pdf

Wilkinson, R. (2008). English-taught study courses: Principles and practice. In C. Gnutzmann (Ed.), English in academia: Catalyst or barrier? (pp. 169-182). Gunter Narr.

Wilkinson, R. (2018). Content and language integration at universities? Collaborative reflections. International Journal of Bilingual Education and Bilingualism, 21(5), 607-615. DOI: 10.1080/13670050.2018.1491948

Zhang, Z. (2018). English-medium instruction policies in China: Internationalisation of higher education. Journal of Multilingual and Multicultural Development, 39(6), 542-555. DOI: 10.1080/01434632.2017.1404070

\section{About the author}

Branka Drljača Margić is Associate Professor in the English Department at the University of Rijeka, Croatia. Her research interests include EMI, language contact and attitudes. She has run six national and international research projects on EMI, and is co-author of Uncovering English-Medium Instruction: Glocal Issues in Higher Education (Peter Lang, 2017). 



\title{
15 Affect in EMI at a German university
}

Comparing insights from teachers, home, and international students

\section{Michelle Hunter and Ursula Lanvers}

\begin{abstract}
Englishization in German education is progressing rapidly, driven both by top-down and bottom-up forces (Lanvers \& Hultgren, 2018). HE institutions are under pressure to be internationally attractive to fee-paying foreign students, but also need to offer high quality HE for home students. In the rapid move towards 'Englishizing' German HE institutions (Earls, 2014), little attention has been given to how stakeholders themselves - as participants but not enactors of this change - experience Englishization (Göpferich et al., 2019). This chapter explores how stakeholders experience affective dimensions of Englishization in a German HE institute. These insights can inform future training needs for English-medium instruction (EMI) staff and students. We conclude by linking our affective focus to wider development of Englishization in Germany.
\end{abstract}

Keywords: affect, EMI, self-determination theory, teacher affect, student affect

\section{Introduction}

Englishization is a global phenomenon of the developed world (Macaro, 2018), and in Europe especially (Dimova et al., 2015). It is to be found at all levels of education, in different guises across Europe (Lanvers \& Hultgren, 2018). With ever-expanding internationalization of tertiary education, English is becoming embedded into higher education institutions (HEIs) and increasingly used as the medium of instruction (Wächter \& Maiworm, 2014). Englishization and English medium instruction (EMI) are often

Wilkinson, Robert, and René Gabriëls (eds), The Englishization of Higher Education in Europe. Amsterdam, Amsterdam University Press 2021 DOI: 10.5117/9789463727358_CH15 
driven by top-down pressures, from tertiary level down to lower phases of education, and from institutional leadership down to the main participants of Englishization, that is, students and teachers (Lanvers \& Hultgren, 2018). As a result, participants may display a low sense of autonomy, negative affect, and poor engagement in their learning (Al-Khairy, 2013).

With increasing awareness of the importance of emotional wellbeing in language education settings (MacIntyre et al., 2020), researchers have started to address affect in EMI contexts among learners (Gomes, 2020) and teachers (Göpferich et al., 2019); however, empirical studies on the issue remain scant. So far, evidence suggest that EMI demotivates teachers (Doíz et al., 2011), and adds to a potential negative motivational cycle between teachers and learners. Until now, however, there have been no studies looking into the impact of affect in EMI on both students and teachers. The study presented here contributes to addressing this specific lacuna in our knowledge on Englishization and hopes to inform future designs of EMI programmes and student/staff preparation for EMI.

As with the rapid advancement of Englishization across domains as diverse as business, computing, social media (Ammon, 2006), the adoption of EMI in German higher education is fast expanding (Lanvers, 2018). In its pursuit of a strong economy and dominant positioning in the global market, Germany's reliance on English as a business lingua franca (Ehrenreich, 2010) is making it an increasingly diglossic society (Coleman, 2006). In keeping with the globalized thrust of the top-down policies of German government, Germany, alongside the Netherlands and Scandinavian countries, has the largest number of English-taught higher education programmes within the European Union (EU) (Wächter \& Maiworm, 2014). When it comes to numbers of international students in German higher education, there has been a clear upwards trend in the last decade (ICEF Monitor, 2018). According to figures from study.eu in 2018, Germany was the highest-ranked destination in terms of its attractiveness to international students, ahead of the UK, France, and the Netherlands (ICEF Monitor, 2018).

From the perspective of HEIs, rationales for universities to transfer their teaching to EMI are manifold: it helps in attracting international students, as well as staff, internationalizes the content, and develops language skills in what is arguably the most important lingua franca. Concerns over the 'stampede towards English' in education (Van Parijs, 2011), however, remain at all levels. At the macro level, there are concerns that language education policy increasingly favours English, and the implication this has for the future of other languages in academia, domain loss (Airey, 2012), and issues of linguistic justice generally (Hultgren, 2019). At the level of teaching and 
learning delivery, one long-standing concern has been over the issue of whether content learning suffers at the expense of EMI (Macaro et al., 2018).

This discussion of Englishization and the concomitant rise of EMI at German HEIs will begin with a look at Germany's long-standing relationship with English, before turning to higher education in Germany, and the place of English within it.

\section{Englishization and multilingualism in Germany}

Since the end of the Second World War, English terms have been widely incorporated into the German language (Mair, 2019). This period coincided with a change in Germans' relationship between identity and language; post-1945, previously 'deep-rooted nationalism ceased to exist' (Gardt, 2004, p. 204). This upsurge in Englishization of the German language was perhaps aided and abetted by a shift in public awareness post-reunification (Gardt, 2004) and in the changing political focus of government. The economic advantages of actively participating in the global market and being a significant player in international politics are compelling motivators for the strong interest, in Germany, to develop English proficiency (Hilgendorf, 2007).

For some, Germany's anglophilia is linked to 'an idealized picture of American society' (Meyer, 2004, p. 78). Among German academics, some of whom express concern at academic domain loss (Lanvers, 2018), there is a tendency to default to English in multinational settings (Hilgendorf, 2007). At university, German students demonstrate a broad acceptance of English as a lingua franca, with many more using it on a daily basis in their free time more than for study purposes (Gnutzmann et al., 2014).

The takeover of the German language - and culture - by English has not been embraced by all. Efforts were made in the mid-199os towards protecting the purity of German (Braselmann, 2004, p. 106). The Federal government decided against any amendment to the 1949 German constitution (Grundgesetz), deeming any language law neither 'worth striving for nor desirable' (Braselmann, 2004, p. 106). In 2005, a call for the protection of the German language was again made, followed a few years later by support from Bild Zeitung demanding the addition of the statement 'The language of the German Federal Republic is German' ('Die Sprache der Bundesrepublik ist Deutsch') to article 22 of the Grundgesetz (Pfaff, 2011, p. 4). Further public discussion was provoked by a petition to the Bundespräsident in 2010.

In the EU, the vision for language learning centres around multilingual competencies, not just English. The EU's vision of multilingualism across 
the continent was foregrounded in 2001 with the initiation of the policy of mother tongue plus two other languages (' $1+2$ ') and the proclamation of 2001 as the 'European Year of Languages'. With its strong tradition of foreign language teaching (Lanvers, 2018, p. 40), Germany embraced the idea of its multilingual children being further enabled to actively participate on the global stage (Jakisch, 2012). Without making explicit provision, however, for which languages should be taught, English became the de facto second language in most schools across the country.

\section{Englishization in German higher education}

\subsection{The role of English in German HE}

Germany has a long-standing relationship with English as a language of scholarship (Gardt, 2004). Until the middle of last century, both languages held equal sway within academia (Coleman, 2006). The marginalization of German scientists after the First World War, the national 'scientific selfdestruction' wrought by the Nazis (Ammon, 2004, p. 164), and US universities' abolition of foreign language requirements in the 196os, all contributed to German's lost standing as a language of science. Today, Germany has regained much lost ground in the global higher education market (ICEF Monitor, 2018), but a significant factor in this lies in the adoption of English as a medium of instruction on the auslandsoriententiert (internationallyoriented) degree programmes (Erling \& Hilgendorf, 2006). Qualifying international degree programmes (IDPs) must meet the following criteria: use English as partial or full language of instruction, an internationalized curriculum with integrated study periods abroad, offer an internationally recognized qualification, and support services for students beyond the study area (Earls, 2014, p. 155). The IDPs offering courses in EMI are intended to attract a mix of approximately 50/50 home and foreign students. Where active promotion of English alongside German occurs, it is reportedly welcomed by both home and international students, and faculty, who feel such integration and interaction improves their experiences (Earls, 2013).

Regarding prescriptive rules about language choices in German education, the sovereignty of each Bundesland (Länderhoheit) (Lanvers, 2018) prohibits nation-wide policy. Similarly, there is no explicit policy for how the participants on any of the differing types of IDPs should be supported in terms of language-related issues (Erling \& Hilgendorf, 2006). HE Englishization in Germany - perhaps even more than in other EU countries - is explicitly 
characterized by its link to internationalization (Earls, 2014), and coupled to the aim of attracting rather than losing academic excellence (both staff and students). Despite this promotion of EMI, none of the German Länder have specifically mentioned that English - rather than other languages - should be promoted (Erling \& Hilgendorf, 2006).

A multilingual policy is strongly supported at government level; in direct alignment with the EU's 1+2 policy for all Europeans, Germany has clear language-teaching guidelines for education institutions at all levels (Lanvers, 2018). In practice, these guidelines are operationalized as favouring English. Even where additional language courses are offered as part of an IDP, the default is often Fachenglisch (English for specific purposes) rather than a variety of other languages (DAAD, 2001, cited in Erling \& Hilgendorf, 2006, p. 274). Economic motivations behind such a bias notwithstanding, public feelings regarding the dominance of English as the primary choice of foreign language are mixed (Lanvers, 2018); we return to this issue below.

\subsection{The internationalization of German HEIs}

As the rise of EMI in German HEIs is closely linked to internationalization, both of students and staff, and curricula, this outward-focused perspective has influenced - and continues to do so - structures of degree programmes themselves. In 2002, in line with Bologna Declaration objectives, federal law demanded the phasing out of traditional German 'Magister' and 'Diplom' in favour of 'bachelor' and 'master' degree programmes (Erling \& Hilgendorf, 2006). By the academic year 2018/19, 92\% of all study programmes on offer were bachelor's or master's courses (European Commission, 2020).

There are two types of institutions in the German tertiary sector: universities (Universitäten), offering the classical subjects, and universities of applied sciences (UAS) (formerly Fachhochschulen, now Hochschulen für angewandte Wissenschaften or Technische Hochschulen), offering applied subjects such as business, engineering or social service (Gürtler \& Kronewald, 2015). In 2020, there were over 1.8 million students enrolled at Germany's 180 universities and over 1.02 million at the 244 UASs (BMBF, 2020). Despite concerted efforts towards internationalization, the percentage of programmes taught in English-only is modest. Enrolment on an IDP requires proof of English proficiency, even if the programme is only partially delivered in English (Erling \& Hilgendorf, 2006). Often, concerns, such as dilution of academic content (Ehlich, 2000), underdevelopment of German academic skills among both staff and students (Schumann, 2007), and lack of foreign language (FL) 
learning choice among students, are outweighed by institutional ambitions to internationalize HE.

Concerning resistance to Englishization, both linguistic and cultural arguments are made in favour of keeping German as a dominant language in German academia: more than perhaps any other language currently replaced by English in higher education, the German language has a rich and proud history as academic language. Thus, dethroning from lofty heights will be acutely felt. In 2007, German academics created the Special Interest Group ADAWIS (Arbeitskreis Deutsch als Wissenschaftssprache: Working group, German as academic language), aiming to maintain and foster use of German in German HEIs. As in other educational sectors, plurilingualism remains in clear focus in German HE. Furthermore, many international students may have sufficient linguistic skills to follow some German medium education, as German remains, worldwide, a widely taught FL (IALC, 2018). A high percentage of students enrol on multiple FL classes. The IDPs themselves often leverage German as a foreign language, drawing in the foreign students who are actively looking to learn German, and learn (some content) via German (Earls, 2013). Such a bilingual offering may simultaneously attract German and international students. In a context where German HEIs compete with high-ranking Anglosphere universities, Germany might not only benefit from attracting high calibre international students (brain gain), but also link IDP programmes to future employment in Germany in currently understaffed industry sectors, such as engineering (Earls, 2014).

\subsection{Current Trends in German HEI Englishization}

The Eurostat (2021) figures for Germany demonstrate this clear bias towards English: $58 \%$ primary school children were enrolled in English classes in 2019, for French classes 2.9\%, and for Spanish the numbers were so small that the percentage figure was $0 \%$ (European Commission, 2020). According to the website My German University (2021), 2115 BA and MA degree programmes delivered via English were available in spring 2021.

While absolute numbers look impressive, the percentage of EMI programmes may offer a more accurate picture. Based on recent figures provided by the German Rectors' Conference (HRK) of all programmes, $14 \%$ of MA and $2.7 \%$ of BA programmes are offered in English only (DAAD, 2021). Of the over 2.5 million students at German universities in the winter semester of 2017/18,374,951 were international students, placing Germany sixth in the world for study destination (ICEF Monitor, 2018). Within the EU, Germany 
is top of 30 European study abroad destinations for international students (ICEF Monitor, 2018).

\subsection{Public Voices on the Englishization in German HE}

As exemplified by the Special Interest group ADAWIS, Englishization in Germany is subject to criticism: from the point of view of academics, the pressure (and extra time and effort) to publish in a foreign language, the danger of domain loss for discipline-specific specialist terminology, and loss over agency in their professional life all contribute to negative affect. Englishization also endangers the EU's aim of plurilingual education (1+2), and the explicit aim to link European citizenship to plurilingualism - a particular concern for politicians who see increased Englishization as a threat to EU citizenship (Lanvers, 2018). However, parents, students, and the public tend to focus on instrumental benefits gained from improved chances for graduates in the global marketplace (Lanvers, 2018). Thus, German universities, more than other domains of Englishization in Germany, constitute loci of conflictual interest, and positive as well as negative affect to EMI: tensions, and different affective reactions, between top-down and bottom-up interests in Englishization in German HEI, and different stakeholders should be noticeable.

In sum, German HEIs pragmatically leverage Englishization to boost the nation's economic and political future, but German HE also puts high value on supporting German proficiency. Incoming foreigners have access to German classes. In the effort to safeguard the position of German as a world and academic language (Earls, 2013), international students on some programmes are required to engage in German language classes. Those who successfully achieve this goal are in a strong position to join the attractive graduate employment market in Germany.

\subsection{Attitudes towards EMI among students and staff}

Students tend to perceive that the advantages of an EMI programme outweigh the possible concerns over EMI (Macaro et al., 2018), namely that the learning of content suffers at the expense of language learning (Dafouz et al., 2014), that learning and grade outcomes reflect English proficiency more than content knowledge (Martirosyan et al., 2015) and/or that their English proficiency level does not suffice for this advanced level of study (Macaro et al., 2018).

For academics, the significant shift, over the last decades, towards publishing in English rather than a variety of academic languages (Bolton 
\& Kuteeva, 2012), means that they may be required to publish in English by employers or grant funders (Hanauer et al., 2019). For those in pursuit of wide scholarly recognition, English as the academic lingua franca can help them leverage their intellectual capital (Rowlands, 2018). On the other hand, some academics report feeling resentment over English homogenization of academia, 'many non-anglophone contributions are excluded in international fora' (Martín et al., 2014, p.58). Overall, teachers report mixed feelings, those of challenge, emotional burden, but also of achievement and self-development (Doíz \& Lasagabaster, 2018).

German academics may feel disadvantaged compared to English nativespeakers. Studies report that 'multilingual scientists perceived English science writing as $24 \%$ more difficult, generating $21 \%$ more anxiety and $11 \%$ less satisfaction than science writing using their L1 [first language]' (Hanauer et al., 2019). Concerning professional reasons for teaching via English, the issues are more contested still. Although academics may, of course, choose to teach via EMI for a variety of reasons, others may feel incommoded, especially if given little choice over the matter. Concerns voiced by staff asked (or even forced) to teach via EMI include perceptions that

- EMI increases their workload;

- their English proficiency is not sufficient;

- their students' proficiency is not sufficient;

- their professionalism as subject specialists is undermined (Hultgren, 2019);

- the international student body in EMI demands a change in teaching style;

- they end up teaching language more/rather than content;

- their content delivery gets diluted/loses rigour;

- the content becomes (too) internationalized as a result of adapting content to the materials available in English.

Empirical studies investigating if students' content learning outcomes differ between students studying via EMI, or home/first language study, repeatedly report either no or non-significant differences in learning outcomes (Dimova et al., 2015, p. 318). As students are (in many cases, at least) relatively free to choose their country of study, HE institution, or, at a minimum, their degree programme, these reassuring results may simply result from a self-selection effect, whereby those students feeling comfortable with English choose to study via EMI. Thus, the results do thus not necessarily support the thesis that studying via EMI comes at no cost to content learning. As an argument for some degree of 'student choice' can be made in most cases when studying 
via EMI, it may be unsurprising that the majority of students studying under EMI report positively on it overall (Macaro et al., 2018). Furthermore, studies focusing on student experiences report that some students favour 'native speaker English teachers' (Lasagabaster \& Sierra, 2002), while others report little native-speaker bias among students (Kiczkowiak, 2019). Much of this EMI research reports teacher or student perceptions, thus indicating the strength of feelings or emotional response towards aspects of EMI. However, research into teacher and student affect, the feelings, moods, and emotions underlying the perceptions of teachers and students, with respect to EMI is lacking. This study addresses the above-described research lacuna by exploring affect in EMI among, and between, both students and teachers.

\section{This study}

\subsection{Setting}

The study is part of a larger project researching affect and strategies developed by students and teachers in an EMI setting in a German university of applied science. The institution at which the study was piloted belongs to a state-funded co-operative university. It comprises three faculties offering more than 60 nationally and internationally approved Bachelor and Master study programmes in cooperation with around 2,000 organizations. Students are employed by a partner company to alternately study on the three-year bachelor programme, and work at the company and receive a salary. International students attend the university for one semester. They may enrol on a variety of courses, some of which are also attended by home students. The participants of this study follow a mixed English and German medium programme. The home students are all German-speakers in a monolingual cohort and have a $\mathrm{C} 1$ level of proficiency. The international students took German as foreign language (Deutsch als Fremdsprache) classes and attended English-only medium content courses.

In line with the requirement of the Deutscher Akademischer Austauschdienst (German academic exchange service) for a study programme to qualify as an International Degree Programme, the International Business (IB) study programme outlines its goals accordingly: both international and home students may apply; all applicants must have proven language proficiency in both German and English; around $40 \%$ of the lectures are held in English. IB home students must, when possible, spend a practical phase working abroad, and a phase at an overseas university. 
This study investigates how both teachers and students, in the abovedescribed setting, report on their EMI experiences, in terms of the basic psychological needs of autonomy, relatedness, and competence.

\subsection{Research Questions}

1 In terms of autonomy, relatedness, competence, what affect do (a) home students, (b) international students, and (c) teachers, report in their EMI experience?

2 (How) do the three groups differ?

\subsection{Method}

\section{Ethics}

The authors applied for, and were granted, ethics approval at their UK host institution, the German HEI where data collection took place, and from all participants. The first author is a teacher in the department where data collection took place, and, with the exception of two, student interviews were carried out with individuals who are also enrolled on her own course.

\section{Participants and data}

The study sample comprised students and teachers on an International Business (IB) bachelor programme. This presents a unique set of circumstances in comparison to most studies that focus on challenges and difficulties faced by participants on EMI postgraduate programmes. Qualitative data stem from transcripts of semi-structured interviews. Student participants are studying under current pandemic circumstances. The typical home (i.e., German) student at this university, for this IB programme, is highly proficient in English (based on professional experience of the first author $\mathrm{MH}$ ). They tend to have graduated with the highest school-leaving grades, and typically have spent periods of time in English-speaking countries. Many also participated in bilingual lessons or content-and language integrated lessons during their secondary schooling. The international students are more heterogeneous, both with respect to their first languages, and English proficiency, but given the lack of detailed information regarding their English proficiency, no further comment can be made. According to international student testimonials, many overseas students are as motivated to learn about German language and culture as they are to be studying on the IB programme. 
Teaching staff on the IB programme are recruited from industry to deliver their particular expertise. Some also teach at other universities. The majority are native German teachers who use German as the medium of instruction, but international teachers are also brought in to deliver content through EMI. The home teacher participants in this study comprise one German and one Ukrainian national, delivering their teaching via EMI, to predominantly home students. As with the international students, there is no data available as to teachers' language proficiency. The international teacher who participated in the study is a monolingual UK national, employed at a UK university, with extensive international teaching experience.

\section{Instruments}

Following a mixed methods approach, the instruments that were trialled encompassed a survey questionnaire, and semi-structured interviews with students and teachers. As affect is a personal phenomenon, coloured by participants' insider perspective, a purely quantitative approach would not suffice for gathering the deep, rich data held within individuals. Consequently, the primary approach for this study is qualitative. However, initial quantitative data was collected by way of an adapted version of the I-PANAS SF ${ }^{1}$ (Thompson, 2007). The original 20-item PANAS (Watson et al., 1988) is a highly regarded psychological measurement to assess general attitudes. A third set of scales extended the PANAS items into affective statements and required participants to think specifically about their feelings when learning through EMI. Thompson (2007) modified the instrument to 10 items to reflect cross-cultural, non-native English-speaking settings. This validated short PANAS version was deemed suitable for our context. Respondents were asked to rate their affect on a scale of Never (o) to Always (6) both:

- At work / university generally;

- In relation to learning through the medium of English specifically.

Students were also asked to reply to specific situational questions, eliciting affective reactions relating to EMI. Finally, open-ended questions permitted participants to share their opinions and beliefs regarding EMI in German HEIs. Teacher and student versions of the PANAS and interview schedules can be found in the Appendix. 
Figure 15.1 Overview of the coding system
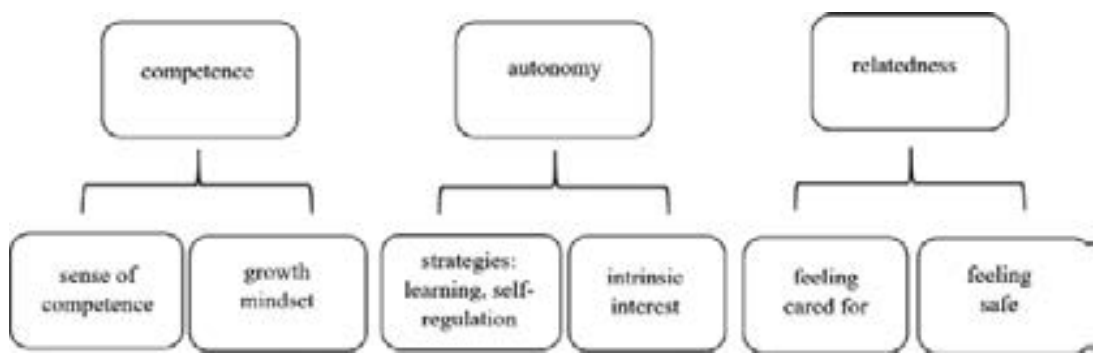

\subsection{Analysis}

Recorded interviews were manually transcribed by the first author $\mathrm{MH}$, enabling close immersion in the data (Creswell, 2009). During initial coding, emergent themes were identified and generally categorized as positive or negative. Subsequent analysis mapped codes more purposefully to three basic psychological needs, according to self-determination theory (SDT), of autonomy, competence, and relatedness. These were divided according to Mercer's (2019) five facilitative conditions, which were further divided to give another layer of detail. Figure 15.1 gives a simplified overview of the coding system. This two-phased process (Charmaz \& Belgrave, 2015) affords a systematic analysis and facilitates 'intercoder' communications (Creswell, 2009, p.191). Double-coding of a small percentage of the data between the researcher and 'intercoder' achieved a 90\% overlap. Responses from the interview data were coded against the SDT-framed coding grid, with each code further differentiated between positive and negative values.

\section{Results}

In analysing and presenting results, we were guided, for both student and teacher results, by the frequencies with which each cohort mentioned certain codes. In the following, we will first present the PANAS results, indicating the representativeness of our interviewees' negativity/positivity scores compared to the whole cohort. We then report, with illustrative citations, on competence, autonomy, and relatedness codes, focusing on a) the ones most frequently used by one cohort, and b) those most differing between cohorts (be these students versus teachers, or home versus international students). Codes awarded fewer than 4 frequencies have been omitted from the results table and will not be discussed. 


\subsection{Students}

A cohort of 31 Students completed the PANAS. Table 15.1 displays cohort means, and scores of the seven students who were interviewed, to indicate how interviewees' affect scores relate to that of the cohort. International interviewees tend to report higher positive affect than the overall cohort, especially in relation to EMI; IS2 is remarkably positive. In contrast, HS2's and HS4's negative affect is above cohort average, and only in the case of $\mathrm{HS}_{4}$ is the negative affect noticeably related to low English proficiency.

Table 15.1 Students' responses to PANAS

\begin{tabular}{lcccccc}
\hline & \multicolumn{2}{c}{$\begin{array}{c}\text { Generally, on aver- } \\
\text { age day at university }\end{array}$} & $\begin{array}{c}\text { Affect when learning } \\
\text { through EMI }\end{array}$ & \multicolumn{2}{c}{$\begin{array}{c}\text { Feelings about } \\
\text { learning through EMI }\end{array}$} \\
\cline { 2 - 7 } & $\begin{array}{c}\text { General } \\
\text { PA }\end{array}$ & $\begin{array}{c}\text { General } \\
\text { NA }\end{array}$ & EMI PA & EMI NA & $\begin{array}{c}\text { Pos to } \\
\text { EMI }\end{array}$ & $\begin{array}{c}\text { Neg to } \\
\text { EMI }\end{array}$ \\
\hline IS1 & 3.6 & 2.0 & 5.4 & 3.4 & 6 & 3 \\
IS2 & 4.4 & 0.4 & 4.6 & 0 & 6 & 0.6 \\
HS1 & 4.4 & 1.2 & 5.8 & 0 & 6.0 & 0.6 \\
HS2 & 3.6 & 1.8 & 3.2 & 1.4 & 4.6 & 2.4 \\
HS3 & 5.2 & 0.6 & 4.8 & 0.2 & 5.0 & 1.0 \\
HS4 & 2.4 & 1.2 & 3.0 & 2.2 & 3.2 & 3.2 \\
HS5 (NES) & 4.6 & 0 & 4.4 & 0 & 6 & 0 \\
Cohort Averages & $\mathbf{3 . 7}$ & $\mathbf{1 . 3}$ & $\mathbf{4 . 1}$ & $\mathbf{1 . 2}$ & $\mathbf{4 . 7}$ & $\mathbf{1 . 7}$ \\
\hline
\end{tabular}

IS = international student, $\mathrm{HS}=$ home student, NES = native English speaker; $\mathrm{PA}=$ positive affect; $\mathrm{NA}=$ negative affect

\section{Interview results}

Table 15.2 lists code frequencies relating to basic psychological needs of SDT (Mercer, 2019), in both home and international students. As we interviewed twice as many home as international participants (among both students and teachers), any frequency comparison needs to bear this in mind.

\section{Competence}

Home students tended to report positively on their self-efficacy, and be confident in their ability to learn the content via English, as these quotes demonstrate:

I feel like in English it's sometimes more - clear to the point, and not much um - well I feel like in German there's more words for the same meaning. And in English it is sometimes more - I dunno - it's easier 
if it's a broad term than a very detailed term, which is sometimes not necessary. (HS2)

Home students also tended to actively welcome the cognitive challenge of EMI: 'I think my attention is higher in those English medium classes, because it challenges me a bit more.' $\left(\mathrm{HS}_{3}\right)$.

International students also expressed high self-efficacy - just not to the same extent:

I realized that my English was besser - better than most of the students... even when I used to interact with the German students - the buddies - I realized that I'm more comfortable in English. (IS1)

Home students also showed more awareness of the difference between learning at school and at University:

in school you just have English classes and then you're so focused in learning grammar that maybe you forget to really start to speak freely and to maybe thinking... in university, also because that I think I learned important contents, not only in German but also in English. (HS1)

As might be expected on an IB programme, both student groups report high awareness of the importance of global English.

In the global business we have nowadays, where everything is connected and in every department you have people from China or from India.... if you want to work there, you need to understand that, because it doesn't work another way. (HS1)

... back in my continent, in America, English is a requisite to obtain a job. (IS1)

The two international students were very favourable towards German universities offering EMI: 'I had the opportunity to choose for another country that teaches their classes in Spanish, but I wanted to practice my English that's why I'm come to Germany' (IS1). 
Table 15.2 Student coding frequencies

\begin{tabular}{|c|c|c|c|c|c|c|c|c|c|}
\hline \multicolumn{4}{|c|}{ COMPETENCE } & \multirow{2}{*}{\multicolumn{2}{|c|}{$\begin{array}{c}\text { AUTONOMY } \\
\begin{array}{c}\text { sense of } \\
\text { autonomy }\end{array}\end{array}$}} & \multicolumn{4}{|c|}{ RELATEDNESS } \\
\hline \multicolumn{2}{|c|}{$\begin{array}{c}\text { sense of } \\
\text { competence }\end{array}$} & \multicolumn{2}{|c|}{$\begin{array}{l}\text { growth } \\
\text { mindset }\end{array}$} & & & \multicolumn{2}{|c|}{$\begin{array}{c}\text { feeling cared } \\
\text { for }\end{array}$} & \multicolumn{2}{|c|}{$\begin{array}{c}\text { feeling safe/ negative } \\
\text { affect avoidance }\end{array}$} \\
\hline Home & Int & Home & Int & Home & Int & Home & Int & Home & Int \\
\hline \multicolumn{10}{|c|}{ positives } \\
\hline \multicolumn{2}{|c|}{$\begin{array}{c}\text { positive } \\
\text { self-efficacy }\end{array}$} & \multicolumn{2}{|c|}{$\begin{array}{c}\text { non } \\
\text { perfectionist } \\
\text { mindset }\end{array}$} & \multicolumn{2}{|c|}{$\begin{array}{c}\text { clear difference } \\
\text { language v. } \\
\text { content }\end{array}$} & \multicolumn{2}{|c|}{$\begin{array}{c}\text { EMI teacher } \\
\text { German=good }\end{array}$} & \multicolumn{2}{|c|}{$\begin{array}{c}\text { awareness of others' } \\
\text { affect; showing } \\
\text { empathy }\end{array}$} \\
\hline 12 & 3 & 5 & 0 & 4 & 1 & 6 & 3 & 13 & 2 \\
\hline \multicolumn{2}{|c|}{$\begin{array}{l}\text { can learn } \\
\text { content via } \\
\text { English }\end{array}$} & \multicolumn{2}{|c|}{$\begin{array}{l}\text { awareness } \\
\text { of growth } \\
\text { trajectory }\end{array}$} & \multicolumn{2}{|c|}{$\begin{array}{l}\text { affective strate- } \\
\text { gies to regulate } \\
\text { emotions }\end{array}$} & \multicolumn{2}{|c|}{$\begin{array}{l}\text { good group } \\
\text { dynamics }\end{array}$} & \multicolumn{2}{|c|}{$\begin{array}{l}\text { PA from engagement: } \\
\text { enthusiasm, focus, flow }\end{array}$} \\
\hline 6 & 1 & 8 & 2 & 24 & 5 & 3 & 4 & 14 & 5 \\
\hline \multicolumn{2}{|c|}{$\begin{array}{c}\text { beliefs } \\
\text { about Global } \\
\text { English }\end{array}$} & & & \multicolumn{2}{|c|}{$\begin{array}{l}\text { intrinsic interest } \\
\text { (both in content } \\
\text { and English) }\end{array}$} & & & \multicolumn{2}{|c|}{$\begin{array}{l}\text { PA from physical } \\
\text { comfort \& security }\end{array}$} \\
\hline 10 & 7 & & & 11 & 3 & & & 1 & 5 \\
\hline \multicolumn{2}{|c|}{$\begin{array}{l}\text { previous } \\
\text { exposure to } \\
\text { English }\end{array}$} & & & \multicolumn{2}{|c|}{$\begin{array}{l}\text { strategies for } \\
\text { content learning }\end{array}$} & & & \multicolumn{2}{|c|}{ PA from teacher action } \\
\hline \multirow[t]{3}{*}{7} & \multirow[t]{3}{*}{2} & & & 5 & 2 & & & 4 & 1 \\
\hline & & & & \multicolumn{2}{|c|}{$\begin{array}{l}\text { communication } \\
\text { \& English learn- } \\
\text { ing strategies }\end{array}$} & & & & \\
\hline & & & & 5 & 5 & & & & \\
\hline \multicolumn{10}{|c|}{ negatives } \\
\hline \multicolumn{2}{|c|}{$\begin{array}{l}\text { negative } \\
\text { self-efficacy }\end{array}$} & \multicolumn{2}{|c|}{$\begin{array}{l}\text { proficiency } \\
\text { as sign of } \\
\text { intelligence }\end{array}$} & \multicolumn{2}{|c|}{$\begin{array}{c}\text { negative } \\
\text { attitude to } \\
\text { non-native } \\
\text { teacher }\end{array}$} & & & \multicolumn{2}{|c|}{$\begin{array}{l}\text { avoidance of errors / } \\
\text { face-saving strategies }\end{array}$} \\
\hline 6 & 3 & 4 & 0 & 9 & 1 & & & 6 & 0 \\
\hline & & & & & & & & \multicolumn{2}{|c|}{$\begin{array}{l}\text { NA from cognitive } \\
\text { overload: boredom, } \\
\text { nervousness, } \\
\text { distraction, frustration, } \\
\text { anxiety }\end{array}$} \\
\hline & & & & & & & & 15 & 9 \\
\hline & & & & & & & & $\begin{array}{r}\text { NA ge } \\
\text { of ridi } \\
\text { shyness }\end{array}$ & $\begin{array}{l}\text { Fear } \\
\text { ame, } \\
\text { anxiety }\end{array}$ \\
\hline & & & & & & & & 8 & 4 \\
\hline & & & & & & & & $\begin{array}{l}\mathrm{NA} \mathrm{fr} \\
\text { action: } \\
\text { impatie } \\
\text { critic }\end{array}$ & $\begin{array}{l}\text { cher } \\
\text { ption, } \\
\text { dicule, } \\
\text { pack }\end{array}$ \\
\hline & & & & & & & & 3 & 5 \\
\hline
\end{tabular}

The numbers refer to the frequency with which the psychological needs of SDT were categorized for home and international students. 
Regarding growth mindsets, it is noticeable that home students reported more awareness of their growth trajectory in their ability to learn via EMI: 'Back then it was like being a little bit afraid if I would succeed that good in those classes. But now it's not a problem anymore' (HS3).

Non-perfectionist mindset and awareness of their own growth in EMI learning were also more prominent in home students: 'when I hear other students talking in not the best English, because then I'm like, "Ok they don't speak perfect English” so nobody cares if I don't do either' (HS4).

However, the fact that home students saw language competence as sign of intelligence more than international students might be perceived as a potential negative effect on efficacy: 'Most of my friends are pretty ambitioned and also have really good grades. They are really intelligent, and that's why I think they have a good level of English' (HSi).

\section{Autonomy}

Home students reported overwhelmingly more use of affective strategies to regulate their emotions:

I have like a notebook and that every night I wrote down things that I'm grateful for and that made me happy... several months or weeks later, I read over it again and then I see 'oh yeah, this day I got a compliment for my English and it made me happy'. (HSi)

Home students reported also more often to be intrinsically motivated both to improve their English and to learn content. 'I think, as I said it's a small advantage and you don't only learn the subject, you learn English. So it's better, in my opinion' (HS2).

Home students also tended to be more critical of their teachers' English competence than international students, while international students used more metacognitive English learning strategies.

When I feel with questions or confused, I first - I think the questions I have - that I'm going to ask to the professor, before I ask it, if the question is too complex or something, I google first and look up later. And then I ask the professor. (IS1)

\section{Relatedness}

Despite overall high English proficiency, especially among home students, nervousness and negative affect generally were very prevalent in both groups. 'I think maybe I might be a little nervous sometimes, so I do not 
tend to be a nervous person but as I do not want to make mistakes... I feel a little insecure' $(\mathrm{HS} 1)$.

Home students were more critical of the teachers' English competency, but international students do seem to prefer 'native speakers' as well: 'it was a little bit distracting because she would make mistakes - I don't want to say quite often, but often enough that it was kind of a regular thing' ( $\left.\mathrm{HS}_{5}\right)$.

International students were more sensitive to negative affect from the teacher,

because, of our accents in the German classes, so the teacher couldn't see us. So the teacher, he couldn't figure out if $\mathrm{R}$ is speaking or if $\mathrm{T}$ is speaking because we had the similar Indian accent. So that was not very - didn't felt good to me that that was happening. (IS2)

Against expectation, and literature regarding cultural differences in the importance of face saving (Nakane, 2007), German students reported using more face-saving strategies than international students.

I know that I participate less when the lecture is in English, because it's - because I always, before I say something, I wanna have it in my head what I want to say because I don't wanna make any mistakes. (HS4)

\subsection{Teachers}

Six EMI teachers (2 native-English speakers, 3 native-Germans, and 1 nativeUkrainian) completed the teacher version of the PANAS (Appendix 2).

Table 15.3 shows the PA and NA scores for the three interviewed teachers in comparison to the cohort mean score of survey respondents. IntTi relates positively to their EMI teaching, compared to their non-EMI professional daily life; they also have higher PA and lower NA scores in relation to EMI teaching than the cohort mean. Both $\mathrm{HT} 1$ and 2 relate overall positively to EMI and their daily professional life generally and are reasonably representative of the cohort. Table 15.4 gives the coding frequencies of the teacher interviews.

Home teachers reported strong self-efficacy when it comes to teaching their content through EMI. 'Fun. Positive. Sometimes difficult. ... Sometimes I feel more comfortable than in German. And Ukrainian, to be honest' (HT2). 
Table 15.3 Teachers' PANAS results

\begin{tabular}{lcccccc}
\hline & \multicolumn{2}{c}{$\begin{array}{c}\text { Generally, on aver- } \\
\text { age day at university }\end{array}$} & \multicolumn{2}{c}{$\begin{array}{c}\text { Affect when teaching } \\
\text { through EMI }\end{array}$} & $\begin{array}{c}\text { Feelings about teach- } \\
\text { ing through EMI }\end{array}$ \\
\hline & $\begin{array}{c}\text { General } \\
\text { PA }\end{array}$ & $\begin{array}{c}\text { General } \\
\text { NA }\end{array}$ & EMI PA & EMI NA & $\begin{array}{c}\text { Pos to } \\
\text { EMI }\end{array}$ & $\begin{array}{c}\text { Neg to } \\
\text { EMI }\end{array}$ \\
\hline HT1 & 5.8 & 0 & 5.8 & 0 & 6 & 0.2 \\
HT2 & 4.4 & 1.2 & 4.4 & 0.8 & 5.4 & $\mathbf{1}$ \\
IntT1 & 3.8 & 1 & 6 & 0 & 6 & 0.4 \\
(NES) & 4.1 & 0.6 & 4.8 & 0.3 & 4.8 & 0.6 \\
Cohort Average & 4 & & & & & \\
\hline
\end{tabular}

IntT = international teacher, $\mathrm{HT}=$ home teacher, $\mathrm{NES}=$ native English speaker; $\mathrm{PA}=$ positive affect; $N A=$ negative affect

Table 15.4 Teacher coding frequencies

\begin{tabular}{|c|c|c|c|c|c|c|c|c|c|}
\hline \multicolumn{4}{|c|}{ COMPETENCE } & \multirow{2}{*}{\multicolumn{2}{|c|}{$\begin{array}{c}\text { AUTONOMY } \\
\text { A sense of } \\
\text { autonomy } \\
\text { (internal locus } \\
\text { of control) }\end{array}$}} & \multicolumn{4}{|c|}{ RELATEDNESS } \\
\hline \multicolumn{2}{|c|}{$\begin{array}{c}\text { Sense of } \\
\text { competence } \\
\text { (self-efficacy) }\end{array}$} & \multicolumn{2}{|c|}{$\begin{array}{c}\text { A growth } \\
\text { mindset (vs. } \\
\text { fixed mindset) }\end{array}$} & & & \multicolumn{2}{|c|}{$\begin{array}{c}\text { Feeling cared } \\
\text { for as individu- } \\
\text { als (experienc- } \\
\text { ing pedagogical } \\
\text { care) }\end{array}$} & \multicolumn{2}{|c|}{$\begin{array}{c}\text { Feeling } \\
\text { psychologically } \\
\text { safe (avoidance } \\
\text { of NA) }\end{array}$} \\
\hline Home & Int & Home & Int & Home & Int & Home & Int & Home & Int \\
\hline \multicolumn{10}{|c|}{ positives } \\
\hline \multicolumn{2}{|c|}{$\begin{array}{c}\text { Positive } \\
\text { self-efficacy }\end{array}$} & \multicolumn{2}{|c|}{$\begin{array}{l}\text { Non perfection- } \\
\text { ist mindset }\end{array}$} & \multicolumn{2}{|c|}{$\begin{array}{c}\text { difference } \\
\text { between } \\
\text { language } v . \\
\text { content problem }\end{array}$} & \multicolumn{2}{|c|}{$\begin{array}{c}\text { EMI student } \\
- \text { German=good }\end{array}$} & \multicolumn{2}{|c|}{$\begin{array}{l}\text { PA from } \\
\text { engagement: } \\
\text { enthusiasm, } \\
\text { focus, flow }\end{array}$} \\
\hline 9 & 2 & 7 & 2 & 4 & 5 & 0 & 7 & 6 & 12 \\
\hline \multicolumn{2}{|c|}{$\begin{array}{l}\text { Beliefs about } \\
\text { Global English }\end{array}$} & \multirow{2}{*}{\multicolumn{2}{|c|}{25}} & \multicolumn{2}{|c|}{$\begin{array}{l}\text { Affective } \\
\text { strategies }\end{array}$} & \multicolumn{2}{|c|}{$\begin{array}{l}\text { Good Group } \\
\text { dynamics }\end{array}$} & \multicolumn{2}{|c|}{$\begin{array}{c}\text { PA from student } \\
\text { action }\end{array}$} \\
\hline 5 & 4 & & & 4 & 2 & 6 & 3 & 7 & \\
\hline & & & & \multicolumn{2}{|c|}{$\begin{array}{c}\text { Strategies for } \\
\text { content teaching }\end{array}$} & & & & \\
\hline & & & & 5 & 12 & & & & \\
\hline & & & & \multicolumn{2}{|c|}{$\begin{array}{c}\text { Communication } \\
\text { \& English teach- } \\
\text { ing strategies }\end{array}$} & & & & \\
\hline & & & & 2 & 6 & & & & \\
\hline \multicolumn{10}{|c|}{ negatives } \\
\hline & & & & & & & & \multicolumn{2}{|c|}{$\begin{array}{l}\text { NA from cogni- } \\
\text { tive overload }\end{array}$} \\
\hline & & & & & & & & 7 & 3 \\
\hline & & & & & & & & \multicolumn{2}{|c|}{$\begin{array}{c}\text { NA from student } \\
\text { action }\end{array}$} \\
\hline & & & & & & & & 0 & 5 \\
\hline
\end{tabular}

The numbers refer to the frequency with which the psychological needs of SDT were categorized for home and international teachers. 
The International teacher felt more strongly that German students flourish in EMI classes. 'They're good enough to get the message across and they're open-minded enough to accept suggestions if they can't' (IntT1).

German teachers report using considerably more affective strategies, with more strategies for regulating students' affect than their own.

I have to be focused and attentive. I have to be present in the class, but only in the class. Thinking about nothing else; about no troubles before or after, or things I have to do before or after. (HT2)

The international teacher seemed to dedicate more thought about how to teach content.

It's my responsibility to make sure the material can be understood in whatever level of English they want to operate at. It then means that I have to tailor assessment, to assess the content in those terms. (IntT1)

The international teacher reported more often on good group dynamics, positive feedback from students and feelings of positive affect. 'I've never had a situation where students disagreed to work together - they're mature enough to get on and get a job done' (IntT1).

\section{Conclusion}

This study looked at affect, in both learners and teachers experiencing EMI at an HEI in Germany. Could learning via EMI trigger student anxiety in some students and teachers, or, conversely, lead to positive affect? Bearing in mind the sample size of this study, we conclude with the following observations.

Students showed positive affect in relation to competence, especially home students, who enjoyed the cognitive challenge of learning via EMI. Home students also used affective strategies to regulate their EMI experiences more than international students, showed more native speaker bias, and were more likely to critique the teaching context. However, we observed negative affect such as nervousness, fear of ridicule, and use of avoidance and face-saving strategies in nearly all, but unrelated to participants' sense of proficiency. In other words: negative affect in one dimension of EMI can be cancelled out by positive self-efficacy, and enjoyment of the cognitive challenge. 
Teachers reported high self-efficacy, but it was higher in home (German) teachers. They also used more self-regulating strategies than international teachers. International teachers focused more on student perspectives, such as classroom dynamics, and the student benefits of learning via EMI overall.

We return to our initial thesis of Englishization in German HEI as loci of conflictual interests (section 3.4), which result in conflicting affect in EMI. The first observation is that international participants - both students and teachers - demonstrated more positive affect towards EMI than home participants. The only exception to this trend, conceivably reflecting cultural differences, was international students' greater concerns with face-saving. Anxiety over proficiency, however, was - as far as was observable - present in most participants, and unrelated to actual proficiency. Relatedly, German students displayed relatively strong English native speaker bias, and intolerance towards international varieties. Thus, among our participants, tensions around Englishization in German HEIs go far beyond the dispute of home language versus English: the heart of the issue, here, addresses native versus international varieties of English standard: who owns English? And who decides what is good English? Judging by our results, international participants in Englishization in Germany have moved on further in conceptualizing English as a truly global language, with Germans seemingly holding on to native speaker ideals. Thus, in addition to the tensions observed by Lanvers (2018) between bottom-up (public) pro-English attitudes versus more cautious top-down (academics' and politicians') attitudes towards the 'English craze', Germany must face the question of standards and varieties of English, if Englishization is to be equally successful for all participants. The findings of this study suggest that German and international participants in HEI in Germany experience different emotions when engaged in EMI. In order to support future participants in EMI and improve pedagogical practice, future EMI studies might also investigate to what extent these differences might align with views of Englishization of HEI, such as a threat to cultural identity, or as instrumentally beneficial.

\section{Acknowledgements}

Many thanks to our reviewers, and the eminently patient editors, for their encouraging response to the pilot study and the valuable pointers offered. A big thank you to my co-author, Ursula, for inviting me to participate in this exciting first-time foray into academic publishing. The whole endeavour has greatly enriched my doctoral experience - and will undoubtedly result in an even better final thesis. 


\section{References}

Airey, J. (2012). 'I don't teach language.' The linguistic attitudes of physics lecturers in Sweden. AILA Review, 25, 64-79.

Al-Khairy, M. H. (2013). English as a foreign language learning demotivational factors as perceived by Saudi undergraduates. European Scientific Journal, 9(32), 365-382.

Ammon, U. (2004). German as an international language of the sciences: Recent past and present. In A. Gardt \& B. Hüppauf (Eds.), Globalization and the future of German (pp. 157-172). De Gruyter Mouton.

Ammon, U. (2006). Language conflicts in the European Union: On finding a politically acceptable and practicable solution for EU institutions that satisfies diverging interests. International Journal of Applied Linguistics, 16(3), 319-338.

Bolton, K., \& Kuteeva, M. (2012). English as an academic language at a Swedish university: Parallel language use and the 'threat' of English. Journal of Multilingual and Multicultural Development, 33(5), 429-447.

Braselmann, P. (2004). Language policies in East and West. National language policies as a response to the pressures of globalization. In A. Gardt \& B. Hüppauf (Eds.), Globalization and the future of German (pp. 99-120). De Gruyter Mouton.

Bundesministerium für Bildung und Forschung (BMBF). (2020). Education and research in figures 2020. https://www.bmbf.de/upload_filestore/pub/Education_and_Research_in_Figures_2020.pdf.

Charmaz, K., \& Belgrave, L. L. (2015). Grounded theory. In G. Ritzer (Ed.), The Blackwell encyclopedia of sociology. John Wiley \& Sons.

Coleman, J. A. (2006). English-medium teaching in European higher education. Language Teaching, 39(1), 1-14.

Creswell, J. W. (2009). Research design: Qualitative, quantitative, and mixed methods approaches. SAGE Publications.

Dafouz, E., Camacho, M., \& Urquia, E. (2014). 'Surely they can't do as well': A comparison of business students' academic performance in English-medium and Spanish-as-first-language-medium programmes. Language and Education, $28(3), 223-236$.

Deutsche Akademischer Austauschdienst (DAAD) (2021). Higher education compass. Courses of study in Germany. Retrieved 9 February 2021 from https://www2. daad.de/deutschland/studienangebote/studiengang/en/?a=result\&q=\&degre $\mathrm{e}=\&$ courselanguage $=\&$ locations $=\&$ admissionsemester $=\&$ sort $=$ name\&page $=1$

Dimova, S., Hultgren, A. K., \& Jensen, C. (2015). English-medium instruction in European higher education. Walter de Gruyter.

Doíz, A., \& Lasagabaster, D. (2018). Teachers' and students' second language motivational self system in English-medium instruction: A qualitative approach. TESOL Quarterly, 52(3), 657-679. 
Doíz, A., Lasagabaster, D., \& Sierra, J. M. (2011). Internationalisation, multilingualism and English-medium instruction. World Englishes, 3o(3), 345-359.

Earls, C. W. (2013). Setting the Catherine wheel in motion: An exploration of 'Englishization' in the German higher education system. Language Problems and Language Planning, 37(2), 125-150.

Earls, C. W. (2014). Striking the balance: The role of English and German in a multilingual English-medium degree programme in German higher education. Current Issues in Language Planning, 15(2), 153-173.

Ehlich, K. (2000). Deutsch als Wissenschaftssprache für das 21. Jahrhundert. German as a Foreign Language, 1, 47-63.

Ehrenreich, S. (2010). English as a business lingua franca in a German multinational corporation: Meeting the challenge. Journal ofBusiness Communication, 47(4), 408-431.

Erling, E. J., \& Hilgendorf, S. K. (2006). Language policies in the context of German higher education. Language Policy, 5(3), 267-293.

European Commission (2020). Programmes outside the bachelor and master structure. European Commission, Eurydice. Retrieved 27 January 2020 from https://eacea.ec.europa.eu/national-policies/eurydice/content/ programmes-outside-bachelor-and-master-structure-31_en

Eurostat (2021). Pupils by education level and modern foreign language studied: $A b$ solute numbers and \% of pupils by language studied. Brussels: Eurostat, European Commission. http://appsso.eurostat.ec.europa.eu/nui/submitViewTableAction.do Gardt, A. (2004). Language and national identity. In A. Gardt \& B. Hüppauf (Eds.), Globalization and the future of German (pp. 197-212). De Gruyter Mouton.

Gnutzmann, C., Jakisch, J., \& Rabe, F. (2014). English as a lingua franca: A source of identity for young Europeans? Multilingua, 33(3-4), 437-457.

Gomes, C. (2020). Outside the classroom: The language of English and its impact on international student mental wellbeing in Australia.Journal of International Students, 1o(4), 934-953.

Göpferich, S., Machura, I. A., \& Murphy, J. T. (2019). Supporting English medium instruction at German institutions of higher education. In R. Hickey (Ed.), English in the German-speaking world (pp.114-140). Cambridge University Press.

Gürtler, K., \& Kronewald, E. (2015). Internationalization and English-medium instruction in German higher education. In S. Dimova, A. K. Hultgren, \& C. Jensen (Eds.), English-medium instruction in European higher education (English in Europe, vol. 3) (pp. 89-114). De Gruyter Mouton.

Hanauer, D. I., Sheridan, C. L., \& Englander, K. (2019). Linguistic injustice in the writing of research articles in English as a second language: Data from Taiwanese and Mexican researchers. Written Communication, $36(1)$, 136-154. 
Hilgendorf, S. K. (2007). English in Germany: contact, spread and attitudes. World Englishes, 26(2), 131-148.

Hultgren, A. K. (2019). English as the language for academic publication: On equity, disadvantage and 'non-nativeness' as a red herring. Publications, 7(2), 31.

ICEF Monitor (2018, April 25). Germany confirms its foreign enrolment growth for 2017. ICEF Monitor. Retrieved 28 March 2019 from http://monitor.icef.com/2018/04/ germany-confirms-foreign-enrolment-growth-2017/

International Association of Language Centers (IALC) (2018). The student perspective on language study abroad: Perfecting the student experience. Retrieved 4 February 2021 from https://www.ialc.org/fileadmin/uploads/ialc/Documents/ Study_Travel_Research_Reports/2018_IALC_Research_Report_Print.pdf

Jakisch, J. (2012). Mehrsprachigkeit und Englischunterricht. Möglichkeiten und Grenzen schulischer Mehrsprachigkeit im Spannungsfeld von Theorie und Praxis. FLuL - Fremdsprachen Lehren Und Lernen, 41(1), 104-108.

Kiczkowiak, M. (2019). Students', teachers' and recruiters' perception of teaching effectiveness and the importance of nativeness in ELT. Journal of Second Language Teaching \& Research, $7(1), 1-25$.

Lanvers, U. (2018). Public debates of the Englishization of education in Germany. European Journal of Language Policy, 10(1), 39-76.

Lanvers, U., \& Hultgren, A. K. (2018). The Englishization of European education. Foreword. European Journal of Language Policy, 10(1), 1-11.

Lasagabaster, D., \& Sierra, J. M. (2002). University students' perceptions of native and non-native speaker teachers of English. Language Awareness, 11(2), 132-142.

Macaro, E. (2018). English medium instruction. Oxford University Press.

Macaro, E., Curle, S., Pun, J., An, J., \& Dearden, J. (2018). A systematic review of English medium instruction in higher education. Language Teaching, 51(1), 36-76.

MacIntyre, P. D., Gregersen, T., \& Mercer, S. (2020). Language teachers' coping strategies during the Covid-19 conversion to online teaching: Correlations with stress, wellbeing and negative emotions. System, 94, $10235^{2}$.

Mair, C. (2019). English in the German-speaking world: An inevitable presence. In R. Hickey (Ed.), English in the German-speaking world (pp. 13-30). Cambridge University Press.

Martín, P., Rey-Rocha, J., Burgess, S., \& Moreno, A. I. (2014). Publishing research in English-language journals: Attitudes, strategies and difficulties of multilingual scholars of medicine. Journal of English for Academic Purposes, 16, 57-67.

Martirosyan, N. M., Hwang, E., \& Wanjohi, R. (2015). Impact of English proficiency on academic performance of international students. Journal of International Students, 5(1), 60-71. 
Mercer, S. (2019, May 4). Designing language classes and tasks with learner engagement in mind. [Webinar]. IATEFL. Retrieved 5 May 2019 from https://www.iatefl. org/resources/designing-language-classes-and-tasks-learner-engagement-mind Meyer, H.J. (2004). Global English: A new lingua franca or a new imperial culture? In A. Gardt \& B. Hüppauf (Eds.), Globalization and the future of German (pp. 65-84). De Gruyter Mouton.

My German University (2021). Study Finder. Retrieved 9 February 2021 from https://www.mygermanuniversity.com/studyfinder?p=1\&pp=20\&sort=applic ation_deadline\&dir=ASC

Nakane, I. (2007). Silence in intercultural communication. John Benjamins.

Pfaff, C. W. (2011). Multilingual development in Germany in the crossfire of ideology and politics: Monolingual and multilingual expectations, polylingual practices. Transit, 7(1), 1-21.

Rowlands, J. (2018). Deepening understandings of Bourdieu's academic and intellectual capital through a study of academic voice within academic governance. Studies in Higher Education, 43(11), 1823-1836.

Schumann, A. (2007). Die Internationalisierung der deutschen Hochschulen: Entwicklungen und Probleme. In A. Knapp \& A. Schumann (Eds.), Mehrsprachigkeit und Multikulturalität im Studium (pp. 15-28). Peter Lang.

Thompson, E. R. (2007). Development and validation of an internationally reliable short-form of the Positive and Negative Affect Schedule (PANAS). Journal of Cross-Cultural Psychology, $38(2), 227-242$.

Van Parijs, P. (2011). Linguistic justice for Europe and for the world. Oxford University Press.

Wächter, B., \& Maiworm, F. (2014).English-taught programmes in European higher education: The state of play in 2014. Lemmens.

Watson, D., Clark, L. A., \& Tellegen, A. (1988). Development and validation of brief measures of positive and negative affect: The PANAS scales. Journal of Personality and Social Psychology, 54(6), 1063-1070.

\section{About the authors}

Michelle Hunter, PhD student, applied linguistics at the University of York. She has a master's degree in Coaching in Education from the University of Chester. She is researching affective strategies among learners and teachers in EMI university classes in Germany. Michelle has lived and worked in Germany as a Business English teacher for 25 years. 
Dr Ursula LanVers, Associate Professor in language education, University of York, has published extensively on language learner motivation, language education policy and the UK language learning landscape. Her co-edited book Language Learning in Anglophone Countries: Challenges, Practices, Ways Forward subsumes the UK language learning crisis within the global move towards English as lingua franca.

\section{Appendix 1: Student PANAS}

Q7 How would you describe yourself generally? Aim to respond quickly trust your intuition!

On an average day at the university, I generally tend to feel:

Q8 How would you describe yourself in relation to learning through English? Aim to respond quickly - trust your intuition!

Learning via the medium of English makes me:

upset / verägert

hostile / feinselig

alert / wach

ashamed / beschämt

inspired / angeregt

nervous / nervös

determined / entschlossen

attentive / aufmerksam

afraid / ängstlich

active

Q.9 How do you feel about learning through the Medium of English? Answer in terms of how well the statement describes YOU. There are no right or wrong answers.

Work as quickly as you can without being careless, clicking in the appropriate column.

1. It upsets me when I feel I'm being left behind in class because I don't understand everything that is being said.

2. I get irritated when others in class don't speak clear, correct English.

3. I am interested in listening to what the instructor has to teach us through the medium of English. 
4. I try to hide the fact that I haven't understood something explained in English in class.

5. Seeing others doing well in English inspires me to keep improving my own language skills.

6. Thinking about going to my English-taught classes makes me feel nervous.

7. I believe I can overcome any gaps in my language skills and achieve good grades.

8. I enjoy engaging with the English language while learning at university.

9. I'm too afraid of making a language mistake that I hardly ever speak in front of the whole class.

10. I enjoy using the English language actively.

Q7-Q9: Interval measure (7-point scale): Never (o) 12345 Always (6)

\section{Appendix 2: Teacher PANAS}

Q7 How do you generally feel at work? Aim to respond quickly - trust your intuition!

Generally at work I tend to feel:

Q8 How would you describe yourself in relation to teaching through the medium of English?

Teaching through English tends to make me feel:

upset

hostile

alert

ashamed

inspired

nervous

determined

attentive

afraid

active

Q9 How do you feel about teaching through the medium of English? 
Answer in terms of how well the statement describes YOU. There are no right or wrong answers to these statements. Work as quickly as you can without being careless, clicking in the appropriate column.

1. It distresses me when I feel students don't understand everything I say.

2. I get irritated when students don't speak clear, correct English.

3. I am interested to see how students react to what I am teaching.

4. I try to hide the fact that I haven't understood something in class.

5. Seeing students doing well using their English inspires me to keep improving my own language skills.

6. I feel nervous when I think about going to my classes taught through English.

7. I believe I can overcome any gaps in my language skills.

8. I enjoy engaging with the English language during class.

9. I'm afraid of making language mistakes when teaching through English.

10. I enjoy using the English language actively.

Q7-Q9: Interval measure (7-point scale): Never (o) 12345 Always (6)

\section{Appendix 3: Semi-structured interview questions Students}

What is your first language (mother tongue)?

How long have you been using English as a foreign or second language?

What semester are in you currently in?

How many classes have you had taught in English only?

How do you feel about learning new subjects (on your uni course) through English?

How do you feel beforehand, when you know you've got a lecture that's going to be delivered in English?

How do you feel generally, during a lecture delivered in English?

How do these feelings, emotions, or moods manifest in your behaviour and/ or physical reactions?

What tends to cause your emotions, moods, or feelings to change during the lecture that's being delivered in English?

How is this different to when you have a lecture in your own language?

What things do you do if the emotions, moods, or feelings arising in the EMI lectures affect your learning and studying?

How is this different to when you have a lecture in your own language? 


\section{Appendix 4: Semi-structured interview questions Teachers}

What is your first language (mother tongue)?

What previous experience do you have of using English (to teach, work, socialize)?

(General views) How do you feel about teaching your subject through English? (Do you also teach it in German/your own language?)

(Before class affect) How do you feel beforehand, when you know you've got a lecture that's going to be delivered in English?

(In-class affect) How do you feel generally, during a lecture delivered in English?

What tends to cause your emotions, moods, or feelings to change during the lecture that's being delivered in English?

How do you manage communication breakdowns with students during a lecture?

How is this different to when you give a lecture in your own language? (Affective strategies) What things do you do if the emotions, moods, or feelings arising in the EMI lectures affect your learning and studying? What strategies do you have for regulating your emotions/emotional reactions to teaching through EMI?

How is this different to when you have a lecture in your own language? What are your overall views about English as an academic lingua franca? 


\title{
16 Englishization as trap and lifeline
}

\author{
Philippe Van Parijs
}

\begin{abstract}
In today's Europe, internationalization is driven by three mutually reinforcing mechanisms: EU funding, rankings, and commodification. And it calls for Englishization because in most cases the learning of the local language by foreign students is too much to expect, whereas a powerful bottom-up 'maximin' dynamics generates such a wide dissemination of English that prior knowledge of it can be taken for granted. Is Englishization a problem? Of course it is, for several reasons. Yet there is no responsible path away from internationalization, nor any reasonable hope of achieving it without Englishization. We must therefore aim at a fragile balance between giving enough place to English not to fall behind and protecting local languages against slow agony.
\end{abstract}

Keywords: Englishization, internationalization, maximin principle, network power, contestation

\section{$1 \quad$ Englishization - a problem?}

Is the Englishization of Europe's higher education a problem? And if it is a problem, is there anything that can and should be done about it that does not create more harm than it cures? ${ }^{1}$

1 The present concluding essay is heavily indebted to the very instructive essays collected in this volume and to useful feedback by René Gabriëls, Robert Wilkinson and Filippo Contesi. It draws on the approach to linguistic issues presented in Van Parijs (2000), and more fully in Van Parijs (2011) (German edition published by Suhrkamp, 2013; Dutch edition by Lannoo, 2015) and discussed in De Schutter and Robichaud (2015).

Wilkinson, Robert, and René Gabriëls (eds), The Englishization of Higher Education in Europe. Amsterdam, Amsterdam University Press 2021 DOI: 10.5117/9789463727358_CH16 
Before addressing these questions, it is prudent to first ask whether the Englishization of higher education - understood as an increase in the share of higher education courses or entire programmes using English as the medium of instruction in European universities - is a fact. Reading the contributions to this very instructive volume leaves no doubt: there has been, over the last two or three decades, a strong and accelerating trend that deserves to be called 'Englishization', but with huge differences. It tends to be more pronounced in countries with 'small' languages than in countries with 'big' languages, at master's and doctorate levels more than at bachelor's level, in certain disciplines like management or engineering more than in medicine or law and in research universities more than in institutions aiming to train highly skilled professionals for the local labour market.

Is Englishization a problem? It certainly is if, firstly, the quality of education suffers badly as a result of transmission and interaction being hampered by a poor command of English by teachers and/or by students, and possibly also as a result of having to use foreign teaching material ill-suited to local needs. Secondly, it is a problem to the extent that it makes access to higher education more difficult for socially less advantaged students, in particular many of those with an immigrant background, or confines them to a downgraded lower-tier higher education sector operating exclusively in the local language. It is a problem, thirdly, to the extent that it contributes to the deepening gap between academia and society at large by inhibiting the development of a lexicon that keeps track, in the local language, of scientific advances and by hindering the flow of knowledge and ideas between universities and the rest of society. Finally, it is regarded by many as a major problem because it weakens the status and grip of the national language, previously the exclusive medium of instruction, as an essential ingredient of the identity of the nation and of the glue that turns a population into a community. For all four of these reasons, Englishization runs the risk of gradually unravelling what European universities had laboriously achieved a couple of centuries earlier by getting rid of Latin in favour of the local vernaculars.

If Englishization is problematic in so many ways, one may wonder why it is progressing at such a rapid pace. In order to understand this, it is essential - as we see being done throughout this volume - to link the Englishization of higher education with its internationalization, here understood as an increase in the share of foreigners in the student 
population of the higher education institutions of a country. ${ }^{2}$ Before turning to that link, however, it is useful to note that these two processes are not necessarily coupled.

Firstly, there can be high degrees of internationalization without Englishization. Think, for example, of Rome's Latin-medium Gregorian university; of the USSR's Russian-medium university system, with over $10 \%$ of its students coming from friendly countries close by or far away; of today's Russia attracting Russophones from countries that used to be part of the USSR; of France, Spain or Portugal attracting many students from former colonies that kept the colonial language in much of their own education systems; or of Francophone and Germanophone universities attracting students from countries in which French or German was, until not so long ago, the first foreign language for many pupils.

Secondly, there can also conceivably be high degrees of Englishization with no internationalization. The authorities of a country may regard higher education in English as useful for their own population despite English not being the local native language. This is the case on a massive scale, and not only for higher education, throughout the Commonwealth. It is also the case, on a more modest scale, in much of the rest of the world, with $\mathrm{CLIL}^{3}$ instruction in English meant to better prepare local students for a career in scientific research or international business.

Thus, Englishization and internationalization must be distinguished, but it is the close link between them in today's Europe that we must scrutinize in order to better identify the source of what is experienced as a problem and the best way to address it.

\section{Trapped in internationalization}

In order to understand the joint forward march of internationalization and Englishization, one may wish to depict European higher education as a battlefield between ideologies and the material interests associated with them. However, I believe it is more illuminating to identify and describe the mechanisms that underlie the current trends and explain their irresistibility,

2 The internationalization of the university staff is closely associated with the internationalization of the student population only in case of Englishization or, more generally only when a lingua franca different from the local language is adopted as the medium of instruction. When foreign students are attracted from former colonies or satellite states, for example, there is no strong pressure for the staff to internationalize.

3 Content and language integrated learning. 
perhaps even their irreversibility. All of them are neatly illustrated in the instructive country case studies gathered in this volume. There are, first, three very different mechanisms that trap universities in a process of internationalization, and next three mechanisms that, combined, are bound to turn internationalization into Englishization.

Why do universities internationalize? A first cause is demographic. As international migration proceeds without leading systematically to the naturalization of immigrants - especially when they are coming from another member state of the European Union (EU) - the share of foreign citizens in the student population of our universities can be expected to slowly increase. A second cause might be called scientific. At least for advanced specialized degrees, it is often healthy for students to bear the costs of expatriation in order to find abroad what they cannot find at home. The third cause is rather educational: it can be very valuable for local students to develop personal relationships with people who grew up in different material and cultural contexts thanks to 'internationalization at home', the active hosting of foreign students. But over above these three 'natural' causes, there are three other causes, each rooted in a distinct mechanism, that can end up 'trapping' universities in a process of internationalization that they would not have spontaneously chosen.

The most obvious such mechanism is the funding of student mobility by the European Union, from the massive Erasmus programme established over three decades ago to the recent European Universities Initiative. The rationale is plausible enough: if you want to build a real European community, its future elite at least must have a taste of education and life in other member states and establish friendships outside their national community at an early stage in their adult lives. When quite a large amount of money is made available for the benefit of one's students in exchange for welcoming students from other universities across Europe, it is hard for university authorities to turn it down, despite the considerable administrative and pedagogical burdens this unavoidably involves.

Slightly less visible and far more general is a second mechanism: university rankings. Influential rankings such as the annual QS World University Ranking give significant weight to the share of foreigners among both students and staff. The rationale behind this simple criterion is plausible enough. How many foreigners choose to study at a university or to work for it provides a very rough but objective index for its attractiveness and hence its presumed quality. The degree of internationalization also enters such rankings indirectly through the component of the index that relies on academics mentioning what they regard as the best departments in their 
field. If your university hosts many foreign students, it is more likely to be positively remembered by your foreign colleagues when they answer the survey. Every academic realizes how arbitrary these rankings are, but no one can deny their impact, not least through the echoes they trigger in the national media. Those who criticize them when their universities do badly are discredited as bad losers. And those whose universities happen to do well by the standards of some ranking can seldom resist the temptation to boast about it. As the degree of internationalization is one of the factors affecting the rankings that is most directly under the control of universities, it is hard for university authorities not to let this affect their admission policies, irrespective of whether it is in their interest to attract more foreign students for other reasons. The sheer prestige of featuring high up in the rankings suffices as a driving force.

The first mechanism had to do with accessing public funding, the second one with gaining recognition. Only the third one is directly connected with the 'commodification' of higher education, its subjection to a market or a quasi-market. In most countries, how much money universities receive for their teaching activities is closely related to the number of students they attract, either through the fees paid by the students or their parents or through the per capita subsidies paid by the government (or both). Due to economies of scale, it is then often in the material interest of a university to attract as many students as possible. Moreover, even when it is not - because the marginal cost exceeds the marginal revenue - university authorities tend to take pride in growing enrolments. If student choice is not narrowly constrained on a geographical, linguistic, or religious basis, competition for market shares can already be intense within countries. But as soon as studying abroad is viewed as a real possibility by students, competition starts operating on a much larger scale. The harmonization of degree structures triggered by the 1999 Bologna declaration and the Bologna process it launched (which now involves 48 countries) and the mutual recognition of degrees realized step by step within the EU increased considerably the real choice for students and thereby, inseparably, the (quasi-)market pressure on universities. As a result, these had arguably no option but to try to internationalize, if only in order to compensate for their own pool of students being depleted by foreign attraction and in several countries also by a downward local demographic trend. As international mobility intensifies, universities that do not enter the international market game will sink.

Once this third mechanism becomes significant, the other two gain in importance: getting more EU funds for student exchanges and achieving a better position in international rankings are precious assets in the 
international competition for students. This makes clear enough why university authorities tend to promote internationalization. If the studies of foreign students were entirely covered by their fees, attracting them would also unambiguously be in the material interest of the national authorities. But this is far from being the case, especially for EU students, who enjoy the same fee regime as local ones. Whether governments can expect an overall net material benefit from internationalization despite an immediate net cost will then depend on how much foreign students spend on local goods and services and on how likely they are to remain in the country and contribute to its economy after completing their studies. For this reason, and also for other reasons we shall turn to after discussing the connection with Englishization, there is no pre-established harmony between what governments and universities are inclined to push for.

\section{Stuck with English}

Next then, what accounts for the close association between the push for internationalization and the push for Englishization? As pointed out above, you can in principle have the former without the latter. All programmes could be organized in the local language and foreign students who do not know that language before coming would be expected to learn it soon after their arrival to an extent sufficient for attending classes and taking exams. This would require providing good intensive language courses free of charge. Even so, the investment by each student would be considerable, especially if the language to be learned is very different from their own native language and if they had little exposure to it before their arrival. The cost of this investment will easily be found prohibitive if the local language is not a widely spoken one and if the student does not expect to stay more than a short period. In most countries, therefore, sticking to this strategy does not have the slightest chance of bringing about the internationalization universities are eager to achieve. The alternative consists in offering the programme in a language - if there is one - that is already far more widely known by potential foreign recruits and/or which these potential recruits are keen to learn better. It is then the local teachers rather than the foreign students who will have to bear the (time) cost of the linguistic investment, and if the linguistically competent supply from local resources proves insufficient, teaching staff can also be recruited from abroad.

It so happens that there is now such a language. Competence in English has been spreading very quickly, from cohort to cohort, throughout 
continental Europe and beyond, and it is bound to keep spreading. Why? Not because of some opaque neo-liberal or imperialistic plot, but because of the mutual reinforcement of two very simple and ubiquitous mechanisms. One is rooted in the concern to be understood with as little trouble as possible by those with whom we are communicating. Among the various languages we could conceivably use in a particular conversation, this leads us to pick systematically, not the language best known by the majority or best known on average, but the maximin language: the language best known by the person who knows it least well. And given that it is by practising a language that we maintain and develop our linguistic competence, competence in the language that features in maximin position keeps spreading. To illustrate, just reflect on the following fact reported to me by a Dutch language teacher at the University of Lille (in Northern France): he was delighted to have been able to send his students for a semester to the University of Leiden, pleased to hear that they had had a good time, but flabbergasted to discover on their return that their Dutch was hardly better than before, whereas their oral English had made impressive progress.

The anticipation of a language featuring in maximin position and hence being used triggers a further mechanism: deliberate investment in the learning of a language through language classes and in other ways. This mechanism is an instance of 'network power', analogous to what is going on when we or our institutions purchase Word or PowerPoint because many others with whom we wish to interact have done so before. It is the (correct) anticipation that English will be (increasingly) used in international linguistic encounters, active or passive, real or virtual, that makes countless students gladly devote to the improvement of their English an effort few would have dreamt of devoting to the learning of other languages. Further upstream, it is also that anticipation that makes pupils and their parents want the learning of English to be given high priority in all European schools.

This network power mechanism interacts with the maximin mechanism to produce a snowball effect. The more that is invested in the learning of English, the more often it features in maximin position, the more it is therefore used and thereby maintained and improved, and the more this further strengthens the incentive to invest in learning it. Needless to say, the choice to use English and to learn it comes generally - and regrettably - at the expense of the use and learning of other foreign languages. This twofold mechanism shapes the linguistic dynamics in society at large, but it has most deeply affected, discipline after discipline, the increasingly internationalized scientific communities, triggering the irreversible agony of countless journals and associations operating in languages other than 
English. It is also at work in the 'ripples' around internationalized higher education institutions and among the educated young adults who form the increasingly common pool of European universities. Higher education institutions that want to internationalize then face a simple choice: they must either stick to their own language and be prepared for a poor outcome at a high cost or go for an expansion of English-medium instruction.

The interlocking of these various mechanisms is what explains the strong combined pressure towards internationalization and Englishization at least at the meso level, the level of university authorities. Support at the macro level of governments, however, is far from self-evidently guaranteed, as several contributions to this volume document. First of all, as mentioned earlier, many foreign students come at an immediate cost for the local government, which the latter is by no means sure to recover. This is particularly the case if internationalization is achieved entirely or mainly thanks to Englishization. Foreign students then acquire little or no proficiency in the local language and therefore have only a low probability of joining the local labour market after their studies. To increase this probability, some countries have introduced an obligation to take a course in the local language. But if this is a light obligation, it will have no effect, and if it is a heavy one, it may be nearly as much of a deterrent as if the programme were offered in the local language. By offering English-medium instruction to all students, foreign or not, governments may even achieve exactly the opposite result: they may find that they are depleting rather than feeding the local market for high-skilled labour. English-medium instruction will result in many of the better local students becoming footloose and both able and tempted to find jobs elsewhere, especially in Anglophone countries.

Moreover, the national authorities may be more concerned with the vitality of the national language, culture, and identity than with the national economy. Especially in countries (or regions) with 'smaller' languages - and therefore with a lower expected stay rate among foreign students and a more acute feeling of linguistic vulnerability - macro-resistance is likely to temper meso-enthusiasm. As several countries illustrate, governments often impose restrictions on the development of English-medium instruction. For example, they require that parallel degrees should be organized in the local language or that the use of 'another language' than the local one should be strictly confined to cases in which the linguistic competence of the students requires it. Meso-activism, however, often circumvents macro hurdles. Universities tend to interpret restrictive legislation creatively so as to make themselves as attractive as possible to students with no prospect of learning the local language. 
Whereas it is in countries with 'small' languages that macro-resistance can be expected to be strongest, it is in countries with 'big' languages that one should expect greater resistance at the micro-level, the level of individual members of the academic or administrative staff. Other things equal, proficiency in English is inversely correlated with the spread of one's language. Therefore, it is in countries with 'bigger' languages that it will be more difficult to find teachers and administrators able - or disposed to become able - to operate in a language other than their own. In some of those countries pride in the national language may also nourish some macro-resistance (French, German and Russian used to be major academic languages). But in all of them, one can expect micro-resistance to temper meso-enthusiasm more than it does in countries with 'smaller' languages.

\section{Could and should Englishization be stopped?}

While the mechanisms listed above should suffice to explain the strong pressure towards internationalization and Englishization at a meso level - with frequent contagion to sectors of the macro and micro levels - the considerations spelt out at the end of the previous section should suffice to explain the tensions it keeps triggering at both the macro and micro level. I shall close this contribution by asking whether, in order to avoid these tensions and accommodate the underlying concerns, the twofold process of internationalization and Englishization could and should be stopped.

In order to switch off the pressure to internationalize, or at least to reduce it drastically, action would need to be taken at European level. The European Union would need to stop funding international student mobility. It would need to develop a sufficiently authoritative and influential ranking that attaches no weight, directly or indirectly, to the share of foreign students. And it would need to prevent governments from subsidizing foreign students, instead of forcing them to do so, as it does now in the case of EU students, at the same level as local students. Would that be desirable? It would certainly be a massive setback for the attempt to develop a mobile, truly European elite, inclined to think from a European and not just a national viewpoint. Moreover, it is in the interest of each member state and of the EU as a whole to keep hosting talented young people from around the world in their universities and their labour force, rather than letting British and American universities attract and retain them, thereby generating a massive brain drain in their favour. Let us bear in mind, for example, that Brexit deprived the EU of all of its universities usually ranked among the world's top 10 (3 
in the QS ranking) and most of those ranked among the top 100 (17 out of 27), and that the current net brain gain of the UK at the expense of EU27 is estimated to exceed 600,00o working-age people. Making EU universities less international in this context, one could argue, is nothing short of suicidal.

However, would it not be possible to emancipate the internationalization of European higher education from its connection with Englishization? Brexit itself seems to offer a unique opportunity to do so. With the UK out, why should English keep functioning as the lingua franca of European institutions, of Europe's transnational civil society and of its mobile youth gravitating around our universities? If internationalization could operate in another European language, the EU would stop shooting itself in the foot by contributing to the brain drain, as pointed out above, through preparing its own students for easy integration in the economic and social life of Anglophone countries. This hope is misplaced. Now that English is no longer the official language of one of the EU's big member states, it provides a more neutral medium in the EU context, and therefore a more appropriate instrument for that role - as it is also, for example, in India or in Nigeria. And in contrast with other parts of the world, opting for English in Europe does not carry with it the embarrassment of surrendering to a colonial language. Quite the contrary. English is a continental European language that was imposed on the population of Great Britain in two instalments - a Germanic one 1,500 years ago and a French one 1,00o years ago. It is high time that we should reappropriate it as our language and stop representing it, as some of our websites still do, by the Union Jack. In any case, no attempt to replace English by German or French as the EU's lingua franca has any chance of succeeding because of the resentment and resistance any such attempt would create among speakers of other languages and their governments, and above all because the bottom-up maximin dynamics that keeps strengthening the position of English will keep working throughout Europe and throughout the world.

There is, however, a more radical, yet (some would argue) less unrealistic alternative to Englishization than a shift to another European language. Could technological progress in voice recognition not enable us one day to dispense with English as a common medium of instruction, or indeed as a lingua franca? Once everyone can understand what is being taught in any language, there is no need for everyone to learn a common language. Unfortunately - or rather, fortunately - teaching does not consist in delivering unilaterally, under good acoustic conditions, a text that could also have been provided in writing. It consists in interacting in a lively, sometimes animated way, using proper names and neologisms, developing a micro-culture. And 
this purpose is still far better served even by somewhat broken English than by a stiffening technological prosthesis. This does not mean that the fast AI-driven improvement of translation software cannot make a difference. It will make it easier for non-native academics to produce publications and course material in good English and for students to use material in any language. This will make it possible to counteract one major negative side effect of the Englishization of higher education: the 'Americanization' of textbooks and more generally the use of course material designed for students living in the Anglophone part of the world. Technology can thus serve the purpose of producing a more diverse and more suitable course material - at least if not offset by the one-directional diffusion of massive open online courses (MOOCs) from Anglophone countries - but cannot provide a substitute for a shared language.

There is, therefore, no responsible path away from internationalization, nor any reasonable hope of achieving internationalization without Englishization. Owing to the four reasons (mentioned at the start) that this Englishization is a problem, this process will not be smooth. The tensions to which it leads are likely to remain or become passionate in some countries, though unlikely to reach the intensity of the conflicts unleashed by competition, often at all levels of education, between local languages and powerful neighbours: Spanish in Catalonia, Galicia, and the Basque countries, French in Flanders, Russian in the Ukraine and the Baltic states, Serbo-Croat in Slovenia or Kosovo.

Nonetheless, the tension is likely to become more severe because of the measures that will need to be taken in order to address the various problems mentioned. For example, in order to prevent the exclusion of less advantaged students from higher education or from its top tier, more English will need to be introduced at secondary level, including in the form of CLIL. In order to attract enough high-quality staff, universities will be under pressure to reduce the expectation of sufficient competence in the local language and consequently to switch to English, for maximin reasons, in internal communication and meetings. And in order to prevent higher education in English from feeding Anglophone countries with highly-skilled workers at low cost, non-Anglophone countries will need to make it more comfortable for the families of foreigners to get by without knowing the local language, including through the provision of English-medium public services and schools. These various 'ripples' entail a more profound invasion of English into the domain of the local language, easily amplified by the maximin dynamic. One can try to confine this invasion in 'linguistically free zones', while maintaining a 'linguistic territoriality principle' over the 
bulk of the territory. But the perimeter of this zone and the extent of the linguistic freedom allowed within it is most likely to remain the object of chronic contestation.

Is this, then, all we can expect: a fragile, conflict-ridden balance between giving enough place to English not to fall behind and protecting the local languages against domain loss and slow agony? Being in a position to avoid this uncomfortable balancing act is and will remain a major structural asset for Anglophone countries in general, and for their higher education sector in particular. It is this robust asset, together with its manifold consequences, that made Brexit, at the most fundamental level, a reasonable risk for the United Kingdom to take. The irreversible installation of English as the global lingua franca turns Anglophone territory into the 'ground floor of the world', into an attractor which can cherry-pick the most promising and talented among the many who want to enter. Is there a price to pay? Not by Anglophone territories but by Anglophone people: because of the maximin dynamic, the spreading of English as everyone else's second language will make it increasingly difficult for Anglophones to learn and maintain any other language. Our own advantage is the mirror image of this handicap. As English spreads, it will become ever easier for us non-Anglophones to become bilingual and enjoy the associated cognitive, aesthetic, and cultural benefits. These benefits will spread to our institutions and our countries if we academics resist the pull of the 'ground floor', if our affectio institutionis and/or our affectio societatis are sufficient to keep us, at least for the long term, on our linguistically so diverse continent. We are needed here for many reasons, but in particular to play the uncomfortable yet often gratifying role of go-betweens, of bridge builders between the irreversibly internationalized and Englishized academic community and our stubbornly distinctive local communities.

\section{References}

De Schutter, H., \& Robichaud, D. (Eds.) (2015). Linguistic justice. Van Parijs and his critics. Routledge.

Van Parijs, P. (200o). The ground floor of the world. On the socio-economic consequences of linguistic globalisation. International Political Science Review, 21, 217-233.

Van Parijs, P. (2011). Linguistic justice for Europe and for the world. Oxford University Press. 


\section{About the author}

PhILIPPE VAN PARIJs is a guest professor at the Universities of Louvain and Leuven and chairs the Brussels Council for Multilingualism. He was the founding director of Louvain's Hoover Chair of Economic and Social Ethics (1991-2016) and a regular visiting professor at Harvard and Oxford. 



\section{Contributors}

Elena Belyaeva (MA in Applied English Linguistics, $\mathrm{PhD}$ in Pedagogy) is an expert in ELT/EAP/ESP/EMI in higher education. She works as a university teacher/lecturer and a researcher at St Petersburg University (SPbU), Liberal Arts and Sciences Faculty. Since 2018 she has been an EMI teacher trainer for SPbU faculty.

lena.belyaeva@gmail.com

AgnieszKa Cierpich-KozieŁ, PhD, is an Assistant Professor at the Institute of Modern Languages of the Jesuit University Ignatianum in Kraków. She holds a master's degree in English Studies and German Studies and a PhD in linguistics. Her research interests lie in the fields of sociolinguistics and contact linguistics. She is a freelance interpreter.

ORCID oooo-0002-9669-550X

agnieszka.cierpich@ignatianum.edu.pl

MONIKA DANNERER is professor of German Linguistics at the University of Innsbruck, Austria. Her research in Applied Linguistics and Sociolinguistics is currently focused on first and second language acquisition and language attitudes, as well as multilingualism and repertoires in higher education and tourism.

ORCID: 0000-0002-0179-3861

Monika.Dannerer@uibk.ac.at

Slobodanka Dimova (MA and PhD Purdue) is an Associate Professor in Language Testing and Assessment at the Centre for Internationalisation and Parallel Language Use at the University of Copenhagen. Her work focuses on fairness and justice in language assessment as a policy tool in the internationalized higher education.

ORCID: 0000-0002-0017-6255

slobodanka.dimova@hum.ku.dk

Branka DrljaČa Margić is Associate Professor in the English Department at the University of Rijeka, Croatia. Her research interests include EMI, language contact and attitudes. She has run six national and international research projects on EMI, and is co-author of Uncovering English-Medium Instruction: Glocal Issues in Higher Education (Peter Lang, 2017).

ORCID: 0ooo-0oo2-7617-66o6

bdrljaca@ffri.uniri.hr 
RENÉ GABRIËLS is a lecturer in philosophy at Maastricht University (Netherlands). His research concerns social philosophy, sociolinguistics, philosophy of language and sociology of stratification. He focuses on democracy, inequality, human rights, linguistic justice, poverty and the relation between semantics and pragmatics, with current research on English-medium instruction (EMI) at universities and on food banks.

ORCID: 00oo-0002-2259-0983

r.gabriels@maastrichtuniversity.nl

MaRtina GAISCH is professor of English, Intercultural Competence and Diversity Management at the University of Applied Sciences Upper Austria, Austria. As an applied linguist working at a school of informatics her research focus is at the interface of educational sociology, higher education research and sociolinguistics.

ORCID: oooo-0oo2-4255-9967

Martina.Gaisch@fh-hagenberg.at

Magnus Gustafsson is an Associate Professor at the Division for Language and Communication, Chalmers University of Technology, Gothenburg. His work focuses on academic and disciplinary discourse for faculty and students. In his educational development work, he strives to promote seamless integration of communication-oriented learning activities to enhance disciplinary expertise.

ORCID: oooo-0oo2-8614-638X

magusta@chalmers.se

Anna Kristina Hultgren (DPhil Oxon, MA Copenhagen, SFHEA, Cert LSE) is UKRI Future Leaders Fellow and Professor of Sociolinguistics and Applied Linguistics at The Open University, UK. Her work centres on uncovering fundamental principles governing language shift in our globalized world by bringing together linguistics and political science.

ORCID: 0000-0003-2379-1290

kristina.hultgren@open.ac.uk

Michelle Hunter, PhD student, applied linguistics at the University of York. She has a master's degree in Coaching in Education from the University of Chester. She is researching affective strategies among learners and teachers in EMI university classes in Germany. Michelle has lived and worked in Germany as a Business English teacher for 25 years.

ORCID: oooo-0001-5693-2235

meh56o@york.ac.uk 
JoYCE KLING (PhD Copenhagen, EdM Harvard, MA MIIS) is Geise Foundation Associate Professor at the University of Copenhagen. Her research focuses on English-medium instruction (EMI) and professional development of lecturers, with particular interest in the integration of content and language in multilingual higher education.

ORCID: 0000-0002-8491-4701

joyce@hum.ku.dk

Lyudmila Kuznetsova, MPA (Rutgers University, USA), PhD in Linguistics, Associate Professor, Cambridge ESOL examiner, teaches Effective Professional Communication and Academic English to master's and PhD students at St Petersburg University. She has coordinated the British Council project RESPONSE and co-authored the English for Academics course book series (Cambridge University Press, 2014, 2015).

ldm.kuznetsova@gmail.com

Dr Ursula Lanvers, Associate Professor in language education, University of York, has published extensively on language learner motivation, language education policy and the UK language learning landscape. Her co-edited book Language Learning in Anglophone Countries: Challenges, Practices, Ways Forward subsumes the UK language learning crisis within the global move towards English as lingua franca.

ORCID: 0000-0003-1829-25oX

ursula.lanvers@york.ac.uk

David Lasagabaster is Professor of Applied Linguistics at the University of the Basque Country UPV/EHU, Spain. His research revolves around EMI (English-Medium Instruction), CLIL (Content and Language Integrated Learning), attitudes and motivation, and multilingualism. He has published widely in international journals, books and edited volumes.

ORCID: 0000-0001-7750-2314

david.lasagabaster@ehu.eus

FrANÇOISE LE LIÈvRE is Assistant Professor in Language Sciences, focusing on language policy issues in higher education. She is currently in charge of Francophonie at the University of Galatasaray (Istanbul). She is general secretary of Poclande (People, Cultures, Languages and Development), an international network of researchers, experts and practitioners on development issues.

PLIDAM EA 4514

francoiselelievregsu@gmail.com 
ELŻBIETA MAŃCZAK-WOHLFELD is a full professor of English linguistics at the Jagiellonian University in Kraków. She has published over 140 papers and books. Since 2006 she has edited the journal Studia Linguistica Universitatis Iagellonicae Cracoviensis. Her academic interests concern contact linguistics, the influences of English on Polish and other European languages and English-Polish contrastive studies.

ORCID: oooo-0002-7839-4957

manczak@uj.edu.pl

Amanda C. Murphy, PhD, is Professor of English language at Università Cattolica del Sacro Cuore, Italy. Her interests include corpus-related analyses of language, English as a medium of instruction and the internationalization of higher education. She is the co-editor (with Hugo Bowles) of English-medium Instruction and the Internationalization of Universities (Palgrave 2020). ORCID: oooo-0001-9366-5105 amanda.murphy@unicatt.it

Olga Nikiforova, PhD in Sociology, Associate Professor at the Department of Economic Sociology and Head of MA programme 'Studies in European Societies', St Petersburg University. Her sphere of scientific and research interests covers such topics as sociology of markets, the labour market and human resource development.

nikifolga@gmail.com

KERTTU ROZENVALDE is a research fellow in language policy at the University of Tartu. Among her fields of research are language policies and higher education policies, particularly in Estonia and Latvia. She is currently conducting research on language use and ideologies in a multilingual university in Estonia.

ORCID: 0ooo-0oo1-7914-7934

kerttu.rozenvalde@ut.ee

Josep Soler is Senior Lecturer in Applied English Linguistics at Stockholm University. He has published extensively on language policy and the internationalisation of higher education, with Estonia as a focal point of interest. His other research interests include the politics of English as a global language and family multilingualism.

ORCID: 0000-0002-2813-0101

josep.soler@english.su.se 
FrANK VAN Splunder holds a PhD in Applied Linguistics from Lancaster University. Currently, he teaches academic writing in a multilingual context at the University of Antwerp. The focus of his research is English as the language of globalization and its use in higher education in Flanders and the Netherlands.

ORCID: oooo-0oo1-7656-8610

frank.vansplunder@uantwerpen.be

Dr AIsHA SIDDIQA, Research Associate in ZHAW since 2020, completed her PhD in Linguistics (2018, Université Cote d'Azur), focusing on the acquisition of second language pragmatics by young learners of English as a foreign language in France. Her research interests include the interface between pragmatics and second language acquisition, English-medium instruction and internationalization of the curriculum.

sidd@zhaw.ch

UTE SMIT is professor of English Linguistics at the University of Vienna, Austria. Her applied linguistic research focuses mainly on English in, and around, education. Besides involvement in various international research projects, Ute is a board member of ICLHE (Integrating Content and Language in Higher Education).

ORCID: 00oo-0003-1577-086o

ute.smit@univie.ac.at

PATrick StUder has been Professor of Applied Linguistics in ZHAW since 2012 and is a founding member of the association ICLHE (Integrating Content and Language in Higher Education). His research interests include the study of English as a world language. He has published widely on language ideology, EMI and internationalization of higher education.

ORCID ID: 0ooo-00o2-7326-298X

stup@zhaw.ch

Svetlana Suchkova, PhD in Linguistics, Associate Professor, teacher trainer, and Cambridge ESOL examiner, is the current director of the Academic Writing Center at the Higher School of Economics, Moscow. She has published a number of EFL coursebooks for Russian university students and researchers, and co-authored the English for Academics series (Cambridge University Press, 2014, 2015).

s.suchkova@gmail.com 
JENNIFER VALCKE is an Educational Developer for the unit for Teaching and Learning at Karolinska Institutet (KI) in Stockholm, Sweden. Her role includes teaching, training and advising on issues related to curricular integration, sustainable education, international education, intercultural education and English-medium education (EME); and she also provides support for educational leaders to implement educational strategies.

ORCID: 0000-0002-1570-0750

jennifer.valcke@ki.se

PhILIPPE VAN PARIJS is a guest professor at the Universities of Louvain and Leuven and chairs the Brussels Council for Multilingualism. He was the founding director of Louvain's Hoover Chair of Economic and Social Ethics (1991-2016) and a regular visiting professor at Harvard and Oxford.

ORCID: oooo-0003-3348-1317

philippe.vanparijs@uclouvain.be

Robert WiLkinson is a visiting Research Fellow in the Department of Philosophy at Maastricht University (Netherlands) and conducts research on English-medium instruction (EMI) and multilingualism. He previously worked at Maastricht University's Language Centre, and earlier in Scotland, Czechoslovakia and France. He is currently chair of the ICLHE Association. ORCID: oooo-0002-8737-3357

b.wilkinson@maastrichtuniversity.nl

BEATRICE ZuARo is a PhD candidate at the Department of English of Stockholm University. Her PhD project is an investigation of English-medium Instruction (EMI), specializing in the context of Italian Higher Education. Her main research interests encompass language policy and language ideologies, EMI and academic discourse in general.

ORCID: oooo-0003-1464-6614

beatrice.zuaro@english.su.se 


\section{Index}

Terms occurring in references are excluded.

academic discourse (see discourse) academic domain loss (see domain loss) academic lingua franca (see lingua franca) academic literacy $15^{\circ}, 154,313$

access

of less advantaged students 30

open access $\quad 189$

to communities 48

to Dutch programmes 242

to EMI 23, 153

to English 49

to (English versions of) websites 274

to German classes 333

to (higher) education $62,166,356$

to (learning and) research 154,168

to observation 317

to power and prestige $\quad 112$

to research results 69,249

to scientific knowledge $\quad 20,146$

to the world $27,48,5^{2}$

university access grades 87

accreditation $\quad 20,39,81,82,89,90$.

affect (psychological) 6, 17, 30, 327, 328,

$335-337,339,345,346,354$

negative affect $333,339,342,343,345$

positive affect $30,339,345,346$

student affect 327,335

teacher affect $\quad 327,335$

Africa 21, 191

African 100,270

Alsatian 13

America 21, 340

American 8o, 145, 153, 192, 239, 245, 329, 363

American English (see English)

North America 99

Americanization $14,49,107,365$

Anglicism 177, 178, 276, 284

Anglo-American $43,47,49,108,245,248$, 249, 251

Anglophone $16,23,24,30,109,115,177,241$, 250, 251, 334, 351, 362, 364-366, 371

anglosphere $33^{2}$

anxiety $313,314,334,341,345$ over proficiency $\quad 30,346$

Arabic 41-43, 150

Asia 21, 191

Asian 270

attitude $21,38,43,45,48,51,68,78,79,90,95$, $113,148,166,172,176,181,182,190,191,200$, $203,206,229,305,307,308,310,313,315,318$, $322,325,333,337,341,346,369,371$

Australia 21, 100

Australian 153
Austria $18,20,30,102,195,281-305$ (ch. 13), $369,370,373$

Austrian 6, 7, 30, 281-305 (ch. 13)

autonomy $39,78,99,100,328,336,338,341$,

342,344

autonomous $78,90,200$

barrier(s) 21, 26, 49, 52, 106, 109, 242, 314, 317 linguistic barriers 202 to publication $6,200,201$

Belgium 6, 7, 18, 27, 37-52 (ch. 2), 195, 262 Belgian 14, 38-40, 41, 52

Belarus 202, 270

Basque $\quad 15,28,78,84,90,95,109,365,371$

bilingual $11,13,17,47,80,85,113,126,128,129$, $205,223,240,285,297,332,336,366$

education $79,80,122,173$

programmes $64,79,80,89,130,131,135$

regions $39,77,83,84,122$

state 41

universities $\quad 28,41,78,85,126,128,129,135$

bilingualism $38,77,114,135,136,247,261,282$, 297,315

binary HE system $\quad 286$

Bologna agreement $\quad 146,224,226$

Declaration 240, 331, 359

process $99,122,175,191,193,227,268,282$, $307,308,317,359$ university 165

Bosnia/Bosnian 299

bottom-up $18,21,43,135,189,327,333,346$, 355,364

brain drain $\quad 30,308,311,320,363,364$

brain gain $\quad 332,364$

Brazil 106, 108, 114

Breton 13, 105, 109

Brexit $267,363,364,366$

BRICS countries 108

Britain (Great) $\quad 173,364$

British 45, 153, 172, 173, 245, 363

British English 46

British Council 18, 192, 371

Bulgaria 267,290

CADS (corpus assisted discourse studies) 163, 169,170

capitalism 64

Catalonia $\quad 78,84,85,365$; Catalan $\quad 13,28,78$, $82,84,85$

Certification $82,104,134,15^{\circ}, 151,198$ international certification 134

language certification 104,150

lecturer certification $148,15^{\circ}, 15^{1}$ 
China $101,104,106,108,270,340$

Chinese 29, 79, 114, 150, 204, 206

citizenship $\quad 265$

European (EU) citizenship $\quad 102,333$

global citizenship 220

CLIL (content and language integrated

learning) $40,42,78,95,125,365,371$

code-switching $28,112,115,231$

codification 167

commodification $17,23,48,84,97-99,101,104$,

$115,145,155,355,359$

commodity 253,317

competence(s) $\quad 77,82,85,87,104,133,134,150$,

$151,165,246,321,322,336,33^{8-341,344, ~} 345$

communicative competence $\quad 51$

English (language) competence(s) 82, 203, $310,342,360$

foreign language competence $\quad 79,134$

global competence 229

intercultural competence $134,216,217$, $229,230,305,321,370$

language competence(s) 134, 230, 299, $342,361,365$

linguistic competence $25,155,361,362$ pedagogical competence $15^{2}$

plurilingual competence 180

competition $27,66,98,121,155,192,251,273$, $283,308,359,360,365$

academic competition $\quad 98$

global competition 100,105

job competition $\quad 30,259,260,273,274$

conceptualizations $5,6,41,42,143,217,218$, $232,283,307,309,318$

contestation 355,366

corpus linguistics $\quad 169$

Corsican 109

court case (Italian) 164, 166, 171, 181; (Dutch) 238,246

Croatia 14, 21, 30, 102, 290, 307-325 (Ch. 14), 369

Croatian 6, 14, 30, 299, 307-325 (Ch. 14)

culture(s) 14, 15, 16, 20, 27, 29, 30, 59, 60, 63, $80,99,103,104,107,119,130,131,135,146-149$, $164,165,173,176,178,182,183,202,205,220$, 241, 250-252, 262, 271, 274, 300, 371

American culture 239

Anglophone culture 16, 177

and identity $136,137,313,314,362$

and society 250

academic culture $29,155,158,183$

audit culture 245

Belgian culture 14

Chinese culture 204

Croatian (language and) culture 308 , 314,315

Dutch (language and) culture $29,30,238$, $239,241,243,245,247,248,25^{1-253}$

educational culture $111,151,15^{2}$

Estonian (language and) culture $\quad 61,64,66$
French (language and) culture $\quad$ 109, 111, 113 German language and culture $\quad 329,336$ micro-culture 364

national (language and) culture 131,143 , 264

Polish language and culture $\quad 264$

political culture 25

Russian (language and) culture 190, 198, 202

Spanish culture 80

cultural capital 85

cultural heritage $\quad 29,146$

cultural identity (see identity)

Cyprus 102

Czech 260, 296

Czech Republic $\quad 262,270,296$

Danish 5, 29, 111, 143-162 (Ch. 7)

democracy $21,24,25,26,27,36,69,257,370$

democratization 103 democratization of knowledge $\quad 21,146$

Denmark 20, 21, 28, 29, 111, 143-162 (Ch. 7), 262,270

development plan $\quad 201,285,289,299,300$

diglossia/diglossic $168,322,328$

disciplinary $7,85,86,133,144,150,168,170$,

$173,175,181,219,223,227,228,231,236,263$,

$298,319,370$

differences $17,28,88$

discourse (see discourse); disciplinary identities 85,86

knowledge 88,149

learning $150,229,230,231$

discipline(s) $27,48,77,85,87,88,124,154,155$, 166, 168-170, 173, 181, 182, 196, 198, 203, 215, $223,225,226,229,231,262,263,297,298,318$, $333,356,361$

discourse(s) 21, 29, 48-50, 57, 60, 61, 86, 114, $121,123,165,168-170,173,174,176,237,250$, $264,265,283,284,317,374$

academic discourse 49,188

analysis 58,61

archive 123,124

culturalist discourse $\quad 60,67,72$

disciplinary discourse $86,88,232,236$, 314,370

of globalization $\quad 48$

identity discourse $\quad 48,49$

internationalist discourse 67,69

language policy discourse $60,68,69,124$

nationalist discourse $\quad 72$

quality of education discourse 49

social discourse 49

studies 163

discrimination 69

domain loss $15,27,28,31,49,108,109,112,113$, $124,143,146,147,154,168,225,227,308,315$, $320,328,329,333,366$ 
Dutch $6,29,30,37-56$ (Ch. 2), 80, 237-257 (Ch. 11), 355,361

Dutch as an academic language $49,241,242$, $247,249,250,25^{2}$

economics $14,44,83,87,88,130,170,173,194$, $196,198,213,240,273,274,289,310,318,373$ economic ideology (see ideology)

EMEMUS (English Medium Education in Multilingual Universities Settings) 29, 144, 217

England 104, 107

English $\quad 5-7,13-30,36-52,58-72,75,77-90$, 95, 97-115, 121-137, 142-155, 162-168, 170-183, 188-206, 212-213, 215-218, 223-232, 236-252, 256, 259-277, 279-286, 288-301, 305, 307-322, $325,327-337,339-346,350-357,360-366$, 369-374

English as a lingua franca (ELF) 39, 49, 52, $103,122,145,151,218,259,329$

English as an academic lingua franca 290, $307,319,354$

English as a business lingua franca 328

English for research publishing purposes 189 , 196

English for teaching 152,198

English in higher education $41,43,67,72,103$, $121,123,124,148,203,332$

English language $7,14,16,22,24,40,46$, $66,69,70,82,85,86,104,105,111,134,143$, $144,146,148,151-154,165,172,175,176,188$, 190-193, 195, 196, 200, 203, 205, 206, 229, 240, 249, 266, 270-276, 284, 295, 299, 309, 311, 312, 314-316, 352, 353, 372

American English (see English) $\quad 45,46$ British English $\quad 46$

English language websites $\quad 274,275$

English Medium Education (EME) 6, 144, 168, $215,236,284,374$

English Medium Education in Multilingual Universities Settings - see EMEMUS

English-medium higher education $\quad 282$ English-medium instruction (EMI) $5,6,7$, 13-21, 23, 26-30, 36, 40, 43, 49, 51, 52, 6o, 77-90, 95, 108, 109, 110, 121, 125, 134, 142, 143, 144-155, 162, 165, 166, 168, 188-191, 194-198, 201-203, 205-206, 212, 215-216, 237, 239, 240-245, 247-252, 256, 257, 259, 270-273, 282, $285,294,299,300,307-322,325,327-337$, $339-346,350,353,354,362,369-374$

English-medium programmes $67,239,240$, 260, 294, 297, 309, 321

English-only $\quad 5^{0}, 5^{2}, 246,272,276,315,331,335$

English proficiency $\quad 20,23,26,28,29,80,81$, $86,111,147,150-153,197,218,226,270,310,311$, $329,331,333-335,339,342$

English-taught programmes (ETPs) 7,44 , $63-65,72,90,124,125,295,307,309-312$, 314,321
Englishization $\quad 5-11,14-30,37,42,46,48-51,57$, $58,60,62,70,72,77-79,81-83,87,97,98,102$, $103,106-115,121-123,134,143-148,152,154,163$, 164, 166-172, 174-178, 180-183, 189-191, 195,

$203,205,215,219,225,232,237-245,247-253$, 259, 26o, 263-265, 271, 275-277, 281-284, 292, 296-298, 300, 307, 308, 310, 314-318, 320-322, 327-33o, 332, 333, 346, 355-358, 36o, 362-365 anglizacija 314

anglicizzazione $16,163,164,171,172$, 176-179, 181, 182

Englischisierung 284

verengelsing $46,48,239,241,243,249$

Глобанглизаиия (Globanglization) 190

equality $21,27,37,42,48,49,107,146,321$

equity 109,143

Erasmus (programme) 192, 274, 275, 308, 323

Erasmus University $\quad 238,240,245$

Esperanto 202

Estonia 5, 13, 15, 28, 57-75 (Ch. 3), 372

Estonian $\quad 57-75$ (Ch. 3 )

ethics (ethical) 130, 168, 336, 367, 374

Ethiopia 17

European (EU) citizenship (see citizenship)

European Higher Education Area (EHEA) 81, 99, 106, 191, 268, 307

European Research Area 99, 268

European Union $13,14,25,58,99,107,223,238$, $25^{2}, 261,268,282,328,35^{8}, 363$

Europeanization $\quad 282,285,300$

Finland $51,68,72,111,262,286$

Flanders $5,14,37-56$ (Ch. 2), 238, 262, 365, 373

Flemish $37-56$ (Ch. 2)

Flemish government $\quad 37,43,45,46,49-5^{2}$

Flemish higher education $37,44,46,48$, $5^{0,} 5^{1}$

Flemish identity $42,48,5^{\circ}$

foreign students (see international students)

France 5, 12, 14, 28, 36, 40, 77, 97-119 (Ch. 5), $121,142,191,256,328,357,361,373,374$.

Francophonie 103, 106-109, 119, 371

French 14, 16, 20, 28, 37-44, 46-48, 51, 52, 97-119 (Ch. 5), 121, 122, 124, 126, 129-131, 134, $135,144,150,177,178,204,238,246,260,263$, $264,299,332,357,363-365$

Frenchification 48

Galicia / Galician $28,78,365$

German 6, 20, 28, 30, 38-42, 46, 51, 52, 111, 121, $124,126,128-131,134-136,144,150,204,238$, 246, 260, 263, 264, 270, 279, 281-305 (Ch. 13), 327-354 (Ch. 15), 355, 357, 363, 364, 369

Germany $20,40,100,103,107,111,121,179,270$, 286, 290, 294, 327-354 (Ch. 15), 370

global citizenship (see citizenship)

globalization $15,22,37,48,51,56,87,97,112$, $114,115,123,167,190,205,238,250,268,373$ globalized bilingualism $\quad 282,297$ 
glocalization $\quad 11,17-19$

governance $6,12,100,215,218,219,232,269$

Greek 150, 26o

harmonization $\quad 106,359$

harmonized 146

heritage $15,29,103,146,149,165,274$

higher education $5,6,11,13-20,22-30,37$,

$39-52,56,57-72,75,77,80,81,89,90,97-115$,

119, 121-128, 130-132, 134, 136, 137, 142, 143-146,

148-150, 152-155, 161, 162, 163-167, 170, 171, 173, 175, 188, 189-191, 193, 195, 203, 205, 206, 212,

215-221, 223-225, 228-232, 237-243, 247-253,

259, 26o, 265, 267-269, 271-276, 281, 282, 284 ,

$305,307,308,325,327-330,332,355-357,359$, $362,364-366,369-374$

higher education institutions (HEI) 29, 39, 40, 48, 52, 78, 89, 90, 164, 191, 216, 221, 269, 275, $281,327,357,362$

homogenization 334

hybrid(s) 18, 25, 28, 112, 115, 294

Hungary 270,290

identity $20,23,25,27,29,30,37,49,5^{0}, 71,78$, $83,98,108,109,130,131,136,137,145,163,183$, $329,356,362$

Croatian identity $313-315,320$

cultural identity $11,12,15,19,20,21,23,26$, $28,29,70,241,346$

disciplinary identity 86

discourse 48,49

Flemish identity $42,48,5^{\circ}$

loss 83

national identity $12,107,172,190,242$

professional identity 83,85

Swiss identity 126

teacher identity 86,218

ideology/ideologies $26,42,71,75,84,112,124$,

$218,284,285,298,300,357,372$

ideological $61,68,91,107,145$

economic ideology 123

language ideology/ideologies $26,27,41,51$, $5^{2}, 84,112,113,142,188,319,373,374$

language ideological debates $57-59,61$, $62,70-72$

inclusion $115,144,149,151,228,232,247$

inequality $11,19-21,23,28,36,108,109,151,168$, $217,220,257,370$

India $106,108,270,340,364$

Indian(s) $\quad 270,343$

individual multilingualism (see multilingualism)

injustice $\quad 29,182$

intercultural competence $\quad 134,216,217,229$, 230, 305, 321, 370

interdisciplinarity 114, 217

interdisciplinary $82,131,133,271$.

international students $\quad 6,20,23,30,63-65,72$, $80,84,100,105,108,109,111,113,146,149,15^{2}$,
$154,164,181,191,193-195,198,202,205,215$, $223,226,228,230,238,240-242,244,246$, 247, 251, 252, 290, 292, 294, 296, 298, 308, $311,312,321,327,328,330,332,333,335-343$, 345,346

foreign students $\quad 64-66,100,105,107,111$, $125,134,165,251,25^{2}, 270,327,330,33^{2}$, $355,357-360,362,363$

international degree programmes

(IDPs) 330-332

international research $154,193,296,297,305$,

$325,369,373$

collaboration $192,228,267$

cooperation 262,285

internationalization $5,17,23,27-30,42,46$, $51,5^{2}, 58,61,63,66,77-82,88,90,97,98$, 100-103, 107, 111, 114, 115, 128-131, 132-136, 142, $146-148,154,163-177,180-183,188,189-196$, 201, 202, 205, 215-217, 220, 223, 224, 226-228, 230, 231, 239, 243, 244, 247, 250, 252, 259, 26o, 262, 267, 269-271, 274, 276, 281-285, 289, 290, 293-297, 299, 300, 307, 308, 310, 317, 318, $327,331,355-360,362-365,372,373$

internationalization at home $(\mathrm{IaH}) \quad 88,146$, $176,177,181,217,218,230,285,289,299,358$ internationalization of higher education (IHE/ IoHE) $17,51,58,61,98,142,164,188,205$, $216,218,220,229,231,267,270,284,307,308$, $318,372,373$

internationalization of tertiary education 327

internationalization of research 192 internationalization of the curriculum (IoC) 142, 146, 215, 231, 373

internationalizing the curriculum 177 internationalization strategy/strategies 90 , $128,129,133,134,136,148,215,285$

investment theory (see theory)

ITACE (Interuniversity Test of Academic English) 46,50

Italy $12,13,16,19,21,29,77,102,121,163-188$ (Ch. 8), 270, 290, 372

Italian $5,12,13,16,20,28,29,41,114,121,122$, $124,126,130,131,134,135,163-188$ (Ch. 8), 204, $260,263,289,299,274$

Japan 101, 115 Japanese 204

job market $20,166,274,277,289$ job competition $30,259,260,273,274$ job opportunities 23

Kazakhstan 202, 270

Korea 106

Kosovo $\quad 365$

knowledge society 81,300

lingua franca $25,39,45-47,49,52,80,84,85$, $101,103,114,115,122,145,151,166,167,193$, 
202, 218, 231, 248, 249, 259, 261, 264, 272, 276, 290, 293, 307, 316, 319, 328, 329, 334, 351, 354, $357,364,366,371$

language choice $60,93,132,133,298$

language debate(s) $61,123,225$

public debate(s) $13,14,19,21,27,28,37,42$, $48,57,5^{8}, 98,107-110,113,114,122,147$, 206, 239, 241, 244, 248, 250, 253 public controversy $29,122,237,238,240$, $241,25^{\circ}$

language ideological debates/language ideology (see ideology)

language law(s) (see law)

language of instruction $7,40,43,44,46,59$, 112, 126-128, 130-133, 135, 137, 149, 152, 202, 219, 227, 229, 230, 246, 271, 272, 293, 321, $33^{\circ}$ language of wider communication 41 language ideology/ideologies (see ideology) language policy/policies $6,7,12,13,15,16,18$, 21, 22, 24-26, 28, 29, 37, 39, 40, 42, 43, 45, 47, $48,51,52,57,59,60,67-71,81,84,89,90,97$, $98,102,109,110-112,115,119,121,123,125,127$, $130,135,136,137,143,147,148,173-175,188$, $215,217,221-225,229,237,239,242-247,250$, 252, 260, 264, 276, 281, 282, 284, 293, 309, $371,372,374$

language practice(s) $\quad 15,42,43,47,48,5^{\circ}, 5^{2}$, $67,97,103,110,231,282,283,299,300,319$

language proficiency $19,40,83,146,150,151$, 153, 154, 193, 203, 206, 218, 229, 241, 250, 282, 284, 297, 299, 309, 311, 312, 314-316, 318, 319, $321,335,337$

language sensitivity $\quad 43,46$

language shift $79,143,146,161,370$

language struggle $\quad 37-39,41,48$

language testing/tests $\quad 42,45,46,15^{2}, 161,369$

Latin 12, 150, 26o, 264, 356, 357

Latin America $17,114,191$

Latvia $5,13,16,28,57-75$ (Ch. 3), 267, 372

Latvian $57-75$ (Ch. 3 )

law $13,42,44,59,63,64,66,69,70,106,169$, $170,175,179,225,239,242,243,246,252,260$, $263,297,331,35^{6}$

Flemish law 2012 Decree 43

Fioraso Law (France) 16, 97, 106-111, 113, 114 language law(s) 39, 68, 147, 329

Law on Higher Education (Poland) 26o, 268

Law on Higher Education and Science (Poland) 269, 273, 275

Lawn. 482/1999 (Italy) 165

Loi sur l'université (Fribourg) 129

LRU Law (France) 100

Polish Language Act $\quad 261$

Swedish Language Act (law) 221-226, 231 Toubon Law (France) 97, 103, 106, 107, 114 University Law (Zurich) 128 University Law (Ticino) 130 lecturer certification (see certification)
Liechtenstein 102

lifelong learning 220, 293

lingua receptiva 39

linguistic community/communities $\quad 25,39$, 127

linguistic diversity $11,25,39,40,48,102,106$, $109,111,112,126,165,252,293,296$

linguistic ecology 84,90

linguistic harmony $122,127,135$

linguistic hegemony 112,167 economic hegemony 112 global hegemony 215

linguistic hierarchy/hierarchies $13,57,58,67$, 216, 322

linguistic identities (see identity)

linguistic imperialism 18, 19, 147, 204

linguistic justice $11,16,24,25,36,257,328,370$

linguistic plurality/pluralism $98,102,115,290$

linguistic repertoire(s) $20,84,145,149$

linguistic rights 90

linguistic strains $28,78,79$

linguistic tension(s) $\quad 5,57,79,83,84,90$

Lithuania 270

Luxembourgian $\quad 41$

macro level $17,22,25,81,123,135,191,307$, 328,362

Malta 102

marketization $48,191,315$

maximin dynamics/principle 355,361 , 364-366

Meänkeli 223

media (news) 14, 46, 61, 62, 67, 103, 107, 112, 122, 126, 132, 147, 166, 171, 204, 239, 241, 261, $264,312,359$

media of instruction 60

social media $40,47,328$

meso level $17,22,81,123,131,193,298,362,363$

micro level 17, 22, 190, 202, 206, 307, 321, 322, 363

minority language(s) $12,13,15,28,39,42,77$, $79,84,85,90,102,109,149,165,223,260$ mobility $82,99,100,130,132,133,174,176,181$, $215,220,224,226,228,230,251,282,289$,

294, 311, 319, 359

academic mobility $\quad 192,193$

social mobility 39

staff mobility $194,228,284,285,297$

student mobility $91,100,134,192,195,217$, $285,286,297,358,363$

modern languages $102,263,264,279,369$

modern language programmes $7,271,272$

monoglossic habitus $282,286,298$

monolingualism $5,11,12,13,16,38,102,109$,

$114,135,177,252,253,265$

monolingual (language) ideologies 41, $5^{2,}, 285$

regional monolingualism 38,135 territorial monolingualism $\quad 42$ 
multiculturalism $\quad 217,231$

multilingualism $5,11-13,28,36,37,39,40$, $42,45,46,51,52,75,77,79,90,95,110,111$, 121-123, 126-130, 133, 135-137, 144, 148, 149, 155, $175,182,217,218,231,256,281,282,300,305$, $329,367,369,371,372,374$ individual multilingualism 297 multilingual values 252 multilingual communication $\quad 145$ multilingual university/universities 29, $75,143,144,217,324,372$

national culture (see culture)

native speaker $109,151,200,335,346$

debate 85

(English) native speaker bias $\quad 335,345,346$ model 45

negative affect (see affect)

negative semantic prosody $174,175,177,178$, $181,182,284$

neoliberalism $22,23,115,237,250$

neoliberal $23,29,98,123,25^{\circ}$

neoliberal policies 22

neoliberal principles 22

Netherlands $16,29,36,37,39,40,43,44,50,51$, $56,83,103,104,125,144,195,237-257$ (Ch. 11), 270, 286, 294, 328, 370, 373, 374

New Public Management $\quad 23,25,29,245,250$

Nordic Council Language Convention/ policy 15,223

Nordic countries $15,51,60,72,218,225$

normalization 171 normalization processes $\quad 78,84$

North Macedonia 102

Norway 221, 262

Norwegian 80

Occitan 13

Oceania 104

parallel language use/policy $15,60,65,111$, $143,148,149,155,161,222,223,225,297,369$ parallellingualism $\quad 5^{2}$

path dependence 26,27

pedagogy $67,82,89,151,152,212,274,321,369$ perceptions of English $\quad 155,189,196,201$

plurilingualism $102,114,115,127,192,265,296$, 332,333

plurilingual 102, 114, 149, 180, 264, 333

Poland $7,102,259-280$ (Ch. 12), 290

Polish 6, 30, 41, 259-28o (Ch. 12), 372

Polish Language Act (see law)

politics $14,39,75,122,173,329,372$

politicization $5^{2}$

political economy 21-23

Portugal 270, 357

Portuguese 114

positive affect (see affect)

power $17,108,112,113,116$ economic power $\quad 112$

imperial power 18

imbalance $15^{0}$

institutional power 26

network power 355,361

political power 39

relations 21,27

soft power 65,66

pragmatic $\quad 52,121,136,137,148,151,204$

pragmatism 136

the pragmatic way $5,121,137$

precondition(s)/prerequisites (for EMI) 39, $48,269,284,308,309,311,316,317$

professional development $82,89,162,202$, $203,217,231,232,371$

professional development programme(s)/ course(s) 82, 195, 196, 229, 245

professional identity/identities (see identity)

public controversy/debate (see language debate)

public interest 69

quality $19,21,66,67,69,90,98,109,111,132$,

$133,151,153,165,192,205,215,229,233,244$, 248, 249, 309, 313, 316-318, 320, 358, 365 assurance $20,82,170,231,317,321$

control 317

of education $6,17,23,26,30,46,50,51,69$, $109,143,167,215,216,231,241,25^{\circ}, 251$, $307,308,311,317,320,356$

of higher education $11,13,19,39,49,57,63$, $65,67,215,242,320,327$

of research 19

ranking(s) $23,27,49,80,100,101,123,130,146$, 192-195, 251, 270, 308, 319, 332, 355, 358, 359, 363,364

regional monolingualism (see monolingualism) research and scientific communication $\quad 259$ research publication/publishing (in Eng-

lish) 181, 189, 196, 197, 199, 203, 204, 263, $266,276,333$

research universities $\quad 6,30,192,238,243,245$, $281,283,285^{-289}, 293,294,297,300,35^{6}$

resistance $16,18,19,62,83,115,166,176,181$, $315,320,362-364$

resistance to EMI 166

resistance to Englishization 110, 307, $33^{2}$

ripple effect of English $\quad 47$

ROAD-MAPPING framework 217

Romania 267,290

Romanian 263

Romansh 28, 121, 122

Russia (Russian Federation) 5, 14, 20, 29, 62, 104, 108, 189-213 (Ch. 9), 357

Russian 28, 58-6o, 69, 189-213 (Ch. 9), 26o, $263,264,270,290,357,363,365,373$

Russification $\quad 5^{8}$ 
Saami 223

Scandinavian 144,328

self-determination theory (see theory)

self-efficacy $339-340,343-346$

Serbia 290

Serbian 299

Serbo-Croat 365

Slovakia $262,270,290$

Slovenia $\quad 262,365$

Slovenian 99,264

social discourse (see discourse)

social inequality/inequalities 168,216

South Africa 108

Soviet Union 191, 202

Soviet 58,59

Soviet universities 191

Spain $5,17,28,77-95$ (Ch. 4), 121, 357, 371

Spanish 17, 41, 77-95 (Ch. 4), 114, 150, 178, 204, $264,299,332,340,365$

specialized language $\quad 89$ specialized terminology 86

specialized vocabulary 87

staff mobility (see mobility)

stakeholder(s) 11, 15, 16, 19-21, 24, 26, 27, 62, 70, $80,81,112,125,136,145,151,166,167,182,189$, 190, 201, 202, 231, 237-239, 243, 247, 250-253, $286,297,307,310,315-317,320-322,327,333$

state policy/policies $\quad 58,189-191$

student-centred approach 319,321

student mobility (see mobility)

student perceptions $\quad 7,237,244,249,335$

sustainability $6,215,224,247$

sustainable development $17,216,220$

Sweden $6,7,15,29,60,103,215-236$ (Ch. 10), 374

Swedish $20,29,60,103,215^{-23} 6$ (Ch. 10)

Swedish Language Act (see law)

Swiss $5,12,28,111,121-142$ (Ch. 6)

Switzerland $13,28,121-142$ (Ch. 6), 195, 270

Taiwan 101, 227, 270

Tamazight $\quad 41$

teacher accreditation $\quad 81$

theory $134,181,324$

deficiency theory 48

ideology theory 112 investment theory 85

self-determination theory 327,338

TOEPAS (Test of Oral English Proficiency for

Academic Staff) $\quad 151,310$

top-down $18,25,26,46,102,135,205,206,320$,

$327,328,333,346$

approach $\quad 136$

discourses 21

incentive measures 203

initiative(s) 189, 193

language regulations $\quad 283$

(language) policy $\quad 21,28,43,51,71,123,328$

strategies 154

transculturality and interculturality 285

translanguaging $18,113-115,149,231,312$

translingual practices $\quad 28,97,98,110$, 113-115

trilingualism 77

Turkey 270

Turkish $\quad 41-43,49,299$

Ukraine $\quad 62,270,365$

Ukrainian 337,343

United Kingdom (UK) 100, 101, 155, 161, 245, $286,328,336,337,351,364,366,370,371$

United Nations Sustainable Development Goals 17,220

United States (USA) 22, 100, 101, 104, 112, 191, $212,245,371$

universities of applied sciences (UAS) 7, 30, $43,44,55,125,127,128,133,134,136,238,281$, $283,285-288,293-297,300,331$

university administrators/administrations $23,29,71,235,237,239,250$ university management $135,247,318$ university managers $\quad 82$

utilitarian approach $\quad 298,300$ cost-benefit analysis $\quad 136$

market value $\quad 284$

relevance 281

view $30,133,282$

USSR 191,357

Uzbekistan 202

Wallonia $14,37-43$

Walloon $38,39,41$ 
